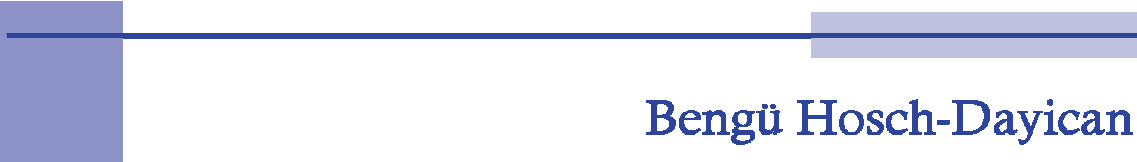

Political

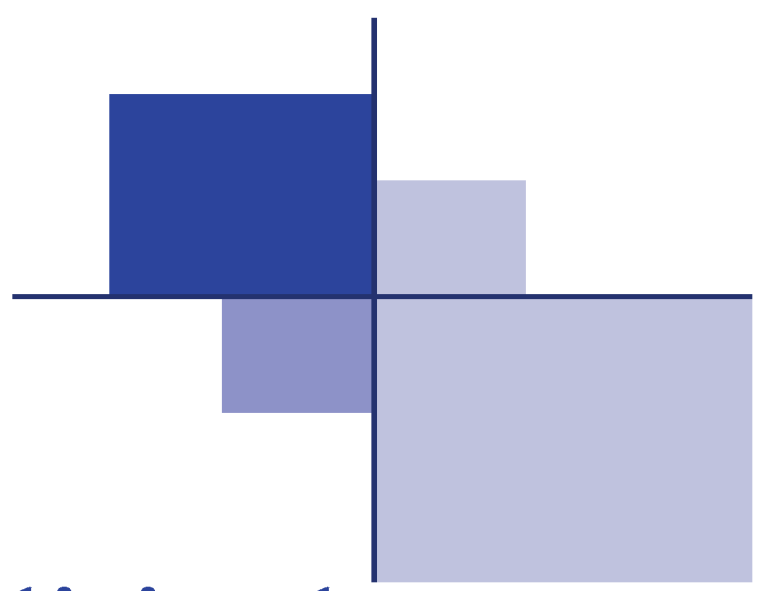

Involvement and Democracy

How Benign is the Future of Post-Industrial Politics? 


\section{Political Involvement and Democracy}

How Benign is the Future of Post-Industrial Politics? 


\section{Promotion committee:}

Prof. dr. P.J.J.M. van Loon (chairmen / secretary)

Prof. dr. J.J.A. Thomassen (promotor)

Prof. dr. C.W.A.M. Aarts (co-promotor)

Prof. dr. S.A.H. Denters (University of Twente)

Prof. dr. J.W. van Deth (University of Mannheim)

Prof. dr. D. Fuchs (University of Stuttgart)

Prof. dr. A. Need (University of Twente)

Political Involvement and Democracy: How Benign is the Future of Post-Industrial Politics?

PhD thesis, University of Twente, The Netherlands, 2010.

ISBN: 978-90-365-3123-8

Cover Design: Janine van der Woude

Printed by: PrintPartners Ipskamp, Enschede, The Netherlands, 2010 


\title{
POLITICAL INVOLVEMENT AND DEMOCRACY HOW BENIGN IS THE FUTURE OF POST-INDUSTRIAL POLITICS?
}

\author{
DISSERTATION
}

\author{
to obtain \\ the degree of doctor at the University of Twente, \\ on the authority of the rector magnificus, \\ prof.dr. H. Brinksma,
}

on account of the decision of the graduation committee, to be publicly defended on Wednesday the $8^{\text {th }}$ of December 2010 at $13.15 \mathrm{hrs}$

by

\section{Bengü Hosch-Dayican}

born on the $12^{\text {th }}$ of February 1976

in Istanbul, Turkey 
This dissertation has been approved by Prof. dr. J.J.A. Thomassen (promotor)

Prof.dr. C.W.A.M. Aarts (co-promotor) 


\section{Contents}

1 Introduction: Post-Industrialization, Political Involvement, and Democracy 1

1.1 Introduction to the Research Puzzle 2

1.2 Instrumental and Expressive Political Involvement 4

$\begin{array}{lll}1.3 & \text { State of Research } & 7\end{array}$

1.4 Theoretical Framework and Analytical Design 9

1.5 Outline of the Book 13

$\begin{array}{ll}\text { PART I: THEORETICAL BACKGROUNDS } & 15\end{array}$

2 How Much Participation? Citizen Involvement in Democratic $\begin{array}{ll}\text { Theory } & 17\end{array}$

2.1 Political Participation and Democracy: Concepts in Flux? 18

2.2 The Development of Democracy and the Understanding of Citizen Participation 20

2.2.1 Classical Athenian democracy and the practice of citizen involvement 21

2.2.2 Political involvement in modern democracy 23

2.2.3 The freedom vs. equality paradox and the division in modern democratic thought 28

2.3 Political Involvement in Democratic Theories of Contemporary

Western Society 30

2.3.1 Liberal theories of democracy 32

2.3.1.1 Competitive elitist theory $\quad 32$

2.3.1.2 Pluralist theory of democracy $\quad 35$

2.3.2 Participatory theory of democracy 37

2.4 Conclusion: A Critical Overview of Democratic Theories 40

3 From Normative Theories to Empirical Reality: Development and Backgrounds of Political Involvement

3.1 The Evolution of the Concept of Political Participation and its Research in the Past Decades

3.1.1 Early research on political participation: classical political activities and expansion of the repertoire $\quad 46$

3.1.2 Classifications and dimensions of political participation 49

3.1.3 Recent developments in participation research: new dimensions and actual trends $\quad 52$

3.2 Determinants of Political Participation 58

3.2.1 Analyzing political participation: macro- and micro-level explanations $\quad 58$

3.2.2 The socioeconomic model of political participation $\quad 60$ 
3.2.3 Criticisms to the socioeconomic model and the puzzle of participation $\quad 63$

3.3 Conclusion

4 Changing Society, Changing Politics? Cultural and Political Implications of Post-Industrialization and Post-Modernization

4.1 Modernization and Post-Modernization: The Emergence of Post-Industrial Society $\quad 70$

4.2 Changing Citizens: Implications of Individual Modernization $\quad 75$

$\begin{array}{lll}\text { 4.2.1 Increase in personal skills } & 75\end{array}$

$\begin{array}{ll}\text { 4.2.2 Value change and individualization } & 78\end{array}$

4.2.2.1 The post-materialist value change 78

4.2.2.2 Generational differences in post-materialist values and political skills

4.3 Changing Politics: The Shift towards Post-Modern Citizen and its Consequences

4.3.1 Individualization of politics 84

4.3.2 Changes in political orientations $\quad 85$

4.4 Conclusion: A Post-Modern Political Culture 88

5 Post-Modern Citizens, Political Involvement, and Democracy:

Two Contending Perspectives $\quad 93$

5.1 The Concept of Democratic Citizenship 95

5.2 The Theory of Human Development: An Optimist View of the Post-Modern Citizen

5.3 Concerns on the Future of Democracy: The Theory of Post-Modern Politics 103

5.4 The Post-Modern Citizen and the Rationality of Political Action: Instrumental vs. Expressive Political Involvement 107 5.4.1 The rationality of political action 108 5.4.2 Instrumental and expressive political involvement 110

5.5 Citizen Involvement and Post-Industrial Society: Quo Vadis? 113

PART II: EMPIRICAL ANALYSES

6 Levels and Development of Political Involvement Types in Post-Industrial Democracies

6.1 Hypotheses on the Levels and Development of Involvement Types

6.2 Data and Measurement

6.2.1 The European Values Survey

6.2.2 Measurement of instrumental and expressive political involvement

6.2.2.1 Political participation $\quad 124$

6.2.2.2 Political interest 126 
6.3 Development of the Levels of Political Involvement 129

6.4 Generational Effects on Political Involvement 136

6.4.1 Life-cycle and period effects on political involvement $\quad 139$

6.4.2 Cohort effects on political involvement 142

$\begin{array}{lll}6.5 & \text { Conclusion } & 146\end{array}$

7 The Impact of Values on Political Involvement: Hypotheses and Operationalizations $\quad 149$

7.1 Individual Values and Political Involvement 150

7.1.1 Value effects on political involvement 150

7.1.2 Control factors for the value effects 153

7.1.2.1 Cognitive mobilization 153

7.1.2.2 New political orientations 154

7.1.2.3 Age 155

$\begin{array}{lll}7.2 & \text { Data and Operationalizations } & 157\end{array}$

7.2.1 European Social Survey 157

$\begin{array}{lll}\text { 7.2.2 } & \text { Measuring value orientations } & 158\end{array}$

7.2.3 Measurement of control variables 167

8 Values and Political Involvement: Testing the Causal Model 169

8.1 Distribution of Values among Post-Industrial Countries:

Descriptive Analysis $\quad 170$

8.2 Testing the Causal Model 175

8.2.1 Bivariate analyses 175

8.2.2 Testing the multivariate model 179

8.2.2.1 The logistic regression model 179

8.2.2.2 The results 181

$\begin{array}{lll}8.3 \text { Conclusions } & 187\end{array}$

9 The Future of Post-Industrial Politics: Benign or Less Benign? 191

9.1 Political Involvement in Post-Industrial Societies: What

Have We Found? 192

9.1.1 What is the prevailing type of political involvement in post-industrial democracies? 194

9.1.2 How are instrumental and expressive involvement types likely to develop in post-industrial democracies? 195

9.1.3 Which value orientations prevail in post-industrial democracies? 196

9.1.4 To what extent do value orientations account for the type of political involvement? 197

9.2 Political Involvement and Democracy: What is the Future

Likely to Bring? 198

9.3 Perspectives for Future Research 200

$\begin{array}{ll}\text { Appendix A } & 205\end{array}$

$\begin{array}{ll}\text { Appendix B } & 213\end{array}$ 
References

Nederlandse Samenvatting 


\section{List of Figures}

$\begin{array}{lll}\text { Figure 1.1 The analytical framework of this study } & 11\end{array}$

$\begin{array}{lll}\text { Figure 4.1 Modernization processes and political orientations } & 74\end{array}$

Figure 5.1 The two contending views on post-modernization effects 114

Figure 6.1 Shifts in instrumental political involvement, 1981-2000 140

Figure 6.2 Shifts in expressive political involvement, 1981-2000 141

Figure 6.3 Development of instrumental political involvement among birth cohorts 143

Figure 6.4 Development of expressive political involvement among birth cohorts:

$\begin{array}{lll}\text { Figure } 7.1 & \text { The causal model } & 156\end{array}$

$\begin{array}{lll}\text { Figure 7.2 } & \text { The Value Concept by Schwartz } & 160\end{array}$ 


\section{List of Tables}

Table 1.1 Typology of political interest and political action 5

Table 2.1 Citizen involvement in democratic theory 31

Table 3.1 Dimensions of political participation according to Verba and Nie (1972)

Table 3.2 The typology of political activism developed by the Political Action Study (1979)

Table 3.3 The five-fold typology of modes of political participation by Teorell et al. (2007) 55

$\begin{array}{lll}\text { Table } 4.1 & \text { The process of societal modernization } & 71\end{array}$

Table 5.1 The human development sequence 98

Table 6.1 Hypotheses derived from contradicting interpretations of modernization 121

Table 6.2 Hypotheses on the development of political involvement types by generation replacement

Table 6.3 The European Values Survey (EVS): Number of respondents and year of data collection for each analyzed country 124

$\begin{array}{lll}\text { Table 6.4 Political participation items (EVS and ESS) } & 126\end{array}$

Table 6.5 Development of political participation in post-industrial countries, 1981-2000

Table 6.6 Development in the levels of political interest in post-industrial countries, 1981-2000

Table 6.7 Development of expressive political involvement in post-industrial countries, 1981-2000

Table 6.8 Development of instrumental political involvement in post-industrial countries, 1981-2000

Table 6.9 Development of the ratios of expressive over instrumental political involvement in post-industrial countries, 1981-2000

Table 6.10 Percentages of instrumental and expressive political involvement by age and year

Table 6.11 Percentages of instrumental and expressive political involvement among birth cohorts

Table 7.1 Hypotheses on values and their effects on political involvement 152

Table 7.2 Basic human values by Schwartz (2003) 
Table 7.3 Comparing Schwartz's values concept with the traditional vs. secular-rational values by Inglehart

Table 7.4 Comparing Schwartz's values concept with the survival vs. self-expression values by Inglehart

Table 7.5 Underlying items for self-direction, universalism and hedonism 165

Table 7.6 Dimensional analyses with the value items 166

$\begin{array}{lll}\text { Table 8.1 Mean levels of value orientations in countries } & 170\end{array}$

$\begin{array}{lll}\text { Table } 8.2 & \text { Correlation matrix independent variables } & 173\end{array}$

Table 8.3 Bivariate correlations of values and control factors with involvement types on a pooled basis and in individual countries 178

$\begin{array}{lll}\text { Table 8.4 Stepwise logit analysis with pooled data } & 182\end{array}$

$\begin{array}{lll}\text { Table } 8.5 & \text { Logit analyses with values in twelve countries } & 183\end{array}$

$\begin{array}{lll}\text { Table } 8.6 & \text { Logit models in countries } & 185\end{array}$ 


\section{Acknowledgements}

This dissertation has been the result of a process of more than just five years. There have been a number of people who have helped me into, through, and out of this process; I would like to express my gratitude here for the role they have played. It is their achievement as well as mine.

First of all and above all, I thank my parents for believing in my dreams and setting me free to chase after them. Without their support, it would never have been possible to start - and withstand - the long journey which has led to the completion of this dissertation. Thank you both!

Furthermore, I am grateful to Oscar W. Gabriel, for whom I have worked as a student assistant at the University of Stuttgart, for having realized how much "pleasure" I have in scientific work and encouraging me to go further in the academic profession. He was the one who made me aware of the $\mathrm{PhD}$ position at the University of Twente, and who literally "talked me into this". I am so glad he did!

During my research in Twente, I was lucky to have two experts in the fields of democratic theory and political behaviour as my supervisors: I am very indebted to my promotor Jacques Thomassen and co-promotor Kees Aarts for motivating and guiding me through this research. They have been great mentors throughout the whole writing process, from setting up the research design to finalizing the book. I always felt free to drop by for each new idea, question, or problem I had; and they were always there to help. Thank you very much for your support!

Also to all my colleagues at the Department of Political Science and Research Methods I owe so much; not only for their work collaboration and their comments at various stages of my dissertation, but also for providing me the nicest working atmosphere I have ever had. Andreas, Bas, Harry, Henk, Judith, Kostas, Martin, Mirjan, Peter, Rik Reussing, Rik de Ruiter, Ron, Yfke: Thanks for your company! I thank furthermore to my roommates Kasia, Gideon, Jarno and Ann-Kristin for sharing the "solitude" of writing a dissertation with me, also to my other former colleagues Bojan, Catia, Hanna, Juul, Merel, Mijke, and Rory for their guidance and friendship. As a non-native English speaker and an "Undutchable", I have had valuable support from other people as well: I thank Elwin and Leonie for helping me out with translations of articles - and, of course, the summary of this book - into Dutch. For the English language edition I am grateful to Zethyn Ruby, who helped 
me to meet the deadline for the delivery of the manuscript with her swift correction: Thanks a lot Zethyn! Finally, special thanks go to Janine, our department secretary. She has been a real life-saver in even the most hopeless looking situations. One can count on her especially when it's about creative work: the beautiful cover of this book is purely her design. Thank you for that!

Coming to Twente to write a dissertation has not only been a decisive milestone in my scientific career; it has changed my life also in a different way. During this time I met my husband, who eventually became one of the most important people within the dissertation process. Thomas, all this would definitely not have been possible without your support. You never gave up encouraging me throughout the past three years, and believed in me even at times when I stopped believing in myself. Thank you for being there, and for being who you are. This book is dedicated to you.

Enschede, November 2010 
INTRODUCTION 


\section{Chapter 1}

\section{Introduction: Post-Industrialization, Political Involvement, and Democracy}

"Any book about participation is also a book about democracy", as rightly put forward by a former study on citizen participation in Britain (Parry et al. 1992: 3). This is another book about both; our aim is here to study the link between political involvement and democracy in European post-industrial democracies. The relationship between participation and democracy is taken for granted by many scholars, but it is at the same time a complex relationship, which makes its study a difficult task. The bad news is that refraining from this task is impossible for someone who is interested in the study of democracy. Particularly in advanced democracies of the West, where the qualities, values, attitudes, and behaviors of citizens are in continuous change, political participation and its relevance for democracy is and remains a highly relevant topic. The question poses itself over and over again, to what extent do the increasing demands of citizens to have more say in political decision-making form a challenge for government in these democracies, and further, how democratic governance should face this challenge. We intend to contribute to this debate by providing an extensive discussion on participation in political decision-making processes and the underlying motivations for this behavior as well as by reflecting on its consequences for the stability of democratic governance in Western post-industrial societies. Our main premise here is that the quality of democracy is not only determined by the extent to which citizens are getting involved in the political decision-making process, but also by citizens' motivations driving these activities.

In this introductory chapter, we will first make the reader acquainted with the main puzzle which led us to this research. The main impulse of this book is a scholarly debate on the effects of societal modernization at its post-industrial stage and the resulting changes in political involvement on the stability of democracy in the concerned societies. The details of this debate will be described in the next 
section. Following upon this, we will explain more specifically what our research question is, what strategy we will follow to answer this question, and which contribution this research aims to make.

\subsection{Introduction to the Research Puzzle}

Western democracies have gone through some pervasive changes in the past decades. Perhaps the most important issue among these changes has been the radical shift in citizen participation in the policy-making process, particularly in countries which are at an advanced level of modernization and democratization which are addressed as "post-industrial societies" (Bell 1973; Huntington 1974; Inglehart 1977, 1990). While voting in elections was the main tool citizens used to get involved in political decision-making until the late 1960s, the so-called "participatory revolution" has brought about a rapid increase in both the levels and modes of citizen involvement in politics in post-industrial democracies. This development has invoked an intense debate in the decades following this explosive increase in citizen involvement in politics; particularly in the 1970s opinions diverged widely on how to interpret this sudden increase.

As democracy refers to "government by the people", political participation is its most essential component. Therefore, the recent changes were welcomed eagerly by many politicians and political scientists. One of the most prominent scientists studying this change is Ronald Inglehart (1971, 1977), who has repeatedly put forward the idea that the recent participatory expansion is due to the evolving modernization in post-industrial societies. The economic prosperity in these societies has led to two important changes in citizens' characteristics. First of all, a shift in citizens' value priorities has taken place, which implies a shift away from material and physical security concerns towards an increased emphasis on post-materialist values of freedom, self-fulfillment, and quality of life issues. Second, rising levels of education and better sources of information have improved citizens' skills and selfconfidence to better pursue their political goals and interests which enfold now a wider scope of issues due to the shift in values mentioned above.

According to Inglehart, these developments, also known as "individual modernization", explain why the tendency exists to participate in alternative and unconventional activities in post-industrial democracies. First, due to their increasing education levels, information, and skills, people have a better chance to pursue their political goals more directly through these new activities. Second, since new political 
actors like social movements or action groups that stand for new political issues better represent the post-materialist value orientations, citizens become more inclined to join them in order to pursue their political objectives. Moreover, the unconventional forms of participation can better meet their needs of selfactualisation. There is thus reason for optimism about the future of the functioning of democracy in these societies, since the better educated and better informed citizens do nothing more than ask for more direct channels to express their increasing demands and more immediate responsiveness from authorities to these demands, therefore asking for more democracy.

Yet not all scholars shared this enthusiasm. The participatory expansion in postindustrial societies resulting out of societal modernization processes invoked also criticism and concerns about a possible crisis in Western representative democracies. The common point of these concerns was that the increased level, as well as range and variety of popular political participation, and an increasing range and variety of political demands would lead to an "overload of government" and thus reduce the ability of these governments to make political decisions and resolve political problems, which would end up in an increasing dissatisfaction of citizens (e.g. Crozier et al. 1975).

The criticism concerning societal modernization, increasing political participation, and government overload, was most clearly summed up by Samuel P. Huntington (1974). In his essay Post-industrial Politics: How Benign Will It Be? he speaks about the dark side of post-industrial society, in which expanding political participation is assumed to make the society extraordinarily difficult to govern. He sees a danger in both components of individual modernization, namely the processes of increasing skills and the post-materialist value change. Growth in education and the resulting sense of political efficacy mean an increase in the knowledge of political and social problems and of the desire to do something about those problems. This in turn leads to a steep increase of citizen involvement in politics. Up to this point Huntington's views are identical with modernization theorists. Yet he differs from them through his rather pessimist view on the consequences of this development. According to Huntington, effective governmental action is more difficult in a society with a more highly educated and participant population, since in such a society there will more likely be a gap between people's ideas on what the government should accomplish and the actual output of the government. If this gap were sustained for a longer time, it could lead to "deep feelings of frustration, a reaction against existing political institutions and practices, and a demand for a new political system that could count and would do what had to be done" (Huntington 1974: 177). 
This frustration would possibly lead to increasing dissatisfaction with and lack of confidence in the functioning of the institutions of democratic government, which will weaken the legitimacy of the state. Further, frustration with existing political practices can produce radical ways of expressing demands such as violence, or political extremism. The result, in any case, would be a crisis of the regime, which might call for the adoption of a more authoritative and effective pattern of governmental decision-making. This development, according to Huntington, constitutes the darker side of post-industrial society, which makes it likely that postindustrial politics will be less benign than industrial politics (1974: 166). Following this line of thinking, it has even been claimed by prominent politicians that "Western Europe has only twenty or thirty years of democracy left in it; after that it will slide, engineless and rudderless, under the surrounding seas of dictatorship, and whether the dictation comes from a politburo or a junta will not make that much difference" (Willy Brandt, quoted in Crozier et al. 1975: 2).

\subsection{Instrumental and Expressive Political Involvement}

Huntington's gloomy predictions about the possible negative implications of the increase in the levels and forms of political action on the stability of democracy are hardly shared anymore; after all, European democracies have weathered all storms in the thirty-five years after these claims. Yet as government overload and crisis of democracy theories were popular in the 1970s, these views were highly influential and have flowed into the reflections of Max Kaase and Samuel H. Barnes in the concluding chapter of the Political Action Study (1979). The main findings of this study are, in a nutshell, that the new repertory of political action - which they call unconventional or protest action - is increasing, most commonly among the youth and reinforced mainly by the increase in level of education, cognitive skills, and postmaterialist value orientations. Since these determinants are structural features and therefore permanent, Kaase and Barnes have concluded that the increase in new forms of political participation was likely to be "a lasting characteristic of democratic mass publics and not just a sudden surge in political involvement bound to fade away as time goes by" (1979: 524). However, they have also expressed concern about the linkage between post-materialist values and unconventional action, claiming that this may be a potential source of strain in post-industrial societies (1979: 525).

Reflecting on Huntington's question of how benign post-industrial politics will be, they have posed the critical question on the future implications of this development in democratic societies. However, their arguments differ from 
Huntington's at a very decisive point: Huntington has suggested that the dynamics of post-industrial society produce both high political interest and political participation, both of which would hinder effective governmental action. Kaase and Barnes, on the contrary, have claimed that political participation accompanied by political interest is rational and responsible action which broadens the legitimacy basis of democratic decision-making. In case this growing potential is channeled and dissatisfactions can be absorbed through new institutions which are compatible with these demands, this development will form no threat to democratic stability. Yet if participation is irrational, i.e. does not involve clear political goals, it can be interpreted as a sign of eventual problems. By referring to political interest as the main motivation behind participation, Kaase and Barnes have developed a typology of political action, which includes four different types of involvement as displayed in table 1.1 below.

Table 1.1 Typology of political interest and political action

\begin{tabular}{|c|c|c|c|}
\hline \multicolumn{2}{|c|}{} & \multicolumn{2}{c|}{ Political Action } \\
\cline { 2 - 4 } & Yes & No \\
\hline \multirow{2}{*}{$\begin{array}{c}\text { Political } \\
\text { Interest }\end{array}$} & Yes & Instrumental political action & Political detachment \\
\cline { 2 - 4 } & No & Expressive political action & Political apathy \\
\hline
\end{tabular}

Source: Kaase \& Barnes 1979: 524

According to Kaase and Barnes, the key to predict the future of post-industrial politics is the balance between instrumentally and expressively motivated political actions (1979: 526). They claim that democratic government is not being threatened by the rise of political action itself, but rather by the potential increase in expressive political involvement, which they describe as an "orientation toward political action without political motivation" (1979: 527). This political style is supposed to be highly disruptive for the functioning of democracies, since "an expressive political style undermines the basis for rational decision-making by hindering rational interchanges between authorities and partisans" (1979: 528). Articulation of ambiguous goals hampers the capacity of the government to take action in order to respond to demands appropriately, which, in the long run, may lead to delegitimization rather than the stabilization of the political system (1979: 530). Kaase and Barnes have thus interpreted Huntington's (1974) prediction, that the future of post-industrial politics will be less benign, as implying this kind of development. They warn against the possible development of an expressive political style, though 
they do not share Huntington's pessimism completely. They are even critical toward Huntington's approach to benign politics as the maintenance of the political order. Unconventional political action becoming widespread is in their view not a matter of concern, as long as they are being motivated by an instrumental orientation of the citizens.

The empirical analyses in the five Western democracies analyzed within the Political Action project have shown first of all that both political action types have considerable levels in all countries. While instrumental political action was found to dominate everywhere, analyses have shown that the expressive political mode does not exceed one-third of the population in any country (1979: 528). A second and perhaps more interesting finding was that respondents with a prevailing preference for conventional political activities - such as voting, party activities, and contacting officials - as well as those who are prone to both conventional and unconventional political participation have a predominantly instrumental political style, while expressive political action is most common among those who make disproportionately high use of unconventional activities. Since younger generations were also highly represented in this group, Kaase and Barnes have argued that expressive political action is a political style which probably reflects youth and its fads; and concluded that since research has repeatedly shown that political interest increases as people grow older, expressive political action will probably not develop to a greater extent in the future. Their main inference therefore is that there is no serious threat for rational politics and democracy, in other words, the scenario that the "darker side of post-industrial politics" will show its face is highly unlikely.

With the development of this typology, Kaase and Barnes have made a valuable contribution to the debate on post-industrial modernization, participation, and democracy. They have provided a new insight into this complex relationship by suggesting that it is not only the amount of participation that matters for democratic quality; the motivations behind political participation are just as essential for future prospects on the stability and efficiency of democratic government. An important limitation is however the vagueness of their arguments on the link between instrumental or expressive types of involvement and the rationality of political action, and how this relates to democratic stability: They make clear that political participation without political motivation should be regarded as a sign of irrational behavior and would weaken the foundations of democratic decision-making. Yet they do not clearly explain why this should be the case. Moreover, they do not provide a clear argument on how rational-instrumental or irrational-expressive political action could be related to post-industrial society and its politics. As 
indicated above, the modernization processes in Western post-industrial societies have invoked a multitude of societal-cultural changes including the increasing sophistication of citizens and their changing value preferences from materialist to post-materialist values. Yet these shifts which were supposed to have led to the big participatory change have not been taken into consideration in the arguments of Kaase and Barnes. We suggest that if one establishes links between these types of political action and certain characteristics of post-industrial society as well as its citizens, one could make more reliable predictions on the possible development of democracy in these societies. The central research question of this study is therefore as follows:

What kind of political involvement is generated by the changes in social-cultural conditions in post-industrial societies?

In answering this question, we will focus particularly on the individual-level cultural determinants of political involvement types. It is important to note that we will use the term "political involvement" for the types of political action mentioned above. The usage of this term varies highly in the literature; it has been used simultaneously as a synonym for interest in or awareness about politics (e.g. Almond \& Verba 1963; Zaller 1990; Van Deth \& Elff 2000, 2004) or even for political participation (e.g. Barnes \& Kaase et al. 1979; Topf 1995a). Some authors, however, suggest that political involvement "can be indicated by attitudes towards politics and actual behavior to influence politics" (Thomassen \& Van Deth 1998: 143). We also intend to use this term here as an expression for a phenomenon including both an attitudinal and a behavioral dimension and therefore prefer to use it as an expression for instrumental and expressive political behavior.

\subsection{State of Research}

The development of unconventional and/or protest participation has been observed by diverse authors over the past three decades. Since then, political participation has been the central object in almost all comparative studies of empirical research on democracy in the last decades (e.g. Verba et al. 1978; Barnes \& Kaase et al. 1979; Jennings \& Van Deth et al. 1990). Also, many single case studies have focused on citizen participation in a given country (e.g. Parry et al. 1992; Verba et al. 1995; Norris 2002). The common conclusion of this research is that citizens have been making less use of conventional means of political participation, and the inclination to use alternative channels such as petition signing and participating in demonstrations has 
been growing rapidly. Other research has shown that new social movements such as the women's movement, the environmental movement, and diverse nongovernmental organizations have become important channels of political mobilization and expression (e.g. Dalton \& Küchler 1990; McAdam et al. 1996; Tarrow 1998). In the last couple of years the new repertoire of political participation has broadened towards the engagement in consumer activities like buying or boycotting products for political reasons and further the internet has also become a popular tool to influence public policy (e.g. Stolle et al. 2005).

Yet with respect to instrumental and expressive types of political involvement there has hardly any research been done in the same period. The only existing study is by Richard Topf, which he conducted within the Beliefs in Government Project of 1995. Topf has observed the development of non-institutionalized participation ${ }^{1}$ using data for four time points: 1959, 1974, 1980, and 1989/90 in thirteen Western European democracies ${ }^{2}$. He found, with respect to these types of participation, that $85 \%$ of the respondents had not engaged in non-institutionalized political activities by 1959 , whereas by 1990 this percentage had almost halved to $44 \%$. Thus there has been a remarkable increase in the use of non-institutionalized forms of participation.

Topf has furthermore analyzed the four modes of political involvement based on the typology of Kaase and Barnes. His results showed that instrumental political involvement had remained the dominant mode in all of the countries. There is little evidence that the large increase in non-institutionalized political participation was primarily due to an increase in expressive modes of action. Furthermore, expressive involvement appears more frequently in the economically less developed countries of Southern Europe, while the post-industrial nations of Central and Northern Europe are dominated by instrumental behavior. There is a small increase in expressive political activism, which, in the light of overall expansion in noninstitutionalized political participation, seems quite plausible. The assumption on the possible shift towards expressive political behavior finds little empirical support in the data which Topf presents. He concludes that if processes of post-modernization have indeed taken place in Western Europe over the last decades, then those

\footnotetext{
${ }^{1}$ Non-institutionalized participation was measured by a cumulative index based on the types of political activities first used in the Political Action Surveys. The index consisted of the following activities: joining citizens' action groups, signing petitions, attending lawful demonstrations, joining boycotts, joining rent/tax strikes, joining unofficial strikes, occupying buildings, blocking the traffic, damaging things, and using personal violence.

2 The analyzed countries are Belgium, Britain, Denmark, Finland, France, Germany (West), Iceland, Ireland, Italy, the Netherlands, Norway, Sweden, and Spain.
} 
processes have been accompanied by increasing instrumental political involvement, not by the expressive one.

Although Topf's analysis conveys trends in the development of both involvement types, it is solely based on changes over time of the population at large. Therefore the results are hardly appropriate to make connections between post-industrialization and the developments in political involvement. The individual-level implications of post-industrial modernization, namely the increase in skills and value change reflect gradual developments; especially the changes in value orientations certainly do not occur overnight. The main premise of Inglehart's above described theory of postmaterialist value change is that this change takes place due to generation replacement, which means that the emphasis on post-materialism of the younger generations tends to remain over their life and is not likely to become less important as they get older. As a consequence, these new values get established in the society as old values die away with older generations. Accordingly, one could expect specific types of political involvement, which are supposed to result from these changes, to become an established pattern due to the same mechanism. However, this mechanism cannot be captured by observing the raw development of political involvement: one should take the developments among generations also into consideration. Only in this way it is possible to make predictions about the future trends of political involvement and therefore on the future of democratic stability.

More recent studies which have analyzed the generational trends in these involvement types indicate that in successive generations the balance between expressive and instrumental political participation gradually shifts towards the expressive mode (Aarts \& Thomassen 2000; Aarts et al. 2000; Thomassen \& Van der Kolk 2002). They have concluded that expressive participation does indeed dominate among the younger birth cohorts. Yet these analyses have been conducted only in the Netherlands and therefore cannot provide enough information on whether this is a general pattern for post-industrial societies.

\subsection{Theoretical Framework and Analytical Design}

The ambition of this study is to fill in the research gap discussed above by analyzing the development of instrumental and expressive political involvement in a broader context, namely, in twelve Western post-industrial democracies in a comparative perspective. Also, the development of both types of involvement among generations will be observed. Additionally, we intend to provide a comprehensive theoretical 
framework as well as a solid empirical foundation for the causal relationships between certain characteristics and attitudes of citizens and their political involvement, which shall provide a basis for answering our research question.

Not only understanding the causes of different forms of political involvement, but also anticipating their implications is of the utmost importance for the future of democracy debate. As we focus exclusively on well-established post-industrial democracies in this study, it will unfortunately not be possible to test empirically if and in what way instrumental or expressive political involvement are related to the stability of democratic systems. Yet by assessing whether democratic qualities and attitudes underlie these involvement types or not, we can strengthen the arguments of why a specific type of involvement would be advantageous or detrimental to democratic stability. We will base this assessment on a solid theoretical framework by drawing on normative democratic theories, which evaluate the meaning of citizen participation in decision-making processes from different perspectives. More specifically, we will compare theories of liberal-representative and participatorydirect democracy to understand the intellectual backgrounds of the interpretations of contemporary developments in citizen involvement.

For the explanation of why specific types of political involvement develop, we will refer to the value change hypothesis within the modernization theories. As indicated above, the post-materialist value change which has taken place in postindustrial societies is thought to have influenced people's political orientations and participatory behavior. According to Inglehart, new value priorities of citizens imply pro-democratic orientations which emphasize new quality of life issues, human freedom and choice, self-determination, and self-expression. On these grounds, the expectation is that citizens will get increasingly involved in the political decisionmaking process, and that they will do so in order to reach their individual goals by making their demands heard. Yet there are also competing views on changing value priorities and their implications in post-industrial societies. These critical analyses, while agreeing that a change in value orientations among citizens has taken place, predict a highly different direction of this change. In his work The Cultural Contradictions of Capitalism, Daniel Bell (1976) has claimed that individual modernization leads to a consumer culture dominated by irrationality and hedonistic value orientations, where citizens' behavior is primarily driven by motivations such as self-fulfillment, enjoyment, and consumption, and less by collective goals and ideals (see also Bellah et al. 1985; Turner 1989; Crook et al. 1992; Fuchs \& Klingemann 1995). Especially the self-actualization component of Inglehart's value concept, which he himself regards as the central constituent of post-materialism, is thought to 
contain hedonistic and irrational elements. The search for hedonistic selfactualization can, in turn, lead to a lack of interest in politics while participation in new forms of political action increases (Fuchs \& Klingemann 1995).

Building upon this theoretical background, we will design our study according to the following analytical framework:

Figure 1.1 The analytical framework of this study

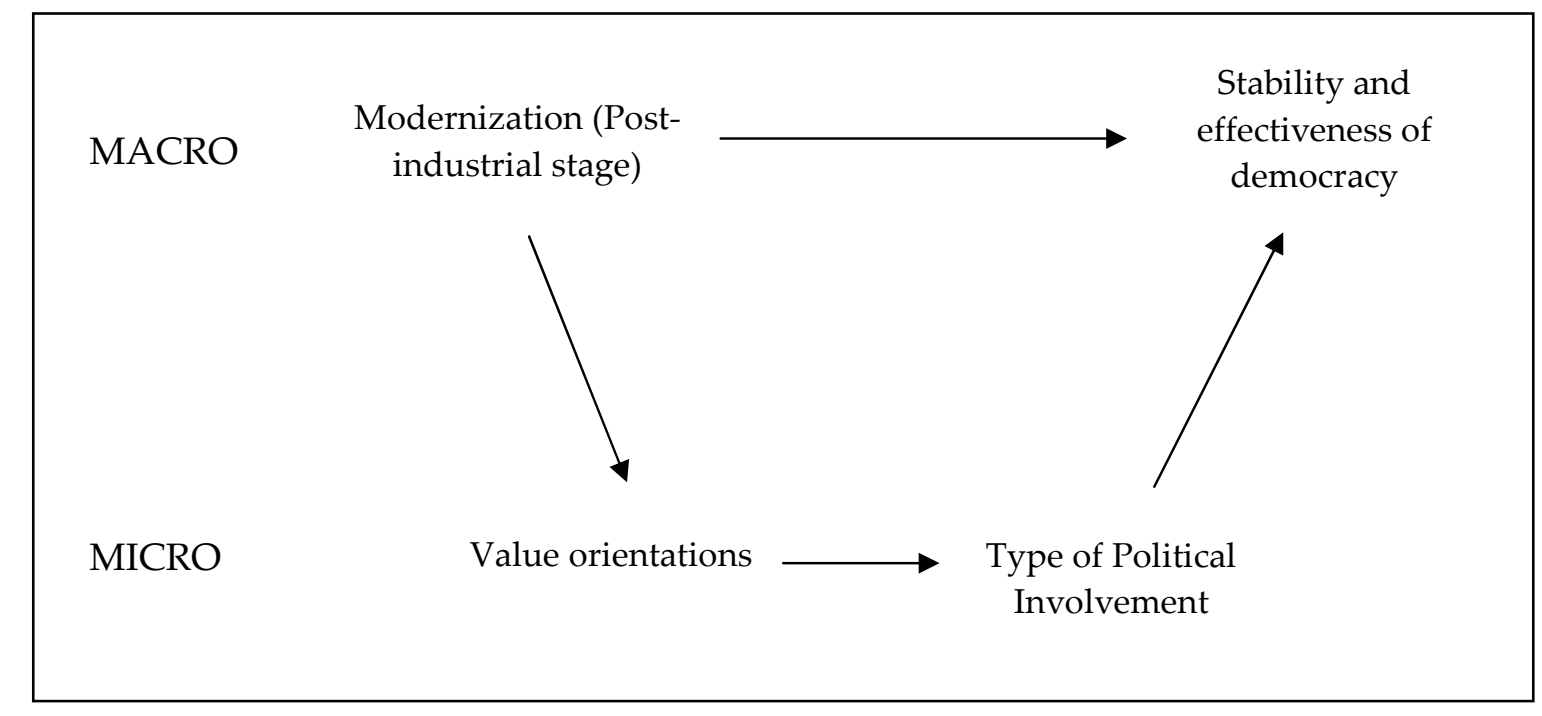

The two contending views by Inglehart and Huntington - introduced in section 1.1 - assess relationships between two macro-level phenomena: Post-industrial modernization and the stability of democracy. While doing this, they depend on two different causal mechanisms. Inglehart's theory emphasizes the value change component of modernization and focuses upon its democratic implications. Therefore, the causal order he suggests is Modernization $\rightarrow$ Values $\rightarrow$ Democratic stability, where values, as cultural factors, are thought to be the intervening variable in the above mentioned macro-level link between modernization and democracy. Huntington, on the other hand, stresses the importance of increasing levels of political participation which are due to the modernization process, and predicts negative conclusions for democratic stability. Thus his pattern of arguments follows the causal order Modernization $\rightarrow$ Level of Participation $\rightarrow$ Democracy. We have shown in section 1.2 that Kaase and Barnes have improved this causal sequence by emphasizing the relevance of the type of political involvement, which can be specified according to the motivations of participation: thus the new causal chain they suggest is Modernization $\rightarrow$ Type of Political Involvement $\rightarrow$ Stability of Democracy. 
We improve these arguments in this study by adding the much contested value orientations into the causal scheme, as shown in figure 1.1. We will first concentrate on the theoretical relationships between the micro- and macro-level phenomena in the first section. After that, we will observe the two micro-level phenomena - values and instrumental-expressive political involvement - and their relationships with each other empirically. Here we will try to provide answers to the following subquestions:

1. What is the prevailing type of political involvement in post-industrial democracies?

2. How are instrumental and expressive involvement types likely to develop in postindustrial democracies?

3. Which value orientations prevail in post-industrial democracies?

4. To what extent do value orientations account for the type of political involvement?

We will try to answer the first question by doing descriptive analyses of the levels and development of both instrumental and expressive political involvement in twelve European post-industrial democracies. We selected these cases based on the three most common indicators of post-industrial societies: a high GDP per capita, long democratic experience, and the majority of the work force employed in the tertiary sector. Using these criteria, we picked the following countries: Austria, Belgium, Denmark, Finland, France, Ireland, the Netherlands, Norway, Sweden, Switzerland, the United Kingdom, and West Germany. Countries such as Spain, Portugal and Greece as well as the Eastern part of Germany will not be included due to their relatively short experience with modern democracy. Additionally, in Portugal and Greece the percentage of workers in the industrial sector exceeds the number of those working in the service sector; therefore these countries fail to fulfill this important criterion for post-industrialization. Finally, Italy has also been left out because the values items have not been surveyed in this country. By this method we aim to establish if there is a general pattern of involvement in all countries with a similar level of post-industrialization or if there are cross-country differences.

To answer the second question we will observe the development of involvement patterns among birth cohorts in order to see if these involvement types - just like the values - are likely to become established through generation replacement. For the last two questions, we will observe the distribution of value priorities among countries and conduct causal analyses to find out through which mechanism the 
relationship between individualization processes and political involvement operates. Again here, we are interested in potential cross-country differences.

If we find evidence that the specified causal mechanisms in figure 1.1 indeed exist, it will provide insights not only into the future of democratic stability, but also into possible measures to deal with the challenges to democracy. Although Huntington's views on a possible collapse of democratic government due to increasing demands and political activities of citizens are not anymore popular, he has made a good point by diagnosing that the existing political institutions - such as political parties, interest groups, associations, and the electoral mechanism - are not anymore adequate to deal with the broadening demands to participate in political decision-making. In order to overcome this shortcoming, there have been numerous innovative attempts to design the democratic institutions anew to include more citizens in democratic decision-making in advanced Western democracies in the past decades. Having focused upon an area which has been highly neglected in the research until now, this study can contribute to this democratic innovation process with its findings on the prevailing type of political involvement and its backgrounds as well as through its reflections on the stability of democracy debate.

\subsection{Outline of the Book}

The first part of the study will focus on the theoretical backgrounds which form the backbone of the main arguments to be tested here. Chapter 2 will focus on the first micro-macro-link between political involvement and democracy (see figure 1.1). Here, we will discuss the meaning of political participation for democracy based on the theoretical ideals on the appropriate levels of political participation, starting from ancient Athenian democracy to contemporary normative democratic theories of the $20^{\text {th }}$ century. We have mentioned above that the link between participation and democracy cannot be tested empirically, thus an elaboration on this relationship in this chapter, by focusing on normative theories, should act as a basis for later evaluations. Chapter 3 will concentrate on the phenomenon of political participation by giving an extensive overview of its development in the past decades as well as the development of its research. In chapter 4, we will discuss the mechanisms underlying the portrayed changes in political involvement in Western post-industrial democracies. The main focus will be here on the processes of post-industrialization and post-modernization: these processes are assumed to have changed the political behavior of citizens due to the so-called individual modernization, which implicates shifts in their skills, value orientations, and attitudes. The possible links between the 
types of political involvement, individual modernization, and the implications of these relationships for the stability of democracy will be addressed in chapter 5 . More specifically, referring to the above mentioned two contending theories, we will try to outline which types of post-modern orientations among citizens are supposed to lead to which type of political involvement, and whether these involvement types will have positive democratic consequences or not. Utilizing these arguments, we will develop alternative answers to the four empirical questions presented above in the form of testable hypotheses.

Using survey data, these hypotheses will then be tested in the second part of this study. Chapter 6 will discuss and test the hypotheses on the development of political involvement over time and among generations. In chapter 7 , we will prepare the backgrounds for the analysis of the value effects on political involvement types by formulating testable hypotheses and operationalizing the concept of values. Chapter 8 will present the causal analyses and discuss their results. In the concluding chapter 9, we will sum up the main findings of this study and draw conclusions for the future of democracy in post-industrial societies as well as for the future research prospects. 
PART I:

THEORETICAL BACKGROUNDS 


\section{Chapter 2}

\section{How Much Participation? Citizen Involvement in Democratic Theory}

"Citizen participation is at the heart of democracy. Indeed, democracy is unthinkable without the ability of citizens to participate freely in the governing process."

-- Verba et al. 1995

In this chapter we will start providing the theoretical background for our study by discussing the meaning of citizen participation in collective decision-making processes within democratic political systems. As we aim in this study to analyze certain types of citizen involvement and draw conclusions on the implications of these different types of involvement for the future of democracy, this chapter will form the backbone of the whole theoretical discussion that will follow.

As to be taken from the famous statement by Sidney Verba, Kay Lehman Schlozman and Henry E. Brady quoted above, democracy as a regime of "government by the people" is simply inconceivable without the political participation of its citizens. However, the question remains on how much participation is needed: opinions differ about the desired level and type of participation for an effectively functioning and stable democracy. Should citizens play an active role in policy-making and attempt to influence as many government outputs as they can through a variety of channels? Or should their activity be restricted to selecting elites and leaving the responsibility of policy-making to them? Which level and type of citizen participation make a democracy function more effectively? This chapter will evaluate the interconnection between citizen participation and democracy by focusing on different strands of democratic thought and the answers they have provided to these questions.

While dealing with this topic, we will apply the following strategy: first, to introduce the discussion of different democratic models, we will attempt to provide a 
basic description of the notion of democracy as well as a discussion on the meaning of political participation. The forthcoming sections will show that there are a wide variety of ideals which are attributed to the democracy concept. However, some of these ideals contradict each other strongly, resulting in different understandings of democracy which then in turn leads to differing understandings of the value of citizen participation in the decision-making process. Therefore, it is important to establish an elementary introduction of these concepts in order to provide a theoretical foundation.

Following upon this, we will try to strengthen this background by giving an overview of the historical development of the relationship between democracy and participation. We will do this in a chronological sequence from classical Athenian democracy to the democratic thought and practice of the modern age. Section 2.2 will first focus on the practice of citizen participation in the antique Athenian democracy. It is important to take the ancient democratic practices into account for at least two reasons. First of all, the concept of democracy as a form of rule has developed out of this practice. Second, as we will discuss later, modern theories of democracy are characterized by an entangled use of descriptive-explanatory and normative statements. More specifically, they strongly tend to base their normative statements on democracy on the empirical reality. By having the Athenian democracy as a reference point, one can avoid running the fallacy of deriving normative criteria for modern democracies and their empirical practice (see Fuchs 2007).

In section 2.3, we will then discuss the development of modern democratic thought starting from the emergence of the liberal (or respectively representative) democracy. Although there is a wide range of contemporary democracy models, we will here restrict ourselves to two main contradicting views on the relation of democracy and citizen participation: the so-called "liberal theories of democracy" (e.g. Schumpeter, Dahl) and the model of "participatory democracy" (e.g. Pateman, Barber) (see table 2.1). This theoretical debate will be addressed extensively in this section, followed by a critical review of the whole discussion and concluding remarks.

\subsection{Political Participation and Democracy: Concepts in Flux?}

The word democracy is derived from the Greek word Demokratia, the root meanings of which are demos (people) and kratos (rule). Even the contemporary studies on the theory of democracy are based on this simple etymology of the word (e.g. Pennock 
1979; Sartori 1992; Schmidt 2000). Accordingly, we can literally translate democracy to be a form of government in which - contrary to monarchies and aristocracies - the people rule.

However simple and unambiguous the definition of the concept of democracy as "government by people" may appear, there is a wide variety of types and concepts of democracy in contemporary political science. In fact, the whole history of the idea of democracy is "complex and marked by conflicting conceptions" (Held 2006: 1). This is the case because democracy is understood both as a "set of political institutions" and a "set of political ideals" (Hansen 1996: 90; see also Sartori 1992; Eder 1998); yet there is no consensus on the composition of these sets. The plurality of democratic ideals as well as their interpretations has led to a wide set of normative views which in turn had consequences for democracy as a "set of political institutions"; as the dominance of one specific understanding of democracy within a context requires specific institutional arrangements in line with that understanding, a diversity of democratic practices has resulted out of the variety of democratic ideals and of normative democratic thought.

Another reason why definitions of democracy differ to a great extent is that each element of the phrase democracy, demos and kratos, is open for interpretation. First, it is a matter of dispute how demos can be defined (citizenship), what its characteristics are (in terms of resources, skills, motivations, and attitudes) and finally what the scope of their competences in ruling should be (kind and amount of participation). Second, the element kratos (rule) is being disputed in terms of what the term rule covers (fields of government activity) and how broad the scope of rule should be (see Held 2006). The differences in the interpretation of these terms result inevitably in a multitude of conceptions and debates about the meaning of "rule by the people". Positions vary particularly around the question on how to guarantee the success and efficiency of people's rule; the answer of which requires a strict definition of the rulers and the ruled, and of the division of executive power between them. The divided answers to this question have led to different strands of democratic thought with highly differing normative ideals on citizen-state relationships, which still form a basis for the ongoing discussion on how to design democratic institutions and how to respond to contemporary challenges of democratic government.

This multi-faceted interpretation of rule by the people is above all being reflected in the dispute on the role of citizens - the demos - in democratic decision-making. Citizen participation in political life is the main instrument to put government by the 
people into practice, thus it is the constitutive characteristic of democracy. Democracy differs from other political regimes in the way that state power is legitimized through the principle of sovereignty of the people. By participating actively in political decision-making as well as by getting involved in the formation of the collective will through articulating their interests and demands, citizens exercise their sovereignty rights. In this regard, participation is the necessary link between the exercise of state power and the citizens' will. However, throughout the historical development of democracy, the role ascribed to citizen participation has varied strongly. The main issue where the positions clash has been determining whether democracy will mean some kind of "popular power", i.e. a form of life in which citizens are engaged in self-government and self-regulation, or an aid to decision-making in terms of legitimizing the decisions of those voted into power"representatives"- from time to time (see Held 2006: 3). Thus, like democracy, the nature and amount of citizen participation in the political decision-making processes have always been a matter of discussion in the history of theoretical views on democracy; and this discussion still continues.

In the following, we will start reviewing this discussion by going to the "roots" of the idea of democracy, namely, by presenting the democratic experience of antique Athenian democracy. It is important to take this into account for at least two reasons. First of all, democracy as a form of rule has developed out of Athenian democracy, which was the first democratic rule in which people literally governed themselves. Therefore, this democracy model serves as an archetype for many contemporary democratic theories, particularly the participatory theory of democracy. Second, relying on the Athenian model democracy as a reference point helps to reduce the above addressed complexity with respect to the conceptualization of democracy, which has transformed the term "into an empty shell that can be filled by everybody almost ad lib" (Eder 1998: 109). By having this model as the reference point one can avoid this arbitrariness as well as the danger of running the fallacy of deriving normative criteria for modern democracies based solely on their empirical development (see Fuchs 2007: 29).

\subsection{The Development of Democracy and the Understanding of Citizen Participation}

Above we have shown that a multitude of different understandings of democratic governments has developed out of differing interpretations of the term democracy. In this section we will present the milestones of this development. We start by 
demonstrating how people's rule was realized in classical Athenian democracy, and then move on to the understanding of democratic citizen participation in modern times.

\subsubsection{Classical Athenian democracy and the practice of citizen involvement}

To analyze the ideal and the working of democracy in the ancient Athenian democracy, we will have to focus on both components of the democratic governance: demos and kratos. In the democracy of Athens, the demos included all citizens, i.e. all male inhabitants with political rights (this excludes women, immigrants and slaves from participating). The rule of citizens was based mainly on two essential principles. On the one hand, as stressed by Herodotus (and later by Aristotle), democracy literally meant rule by the mass (plethos), the majority (polloi), or the people (demos), and not by the few let alone an individual (see Fuchs 2000: 252). Also, the equality of citizens in the exercise of political rule was of decisive importance in the antique understanding of democracy, which meant that poor and rich citizens had equal part in government regardless of class and level of education (Bleicken 1994: 288).

Certain aspects of the institutional structure of democratic government in antique Athens - i.e. the kratos component of democracy - are relatively similar to those of the modern democratic system: there was a citizens' assembly which fulfilled a legislative function, the "council of the five hundred" which functioned as an executive, and people's courts whose members were chosen yearly by lot. These institutional arrangements were intended and actually did ensure that the demos itself did literally rule. By permanent rotation of rulers and the ruled, the choice of office-holders by lot, and especially the concentration of the power to make binding decisions for the city-state (polis) in the assembly, it could be achieved what modern democracy theory calls the identity of rulers and the ruled.

From many other perspectives, however, Athenian democracy was quite different from the modern democratic governance. Perhaps the most important difference was that in the Athenian state the distinction between state and society, specialized officials and citizens, or the "people" and the government was not part of the political philosophy (Held 2006). The principle of democratic government was direct participation. The notion of an active, involved citizenry in a process of selfgovernment was central to the understanding of governance; the governors were literally the ones to be governed. All citizens met to debate, decide, and enact the law; there was an enormous extent of political engagement (see e.g. Hansen 1991; Meier 1993). Nearly a quarter of all citizens were involved each year by holding and 
exercising public office. This unique level of citizen involvement in politics raises questions of motivation. Material gratifications in the form of allowances, pay and land grants, and increased public status have been suggested as motivating factors for high involvement (Meier 1993; Bleicken 1994). We may however also count the type of public opinion-building and the nature of the demos among these motivating factors (Fuchs 2000: 255 ff.).

The public opinion, first of all, was formed mainly through extensive discussions and deliberation of public affairs at the assembly and the council. Freedom of speech was hereby the key element in opinion building (Bleicken 1994). The will of the demos was, then, formed through joint deliberation by the physically present demos in the assembly. To this extent one can speak of a collective will of the demos that is more than an aggregation of individual opinions. A decision adopted by the assembly was an outcome of the deliberations and accordingly constituted an authentic expression of the collective will. Hence, the process of government was based on deliberative decision-making and not solely casting one's vote. What Pericles refers to as "proper discussions" (as cited in Held 2006: 15), is a free and unrestricted discourse, guaranteed by an equal right to speak in the sovereign assembly. The only restriction was that the proposed issue should be justified in terms of the utility for the polis, i.e. an issue subject to discussion was only legitimate if it appealed to the common good and was therefore non-particular in nature.

Finally, the demos of Athenian democracy was "not an imagined collective subject (as it is the case in the modern nation-states) but a tangible collective subject" (Fuchs 2007: 33). This was among others because of the fact that political deliberation was not limited to the assembly; discussions were conducted also in other public places like the marketplace, gymnasiums etc. Yet one should take into account that this was made possible to a great extent by the small number as well as the ethnic-cultural homogeneity of the citizenry (see Fuchs 2007).

In sum, Athenian democracy was a community in which all citizens could and indeed should participate in political life and in the conducting of public affairs. The principle of equality was guaranteed in the sense that citizens faced no obstacles to involvement in public affairs or engagement in legislative and judicial functions based on rank or wealth. Though this freedom also included the freedom of nonparticipation, each individual was expected to be interested in the affairs of the state, no matter how occupied they were with their own personal business. As Pericles says, "we do not say that a man who takes no interest in politics is a man who minds his own business; we say that he has no business here at all" (as cited in Held 2006: 
14) As it will be clear from this statement, Athenian democracy was marked by a general commitment to the principle of civic virtue; that is, dedication to the republican city-state and the subordination of private life to public affairs and the common good (Held 2006: 14).

The development of democracy in Athens has formed a central source of inspiration for modern political thought. Athenian political ideals, such as equal rights to participate in the assembly or to hold and to control public office, have shaped political thinking in the West through the ages. Yet the Athenian democracy falls short of contemporary democratic models in several aspects. There are some central ideas - for instance, the modern liberal notion that human beings are 'individuals' with 'rights' - that notably cannot be directly traced to Athens. These aspects have been addressed by modern as well as ancient critics (see e.g. Plato, The Republic). Perhaps the most important deficit of Athenian democracy is the highly restricted understanding of citizenship. Only male citizens with an Athenian background were given citizens' rights; other groups in the society (women, slaves, non-Athenians) were excluded from this status and the rights attached to it. In that sense, the principle of equality was realized only to a limited extent and the principle of freedom was nonexistent. The arbitrariness of decision-making and legal processes - as it has become visible e.g. in the trial and death of Socrates in 399 BC - was another point of criticism on ancient democracy. A common understanding of rule of law, or Rechtsstaat, in terms of modern liberal practice was not present in Athens. Yet despite these limitations, certain aspects of the antique democracy, such as the extent of participation by citizens and the nature of public opinion building and decisionmaking have inspired modern Western democratic thought. These aspects, as we will discuss later, have been a source of inspiration particularly for participatory democracy theories.

\subsubsection{Political involvement in modern democracy}

Though having an enduring impact upon modern Western political thought, neither the model of classical Athenian democracy nor its critique had immediate theoretical and practical influence on contemporary democracy. This has resulted in historical discontinuity between antique and modern democracy; the latter began to develop in North America and Europe in the $17^{\text {th }}$ and $18^{\text {th }}$ centuries. Nevertheless, the two types of democracy are comparable in manifold ways. Most importantly, the conceptual core of both democratic models consists of the values of citizen participation, freedom, and equality (see Hansen 1996). Yet there are also fundamental differences between the two models, particularly with respect to the institutional settings (choice 
of rulers) as well as the scope of citizen involvement in the exercise of rule (see especially Sartori 1992; Eder 1998).

The relationship between antique and modern democracy has been a subject of debate among political thinkers in the $17^{\text {th }}$ and $18^{\text {th }}$ centuries. Due to events such as the English Revolution (1640-48), the American Declaration of Independence (1776), and the French Revolution (1789), dramatic changes began to take place in the nature of politics in this era. Especially the latter evoked a debate about the "rights of men" (droits de l'homme et du citoyen) and gave way to a decline of the significance of old political and religious traditions. The nature and consequences of citizens' involvement in government became a special concern. As a result, the (re)regulation of the relationships, between individuals, and between the individual and the government, gained importance. Philosophers of this era such as Thomas Hobbes, John Locke, and Jean-Jacques Rousseau developed the earliest concepts on these relationships around the idea of a "social contract". Hobbes and Locke emphasized the need for citizens to willingly give up some of their rights in favor of others' rights in order to establish the state as a sovereign which would protect the rights of individuals and regulate their relationships with each other. Almost a century later, Rousseau stressed the idea of popular sovereignty, which can only be realized when each individual puts his power under the rule of law. This requires the delegation of power to a government which will apply the law and thus protect the popular sovereignty - or the general will - against individual interests. In short, through delegation of power it would be possible for individuals to participate in a social arrangement which enhances the shared prospects among all participants in a defined community.

This early thought was thus the precursor of modern democratic terms such as people's sovereignty and the legitimation of political authority by the rule of law. Despite this achievement, however, the dominant view for a long time remained that democracy was possible only in a small territory among a small number of citizens (e.g. Rousseau, Montesquieu). Therefore, little chance was given to the newly developed nation-states, which encompassed large territories and had populations in the millions, to implement a democratic system of governance.

The solution to the problem of increasing size and extent of the populations and territories was offered by the principle of representation (Dahl 1989). Representation originally did not arise as a democratic institution; it developed in the Medieval Ages in the context of monarchical and aristocratic systems of government (Kielmansegg 1988; Dahl 1989). John Stuart Mill was the first to suggest the combination of the 
principle of representation with the classical idea of democracy. According to Mill, it became necessary with the emergence and growth of the nation-state to set up a system of representation in which those defined as citizens with economic, legal, and social rights would elect representatives: "since all cannot, in a community exceeding a single small town, participate in any but minor portions of the public business, it follows that the ideal type of a perfect government must be representative (cited in Dahl 1989: 346).

With the combination of the principle of representation with the classical democratic principle, a democratic revolution was set in motion. This so-called "second democratic transformation" (Dahl 1989) led to the development of a completely new democracy. This new type of democracy is referred to as "liberal democracy", which can also be defined as representative democracy considering its institutional structures. Indeed, the combination of the democracy principle with the representation principle proved to be so decisive that the view that a democracy was only possible in small states was completely abandoned (Kielmansegg 1988; Dahl 1989).

As a matter of fact, representative government is not government by the people per se; then why label this form of government a democracy? The democratic character of representation is supposed to be ensured by free, equal, and competitive elections; the demos is free to take part in or abstain from them, has the opportunity to choose between alternatives, and every vote has equal weight. However, the mere act of electing representatives is not a satisfactory criterion for democracy. The idea of government by the people should also be ensured in the sense that the representatives rule in accordance with the will of the demos, that is, after being elected they cannot govern without any regard to the citizens. In other words, responsiveness of the rulers to the ruled must be guaranteed, which is enabled through the periodicity of elections and the possibility of change in government in representative democracy. Holding elections in regular intervals obliges the selected officials to be responsive: if they want to be re-elected again, they ought to take the demands, interests, and opinions of the demos into account.

The principles of election and the responsiveness of the rulers are crucial in liberal democracy since -unlike the Athenian democracy- there is a structural difference between the rulers and the ruled. This is characterized by a democratic self-government that is no longer literally government by the people: popular government through direct participation of the demos has been replaced by the selection of the government and the control of its responsiveness to the will of the 
demos, both of which are achieved by the institution of elections ${ }^{3}$. This transformation has inevitably affected the understanding and practice of political participation of the citizenry, the individual aspects of which we will address in the following.

The first consequence of the division of rulers and the ruled by the principle of representation is that the nature and type of participation has changed: "Whereas in antique democracy participation by the citizens in the government was both means and end, in liberal democracy it is now only a means to an end" (Fuchs 2007: 34). The aim of participation was limited to selecting representatives to govern, and therefore the act of participation by demos was limited to electoral participation. This surely cannot be understood merely as casting a vote; it also includes engagement in political parties as well as running for office as a representative of the demos. Next to this, there is the possibility of getting involved in voluntary civil society associations to articulate particular interests. However, since only a minority of citizens is involved in these types of organizations, the practice of self-government still remains limited to the selection of representatives. In connection with the limited types of participation, the extent of participation has been subject to transformation as well. Since elections do not take place very often, and since they are rather directed at the selection of representatives than contributing to policy-making, political participation in liberal democracy can be described as "occasional and limited" (Fuchs 2007: 35).

Other citizen involvement changes in liberal democracy took place in the nature of political opinion-building and the meaning of collective will: direct opinion formation, as it has been the case in Athenian democracy through joint deliberation by the demos in assemblies, is not exercised in liberal democracy. Political opinionbuilding is realized mostly by representatives and much less by involving citizens directly into the process. Moreover, the will of the demos is determined by the majority rule; it is materialized through the aggregation of individual interests by means of procedural rules instead of depending on authentic expression of the collective will of the demos. All these differences arouse the critical question still today: relying on the antique democracy as a reference point, to what extent can we speak of a demos in liberal democracy? Meier (1993: 478) approaches this question

\footnotetext{
${ }^{3}$ Elections can of course provide no entire guarantee that all demands by citizens will be met with response; and in case the rulers - contrary to expectations - do not act in the best interest of the public, it could lead to a lack of legitimacy. Yet the arrangements at the structural level, such as division of powers, protection of basic citizen rights and legal restrictions for political behavior, are directed at keeping the legitimacy of the system intact in the long run.
} 
with skepticism: "In all, it [Athenian democracy] was so abounded in particularities that it must be asked whether our democracy deserves the name at all when compared with the antique model" (as cited in Fuchs 2007: 36).

Advocates of liberal representative democracy have debated against these arguments. Sartori (1987), for example, repeatedly puts forward in his democracy theory that it makes no sense to set up the Athenian democracy as an ideal because of the completely different conditions of modern societies. He also points to the increased societal complexity as a factor which separates modern societies from the Athenian society. The decision-making activity of the political system has increased to a level that can no longer be compared with antique democracy, together with the increase in the complexity of the problems. The strong functional differentiation in the society requires that a multitude of services are to be performed, which is not possible without the differentiation of the political systems into professionalized roles. At the individual level, participation in self-government would mean under these conditions comprehensive and every-day engagement. This, however, involves situational and structural constraints such as high information costs and high expenditure of the scarce resources of time and energy. Investing these resources in actions of other subsystems would be more rational for the majority of citizens ${ }^{4}$, since the probability of realizing personal political goals and benefits through the participation is minimal.

Another justification put forward in favor of liberal democracy is that the power to make binding decisions for others is legally bounded and limited, which ensures the protection of the individual against the power of the state, on the one hand and the protection of minorities against majorities on the other (Kielmansegg 1988: 58). Sartori argues in a similar vein (1987: 283): “So, the limitation and control of power that our liberal democracies provide is not a lesser achievement vis-à-vis Greek democracy. For we have largely solved a problem that the Greeks did not have or did not face: providing a secure freedom for every individual." This discussion rightly emphasizes a major achievement of modern liberal democracies; however, it also points to an essential paradox of liberal democracies: the paradox between the basic democratic values of freedom and equality. The development of Western liberal democracy has been a historical compromise between these two principles

\footnotetext{
${ }^{4}$ There is empirical evidence to support this idea. Verba et al. (1995) found that the low relevance of politics in citizens' lives compared to other things (such as family, work, leisure time) is an important reason stated by American respondents for their political inactivity. Similarly, other studies have found that the subjective importance of politics - in comparison with other spheres of life - is lowest in all Western countries (see Fuchs 2000; Van Deth 2000).
} 
(see Thomassen 1995, 2007). This paradox has unavoidably led to different normative assumptions on citizen-state relationships, which have influenced democratic thought particularly in the $19^{\text {th }}$ and $20^{\text {th }}$ centuries. The following section will focus on the paradox between these two democratic values and the resulting strands of democratic thought.

\subsubsection{The freedom vs. equality paradox and the division in modern democratic thought}

The basic value of freedom, or liberty, has been the central value around which the conception of liberal democracy has been built. The idea of equality surfaced as its counterpart in the $19^{\text {th }}$ century, which at the beginning was strongly built upon the criticism of the liberal state and free market economy by Marx and Engels. The main argument in this criticism was that the liberal democratic state was far from creating an equal justice among individuals in spite of its claims to be acting on behalf of all citizens. The material inequalities among citizens resulting from the capitalist mode of production would inevitably lead to inequalities in participation in government. Therefore, creating social equality is the main prerequisite for creating the possibility of democratic politics 5 .

Another paradox which can be more closely related to participation rights is a dilemma within the principle of freedom. Based on different conceptions of freedom, two different strands of thought can be distinguished in democratic theory: individualist vs. collectivist theory. In both theories, the freedom concept plays a prominent role but the interpretations of freedom are different; this difference is reflected in the arguments on the relationship between citizens and the state, as well as in the views on to what extent freedom and equality are inconsistent with each other (see Thomassen 2007: 424 ff.).

The collectivist theory can be traced back to Rousseau and has a "positive" concept of freedom, which assumes a logical relationship between liberty and selfgovernment, participation, and democracy. Freedom and citizen participation are, according to this concept, the same thing. A free citizen is a citizen who takes part in the processes of decision-making, who actively participates in politics. The idea behind this assumption is that the laws which the citizens have to obey are produced by citizens themselves, thus they characterize the collective will which aims at

\footnotetext{
${ }^{5}$ See Held 2006: $96 \mathrm{ff}$. for an extensive discussion on the criticism of liberal democracy by Marx and Engels.
} 
protecting the collective interest. In this sense this interpretation of freedom comes closer to the equality principle; there is less tension between the two values.

The individualist theory has, on the contrary, a "negative" concept of freedom. It is interpreted as freedom from the constraints of other people, in particular by the state or the government. The participation of citizens in the political process is, in this concept, just an instrument which can be helpful in protecting freedom but is certainly not identical to it (Kielmansegg 1988). The protection of the basic rights (such as freedom of speech, press, association, assembly, and religion, the rights of privacy and lifestyle, the right of due process, the protection and tolerance of minorities, cultural and political diversity processes), which Dahl (1961) describes as the central component of the 'democratic creed', should be understood as the guaranteeing of freedom in democratic systems. As a result, the emphasis is rather on individual liberty and individual interests, which makes the contrast between freedom and equality stronger ${ }^{6}$.

Both theories regard citizen participation positively, but their interpretation of its value is different (see Thomassen 1995: 390). For the collectivist theory, participation of citizens in legislative processes is a basic citizen right, therefore it does not really recognize representative democracy as a type of democracy sui generis, but rather, as a surrogate of true democracy, which is direct democracy. According to the individualist theory of democracy, on the other hand, representative and direct democracy are distinct features. Political participation is nothing more than an instrument to protect one's personal interests; in situations where personal interest is not being challenged, politics should be left to politicians. This perspective on political participation is typical of a utilitarian theory of democracy which accepts that individual citizens primarily act to satisfy their individual wants, not the common good. It is the function of political parties and government to reconcile those differing wants (see Lively 1975).

This dilemma and the contradicting views on the desirable amount of citizen participation have shaped normative democratic theories in the second half of $20^{\text {th }}$ century. The major division has been, in accordance with the discussion addressed above, between liberal (or elitist) and participatory theories of democracy. Below we

\footnotetext{
${ }^{6}$ It should be stated here that individualist theory does not contradict the concept of political equality; the fact that citizens should have an equal say in decision-making is highly recognized, just as the principle of equality of opportunity. Not approved, however, is the concept of social equality as well as the emphasis on collective interest, which would suppress individual rights and interests.
} 
will introduce these two strands of normative thought and their views on citizen participation more in detail.

\subsection{Political Involvement in Democratic Theories of Contemporary Western Society}

In the light of the developments in democratic thought and democratic practice described above, the principle of representation was brought to the fore to a remarkable extent in the second half of twentieth century, and the practice of representative democracy was largely restricted to the selection of political elites for decision-making positions. Contemporary democratic thought has been influenced by this development to a great extent. Several attempts have been made to develop and systemize conceptualizations of democracy, which advocate different opinions on the necessary amount of citizen participation in democratic systems. These can be divided into two broad types (see Held 2006):

1. Liberal or Representative Democracy: a system of rule embracing elected "officers" who undertake to "represent" the interests and views of the citizens within the framework of "the rule of law".

2. Participatory or Direct Democracy: a system of decision-making about public affairs in which the citizens are directly involved.

This classification has been made according to the contradicting views of the two theoretical strands on the relationship between citizen and the state, particularly on the conception of citizens and their role within the political decision-making process. A comparison of the most important views of these theories can be taken from the table 2.1: 
Table 2.1 Citizen involvement in democratic theory

\begin{tabular}{|c|c|c|}
\hline & Liberal Theory of Democracy & $\begin{array}{c}\text { Participatory Theory of } \\
\text { Democracy }\end{array}$ \\
\hline Political Interest & Low or not at all existent & High \\
\hline Saliency of Politics & Low & High \\
\hline Political Knowledge & Poor & High, extensive \\
\hline $\begin{array}{l}\text { Provision of } \\
\text { Information }\end{array}$ & Very limited & Extensive, interpersonal \\
\hline $\begin{array}{l}\text { Willingness to } \\
\text { participate in politics }\end{array}$ & Low & High \\
\hline $\begin{array}{l}\text { Main Scholars of the } \\
\text { Theory }\end{array}$ & $\begin{array}{l}\text { Schumpeter; Dahl; Lazarsfeld } \\
\text { et al.; Campbell et al. }\end{array}$ & Barber; Habermas; Pateman \\
\hline
\end{tabular}

According to liberal theories, citizens of contemporary societies are marked by low interest in and poor knowledge and information about politics; therefore, their willingness to participate in politics would also be rather low. For this reason, their role in the policy-making process should be limited to selecting elites which make binding decisions on their behalf. On the contrary, participatory theories of democracy advocate the idea that the citizens are equipped with high levels of political interest and knowledge, which enhances the possibility that they will be willing and able to be active in politics. Therefore, they should be given the possibility to take an active role in all phases of democratic decision-making. It is striking that the two strands of theories, which claim to be normative theories and describe criteria for contemporary democracies, base their arguments on citizen participation to a great extent on empirical facts about their political skills. Yet as we mentioned in the introductory section of this chapter, the intermingling of the empirical and the normative is characteristic for a majority of the contemporary models of democracy. In this way they differ from the classical Greek thought on democracy which often intended "to be both descriptive and prescriptive, offering a unified teaching of ethics, politics and the conditions of human activity"(Held 2006: 6). Because the rise of social sciences in the late nineteenth and twentieth centuries granted more weight to the use of the "scientific method" in the study of democracy, the reliance on empirical facts in describing normative criteria has become common practice among the modern democratic theories. We will come back to this point later in the concluding section. 
Below we will first introduce both theoretical strands and their views on the necessary extent of political participation in democracies. Within the theory of liberal democracy, we will focus on two variants: first, we will discuss the theory of competitive elitism which was developed by Max Weber and extended by Joseph A. Schumpeter; second, we will focus on the pluralist theory of democracy which forms a basis for the contemporary variants of the theories on representative democracy. We will then continue with the theory of participatory democracy.

\subsubsection{Liberal theories of democracy}

\subsubsection{Competitive elitist theory}

Arguments about the role of elites in stabilizing democracy gained weight especially after the experience with authoritarian and totalitarian governments in the $20^{\text {th }}$ century. Common among the thinkers of the competitive elitist theory was the conception of a political life in which there was little scope for democratic participation and individual or collective development. Thus they have conceptualized a fairly restrictive understanding of democracy, minimizing democratic participation to "a means of choosing decision-makers and curbing their excesses" (Held 2006: 125).

One influential argument in this school of thought was Schumpeter's notion of democracy as a form of government in which the mass of ordinary citizens were restricted, more or less, to the role of choosing between competing elites. This view was largely based on Weber's reflections on modernization and aspects of industrial society such as class conflict, rationalization, and bureaucratization as challenges that the liberal social order had to face. According to Weber, the increasing complexity of the industrial society makes a sophisticated division of work in these societies inevitable. Therefore, the development and expansion of bureaucratization is a part of the process of rationalization in the modern societies. This leads to a very particular conception of politics and democracy, since it makes the emergence of a new type of career politician necessary, which must be capable of mobilizing opinion and of offering a plausible political program. Moreover, he declared competition and freedom of choice to be the central democratic values within the institutional arrangements in these societies to maintain a liberal political culture. While leaning largely on Weber's ideas, Schumpeter concentrated more on developing an empirically based theory to explain how actual democracies work. His classic, Capitalism, Socialism and Democracy (1942), had an extraordinary impact on the development of democratic theory in the aftermath of World War II. Many social scientists sought to widen Schumpeter's main hypotheses on the behavior of political 
leaders and voters, and their relation to each other (e.g. Berelson et al. 1954; Dahl 1956; Almond \& Verba 1963).

Schumpeter's concept of competitive elitism was based on an explicit rejection of classical democracy. He criticized the classical model on mainly two reasons. First, he rejected the idea of a common good "which all people could agree on or be made to agree on by the force of rational argument" (Schumpeter 1942: 251). According to him, in modern economically differentiated and culturally diverse societies there will inevitably be different interpretations of the common good, since individuals have different needs and values. Second, Schumpeter sees the popular will as a social construct which has little, if any, rational basis. This is because citizens have a weak background to make sound judgments about competing ideologies and policies. People are far from holding definite and rational opinions about all political questions; they can only give weight to such opinions by choosing representatives who will carry out their will (see Held 2006: 146ff.).

Particularly this last view on citizens' characteristics has implications for the notion of democratic citizenship. Also later theorists of liberal or elitist democracy are "minimalist" in their approach to citizens, i.e. they assume that mass publics have minimal levels of political attention and competence (Sniderman 1993). Ordinary citizens, according to this view, are poorly informed, have no serious interest in public affairs, do not have the necessary skills and knowledge to understand complex political issues and thus are not qualified for governance. Therefore, the expectation is that citizens play only a very limited role in the policymaking process. This is also important for the quality of governance. As Schumpeter argues, "voters outside of parliament must respect the division of labor between themselves and the politicians they elected...[They] must understand that, once they have elected an individual, political action is his business and not theirs" (Schumpeter 1942: 295). From this point of view, governance is most successful when citizens never interfere with the work of their political representatives, in other words when they refrain from "back-seat driving" (Schumpeter 1942: 295).

According to Dahl (1994), citizen involvement fosters legitimacy on the one hand whereas it impedes effective governance on the other. He refers to this conflict between effective government and citizen involvement as the "democratic dilemma". Parallel to these beliefs, the representatives of the elitist model of democracy are not in favor of direct democratic procedures. This resistance is essentially based on the argument that the citizens are not sufficiently qualified to participate directly in political decisions (Budge 1996). Citizens are usually not interested in politics and 
lack the competence to think and elaborate on politics. Thus, they should be allowed to influence politics only indirectly, solely by choosing their representatives who are responsible for making political decisions.

Another problem that could result from lack of interest and the incapacity of citizens is the so-called "populist paradox" (Gerber 1999), i.e. the risk that regular citizens fall prey to manipulators and become a tool of special interests. Other scholars go even one step further to assume that citizen initiatives are going to destroy representative democracy in the United States (Broder 2000). Thus, this theory adheres to what Riker (1982) termed a "liberal" model of democracy, which has three main premises: "citizens only hold meaningful preferences over the personnel of government, these preferences are only expressed indirectly through a system of representation, and are considered to be fixed and exogenous to the democratic process itself"' (Teorell 2006: 788).

In sum, citizen participation plays only a limited role in competitive elitist theory. Democracy is characterized by political competition between groups of leaders for the support of the population, which is expressed at periodic elections. According to Schumpeter, democracy is nothing more than a method in which the people as electors periodically choose between possible teams of leaders. Thus, citizen participation is limited to the act of voting. Accordingly, the concept of democratic legitimacy is also limited to the legitimation of the rule of competing political elites. Acquiescence to a competitive electoral system is supposed to entail a belief in the legitimacy of the system. Schumpeter, however, has not put much emphasis on legitimacy as a condition for a stable democracy. To him, the following conditions are of greater significance for democratic stability: the quality of politicians, a restricted range of political questions, a well-trained independent bureaucracy to assist politicians, and a culture capable of tolerating differences. Moreover, it is crucial to have "democratic self-control", which means that there should be a broad agreement on the roles of voters and politicians, on the undesirability of excessive criticism of governments, and on unpredictable and violent behavior (Held 2006: 151).

Schumpeter's theory can be criticized for several reasons. The first criticism can be made on his assumptions about the citizens. Schumpeter argues that the majority of citizens are uninvolved, uninterested, and therefore unable to think about politics, because of, among other things, the remoteness of the latter from most people's lives. Therefore citizens are not able to form reasonable judgments about political questions. Yet he does not explain how these populations can be capable of 
discriminating between alternative sets of leaders despite their low skills. Another criticism is aimed toward the conception of legitimacy. Legitimacy points to the belief that something is right or proper according to people's values; and democratic legitimacy refers to the popular acceptance of several components of the democratic political system: authority of incumbents, government, and, of course, the democratic regime itself (see e.g. Easton 1965, 1975). However, the concept has been narrowed by Schumpeter to the legitimation of the position of those in authority by submissive behavior and occasional participation by voting at elections. It is highly disputable if submission to authority or an occasional vote would be enough to legitimate a political system. Furthermore, it has not been made clear why casting a vote from time to time should express the rightness or appropriateness of a whole political system in the eye of the citizens. Finally, Schumpeter focuses exclusively on individual citizens and the elected leadership and does not take mediating factors like interest groups into account.

Despite its weaknesses, competitive elitism has provided a basis for and was extended by the theory of pluralist democracy. This theory has a more developed view of the democratic citizen and the role of participation. We will concentrate below on the most important elements of this theory.

\subsubsection{Pluralist theory of democracy}

Unlike the competitive elitist theory by Schumpeter, where the main focus is on the individual citizen and selected elites, the pluralist theory puts particular significance on intermediary groups and institutions such as interest, or pressure groups (e.g. Truman 1951; Dahl 1956). The theory builds upon the ideas of competitive elitism to a large extent; the principle of representative government and the arguments on citizens' characteristics were widely approved by the pluralists. What the advocates of pluralism criticize Schumpeter about was, however, the idea of concentration of power in the hands of elected representatives. They suggest that power is distributed not only among a group of political elites, but among many power centres. Among them, interest groups and pressure groups which seek to enforce specific group interests upon elites form the most important competitors for power. The existence of diverse, competitive interests in a complex political system is "the basis of democratic equilibrium and of the favourable development of public policy" (Held \& Krieger 1984; see also Held 2006: 159); thus group politics are an important source of legitimation. They ensure that public policy does not emerge solely as a result of direct influence of representatives as opinion leaders, but rather as a result of 
relatively uncoordinated transmission of interests to the government by a plurality of competing forces.

This view has a very utilitarian conception of individuals as satisfactionmaximizers. Accordingly, politics is also defined as a process in which individuals maximize their common interests in competitive exchanges with others. Elections and the competitive party system are crucial instruments for the aggregation and transmission of these interests as well as for ensuring that political representatives will be responsive to citizens' preferences, yet they do not alone secure the democratic equilibrium (Dahl 1956). The existence of active groups, of various types and sizes, is just as important since they also play a role in the formation of public opinion based on citizens' interests, and have the power to achieve these goals.

As mentioned above, pluralists share the views of competitive elitism with respect to the characteristics of citizens. They agree that citizens are apathetic, inactive in, and uninformed about politics. Further, they base these views upon findings from large-scale voting studies conducted at that time (e.g. Berelson et al. 1954; Campbell et al. 1960). Unlike competitive elitism, however, the pluralist theory did not regard this as a reason for limiting citizen participation to voting since, as mentioned above, influencing public policy through forming interest groups, in addition to voting, was desirable. Moreover, pluralists did not argue that people ought to refrain from participating in political life through channels beyond voting. People's decisions to participate in political processes and institutions were their decisions alone. However, the pluralist theory suggested that low levels of involvement in political life or a degree of apathy can be functional for the stability and continuity of the democratic system. A high degree of citizens' involvement in politics can lead to instability and social conflict, as the experience in Nazi Germany and fascist Italy has shown (Berelson 1952; Berelson et al. 1954; Parsons 1959; see also Held 2006).

Lack of political involvement can, on the contrary, be interpreted as a sign of trust in government and high satisfaction with the functioning of the democratic system (see Lipset 1959; Almond \& Verba 1963; for a more recent version of this debate see Hibbing \& Theiss-Morse 2002). In short, democracy in the eyes of pluralists "does not seem to require a high level of active involvement from all citizens, it can work quite well without it" (Held 2006: 162). In this sense, the concept of pluralism does not differ much from competitive elitism with respect to their views on the necessity of citizen participation in a democratic system. 
The pluralist theory distinguishes itself from competitive elitism by the increasing emphasis given to the control function of citizen participation. In Dahl's view (1956), control can be guaranteed if the politicians' scope for action is limited by regular elections and political competition among a multitude of actors. Especially political competition which encompasses not only elites but also a variety of interest groups with differing size and power has been associated closely with control of leaders. It brings about a high number of preferences which have to be taken into account by political elites in making policy choices. The result is a system of rule by multiple minorities, which is referred to by Dahl as "polyarchy". This understanding of participation dominated participation studies for several decades. What this concept adds to the elitist view of democracy is thus that it recognizes the role of participation as a medium for citizens to express their preferences over the "choices made by government personnel", that is, over policies (Miller 1992: 78). Thus participation is seen as an instrumental act through which citizens attempt to make the political system respond to their will. The main goal of participation is the responsiveness of the political system, which leads to equal protection of interests at the individual level. Drawing on classics such as Dahl (1956) and Downs (1957), most attention within this model has been paid to party competition in general elections as a means to bring about responsiveness (Miller 1983). In keeping with the elitist notion, however, participation is still only considered as an indirect action which is unable to determine the policy outcomes. Similarly, no reference is made to the origins of the preferences and perceived needs upon which citizens act (Teorell 2006: 789).

The theoretical view that associates political participation with the act of taking part directly in the political decision-making process is the so-called participatory model of democracy. Although this democratic model has partly developed out of the pluralist and developmental tradition of democracy, there are a number of positions on the citizens' role in government which contradict the positions of competitive elitism, as well as pluralism, to such an extent that it can be regarded as an alternative normative view. We will discuss this model in the next section.

\subsubsection{Participatory theory of democracy}

In contrast to the two models introduced above, the participatory model of democracy puts the greatest emphasis on citizens' political engagement (see e.g. Pateman 1970, 1985; Barber 1984)7. While drawing upon the ideas of Rousseau and

\footnotetext{
7 Within the theory of participatory democracy we can speak of different strands such as the theory of "strong democracy" put forward by Barber (1984), the theory of "discoursive
} 
Mill, the theorists of the participatory model build their arguments around a strict criticism of existing liberal democracy. The most important problem with liberal democracy is, according to this view, the conception of the individual and individual interest where the unquestioned dominance of particular interests in politics is bound to erode the foundations of the democratic process itself (Barber 1984). A further point of criticism towards liberal democracy is its institutional framework and its procedures. Since the participatory theory takes self-government as a reference point for democracy, representative structures are being seen as institutions which are at odds with the democratic principle ${ }^{8}$.

The two central characteristics of participatory democracy are the directness of participation by citizens in governing and the deliberation in public opinion formation (see Fuchs 2007: 39ff.). With respect to citizen participation, participatory democracy contrasts liberal democracy in the sense that it "involves extensive and active engagement of citizens in the self-governing process; it means government not just for but by and of the people" (Barber 1995: 921). Political participation "is characterized by direct and immediate involvement in the process of decisionmaking by the individuals concerned. Thus, in this process, the authority of the individuals is not delegated to some representative but is exercised directly by them" (Gould 1988: 259). According to the theory, citizens are not apathetic because they are not interested in politics (and this is one of the main contrasts to representative democracy), they are simply not able to control the outcomes through the available channels, and therefore remain passive. Participation in elections is therefore a necessary but far from sufficient precondition for a democracy to blossom. Citizens should also be involved in the decision-making process through raising demands, suggesting solutions, and even taking the decisions.

The second point characterizing participatory democracy is the formation of a collective will. Since democratic politics are controlled by the collective will of the demos and its purpose ought to be the pursuit of common goods, a collective will of

democracy" by Habermas (1992), and the "direct-deliberative polyarchy" theory by Cohen and Sabel (1997). It is not the aim of this study to delve into the details of each approach, yet we will refer to some common aspects put forward by these theoretical notions as the participatory theory of democracy.

${ }^{8}$ It should be stressed here however that the various strands of the theories on participatory democracy have different positions towards representative democracy. Some participatory theories reject representative democracy altogether, because a real democracy should include participation of citizens on all levels, thus representation is insufficient. However, other versions see representative democracy as a necessary evil and participation should be increased in order to alleviate these evils (Held 2006). 
the demos should result out of deliberation. Relatively concrete proposals for the institutionalization of deliberations are made by Barber (1984). With reference to Hannah Arendt and Alexis de Tocqueville, Barber regards it as absolutely essential for strong democratic talk to be institutionalized at the level of small local units in the form of "neighborhood assemblies". This is where citizens can deliberate in direct interaction about matters that directly concern them, while at the same time acquiring and practicing civic competence. However this should be expanded to include regional and national levels in order to ensure that the demos participates in discussions and decisions that affect all equally. Barber proposes electronic town meetings, and national referenda and initiatives to institutionalize deliberations at these levels of governance (Barber 1984: 273ff., 281ff.).

Thus according to the advocates of the participatory model, democracy depends on citizen participation, and increases in direct citizen participation would mean in this case more democracy, since this literally guarantees self-government and selfdetermination of citizens". Participatory democracy is hence referred to as "strong democracy" (Barber 1984). This model of democracy generally views elections as too weak in the function of transmitting information from citizens to the political system. When taking part in other forms of political activity such as contacting officials and protest behavior, citizens may express their views on one issue at a time (instead of choosing from bundles of policy positions predetermined by the political parties). The information transmitted in this way can be much more specific and targeted directly towards the actors responsible for dealing with the issue. Thus, political participation beyond electoral activity is supposed to make the system more responsive to citizens' needs and preferences.

Yet besides the expression of interests and ensuring responsiveness, political participation is argued to fulfill another function as well: "One might characterize the participatory model as one where maximum input (participation) is required and where output includes not just policies (decisions) but also the development of the social and political capacities of each individual, so that there is 'feedback' from output to input". As will be clear from this statement by Pateman (1970: 42), political participation is also believed to contribute to the development of citizens. Mill and

\footnotetext{
${ }^{9}$ It's important to note that this normative view pleads for the extension of self-determination rights beyond the sphere of government to other key institutions of society, such as the workplace and the local community (Pateman 1970). This is in line with the assumption that direct citizen participation in smaller contexts serves as a "school of democracy" (Warren 2001) by helping to develop different aspects of democratic citizenship, such as political interest and (subjective) political competences.
} 
Rousseau have already pointed to the educative function of participation for citizens which was touched upon above. Participation could enhance the capabilities of citizens, forcing them to consider what constitutes the collective interest, and in this way help them to become better citizens. Increased participation therefore leads to a positive spiral that enhances the effectiveness of the democratic system. These theses are also defended in contemporary theories of participatory democracy. Pateman (1970), for instance, argued that participation was the basis for a truly free and equal society. She too emphasized the educative aspects of participation: "Participation develops and fosters the very qualities necessary for it; the more individuals participate, the better able they become to do so." (Pateman 1970: 42f.). Thus, the participatory theory views political participation not only as a means of arriving at decisions, but also as a means of developing the democratic personality. This is a crucial aspect which distinguishes the conception of citizenship by the participatory theory from the elitist and pluralist views. Whereas the elitist and pluralist theories of democracy see political competences as an important prerequisite of citizen participation (beyond voting) in the process of policy-making, the participatory theory sees the development of political competences as a consequence (or as a goal) of political participation.

All in all, the main argument of the participatory theory of democracy is that the quality of democracy will increase as more citizens become mentally and effectively involved in politics (e.g. Schmalz-Bruns 2002). Citizens have the special knowledge that is indispensable for political agenda-setting and the development of legitimate, effective politics (Lindblom 1965; Fischer 2000; Geissel 2008). Participatory democrats furthermore argue that direct participation fosters desirable personal and social qualities in democratic citizens (Dahl 1989; Warren 1992). Many scholars tend to place the criteria of citizens' self-realization and self-development at the heart of participatory democracies (Pateman 1970; Macpherson 1977; Gould 1988). Following Pateman (1970), most research in this regard has focused on the effects of participation on the sense of political efficacy. However, the evidence on such a relation is scarce (Sniderman 1975; Pederson 1982).

\subsection{Conclusion: A Critical Overview of Democratic Theories}

The extensive discussion of the views on citizen participation by the three models of democracy, introduced above, has shown that normative thought on participatory ideals has remained divided throughout democratic development in history. The practice of democracy in the ancient Athenian city-states, where democracy was 
literally self-government by the citizens, has been materialized by the inclusion of all citizens into the political decision-making process and is defined as an ideal type of democracy. Yet the changing concept of citizenship, as well as the growing scope and complexity of government, have made it necessary to redefine the norms and criteria for democracy throughout the development of modern democratic thought. The central claim for this redefinition was the necessity to adjust the democratic ideals to the "reality" of the democratic practice, and it involved also the role of citizens within the democratic decision-making process.

Liberal theories of democracy, which emerged parallel to the establishment of representative democratic governance, advocated minimum citizen participation in the democratic decision-making process. It was not desirable for citizens to make use of participation channels which go beyond voting at elections, according to this view. The main argument behind this is that citizens are not interested in politics and are not equipped with the necessary skills to make correct decisions. However, this understanding has been challenged with the recent increase of participation in the last decades and the differentiation of its forms. Moreover, the theory of participatory democracy, which emerged parallel to the participatory increase, criticized the views of the liberal theories and formed an alternative theoretical notion. The participatory theory of democracy holds that participation is a necessary part of a genuine democracy, and therefore more participation and utilizing its more direct forms are not a threat but an enrichment for democracy. According to this view, citizens are not uninterested in politics; on the contrary, their interest and political skills can be enhanced by giving them the opportunity to take an active part in collective decision-making.

One could say that these conceptualizations are ideal types of democracy, and it would not be correct to discuss which one of them offers a better view on citizen participation, since real life democracies reflect these ideals to varying degrees, but are unlikely to fully embrace either ideal. Indeed, the political culture and constitutional basis of all countries to a varying degree reflect both norms of participatory democracy and competitive elitism. Virtually all democracies do encourage some level of citizen participation besides voting, and conversely, no democracy allows citizens to fully participate in the decision-making of the state. From an institutional point of view, modern Western democracies are representative democracies, and they have many recognizable features of the liberal theory of democracy. Yet with respect to the meaning of citizens' involvement in governmental decision-making, the arguments of this theory have been weakened to 
a great extent by the recent developments. The following reasons account for this in our opinion:

To begin with the competitive elitist theory, we can argue that the most important shortcoming of the theory is the invisibility of the borders between the normative models and the empirical reality (e.g. Brecht 1959; Thomassen 1983). As with Weber, his work has clear normative dimensions. Schumpeter's theory also advocates a set of tenets about the proper form of government and therefore has a normativity claim. Yet the apparent correspondence between these tenets and the actual structure of the post-war liberal democracies (in this case Britain and the United States) makes it clear that these "normative" views were derived from the empirical reality. So for instance, based on empirical findings such as low political interest and low levels of political knowledge among the electorate, Schumpeter criticizes the classical doctrine of democracy for incorrectly giving the citizens' will the priority and characterizing the election of representatives as a secondary condition. This criticism was supported by the first American election studies shortly afterwards. Berelson et al. (1954), for instance, concluded in their study that citizens approach politics indeed with little interest, knowledge, and rationality, and put into question whether the practice of a democratic system is compatible with the traditional democratic theory. According to their famous "paradox of democracy", the assumption by classical theories that voters are interested in public life fails to correspond with practical politics, while the system itself functions. The democratic system can apparently function even if the voters do not live up to the requirements of the classical democratic theory. Thus it is being regarded as a shortcoming of the classical democratic theory that there is too much focus on individual citizens, and that the collective characteristics of the electorate and the political system have been neglected.

The pluralist theory of democracy has achieved a significant improvement in conceptualizing liberal representative democracy by emphasizing interest group politics, individual demands and pressures against the idea of elite politics, and the overemphasis on the capacity of politicians to shape contemporary life. Yet the emphasis on the empirical nature of democracy creates the same difficulties as competitive elitism; pluralists have focused exclusively on the existing practices and institutions of liberal democracy, as well as on control mechanisms available to citizens such as periodic elections and pressure-group politics in answering the questions about the appropriate scope of citizen participation and of political rule. In this way, the pluralist theory also "tended to slide from a descriptive-explanatory account of democracy to a new normative theory" (see Held 2006: 166): The ideals 
and methods of democracy were set equal to the ideals and methods of the existing democratic systems.

Therefore we can conclude that it is problematic to deduce normative claims from the empirical reality instead of describing what is desirable in a democratic political system. A normative theory depending so much on empirical reality can be valid at the time and under the conditions it has been developed, and it stays so to the extent that the conditions do not change. However, if such a change takes place, the theory also loses ground; and that actually should not happen in the case of normative theories.

Unlike the models of democracy discussed so far, participatory democracy has a distinct normative character: It is literally directed at answering the question how a democratic system should be designed, bases its arguments on the basic ideal of direct self-government by citizens, and suggests an institutional framework which is directed at materializing this ideal as far as possible. Yet at the same time, it would not be correct to regard the participatory theory as a purely normative model, since its advocacy of direct citizen participation is also to same extent based on empirical assumptions on citizens' qualities (see table 2.1). Moreover, the theory has gained ground parallel to the empirical development of political participation in recent decades. Within the same time span as the theorists of participatory democracy have published their work, there has been a significant shift in the levels of citizen involvement in politics through an increasing number of political activities, a phenomenon which has taken place particularly in advanced Western democracies. The following chapter will focus on the recent developments in political participation and its research. We will show how the reality of political participation has changed and to what extent it forms a challenge to the liberal democratic thought as well as the representative government structures. Then, in the light of these developments, we will again take up the discussion of normative thought characterized by different theories of democracy, and their future prospects. 


\section{Chapter 3}

\section{From Normative Theories to Empirical Reality: Development and Backgrounds of Political Involvement}

The previous chapter has shed light on the relationship between citizen involvement in politics and democracy, and has provided a critical overview of different theories that speculate on the nature of this relationship. We demonstrated that these theories of democracy focus exclusively on democratic systems at a given time and criticized that these normative statements, based on empirical observations, can easily become questionable when the empirical reality changes over time. The aim of this chapter is to demonstrate the changes in the political reality that have indeed taken place in Western advanced democracies in recent decades. This involves the changing characteristics and participatory behavior of ordinary citizens. As we will show in the following sections, the number of citizens getting involved in political decisionmaking processes has increased drastically since the late 1960s. This growing demand for increased participation has changed the limited understanding and importance of citizen involvement in the decision-making process. Also, within the same time span, political participation has become a multifaceted phenomenon: the channels to influence the government have widened to include various new forms of citizen activity, where the empirical level of citizen involvement varies across different forms of participation. These empirical developments in political participation have been met with a great deal of research interest in the recent decades: Studies of participation and its backgrounds have become just as crucial as the theoretical discussion on the "proper level of citizen involvement" in the involved societies.

In the following sections, we will focus on the empirical development of citizen participation in politics, as well as on the development of its research. As political participation research has developed alongside the practice, we will examine the development of political participation simultaneously with the development of its conceptualization: we will show how the research interest on political participation 
has become manifold with the pluralization of participation forms. Following upon this, we will give an overview of the theories of political participation, which interpret the recent changes in political participation in different ways. Finally, in the concluding section, the future of democracy debate will be re-assessed in the light of these developments.

\subsection{The Evolution of the Concept of Political Participation and its Research in the Past Decades}

Studying political participation has been a long tradition within political science. The first studies on participation can be traced back to the 1930s and were mainly focused on voting and electoral activity. By the late 1960s, however, the repertoire of getting involved in the decision-making process began to expand to a broader scope, which was reflected in a parallel increase in interest for this field of research and thus in the number of studies on participation, its forms, and its backgrounds. This section will discuss this change in political participation as well as in its conceptualization extensively.

\subsubsection{Early research on political participation: classical political activities and expansion of the repertoire}

Earlier studies on citizen engagement in political decision-making had a significant focus on the analysis of voting and electoral participation, since participation was mainly understood as voting and campaign activities. The first studies on voting were conducted by Harold Gosnell $(1927,1930)$ and by Herbert Tingsten (1937), and the main objective of these studies was to find out which factors influenced voter turnout in the United States as well as in several European countries; in national as well as in local elections. Gosnell's study was mainly concentrated on the institutional determinants of voter turnout, where he found the level of party competition, the activity of local political party organizations, voting rights, and process-related arrangements (such as the voter registration procedure and Sunday vote) to be relevant predictors. Tingsten was interested in levels of electoral turnout as well; unlike Gosnell, however, he put the emphasis on socioeconomic status as its explanatory factor. He concluded that "voting frequency rises with increasing social standard" (1937: 155), where he additionally found that turnout is higher among men and middle age groups than among women and younger or older age groups.

The studies by Gosnell and Tingsten as well as other studies on political participation conducted until the 1940s were located at the macro level of analysis; 
accordingly, their explanatory factors were also identified at this level. They mostly made use of official statistics on elections and social structure; especially studies focusing on the impacts of institutional arrangements on turnout were based on empirical analyses of constitutional or statutory provisions. This tradition of macropolitical research was sustained also in the post-war period and in contemporary works. Stein Rokkan (1962), for instance, made an attempt to link social-structural and political-institutional approaches in explaining the differences in voting behavior in a number of countries. However, with the establishment of survey research and with the individualist approaches gaining ground, the research interest shifted gradually from the macro to the micro level.

Already in the 1940s, participation research was no longer primarily a question of comparing different participation rates of individual countries with each other in order to find explanations for the similarities and differences. The goal now was to answer the question of why some individuals are active while others remain passive. The first studies which systematically dealt with this issue - The People's Choice (Lazarsfeld et al. 1944) and Voting (Berelson et al. 1954) - focused on the sociological and individual background of voting behavior. Yet they are at the same time characterized by a limited conceptualization of political participation, since they focus exclusively on voter turnout as the main citizen activity to get involved into the decision-making process.

It was not before the late 1950s that the conception and study of political participation began to expand to a broader scope. In the studies around this time, we can see that participation was defined more comprehensively as all activities directly connected to elections and parties. Angus Campbell and his associates, for instance, analyzed in their study, The American Voter (1960), the social-psychological backgrounds of not only voting decisions but also participation in campaign activities. Robert E. Lane (1959) expanded the concept of political participation to include six modes of activity. He considered fundraising, organized group activities, contacting officials, and writing letters as important forms of political participation next to voting and working in election campaigns. Furthermore, Lane classified these action forms in categories of "passive spectator behaviour" and "active participation" according to their level of complexity. He suggested that there is a cumulative ranking of the six participation forms mentioned above, which means that those who make use of modes of participation of higher complexity (e.g. contacting public officials) are likely to use the action forms of lower complexity (such as voting and campaign activity) as well. 
In his work Political Participation of 1965, Lester W. Milbrath expanded the scope of political participation further by adding five other forms of activity ${ }^{10}$. In a similar vein as Lane, he presented a pyramid ranging from active to passive modes of political participation, and his criterion of classification was again the complexity of political activities. Milbrath assumed that the citizens tend to participate in activities with less complexity, i.e. which require fewer resources and less effort than complex ones, i.e. those which need more time and personal initiative. The complexity of a particular activity was empirically measured by the frequency of its use by citizens. Participation forms which are less complex, such as voting, political discussions, and encouraging others to vote, are being more frequently used, thus they are placed in the lower part of Milbrath's hierarchy of action types. In contrast, action types demanding more time, effort, initiative, and information are less common and therefore are placed on the top of the hierarchy.

In sum, the scope of political participation as well as of its research has expanded to feature activities beyond voting in the two decades after the end of World War II. Yet this era was still characterized by the dominance of elite politics: the involvement of citizens did not go far beyond selecting and controlling government officials and the bulk of the citizenry focused on electoral and party activities as the main channels of participation. The dramatic expansion in the types of political participation and the challenges to traditional politics took place in the late 1960s, which has been referred to as the years of "participatory revolution" (Kaase 1984). The late 1960s and early 1970s show a remarkable development of political participation in two directions. First of all, the number of forms of participation increased to such an extent that classifications of participation became necessary to reduce the complexity. Second, these forms of participation did not only include institutionalized forms of action. Newer types of activity such as protest, citizen rights movements, or students' movements emerged and became widespread within a couple of years so that they quickly became a part of the domain of political participation. This in turn led to a necessity of dividing up the forms of political activity into dimensions for analytical reasons. The following will focus on this second wave of expansion in political action forms as well as on the attempts to classify and dimensionalize these activities.

\footnotetext{
${ }^{10}$ Milbrath's action types were as follows (1965: 18): voting, political discussions, trying to talk someone into voting in a certain way, wearing a button, contacting an official, donating money to a party, attending a political rally, contributing time to a campaign, active party membership, candidate for office, and finally holding office.
} 


\subsubsection{Classifications and dimensions of political participation}

The wide variety of channels to influence government activity, which resulted out of the so-called participatory revolution, has persuaded researchers to raise the question whether all these activities can generally be referred to as political participation per se or whether they should be classified into groups of activities which can be distinguished from each other based on certain characteristics. The most common classifications distinguish between institutionalized and noninstitutionalized, direct and indirect, legal and illegal, or legitimate and nonlegitimate types of action (see Gabriel \& Völkl 2005: 530f.). Some other studies go a step further and base their classifications of political participation on empirical tests. Below we will focus on these empirical classifications.

The first prominent classification of forms of participation was provided by Milbrath (1965). As mentioned above, he identified eleven forms of political participation, which range from passive to active forms on the basis of their complexity. Basing his classification on this dichotomy between active and passive, he furthermore distinguished between "gladiator", "spectator", and "inactive" types of citizens. Yet this was a one-dimensional classification of political activities since it was based on complexity as the single criterion. Such a classification was feasible at the time where participation was indeed limited to electoral and party activities. However, due to the rashly increasing plurality of political activities, this onedimensional view could not keep up with the reality of political life anymore. Newer studies used therefore multiple qualitative criteria in classifying political action types, which resulted in multidimensional classifications of participation.

One of the seminal works in which several dimensions of participation have been identified was Participation in America: Political Democracy and Social Equality by Sidney Verba and Norman H. Nie (1972). Using four qualitative criteria ${ }^{11}$, they identified four modes of activities: voting, campaign activity, particularized contacting, and communalist activities. Whereas the two former ones build the dimension of electoral activities, the two latter ones are classified under non-electoral activities. This classification was empirically founded also in a later comparative study of political participation (Verba et al. 1978).

\footnotetext{
11 These criteria were: the conflict potential underlying the activity, the type of interaction with the elites, the scope of the outcome of participation (i.e. whether the outcome concerns exclusively the participants or a greater group of citizens), and finally, the required extent of own initiative.
} 
Table 3.1 Dimensions of political participation according to Verba and Nie (1972)

\begin{tabular}{lcccc}
\hline & \multicolumn{2}{c}{ Electoral Activities } & \multicolumn{2}{c}{ Non-electoral Activities } \\
\hline Voting & $\begin{array}{c}\text { Campaign } \\
\text { activities }\end{array}$ & $\begin{array}{c}\text { Communalist } \\
\text { activities }\end{array}$ & $\begin{array}{c}\text { Particularized } \\
\text { contacting }\end{array}$ \\
\hline $\begin{array}{l}\text { Type of interaction } \\
\text { with elites }\end{array}$ & Pressure & $\begin{array}{c}\text { Information } \\
\text { and Pressure }\end{array}$ & $\begin{array}{c}\text { Information } \\
\text { and Pressure }\end{array}$ & Information \\
$\begin{array}{l}\text { Conflict potential } \\
\begin{array}{l}\text { Scope of the } \\
\text { outcome }\end{array}\end{array}$ & Strong & Strong & Moderate & Weak \\
$\begin{array}{l}\text { Extent of own } \\
\text { initiative }\end{array}$ & Little & Moderate & Moderate to & High \\
\hline
\end{tabular}

Source: Verba \& Nie 1972; as outlined in Gabriel \& Völkl 2005: 535

Despite its significant contribution to the participation theory and the empirical research on participation, the conceptualization of participation by Verba and his associates (Verba \& Nie 1972; Verba et al. 1978) was criticized in the scientific debate. The main criticism was that the scope of participation was limited to activities "within the system", that is, "with regular and legal ways of influencing politics" (Verba et al. 1978: 48). Activities like protests, riots, or social movements were not taken into account, since they were not regarded as in line with the societal norms of the 1970s. However, the political reality was changing permanently, and by the time Verba and Nie published their first study, these activities already formed an integral part of the repertoire of participation in Western democracies; however, they found little reflection in these studies.

By the end of the 1970s, the emergence of citizen movements in the United States and Europe brought about an increasing research interest in the role of political protest within the participatory structures of Western democracies. In a five-country study conducted by a research group initiated by Samuel Barnes and Max Kaase, Political Action (Barnes \& Kaase et al. 1979), the famous distinction between "conventional" and "unconventional" forms of political participation was made, which was based on the criteria legality, legitimacy, and institutionalization. According to this, legal, legitimate, and - at least to a certain extent institutionalized forms of political activity were addressed as conventional political participation, while non-legitimate, non-institutionalized, and some illegal activities were classified as unconventional activities. 
The Political Action Study identified twenty different forms of political action along these dimensions. According to them, conventional forms of political participation included reading about politics in newspapers, discussing politics with other people, convincing others to vote in a certain way, working with other people in the community to solve some local problem, electoral activities, attending a political meeting or rally, and contacting officials or politicians. Unconventional political participation, on the other hand, referred to the following activities: signing petitions, joining in boycotts, attending lawful demonstrations, refusing to pay rent or taxes, joining in wildcat strikes, occupying buildings, and blocking traffic. Both conventional and unconventional political action measures were constructed using the Guttman scaling technique. The basic assumption behind Guttman scaling is that the items are one-dimensional and cumulative: the hierarchy of the items is based on the frequency of positive responses for each item, and one is unlikely to score a positive response on items ordered at the high end of the scale unless one has responded positively to all previous items. This procedure allows for the classification of all activities within one dimension along a rank order varying from low to high levels of participation, which is highly reminiscent of the traditional differentiation between inactive citizens and fully active citizens (Milbrath 1965) ${ }^{12}$. Among conventional activities it turned out that reading about politics is the lowest level of activity while contacting officials was the highest; within the unconventional action dimension petition signing ranked lowest in the hierarchy and wildcat strikes scored the highest. All other activities were placed in a rank order between these poles (see table 3.2 below).

Combining this hierarchical rank order of activities with the dimensions of the political activities citizens make use of, Barnes and Kaase et al. furthermore developed a new typology of participants, which covered more complex categories. According to this, five types of political activism could be identified: inactives, conformists, reformists, protesters, and activists (see table 3.2). All groups featured activities from both dimensions; whereas conformists had a stronger orientation towards conventional forms of participation, protesters showed a clear preference for unconventional ones. Reformists were also inclined towards conventional participation, yet they also made use of "legal" unconventional activities such as attending lawful demonstrations and joining boycotts.

\footnotetext{
${ }_{12}$ Milbrath used the same cumulative scaling technique to arrange different forms of participation in a hierarchy.
} 
Table 3.2 The typology of political activism developed by the Political Action Study (1979)

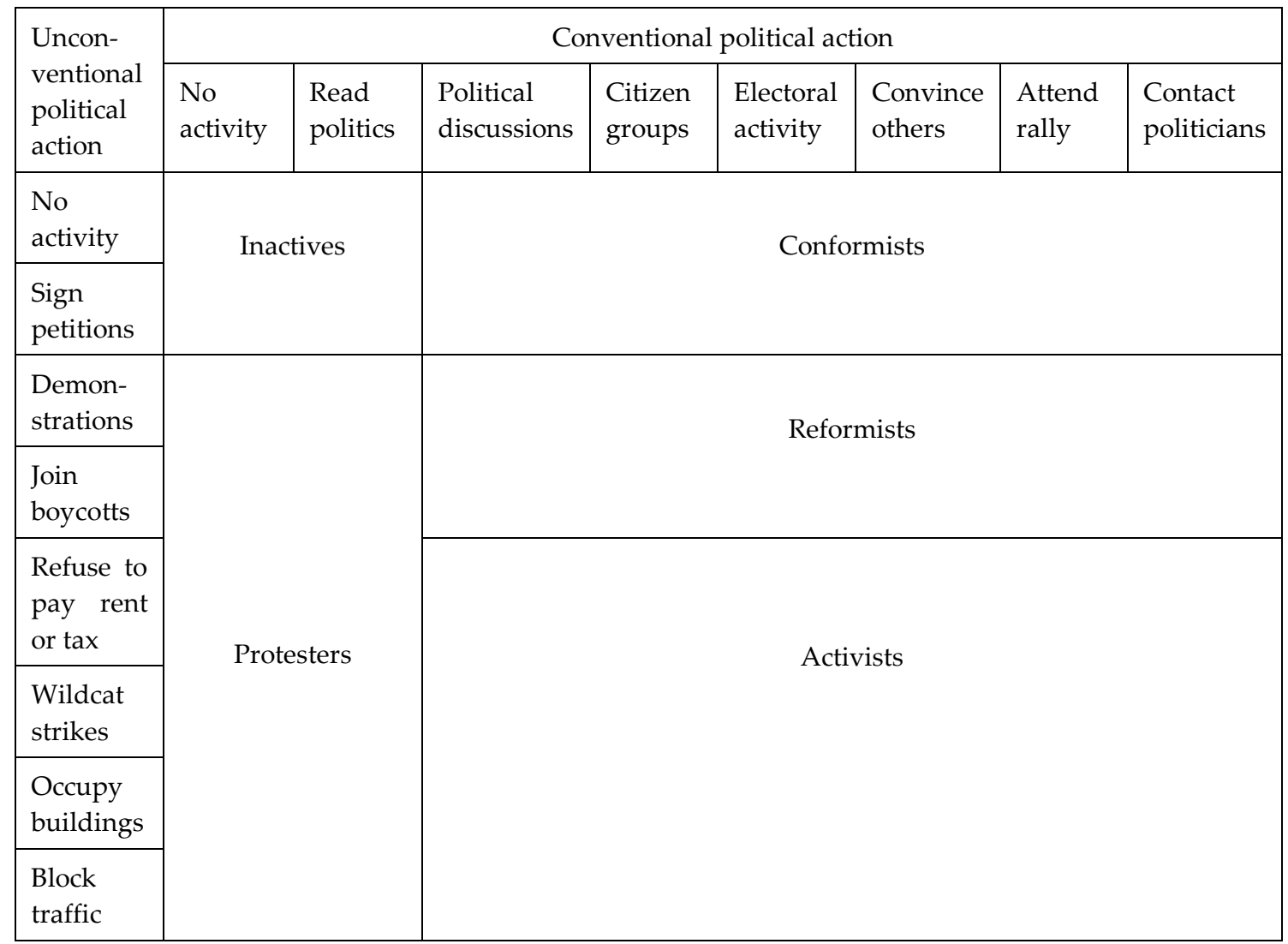

Source: Kaase \& Marsh (1979: 154)

One important finding resulting out of this typology is that citizens combine different action styles while attempting to influence governmental decision-making, which shows clearly that conventional and unconventional activities are by no means mutually exclusive. The results of the Political Action Study has indeed shown that there are people who are only conventionally or only unconventionally active, yet a majority of citizens combine these two modes depending on their goal or on the conditions underlying the action.

\subsubsection{Recent developments in participation research: new dimensions and actual trends}

The classification of action forms into conventional and unconventional political action was one of the most important contributions of the Political Action Study to political participation research. Particular aspects of this work can surely be criticized; such as the use of Guttman scaling to determine the hierarchy of political activities or the definition of certain activities as political participation ${ }^{13}$. Yet the

${ }^{13}$ Barnes and Kaase et al. have counted reading about politics in the newspaper and discussions about politics among conventional political action forms. If one defines political participation as activities directed at influencing government decisions, however, the 
differentiation between conventional and unconventional forms of political action remained the dominant classification for a long time, although the contents of both dimensions have been subject to changes in the following decades. Most of the political activities originally defined as unconventional have contemporarily become established so one can no longer speak of the unconventionality of these action forms; in other words, the "normalization of the unconventional" (Fuchs 1991) has already taken place $^{14}$.

This transformation was possible through the significant expansion of new types of political activism particularly beginning from the 1980s. In this era, diverse new forms of civic and political participation, which have been regarded as unconventional, challenging, and even disturbing in the 1960s, became widespread activities. New social movements such as ecology, peace, and women's emancipation movements became important political actors in Western democracies and thus inspired a large number of studies (e.g. Brand 1985; Tarrow 1989; Dalton \& Küchler 1990; Rucht 1994; Kriesi et al. 1995). Most of these movements were quickly institutionalized and incorporated into established politics (see Koopmans 2007). Political protest also continued to increase "in terms of the frequency of events and number of participants, broadened and diversified regarding the range of issues, forms, and social carriers, diffused spatially across countries and continents, and shifted to the transnational level" (Rucht 2007: 719). Moderate protest activities such as legal demonstrations are largely accepted today and occasionally practiced; confrontational forms like direct action or civil disobedience have also increased, though to a lesser extent.

Most of the research on protest politics have been directed at groups, organizations, and social movements as initiators of protest activities (e.g. Kitschelt 1986; Kriesi et al. 1995; Tarrow 1989, 1998), yet the attitudes of individual citizens towards protest and their participation in such activities have also been the subject of a large number of comparative studies (e.g. Inglehart 1990; Jennings \& Van Deth et al. 1990; Norris 2002; Dalton 2006). The proportion of citizens who participate in demonstrations have "more than doubled since the mid-1970s" (Norris 2007: 639); in many Western European countries about 40 percent of the public have taken part in

inclusion of these activities in the participation index becomes questionable. These activities can by all means be regarded as political activity, yet they can not be considered as participation in decision-making as such.

14 Today, most commonly used terms for this group of actions are "non-institutionalized political participation", "protest participation", "elite-challenging political action", or "causeoriented political activism" (see e.g. Inglehart \& Welzel 2005; Norris 2007). 
such activities (e.g. Van Aelst \& Walgrave 2001; Norris et al. 2005). In addition to demonstrations, other forms of individual-level participation such as consumer activities (buying or boycotting certain products for political or ethical reasons) and petitioning have become common and been spotlighted by research (e.g. Inglehart \& Catterberg 2002; Norris 2002; Micheletti 2003; Stolle et al. 2005; Micheletti et al. 2006).

These developments called for new classification attempts: one of the most recent suggestions is to distinguish between "citizen-oriented" and "cause-oriented" types of political activity (Norris 2007: 639ff.) ${ }^{15}$. Citizen-oriented activities are mainly related to electoral and party activities, whereas cause-oriented forms of political involvement are focused upon specific issues and policy concerns, embodied by the above mentioned consumer politics, petitioning, protests, and demonstrations. One important characteristic of cause-oriented action repertoires is the disappearing borderline between political and social spheres, since most of these activities - such as boycotting products or fundraising for a local service - have direct social and economic consequences. In the face of the increasing prominence of "new politics" issues like globalization, quality of environment, multiculturalism, and gender equality, a strict division of these spheres is no longer possible and also not meaningful ${ }^{16}$. Increasing citizen involvement - also in the form of social activism currently has immediate consequences also for the policy process. Another distinctive feature of these action types is that they are not only directed towards parliamentary and governmental policy-making processes, but also towards other national and international intermediary bodies, such as public, non-profit, and private organizations (Norris 2007: 641). Because newer trends in Western democracies (globalization, privatization, a powerful market economy) are changing the nature of democratic governance by narrowing the role of the national state as

\footnotetext{
15 There have also been other attempts to define new dimensions of political participation in the past couple of years. One well-known distinction is between "individualized and collective" forms of participation (Pattie et al. 2004). This conceptualization was however criticized of being blurred, since protest activities and demonstrations could be ordered to both dimensions (Norris 2007: 640).

${ }^{16}$ A similar state of flux about the boundaries between the social and the political spheres concerns the so-called "civic" activities like voluntary engagement in associations (e.g. Putnam 1993, 2000). These activities have also increased during the 1990s and they have often been referred to as "social participation", yet they are conceptualized as analytically and empirically distinct from political participation (e.g. Van Deth 1997). The most recent studies which are analyzing these new forms of civic engagement are the ones by Sidney Verba, Kay Schlozman, and Henry E. Brady (1995) and various edited volumes that have resulted from the CID (Citizen, Involvement, Democracy) Project (e.g. Van Deth et al. 2007; Maloney \& Rossteutscher 2007; Maloney \& Van Deth 2010).
} 
well as of national political actors, these intermediary bodies gain more and more in importance as addressees of citizens' demands and discontent. Finally, these activities may also aim at drawing the attention of the mass media to specific issues as well as forming or influencing public opinion on these issues.

This conceptualization of cause-oriented activities is somewhat broad since it involves different motivations and targets of the same repertoire of activities. Another recent work has provided a systematical sub-classification of citizenoriented as well as cause-oriented action dimensions by defining five modes of political participation along two criteria (Teorell et al. 2007: 340ff.). The first pertains to the distinction between representational and extra-representational channels of expression, whereas the second captures a division between "exit-based" and "voicebased" mechanisms of influence based on the well-known distinction between individual responses to dissatisfaction in many different contexts, developed by Albert O. Hirschman (1970). The resulting dimensions are voting, party activity, contacting, consumer participation, and protest activities (see table 3.3 below).

Table 3.3 The five-fold typology of modes of political participation by Teorell et al. (2007)

\begin{tabular}{|c|c|c|c|}
\hline \multirow{5}{*}{$\begin{array}{l}\text { Mechanism } \\
\text { of influence }\end{array}$} & & \multicolumn{2}{|c|}{ Channel of expression } \\
\hline & & Representational & Extra-Representational \\
\hline & $\begin{array}{l}\text { Exit- } \\
\text { Based }\end{array}$ & Voting & Consumer Participation \\
\hline & Voice- & $\begin{array}{l}\text { Non-targeted: } \\
\qquad \text { Party Activity }\end{array}$ & $\begin{array}{l}\text { Non-targeted: } \\
\text { Protest Activity }\end{array}$ \\
\hline & & \multicolumn{2}{|c|}{ Contacting } \\
\hline
\end{tabular}

Source: Teorell et al. (2007: 341)

Teorell et al. (2007) have further distinguished between representational and extra-representational activities. According to this, voting, party activity, and - to some extent - contacting activities, belong to the group of representational modes. This distinction is far more sophisticated than the traditional electoral vs. nonelectoral division, since it contains a wider set of activities including contacting elected representatives directly or indirectly by working in a political action group. Yet contacting is a very comprehensive type of political activity and thus difficult to classify along one or the other dimension. Part of contacting activities can also belong 
to the extra-representational dimension, together with protest and consumer activities, when they are directed at addressees other than representatives, such as civil society organizations, media, or a judicial body.

These dimensions can further be divided along exit-based and voice-based influence strategies. Among representational forms of activism, voting belongs to exit-based activities: if the voter is dissatisfied with the performance of the party voted into power at the last election, he or she can "exit" from that option at the next elections and either vote for another party or abstain from voting. The same logic also works for products on a competitive market; the consumers just stop buying a specific product if they are not satisfied with its quality. Therefore, both voting and consumer activities can be grouped under exit-based activities, since both involve an implicit expression of demands by solely choosing between alternatives and leaving the unwanted option. By contrast, party activity, protest, and contacting are aimed at expressing manifest demands and therefore they are labeled as voice-based political activities.

Teorell et al. also distinguish between targeted and non-targeted forms within the voice-based dimension (2007: 343), classifying these forms based on whether the addressee of the activity is a solid political institution or actor (contacting) or not (party activity and protest). Public demonstrations are issue-oriented and mostly aim at expressing discontent about a specific issue without appealing to a concrete institution or politician. Party activities are themselves within-institution activities and therefore do not aim at addressing external political actors.

Thus the new repertoires of political participation have experienced a remarkable spread from the 1980s to date and, as shown above, this has influenced the theoretical conceptualizations of participation to a considerable extent. Empirical research on various forms of activism has also attracted a great deal of attention among scholars. Some scholars have specialized in certain forms of participation to such an extent that these have gradually become individual research fields; one can speak today of the field of electoral, party, protest, or consumer research rather than a comprehensive research field of political participation.

Scholars focusing on classical forms of activism - electoral participation, party and campaign activity, as well as politician contacts - however, have repeatedly observed in recent years that the use of these activities has not increased at the same pace as the popularity of the new repertoires; indeed, the expansion of new activities seems to have taken place at the cost of traditional forms of activity (Barnes \& Kaase et al. 1979; Stolle \& Hooghe 2005). Research on voter turnout in the United States has 
shown that there is an overall downward trend in this form of activity; especially in the 1990s this fall is assumed to have accelerated (see e.g. Rosenstone \& Hansen 1993; Miller \& Shanks 1996; Teixeira 1987, 1992; Patterson 2001) ${ }^{17}$. Comparative research of voter turnout in Western European countries points to a rather mixed trend: there are strong fluctuations between elections where the turnout figures have gone back only in some countries (e.g. Topf 1995b; Borg 1995; Aarts \& Wessels 2005). Yet one can generally speak of a decline in average turnout levels in the post-war period as a whole, even if some countries might deviate from this pattern (e.g. Lane \& Ersson 1999; Blais 2000; Gray \& Caul 2000; Mair 2002; Wattenberg 2002; Franklin 2002, 2004). Not only elections, but also other channels of participation of the institutionalized party politics seem to be losing their attractiveness for citizens. Recent research findings show that a general anti-party sentiment among citizens is rising while party membership and campaign activities are in a continuous deterioration (Schmitt \& Holmberg 1995; Dalton \& Wattenberg 2000; Scarrow 2000; Mair \& Van Biezen 2001; Dalton 2006).

It is worth mentioning, though, that elections remain the most popular channels of influencing the government despite the general decline in turnout in Western democracies. Even most recent turnout figures show that voting is the most frequent form of participation and it clearly dominates over every other activity. Yet it is also a fact that extra-representational activities are already far more preferred than the conventional, representational ones; the proportion of citizens getting involved in protest and consumer activities has become nearly twice as large as the proportion of those involved in party activities and contacting by the mid-2000s (see Gabriel \& Völkl 2008: 282).

All in all, the last three decades in Western advanced industrial societies have been marked by a significant change in the structure of political action (Dalton 2006: 73). The old forms of political participation have been in decline (voting, party work, campaign activity) while participation in citizen-initiated and policy-oriented forms of political activity (direct action, protests, voluntary public interest groups, and other newer forms of political participation) have been increasing. These findings

\footnotetext{
${ }^{17}$ In a recent article, however, Michael P. McDonald and Samuel Popkin have argued these findings which document a constant decline of turnout in the United States might be due to the changes in the composition of "voting age population" which forms the basis of the analyses cited above. They suggest that the inclusion of persons who are not full citizens by legal requirements - e.g. immigrants - in the voting eligible population causes a methodological flaw, leading many researchers to conclude that there is a general decline in electoral participation, although this actually might not be the case (McDonald \& Popkin 2001, The Myth of the Vanishing Voter).
} 
have brought up the questions of whether these trends should be approached with concern or whether they should be regarded as beneficial for the further development of democracies. However, both questions can not be answered without identifying the backgrounds of this change. Researchers of political participation have therefore concentrated on assessing the determinants of various forms of participatory behavior as much as they have focused on the levels and development of participation. The next section will give an overview of these determinants of both the traditional and the new forms of political action, both at the societal-institutional and at the individual level.

\subsection{Determinants of Political Participation}

Explaining participation has been another main challenge in contemporary political participation research. As indicated above, the "why" of participation is at least as important as the "how" in interpreting individual participatory behavior and the literature provides us with a large number of possible reasons why citizens get involved into politics. The differing approaches on this matter will be summarized in the following.

\subsubsection{Analyzing political participation: macro- and micro-level explanations}

The most common analytical distinction made between explanatory theories of political participation is the one between macro and micro levels of analysis. Macrolevel theories of participation focus on structures of political participation in countries (or in local communities or other large units) and seek to find out which characteristics of the society or political system account for these structures. Microlevel theories, on the contrary, study the individual participatory behavior and regard personal characteristics and attitudes as main determinants of the individual decision whether to participate or not ${ }^{18}$. Political participation research often combines these analytical levels in explaining political activism and can therefore provide complementary insights into its backgrounds.

At the macro level, one can differentiate between political-institutional, societal, and cultural explanations for political participation. The two most prominent theoretical approaches at this level are institutional theories, which emphasize the role

\footnotetext{
${ }^{18}$ Newer studies underline the existence of meso-level theories of participation, which focus exclusively on the role of participation in intermediary agencies in encouraging political action (e.g. Rosenstone \& Hansen 1993; Putnam 1995, 2000; Norris 2002). Others prefer to regard it as a micro-level factor determining political participation (e.g. Verba et al. 1995).
} 
of state structure and institutional arrangements in creating opportunities for political participation, and modernization theories, which suggest that the new social trends in Western democracies account for the new trends in political participation (see Norris 2002: 19). Institutional theories aim at explaining differences in participation systems between political contexts, and focus upon the relationship between the structures of the political system - e.g. legal regulations such as compulsory voting laws, type of the election, electoral system, and party system and political activism. The most significant contribution of these theories to the study of political participation does not however go beyond explaining cross-national differences in voter turnout (e.g. Powell 1980; Jackman 1987; Jackman \& Miller 1995; Lijphart 1999; Franklin 2002, 2004). Studies on other, particularly newer forms of participation hardly ever focus on institutional factors ${ }^{19}$. Moreover, the institutions are less adequate at explaining what accounts for participatory change in contemporary Western democracies, since they have remained relatively stable over the past couple of decades where the new forms of activism have emerged.

Unlike institutional theories, modernization theories give plausible explanations for both differences between countries and changing participatory trends over time and provide insights into backgrounds of various forms of political action; particularly of the new repertoires of activities such as protest or consumerism (e.g. Inglehart 1977, 1990, 1997; Inglehart \& Welzel 2005; Dalton 2006). The central premise is that changing structures of economic production in Western societies - the shift from traditional to industrial production on the one hand and from industrial to post-industrial on the other - have changed the living conditions in these societies to such an extent that the social and political spheres in these societies are inevitably affected. Most importantly, the conditions which are strong predictors of individual political activism - resources, skills, and motivations - have been transformed by these societal-level changes, which are supposed to have led to the vast participatory change illustrated in section 3.1. As explained in the introductory chapter, our main focus in this study is on the possible consequences of the modernizationparticipation link for democracy; therefore this link will be given special attention in the following chapter.

Micro-level explanations of political participation include the individual decision of whether or not to participate as their central focus. A variety of factors for the

\footnotetext{
19 The few studies which focus on institutional effects on protest movements are those which emphasize the role of so-called political opportunity structures (e.g. Kitschelt 1986; Tarrow 1989; Kriesi et al. 1995; Tilly 1995). Yet they do not explicitly focus on individual participation in protest movements and activities.
} 
prediction of participatory behaviour has been suggested in the literature, varying from social and economic status indicators to psychological, motivational, and cultural dispositions. Depending on the emphasis given to a specific group of determinants, one could differentiate between several theoretical models explaining political activism. Among them, three theoretical models come to the fore: the rational-choice explanations to participation (e.g. Downs 1957; Riker \& Ordeshook 1968; Olson 1965; Muller 1979), the socio-economic status models of participation (e.g. Verba \& Nie 1972; Verba et al. 1978; Verba et al. 1995), and the models emphasizing the role of network mobilization on participation (e.g. Putnam 1995, 2000; Verba et al. 1995). Our focus will be here specifically on the standard socioeconomic status model, which highlights resources (e.g. time, educational skills, socioeconomic status) and politically relevant motivations (such as political interest, information, attitudes towards political objects) as the most important factors that encourage citizens' involvement in politics. As mentioned in the previous paragraph, these individuallevel characteristics are supposed to have been altered by the societal-level process of modernization. Therefore, it is crucial to clarify their relationship to political participation if we aim to study the link between societal modernization and changing patterns of political activism. We will take a closer look at the theoretical discussion on how these characteristics facilitate political participation and the related empirical evidence in the next section.

\subsubsection{The socioeconomic model of political participation}

The standard socioeconomic model suggests that an individuals' socioeconomic status and political orientations are the main predictors of political participation. The idea is that "high-status individuals" who are "located in social environments which encourage and enforce positive attitudinal and participatory norms as well as civic skills, ... are more likely to participate in politics than are low-status individuals" (Leighley 1995: 183). Central indicators of socioeconomic status are education and income, which are two significant generators of the resources time, money, and skills; yet belonging to demographic groups (gender, age, race, and ethnicity) also form important components of this model since the economic and cognitive resources are thought to be unequally distributed among these groups.

Empirical studies on the relationship between resources indicators and political activity can be traced back to the beginnings of participation research. Already in the 1940s, scholars had documented the impact of belonging to a societal group on electoral turnout (e.g. Lazarsfeld et al. 1944). They had concluded that belonging to social groups with conflicting norms - such as being Catholic and an industrial 
worker - generate the so-called "cross-pressures" on the voters which make them likely to abstain from voting. Beginning in the 1960s, researchers have more intensively focused on how social group belonging (age, gender, race, religion) determines the extent of participation in political life (e.g. Lane 1959; Lipset 1959; Milbrath 1965; Nie et al. 1969). These various indicators of social status were later systematically combined and developed into the standard socioeconomic model of participation by the Verba Group (Verba and Nie 1972; Verba et al. 1978), which has influenced much of the subsequent work in the field of participation research. Since then, participation studies have produced abundant empirical evidence on the link between social and economic resources on the one hand and participation in politics on the other. They have unequivocally concluded that individuals with higher levels of education and income are more likely to participate in politics than those who score low on these indicators, with education being a stronger determinant of participation than income.

These findings have been proven to be consistent also across different forms of participation as well as across countries (e.g. Verba \& Nie 1972; Verba et al. 1978; Barnes \& Kaase et al. 1979; Jennings \& Van Deth et al. 1990; Parry et al. 1992; Verba et al. 1995; Norris 2002; Dalton 2006) ${ }^{20}$. With respect to demographic group belonging, research has found gender and age to be the most important determinants of participation. Women have proven to be less politically active than men in earlier studies (e.g. Milbrath \& Goel 1977), whereas more recent studies have found that the gender gap has become smaller (e.g. Teixeira 1987; Rosenstone \& Hansen 1993; Verba et al. 1995). The findings on the effects of age on participation are somewhat less consistent. Some studies have found participation levels to increase with age; younger individuals proved to be less integrated into the community and less politically active; this was especially the case for traditional forms of political action such as voting, or party and campaign activities, whereas older age groups also seemed to abstain from particularly demanding forms of participation (e.g. Jennings 1979; Wolfinger \& Rosenstone 1980; Jennings \& Niemi 1981). Others have demonstrated that younger age groups are not inactive, but they are more inclined towards newly emerged forms of participation such as protest, and they prefer to abstain from conventional forms of political action (Inglehart 1979).

\footnotetext{
20 See Leighley 1995: 183ff. for an extensive overview of studies until the mid-1990s which have tested the empirical relationship between socioeconomic variables and various forms of participation, e.g. voter turnout, campaign and group activities, contacting officials, and political protest and violence.
} 
Next to the body of research on the impact of economic and social status of individuals on their participatory behavior, a considerable amount of work has stressed the role of civic orientations on political activism (e.g. Almond \& Verba 1963; Nie et al. 1969). Relevant political orientations and skills include political interest, political information, perceived own political competence (or internal political efficacy), as well as positive attitudes towards various elements of the political system, including support for democracy as a system of government, trust in its core institutions, and satisfaction with political officials' performance. Though it can not be counted among participation studies, the work by Gabriel A. Almond and Sidney Verba deserves special attention at this point. Their seminal study The Civic Culture has contributed a great deal to the insights of the field of participation research, where they have empirically tested and affirmed the interrelation between the above mentioned orientations - which they describe as the indicators of a democratic political culture - and political participation.

Later, another group of researchers provided research on participation with the insight that the effect of socioeconomic resources on political participation is not a direct one, but it is mediated primarily through political skills and attitudes (Nie et al. 1969). This means that factors such as education level, age or gender form the background for political interest, information, and internal political efficacy, which in turn determine the level of participation. This has already been signified by Almond and Verba in The Civic Culture: "The educated classes possess the keys to political participation and involvement while those with less education are less well equipped" (1963; cited in Curtice \& Seyd 2003: 93, italics added by BHD). According to some scholars, the relationship between education and turnout works through intervening factors; education fosters the feeling of civic duty to vote and helps individuals attain basic political knowledge and skills that make voting more likely (Wolfinger \& Rosenstone 1980: 18). In a similar vein, Verba et al. (1995) argue that education facilitates political participation by increasing individuals' skills as well as "psychological and cognitive engagement with politics" (Rubenson et al. 2004: 410). They suggest moreover that education makes involvement in networks that recruit citizens into political activity more likely (see also Putnam 1995; Nie et al. 1996), and it becomes more easy to get better paid jobs which increase income.

This way of thinking has affected the subsequent work on political participation to a considerable extent. As shown in Leighley's statement cited above, it has become a general understanding in participation research that socioeconomic status facilitates individual political participation by generating the relevant attitudes and skills needed for it. A more up-to-date and sophisticated model for explaining 
political participation combines several groups of background factors. The so-called Civic Voluntarism Model answers the question why individuals do not participate in politics as follows: "because they can't; because they don't want to; or because nobody asked ... people may be inactive because they lack resources, because they lack psychological engagement with politics, or because they are outside of the recruitment networks that bring people into politics" (Verba et al. 1995: 269). Resources refer to time, money, and civic skills; psychological engagement is defined in terms of interest in politics, sense of political efficacy, the value of participation as a civic duty, simultaneous consideration of community well-being, and individual policy interest, as well as party identification (1995: 271f.). Finally, they have integrated another set of factors that should influence political participation into the model, namely the mobilization effects of network involvement that vary from informal networks such as family and friends to formal memberships in voluntary organizations (1995: 272f.). All of these factors are thought to interact with each other, and their positive impact on mobilizing political activism has been confirmed by recent empirical findings (e.g. Gabriel 2004; Pattie et al. 2004)

\subsubsection{Criticisms to the socioeconomic model and the puzzle of participation}

The models explaining political participation by socioeconomic status and political motivations of individuals have provided valuable insights into the study of the determinants of political participation and have therefore gained recognition in the research. Yet these models have also been met with criticism. The first criticism is on the direction of causality between attitudes and participation. Political participation can also have an impact upon individuals' attitudes ${ }^{21}$, and in case this possibility is ignored, it can lead to an overestimating of the effects of attitudes on participation (Leighley 1995: 186). A second set of criticisms stresses that the socioeconomic model is directed at explaining levels of political participation as such, where individual forms of activity are being disregarded. The main focus of most empirical studies is rather on who participates in what type of activity, yet the question on why individuals prefer one particular form of participation to another is being left unanswered. What is more, the standard indicators of these models - social skills, economic resources, and political orientations - seem not to be able to cope with the latest developments in political action. As discussed above, the increase in newer repertoires of activism such as protesting, consumerism and petitioning has been

\footnotetext{
${ }^{21}$ Finkel $(1985,1987)$ has for instance shown that political efficacy and political participation have reciprocal effects on each other. Other researchers have found similar effects between participation and political sophistication (e.g. Junn 1991; Leighley 1991).
} 
accompanied by a simultaneous decrease in voting and other conventional forms of participation. Particularly this development was a challenge for the linearity assumption of the relationship between socioeconomic status and participation. For instance, the research findings on decreasing turnout levels during a period where substantial growth in educational attainment and affluence has also taken place has ended up in the well-known "puzzle of participation" (Brody 1978). The problem was that the straightforward hypotheses on a linear relationship between education or income levels and participation could not easily be validated anymore; it became necessary to ask the pivotal question "which form of participation". That is because the highly educated may be more inclined towards, as well as more qualified, for newer and demanding forms of political activism than the less challenging act of voting. Recent empirical research on these relationships has provided evidence that the better educated indeed tend to participate in political activities which are beyond electoral and representational forms (e.g. Heath \& Topf 1987; Parry et al. 1992; Norris 2002).

Besides the tendency of the better educated to utilize alternative forms of participation, the decline in turnout has also been caused by generational replacement, which means that the youngest members of the electorate are increasingly turning away from voting at elections (Miller \& Shanks 1996; Lyons \& Alexander 2000; Putnam 2000, 2002; Blais et al. 2002; Franklin 2004; Rubenson et al. 2004). These studies have found clear trends in rates of non-voting among younger generations, particularly for those born after 1970. According to this, non-voting among this group has increased by 14 points between 1993 and 2000 (Blais et al. 2002: 46). Moreover, they conclude that the difference between the age groups is due to a generational effect, i.e. the cohorts display the same tendency in turnout throughout their life cycle.

Not only turnout, but also other channels of participation of the institutionalized party politics seem to be subject to the same paradox. Research findings show that the decline in participation forms such as party membership and campaign activities is most common among the younger generations (Rubenson et al. 2004; Blais 2006; Dalton 2006). In various countries, the youth sections of political parties, which have once been important recruitment channels for young citizens into party politics, are "rapidly losing their members and are almost on the brink of disappearing" (Hooghe 2004: 332, see also Hooghe et al. 2004). Furthermore, Putnam (2000) found that social capital is declining among younger generations in American society, i.e. they are less likely to get engaged in various other forms of civic engagement, and they are more distrusting toward political institutions or their fellow citizens. Putnam further 
claims that this decline is also a function of generational replacement. These findings indicate that young people are increasingly distancing themselves from traditional party politics.

These trends have brought about new questions about the future of democratic politics. Some scholars have approached the new trends with concern, suggesting that they should be a sign of dwindling democratic commitment and engagement among the youth. However, others point at another development; although participation rates for traditional forms among younger generations have been declining, their affinity for participation in protests, voluntary public interest groups, and other newer forms of political participation seems to be increasing. The youth increasingly turns to forms of political participation outside of the traditional arena of politics, such as demonstrating, signing petitions, buying and boycotting products etc. (Barnes \& Kaase et al. 1979; Inglehart 1997; Blais et al. 2002; Norris 2002; Stolle \& Hooghe 2005; Stolle et al. 2005; Norris et al. 2005). This trend supports the idea that the decline in youth involvement in traditional channels of political influence does not necessarily mean a loss of interest in politics and public affairs among young citizens. Rather, changing attitudes, norms and values of the youth seem to account for this trend. Research has found evidence for increasing criticism toward hierarchical and representational institutions among younger generations, and that this accounts for both the turnout gap and the tendency towards the new activity repertoire (Norris 1999, 2002; Inglehart 2003; Dalton 2004). This means that they prefer more informal ways of participating in politics which are more lifestyleoriented and more loosely structured than representational forms of involvement (O'Toole et al. 2003).

To sum up, the developments portrayed so far suggest that high levels of education and skills in affluent societies do not necessarily imply a general shift in the levels of political activism. Contemporary trends in Western advanced industrial democracies such as rising levels of literacy, education, and affluence should push electoral turnout significantly upward, yet research findings indicate that this is not the case. Quite the contrary: turnout levels have been declining particularly in those societies where the societal background is supposed to provide favorable conditions for turnout. Rather, this background seems to have had a more noticeable impact on increasing participation in areas where activity is citizen-initiated, less constrained, directly linked to government, and more policy-oriented. This shows that economic affluence and cognitive skills are not satisfactory predictors of the changing political involvement structures in Western democracies. They seem to be in a complex interaction with other acknowledged determinants of participation such as age or 
political attitudes at the individual level, which might be the main factor underlying the contradicting effects on participation presented above. Therefore, understanding these interactions resulting from complex structural social changes should be the main focus if one wishes to give a better overview of the background of the participatory change.

\subsection{Conclusion}

This chapter outlined the development of political participation through demonstrating the increasing number of politically involved citizens and illustrating the extension of political participation channels. We showed that particularly in Western advanced industrial societies there has been a dramatic change in political involvement structures over the past decades. Channels to influence the policymaking process have increased rapidly and citizens have become increasingly active in politics since the 1970s. Parallel to this, the assessment of different forms of participation in the research has as well been subject to a change. Following the seminal studies by Verba et al. $(1972,1978)$ and Barnes \& Kaase et al. (1979), which defined political participation as a multidimensional phenomenon, several subsequent studies have stuck with the traditional distinction between conventional or unconventional behavior, where turnout and party activities were ordered to conventional participation and protest activities and civil disobedience were counted among unconventional activism. This view, however, has been modified to a great extent in the past years, since the conventional wisdom on appropriate means of political influence has changed over time. While activities outside of the representational democratic structures were defined twenty years ago as unconventional forms of interest articulation, they are now seen as legitimate forms of political behavior. This is among other factors due to the fact that these activities have become common repertoires of influencing politics among the citizenry in contemporary Western democracies, while representational forms of political participation are becoming less and less popular - especially among the youngest age groups - over the past decades.

These developments have posed two main questions in the research on political participation and democracy. The first question was on the determinants of the change in political participation. The fact that this change has taken place in economically affluent countries has led most researchers to think that the resources available to citizens (such as education, political knowledge, time, money) are the main determinants of this change. Yet the simultaneous decrease in electoral turnout 
and participation in traditional forms of exercising influence on the decision-making has caused a "paradox": although economical and cognitive resources have proven to be the main predictors of turnout, the levels of turnout were declining especially in those countries where these resources are available to citizens more than it has ever been in history. What is more, this decline is observed especially among younger age groups, who are supposed to have profited most from these resources. At the same time, the demand for, and participation in, less conventional, more issue-oriented and direct forms of political action has increased to very high levels in a fairly short time. This development is again most significant among the youngest. This clear renouncing of the traditional and embracing of the unconventional can thus not only be due to resources; as we will discuss later, more deep-seated cultural shifts as well appear to account for this change to a high extent.

The second question was on the future implications of these developments for democratic governance in these societies. The maximum level and appropriate type of political involvement for a well functioning democracy is still a highly relevant issue. The most recent changes in participation have challenged the essence of representative democracy as citizens began to claim a more direct role in affecting the political decision-making processes. As discussed above, this has been met with skepticism by many scholars, yet the concern that "too much" participation would overload the democratic decision-making process, decrease its effectiveness, and therefore threaten the stability and efficiency of democratic government (Huntington 1974; Crozier et al. 1975) seems to be dated. Newer critics of the contemporary trends place the emphasis on declining representational political activities (turnout, or party and group memberships) and base their arguments on the fact that citizens of modern societies simply lack the substance for good democratic citizenship; they show low levels of political interest and knowledge, they refrain from civic engagement, and not all of them promote democratic values (e.g. Putnam 2000; Hibbing \& Theiss-Morse 2002; Theiss-Morse \& Hibbing 2005). Another group of optimists, on the other hand, interpret this development positively; not only since from a participatory democratic perspective - higher levels of participation should lead to a better democracy, but also because the public who is inclined towards newer forms of participation has proven to be more democratically minded and adhere more strongly to democratic norms (Inglehart 1997, 2003; Inglehart \& Norris 2003). Participatory behavior accompanied by such motivations should make a better fundament for the further development of citizens and the democratic government (Inglehart \& Welzel 2005). 
There are thus differing views on democratic implications of the participatory change, yet their common point is that they both highlight the importance of motivations in terms of norms, values and attitudes. This idea is anything but new. Already in the 1960s, Almond and Verba had related the stability of a democratic political system to mass political orientations, which they have described as indicators of a democratic political culture (1963: 366). Yet we have shown above that these orientations do not influence political participation in a consistent way in Western democracies; their impact varies among different forms of political activity and they seem to be intertwined with other individual-level characteristics resources and skills - in affecting levels of these activity forms.

These mechanisms can best be comprehended by focusing upon the macro-level processes that may be influencing the changes in participatory behavior within the last decades on the one hand and the reciprocal effects between the individual-level characteristics in determining participation on the other. As we mentioned earlier in this chapter, the process of modernization in advanced industrial societies is thought to be one of the most crucial societal-level factors that is thought to be underlying participatory change. The shifts in political participation - rising levels as well as increasing diversification of its forms - have mainly been associated with the process of industrialization and post-industrialization and the societal changes that have been brought about by these economic developments. Especially the increasing demand for more participation and more direct influence on decision-makers have been attributed to the new characteristics of citizens in these societies generated by the above mentioned processes. We will give a detailed overview of the changing societal and individual conditions for political participation in the following chapter. 


\section{Chapter 4}

\section{Changing Society, Changing Politics? Cultural and Political Implications of Post-Industrialization and Post-Modernization}

In recent decades, Western advanced industrial countries underwent a large-scale economic and societal change. This transition, also referred to as postindustrialization, is thought to have invoked a big change in not only material resources of citizens in these societies, but also in their culture in terms of values, attitudes, beliefs, and skills. A post-modern political culture has emerged in terms of post-material value orientations. As a consequence, behaviors of citizens have also been affected. These changes have taken place in every field of the society; that means political culture and behavior have not remained unaffected.

The cultural changes invoked by post-modernization are crucial since they are supposed to account for the change in patterns of political behavior among citizens. In the previous chapter we discussed the effects of resources and motivations on individual political participation, and further that these influence factors are also related to each other to some extent. In the wake of post-industrialization, it is assumed that these factors have been subject to a change in the sense that social change, in terms of social and economic conditions of living, leads to cultural change in terms of values and attitudes. Political skills and individual values form also a part of this cultural change and are believed to have led to the participatory change we have portrayed in chapter 3. This chapter will focus on the changes in citizens' characteristics and their political implications by employing the following strategy: First, we aim to establish a link between the macro-level phenomenon, postindustrialization (or post-modernization), and the above mentioned individual-level characteristics. Second, we will describe how these characteristics modify political motivations that are believed to determine political participation.

The processes of post-industrialization and post-modernization deserve special attention here since they have consequences for the successful functioning of democratic governance. Former studies have often assumed a direct link between 
societal modernization and democracy ${ }^{22}$. Newer studies suggest that there is not a direct link, but the effect of modernization runs through the cultural change, i.e. cultural change serves as an intervening variable (Inglehart 1997; Inglehart \& Welzel 2005). Democratic stability is guaranteed by congruence between political culture and political structure, i.e. political cultural attitudes are closely linked to the viability of democratic institutions (Almond \& Verba 1963; Inglehart 1988); thus political motivations and attitudes have a special meaning in this debate since their distribution in society forms the political culture in that society. Changing culture in representative democratic systems invokes questions regarding the extent that this congruence is guaranteed. Also, the content of a pro-democratic political culture is still being debated. However, before moving to this debate, it is crucial to establish the extent of political cultural change in societies experiencing the modernization process at the post-industrial stage. Therefore, we will round up this chapter with a discussion on the extent to which a shift in political culture has taken place, and to what extent the congruence between the citizens and the state has been maintained or disturbed in these societies.

\subsection{Modernization and Post-Modernization: The Emergence of Post- Industrial Society}

Over the last two centuries, the social structure of Western societies has gone through dramatic changes. These refer to a multitude of system-level developments including social, economic, demographic, and technological changes, whereas the basis of the change was economic and took place in mainly two phases. The first major phase is the transition to industrial society, which had emerged around the 1750s in England. The central characteristic of this phase is a shift from agrarian to industrialized production, which resulted in a gradual increase in the proportion of workers in the industrial sector in these societies. This trend remained until the $20^{\text {th }}$ century, when the industrial work productivity experienced a rapid rise due to the increasing efficiency of production technologies. As a consequence, the industrial societies experienced a general increase in wealth and existential security, particularly during the second half of the century. Moreover, the balance in the wealth-generating activities began to shift from the industrial sector to the tertiary sector of these economies. A great deal of industrial workers moved from the

22 The work of Seymour Martin Lipset, Daniel Lerner, W. W. Rostow, Karl Deutsch, and Daniel Bell could be counted among the literature which focuses upon the relation between the level of socioeconomic development and democratic stability. 
industrial to the service sector as a consequence of this process, so that gradually more than 50 percent of the paid workforce became employed in the services sector. These shifts refer to the rise of the post-industrial society (Bell 1973; Huntington 1974), which constitutes the second major phase of the societal modernization process.

Though mainly defined on the basis of economic production and wealth indicators, the industrial and post-industrial societies cannot be characterized merely by them. Parallel to the economic developments, a number of other significant structural transformations have taken place in these societies particularly in the domains of the social and the political. These simultaneous shifts form together coherent patterns of development and progress covering all areas of society, which are generally being referred to as the process of societal modernization (Inglehart 1990, 1997; Norris 2002; Inglehart \& Welzel 2005). Table 4.1 provides a summary of these shifts in both types of societies.

Table 4.1 The process of societal modernization

\begin{tabular}{|c|c|}
\hline Agrarian to Industrial Society & Industrial to Post-Industrial Society \\
\hline From agriculture to heavy industry & Service sector \\
\hline Rural to urban & Urban to suburban \\
\hline Division church and state & Secularization and scientific authority \\
\hline Mass education and literacy & Higher education \\
\hline Occupational specification & Flexible careers \\
\hline $\begin{array}{l}\text { Working class and urban bourgeoisie, decline } \\
\text { of peasants and landed interests }\end{array}$ & $\begin{array}{l}\text { From ascribed to achieved status, decline in } \\
\text { political salience of class cleavage }\end{array}$ \\
\hline $\begin{array}{c}\text { Bureaucratization, reliance upon rational- } \\
\text { legal government authority }\end{array}$ & $\begin{array}{l}\text { Growth of multilayered governance, rise of } \\
\text { new participatory demands }\end{array}$ \\
\hline $\begin{array}{l}\text { Basic welfare state and social protection, } \\
\text { education/health }\end{array}$ & $\begin{array}{l}\text { Market liberalization and contracting out of } \\
\text { social protection functions }\end{array}$ \\
\hline From extended to nuclear families & Growth non-traditional households \\
\hline Entry of more women into paid workforce & Growing sex equality at home and workplace \\
\hline
\end{tabular}

Table constructed basing on information from Norris 2002: 20ff.

The table shows the main societal changes that have occurred due to the shifts from agrarian to industrial and from industrial to post-industrial societies. As it demonstrates clearly, the structural shifts associated with the transition from 
agrarian to industrial society do not only comprise the development from agricultural production to heavy manufacturing and industrial production; it has a number of implications for the society. The change in production forms have resulted first of all in a population shift from rural to urban areas and the expansion of the workers' class as well as the emergence of an urban bourgeoisie. The establishment of a paid workforce brought about the need for occupational specialization and the employment of women in paid work. The economic growth achieved through fast and professionalized industrial production changed also the standards of living: basic education and literacy reached higher levels, average life-expectancy and available leisure time increased, and the technological improvements such as the expansion of print and electronic media made information flow among greater masses possible.

Finally, these developments had consequences also for the cultural and political domains. The main cultural change initiated by industrialization was a rising emphasis on rationalization and secularization, bringing about a shift towards a new type of political authority which is based on secular-rational sources rather than traditional-religious ones. Another important consequence was the emergence of interest conflicts around four different cleavages, namely the tensions between center and periphery interests, urban and rural interests, employers' and workers' interests, and finally, religious and secular orientations (Lipset \& Rokkan 1967). These conflict bases have shaped the North American and Western European party systems in the aftermath of the Industrial Revolution.

The changes which amount to the emergence of post-industrial society can be seen as an extension of those transformations that took place with the transition from agrarian to industrial society. Levels of existential security and life standards have improved further; however, changes in other components of the societal development were by no means linear. Surely, paid work has expanded as well as the proportion of women employed, but this has not only implied the growth of the industrial production, but also the majority of the labor force has moved to private and public service sectors. The education levels increased further, but with a wider proportion of people pursuing higher education, since the new jobs which are based on innovation, knowledge, and creativity, required a higher level of cognitive skills.

The further evolution of mass media and modern information and communication technologies increased people's intellectual and informational independence. Other essential changes such as rapid technological and scientific innovation, a shift in class structures, equality of gender roles, secularization, 
suburbanization, globalization, and greater social and geographic mobility also contributed to the significant reduction of natural and social constraints on individuals, providing them with more resources in terms of money, time, skills, and knowledge (see Bell 1973; Norris 2002: 22ff.; Inglehart \& Welzel 2005: 27ff.). In sum, the dominant societal goal shifted from economic growth and achievement of financial capital to human development and enhancing cultural capital during the transformation to post-industrial society, and the changes are more fundamental at this stage. Therefore, the direction of the development cannot be treated as a linear increase of the achievements of the industrial society; the changes at the postindustrial stage comprised major shifts in various domains of the society which partly reflected a "fundamental break with the past" (Van Deth 1995: 1). It appeared thus more appropriate to describe this non-linear development in the second phase of societal modernization as the process of post-modernization (Giddens 1990; Inglehart 1997).

These multifaceted transformations at the societal level are thought to have triggered shifts also on the individual level, especially on the general socio-cultural characteristics of individuals. It was already argued by Karl Marx during the Industrial Revolution in $19^{\text {th }}$ century that socioeconomic development facilitates subsequent changes in people's culture, which, at that time, implied a shift away from traditional to rational-secular value systems. The processes of postindustrialization and post-modernization are also supposed to have given way to a similar cultural shift. Because of the achievements in economic, technological, and educational conditions, and changes in the nature of work and employment described above, the emphasis given to human autonomy and development has expanded to a great extent. This new emphasis had implications particularly on people's skills and cognitive capabilities, but also on their value priorities and personality attributes by creating a growing tendency towards emancipation from authority, individual autonomy, self-reliance, and self-fulfillment (Van Deth \& Scarbrough 1995; Inglehart 1997; Norris 2002; Inglehart \& Welzel 2005). In the scholarly literature, these individual-level reflections of societal modernization are often being referred to as individual modernization (Inkeles 1978; Fuchs \& Klingemann 1995; Welzel 2007).

According to the theorists of modernization and post-modernization, it is this transformation that accounts for the political change from the late 1960s onwards (Huntington 1968; Inglehart 1990, 1997; Van Deth \& Scarbrough 1995; Norris 2002; Inglehart \& Welzel 2005). Due to two key processes within individual modernization - increasing political skills and changing value orientations - the political cultures of 
the concerned publics have been subject to a change, which implies a shift in citizenstate relationships in terms of orientations towards political institutions, identification with political actors and issues, and political behavior. The shifts in participatory behavior which we have discussed in detail in chapter 3 are thus believed to be brought about by these complex societal changes. They have direct impacts on participatory behavior, but also generate indirect influences by a thorough modification of the main individual-level determinants - resources and motivations - of political participation. Figure 4.1 gives an overview of the main political changes initiated by the societal modernization process.

Figure 4.1 Modernization processes and political orientations

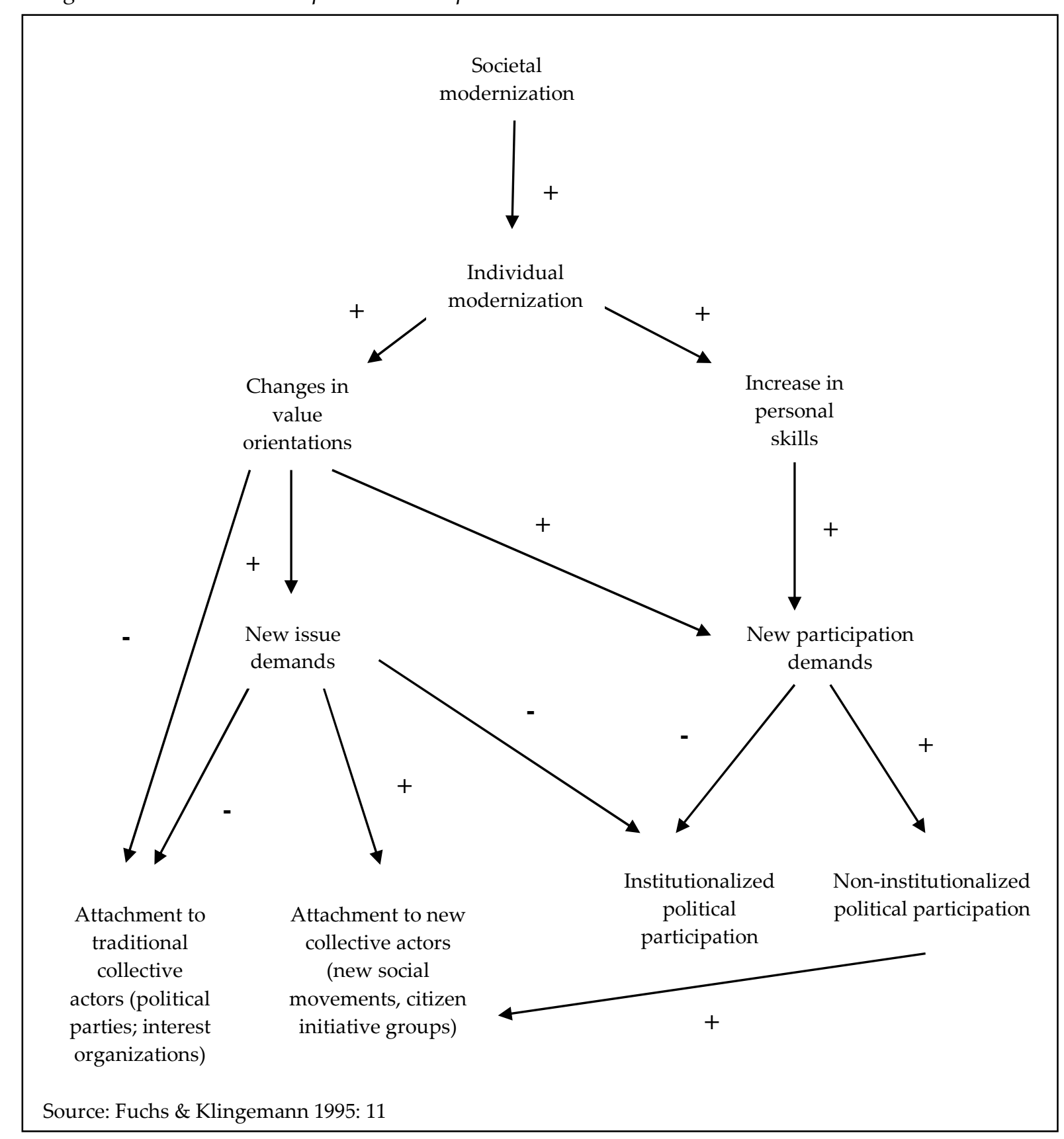


The next sections will provide detailed information on the major political changes brought about by the causal relationships between different phenomena illustrated in the figure. In section 4.2, we will mainly focus on the two key processes of individual modernization and discuss the individual-level cultural changes generated by these processes. Following upon this, we will elaborate on the political consequences of these changes, where particularly the implications on political culture and participation will be paid special attention.

\subsection{Changing Citizens: Implications of Individual Modernization}

In figure 4.1, two main implications of individual modernization have been highlighted: an increase in the citizens' personal skills and a change in their value orientations. As the figure shows, both processes are thought to have affected the citizen-state relationships in many different ways. According to this, the contradictory developments in citizens' political participation - increase in new, extra-representational forms of political participation while distancing from traditional forms - are due to the emergence of both new issue demands and new participatory demands, both of which have been initiated by the change in skills and values. Below we will outline these processes which underlie changing patterns of citizen involvement and discuss why they lead to changing issue and participatory orientations.

\subsubsection{Increase in personal skills}

Earlier empirical studies - as shown in chapter 3 - have found that the public's political skills, in terms of interest in and information about politics, were minimal (e.g. Berelson et al. 1954; Butler \& Stokes 1969; Campbell et al. 1960). As discussed before, this general perception has led to the arguments by some democratic theorists that citizens with such limited political sophistication should better remain politically uninvolved for the sake of a better functioning democracy (Schumpeter 1942). Recent approaches however argue that contemporary publics have better political skills than earlier research has presumed: from the 1960s onwards, citizens in advanced industrial societies became "more interested in politics and more sophisticated in their understanding of politics" (Dalton 2000: 920). This shift in personal skills is generally referred to as the process of cognitive mobilization (Dalton 1984; Inglehart 1990, 1997), and as we will discuss below, components of the post-industrialization and post-modernization processes largely account for this crucial development. 
As mentioned in the previous section, the transition toward an industrial economy was accompanied first of all by a rapid expansion of economic resources, which was followed by an expansion of information, literacy, and education. The transition from an industrial to post-industrial economy was associated with an even more rapid expansion of the material and cognitive resources of individuals. Higher education opportunities and information sources are now available to greater segments of the public than ever before. Particularly the increase in levels of education and media exposure in contemporary societies are believed to have led to the increase in citizens' cognitive and political skills. A rising importance of skilled workers in knowledge-based economies of the post-industrial society has led to a serious expansion of the number of citizens entering post-secondary education, providing them with an ever increasing ability to pursue, collect, and process information. Also, the expansion of the use of modern communication technologies and the resulting high exposure to political news - e.g. on the television or political web sites - has decreased the cost of acquiring information about politics.

The first consequence of these developments is that the level of political information acquired by the publics as well as their ability to process this information has grown to a level that the wide information and skills gap, which separated elites from citizens in traditional and industrial societies, narrowed with the transition from industrial to post-industrial society. Thus contemporary publics who enjoy high levels of formal education are now supposed to be capable of acquiring and organizing knowledge in order to deploy it in the service of reasoned argument (e.g. Dalton 2000, 2006; Nevitte 2000). However, research on the political knowledge of citizens in various Western democracies has produced contradicting results. A study of American citizens has concluded that political information is limited among the American public and further, it is not increasing (Delli Carpini \& Keeter 1996; Wattenberg 2006); whereas other researchers have found high levels of information among American citizens, as well as Western publics in general (e.g. Fiorina 1990; Inglehart 1990, 1997). This ambiguity, as Dalton suggests, can be associated with the different expectations regarding the ideal level of political information and its operationalizations (2000: 920f.). It is somewhat too ambitious to expect that citizens possess high levels of information on every political topic; rather, it is more appropriate to assume that citizens are informed on a limited number of topics in which they are interested, possibly on grounds of personal situation, and that they are more likely to be able to process this information and make decisions based on it (Sniderman et al. 1991; Rohrschneider 1992; Dalton 2000). Due to expanding educational opportunities and modern communication channels it is 
possible to get more in-depth information on the political topic of interest. However, despite these possibilities it is still highly likely that citizens depend on the so-called "heuristics" to obtain political information, i.e. that they make use of information and decision-making shortcuts (Popkin 1991; Lupia 1994; Huckfeldt et al. 1998; Lupia \& McCubbins 1998). This means that not only the political information itself, but also the motivation and interest to obtain the information are crucial factors to assess the level of the cognitive and political skills of citizens.

Political interest, which plays thus a vital role by supplying the motivation for people to seek out information, is also believed to have gone through a significant increase due to the expansion in education and media use. Dalton, for instance, concludes for the years between the early 1950s and the 2000s that "the trend of increasing political interest is unmistakable" (2006: 25). Also earlier studies point out an increasing interest in political affairs in Western post-industrial democracies (e.g. Kaase \& Marsh 1979; Dalton \& Wattenberg 2000). However, there is concurrent evidence that the structure of this development is somewhat inconsistent even in countries at the same level of post-industrialization.

Topf (1995a) found in his study of fifteen European Union countries that the level of political interest is increasing over time, but its distribution among age groups varies to such an extent that we cannot speak of a general pattern. Other longitudinal studies have shown that there is no common trend in political interest in the European post-industrial democracies; on the contrary, huge cross-national differences can be observed. For a large number of Western European countries it can be shown that political interest increases in some countries, decreases in others, or shows trendless fluctuations in remaining countries (see Van den Broek \& Heunks 1994; Gabriel \& Van Deth 1995; Van Deth 1996; Van Deth \& Elff 2000, 2004). Finally, some researchers argue that contemporary publics are disinterested in politics and do not want to take over the responsibilities of democratic citizenship; thus they refrain from politics and tend to leave the responsibility of making crucial decisions to elites (e.g. Hibbing \& Theiss-Morse 2002). As for the effects of societal modernization, it is claimed that this process is not causing citizens to become more engaged in politics, on the contrary, it further alienates them from politics (e.g. Putnam 2000).

In short, while it is one of the main premises of the modernization paradigm that citizens in post-industrial societies are cognitively more mobilized and therefore politically more skilled than ever before, empirical research provides contradictory evidence. Thus it is still hard to determine to what extent political choices made by 
people are based on sound evaluation of the political procedure, and to what extent participatory change in post-industrial societies can be attributed to the shift in political skills. We will return to this issue while debating the political implications of post-modernization in the forthcoming sections of this chapter, yet for now we will move our focus to the other main individual-level change within the societal modernization process, namely the process of change in core value orientations.

\subsubsection{Value change and individualization}

The transition from agrarian to industrial and from industrial to post-industrial society is assumed to have produced fundamental changes in people's prevailing worldviews. Early behavioral research has examined the relationship between the development of industrial society and the changing values of the public (e.g. Inkeles \& Smith 1974). Later on, further processes of value change, that accompanied the development of advanced industrial or post-industrial society, have been diagnosed and analyzed by other researchers. The most widely used framework for studying the changes affecting mass publics in advanced industrial democracies is Inglehart's thesis of post-material value change. He argues that the socioeconomic changes transforming Western industrial societies are impacting the relative scarcity of valued goals and consequently the value priorities of Western publics (see Inglehart 1977, 1990, 1997). We will discuss the main arguments of this theory in detail below.

\subsubsection{The post-materialist value change}

Inglehart's theory of post-material value change provides a very systematic overview of the transformation of value orientations in contemporary publics. He foresees "a shift from materialist to post-materialist value priorities...from giving top priority to physical sustenance and safety toward heavier emphasis on belonging, selfexpression, and the quality of life" (Inglehart 1990: 66) and bases his explanation of this shift on two key hypotheses. The first one, scarcity hypothesis, suggests that individuals' priorities are determined by their socioeconomic environments; people tend to place the highest value on their most pressing needs. When material resources and physical security are scarce, the most important goal will be their possessions and maintenance, in other words "materialistic" goals will be prioritized (Inglehart 1990, 1997, 2007). Yet particularly in the aftermath of the World War II, where the publics in Western democracies have experienced higher levels of economic security provided through societal development, the focus has shifted towards "post-material" goals such as self-realization, self-esteem, affection, a better quality of life, and improved social relationships. The second premise of Inglehart's theory, the socialization hypothesis, holds that people's basic value priorities are 
internalized during adolescence and reflect the conditions that prevailed during this internalization process; their values are largely fixed when individuals reach adulthood, and remain quite consistent throughout their lifetime.

The idea of value change through socialization builds largely upon the theory of generations by Karl Mannheim (1952). According to Mannheim, a generation distinguishes itself through the shared formative experiences of its members. Whether generations emerge at all, and with what frequency, depends on the rate of socio-historical change (1952: 286-320). Mannheim furthermore argued that young people entering society are more inclined to change than people of advanced age who are already a part of society. In other words, people retain the views they acquired when they were young, and with every new generation socialized under new economic and societal conditions, a long-term social change is likely to occur gradually due to the replacement of older generations by younger ones. The value change theory by Inglehart adopts this assumption that social change is brought about by generation replacement, that is why the shift from materialist to postmaterialist values is referred to as the "silent revolution" (Inglehart 1971, 1977, 1990; see also Abramson \& Inglehart 1987; Inglehart \& Abramson 1994). This implies that the above mentioned relationship between material conditions and value priorities "is not one of immediate adjustment" (Inglehart 2007: 224).

Value orientations that were important during the first half of the $20^{\text {th }}$ century have lost much of their significance during the process of post-industrialization and post-modernization. Older generations who have experienced the economic crisis and World War II grew up with the experience that material well-being and security are scarce goods. As a consequence, these goods have a high utility, and citizens are more likely to prioritize materialistic and acquisitive values ${ }^{23}$. For the generations born in the aftermath of the War, material well-being and physical security were almost self-evident. Hence they are expected to be more open to post-materialist values such as liberty and self-fulfilment. In short, a cultural shift in post-modern post-industrial societies is taking place, as older generations with their traditional materialist values are being gradually replaced by younger generations emphasizing post-materialist value orientations.

\footnotetext{
${ }^{23}$ In a similar vein, those most exposed to affluence and education, the middle class, are more likely to develop new values than the working classes, and those societies experiencing higher levels of economic affluence and peace would score most highly in terms of postmaterial orientations.
} 
The shift towards post-materialist values is an important aspect of the broad process of cultural change in advanced industrial societies since they are reshaping societal norms which include political views, religious orientations, gender roles, and so forth (Inglehart 1990, 1997). The emerging orientations place less emphasis on traditional cultural norms, especially those that limit individual self-expression. In an attempt to deepen the understanding of the dimensions of cross-cultural values, Inglehart and Baker (2000) carried out a factor analysis which tapped a wide range of values, out of which two significant dimensions have emerged: traditional vs. rationalsecular values on the one hand and survival vs. self-expression values on the other.

The traditional values place strong emphasis on religion, respect for authority, national pride, and have relatively low levels of tolerance for individual decisions that deviate from the pattern, such as abortion and divorce, whereas secular-rational values have the opposite characteristics. This first major dimension of cross-cultural variation is believed to reflect the value shift that occurred during the transformation from agrarian to industrial society; agrarian societies tend to emphasize traditional values while industrialized ones tend to emphasize secular-rational values. The second major dimension, which reflects a polarization between survival and selfexpression values, is rather linked with the transition from industrial to postindustrial society. Materialist vs. post-materialist values are sensitive indicators of this dimension, for the conditions that give rise to post-materialist values are also conducive to self-expression values.

Self-expression values however tap a number of issues that go beyond the items encompassed by post-materialist values. They reflect mass polarization on issues such as gender equality, tolerance of diversity, priority of environmental protection, and increasing demands for participation in decision-making in economic and political life. Furthermore, societies which rank high in having self-expression values also tend to rank high on interpersonal trust and have relatively high levels of subjective well-being (see also Inglehart \& Welzel 2005). Finally, a major component of self-expression values is a shift away from deference to all forms of external authority. Submission to authority has high costs, since the individual's goals must be subordinated to those of external authorities. Under conditions of insecurity, people are generally willing to submit, but in post-industrial societies where economic and physical insecurities have declined to a much lesser extent, the importance of authorities becomes subject to the same decline as well. Similar to post-materialist values, self-expression values bring also an intergenerational change in a wide variety of basic social norms due to the socialization effect. 
In short, the theory of value shift in post-industrial societies is based on two main premises: First, the increase in economic prosperity is supposed to have initiated the emergence and spread of post-materialist values, so that they are expected to be prevalent in countries with a high level of economic development which we refer to as advanced industrial democracies. Second, these values are expected to be most common among younger generations due to the fact that these generations have not grown up under conditions of hunger and economic insecurity. Moreover, since these values established in the pre-adult formative years tend to be persistent over time, this can be seen an indication of a long-term development in which the postmaterialist value pattern becomes established in the society as older generations are replaced by the younger. Considering the findings described in chapter 3 that younger generations appear to be more inclined to political participation and especially to new forms of participation, we find that the effects of postmodernization on the younger generations deserve special attention. We direct our focus on this matter below.

\subsubsection{Generational differences in post-materialist values and political skills}

Empirical analyses have repeatedly shown that post-materialist values indeed prevail in advanced industrial countries and that younger age groups are more inclined to possess these values. Yet in order to detect if these value differences will remain stable throughout time, the age difference should reflect enduring birth cohort effects and not life-cycle effects. If a life-cycle effect is observed, this will imply that young people will become increasingly materialist as they age, and that the alleged cultural change will not be likely to take place. The cohort effect would, on the contrary, mean that younger generations will remain post-materialist over time, and as they replace the older, more materialist cohorts, the prevailing values of society will change profoundly. Cohort analyses with longitudinal survey data, which have been carried out to answer this dilemma, point rather to cohort effects than life-cycle effects (see Inglehart \& Welzel 2005; Inglehart 2008). Among the five Western post-industrial countries that have been analyzed, the evidence shows a net shift towards post-materialist values from 1970 to 2006 (Inglehart 2008) ${ }^{24}$. Within this time span, period effects are also clearly present which reflect economic conditions such as inflation levels, yet they have no lasting impact: the younger cohorts remain relatively post-materialist despite short-term fluctuations.

\footnotetext{
${ }^{24}$ The analyzed countries are West Germany, France, Britain, the Netherlands and Belgium by using data from Eurobarometer Surveys and World Values Surveys.
} 
The self-expression values show a similar pattern to that found with postmaterialist values. Throughout post-industrial societies, the younger age cohorts emphasize self-expression values more heavily than their elders do. It was not possible to observe the development of these values among birth cohorts for a longer time period since time series data that allowed the analysis of the development of materialist and post-materialist values was not available for them. Yet the evidence from the four waves of the World Values Surveys carried out from 1981 to 2006 showed that younger birth cohorts have placed, consistently throughout the years, more emphasis on self-expression values than older cohorts did, and none of them placed less emphasis on self-expression in 2006 than they did in 1981 (Inglehart 2008: 141). Thus they did not move away from self-expression values toward survival values as they aged, and a cohort effect is also present for these values indicating that these values are likely to increase further.

Other findings from these studies (Inglehart \& Welzel 2005; Inglehart 2008) indicate that the large intergenerational differences with the younger cohorts placing much stronger emphasis on self-expression values than do the older cohorts are displayed by the populations of post-industrial societies. Low income societies that have not experienced substantial economic growth do not show such differences. This evidence supports the thesis that younger birth cohorts differ from older cohorts with respect to the experienced material security during their formative years, and that major cultural changes are occurring through an intergenerational value shift in post-industrial societies.

While the generational effects of value change have been found to be quite unequivocal, empirical findings on the same effects by cognitive mobilization are strikingly ambivalent. Despite the increased possibilities for education and the high exposure to political information, young people in post-industrial countries have been found to be less interested in politics than older generations (Blais et al. 2002; Rubenson et al. 2004). A paradox which is quite similar to the puzzle of political participation (see chapter 3) can be seen here: young people should be more interested in politics due to higher levels of education. The fact that people with higher levels of education tend to show more interest in politics than those with a lower education level has been confirmed by numerous studies (e.g. Lazarsfeld et al. 1944; Berelson et al. 1954; Campbell et al. 1960; Almond \& Verba 1963; Verba \& Nie 1972; Milbrath \& Goel 1977; Marsh \& Kaase 1979; Bennett 1986; Van Deth 1990). So, how can this be the case? 
Several authors have suggested different solutions to this paradox. According to a group of researchers, the changing socio-demographic structure of Western societies account for the declining attendance of younger generations in politics (e.g. Kohli \& Künemund 2005; Schmitter \& Trechsel 2004). Birth rates are declining, thus the older cohorts increase in size and there is much more political weight put on this sector of the society. Another strand of explanation stresses that it is the traditional politics that young people are not interested in. The old political issues and conflict lines do not draw the attention of younger generations anymore, and the issues they are interested in are generally overlooked. In this sense, the absence of younger generations in politics can be interpreted as the absence of interest in traditional politics and not just as political apathy.

In a nutshell, we can conclude that a new type of individual has emerged during the transition from industrial to post-industrial, or respectively, from modern to post-modern society. Due to the changes in citizens' skills and value orientations described in this section, individuals seem to have developed a new post-modern personality, on which they increasingly center their attitudes and actions. This personality should then be reflected in a new type of post-modern citizen with a new set of political attitudes and behavior, since individual political behavior is "determined by behavioral intentions, which, in turn, are shaped by values and political orientations" (Van Deth 1995: 5f.). We assume here that the changes in political orientations - or attitudes - are not completely independent from the value change. Attitudes are influenced by the increase in political skills to a certain extent, but they are mainly shaped by the new values, as can be seen in the example of the emergence of new issue orientations and the shift in attachments from old to new political actors (see figure 4.1). The remaining question, then, is on the scope of this change. Have the political attitudes been transformed to such an extent that one could speak of a new post-modern culture in Western post-industrial societies? The next section will try to answer this question.

\subsection{Changing Politics: The Shift towards Post-Modern Citizen and its Consequences}

The discussion in the previous section has yielded the conclusion that the increase in cognitive and political skills and the intergenerational value shift in advanced industrial societies shall have consequences for politics just like various other domains of the social system. Skills are important for politics because they affect evaluations of political institutions and of the self as a political entity, and because 
they mobilize political action. Values are relevant for politics because they form the basis of orientations that citizens have towards their political environments. They are being referred to as core beliefs, and identified as stable patterns of interconnected attitudes (Van Deth \& Scarbrough 1995). The particular distribution of these orientations towards political objects in a society, in turn, forms the political culture of that very society (Almond \& Verba 1963). Therefore, it can be assumed that a change in political life and the political culture of citizens is inevitable in societies where a fundamental change in value priorities has taken place. Below we will go into the details of this alleged relationship between individual-level changes and political culture. We will first discuss the process of the so-called individualization of politics and then the scope of change in individual political orientations initiated by increasing political skills and value change. Following upon this, we will draw conclusions for the changing political culture in Western post-industrial societies.

\subsubsection{Individualization of politics}

The significant change in citizens' skills, values and life-styles is embodied through an increasing disconnection from traditional structures and loyalties, which is termed as "individualization" in the literature (Giddens 1990; Beck, Giddens \& Lash 1994; Gibbins \& Reimer 1999). This implies that the beliefs, attitudes, and behaviors of individuals are no longer dependent upon tradition and social institutions but increasingly grounded on personal choices (Ester et al. 1994: 7; Halman \& Nevitte 1996: 4). Thus, people become less dependent upon traditional authoritarian institutions and more autonomous in their decisions in the sense that they operate according to principles of their own rationality and personal convictions. In other words, their actions are increasingly rooted in and legitimized by personal autonomy and preference. As a consequence, people are slowly "shifting away from tradition, respect for authority and material well-being towards self-fulfillment, independence and emancipation" (Van Deth 1995: 2). In a sense, then, it is possible to interpret post-materialist and self-expression value orientations as key manifestations in the process of the individualization of publics in contemporary societies.

In the political realm, individualization appears particularly in the search of selfexpression, self-determination, and the growing emphasis placed on quality of life issues (Gibbins \& Reimer 1999; Inglehart 1990, 1997). Self-determination is made possible through increasing the interest in and the information about politics. Citizens are capable of dealing with the complexities of politics themselves and of making their own political decisions. Yet this also implies that citizens can define their own issue preferences independently. As a consequence, specific issues of 
immediate and personal importance become more relevant compared to group interests and politics. Citizens become less dependent on information cues provided by social groups and political parties, and base their political choices increasingly on individually determined interest ${ }^{25}$. This development is accompanied by a rising heterogeneity of political issue interests. The multitude of post-materialist political issues such as women's rights, environmental protection, and quality of life issues are already present on the agendas of post-industrial democracies of the West, which result in the emergence of "a variety of distinct issue publics" (Dalton 2000: 932). These issue publics are likely to be further extended due to the diminishing borderline between collective and private domains: the new perception that "personal is political" has caused the fact that an increasing number of phenomena are perceived as political (see Heunks 1990; Beck 1992). As individuals increasingly become the most important players in society, the "responsible collective" for deciding on and implementing policies need not anymore to be organized in the form of a political party or any other type of organization. All these developments imply "a shift away from a style of electoral decision-making based on social group and/or party cues toward a more individualized and inwardly oriented style of political choice", which ends up in a development towards "an eclectic and egocentric pattern of citizen action" (Dalton 2000: 932).

The dissociation of citizens from traditional political actors and the heterogeneity of political issues have serious consequences for the political structure of the concerned societies. These include the decline of traditional political conflict lines, and accordingly a general de-alignment from class and party politics, increasing electoral volatility, and realignments around new political actors such as social movements, protest groups, and other participatory styles (Gibbins \& Reimer 1995: 304). Among individual-level changes, resulting out of these processes, are changing political attitudes of citizens in terms of the development of attachments to new actors in the political arena and a simultaneous increase in critical attitudes towards traditional actors which represent the hierarchic structures of representative democracy. The next section will concentrate on this specific attitudinal change.

\subsubsection{Changes in political orientations}

The causal connections illustrated in figure 4.1 suggest that the process of postmodernization has two main implications for the political decision-making process.

\footnotetext{
${ }^{25}$ Even under certain circumstances where citizens have the need for information shortcuts, they rely less upon traditional actors such as political parties or interest groups. We will return back to this point later in this chapter.
} 
First of all, new issue demands directed at quality of life issues such as the abolition of nuclear energy, disarmament, and various ecological problems have arisen on the basis of post-materialist value preferences. Second, and this is specifically applicable to this study, demands for more participation -and especially for new forms of participation - arise as a consequence of the shift towards these value priorities. Both of these changes exert influence on the changing patterns of political participation, as we will describe at length in the following.

We have discussed in the previous section that the individualization process has resulted in the emergence of new issue agendas and detachment from traditional group and party politics; we also showed how this development has been evoked through the increase in political interest and information as well as the shift towards post-materialist and individualist value orientations. Numerous studies have provided evidence for the idea that the emergence of "new politics" (new political issues, new movements, etc.) and especially "new forms of political expression" in post-industrial societies has been due to the increase of post-materialist values (Barnes \& Kaase et al. 1979; Baker et al. 1981; Van Deth \& Scarbrough 1995). Serious changes in citizens' engagement in traditional collective organizations and in their attachments to various political actors are believed to have resulted from disaffection towards traditional collective actors on the one hand, and an increasing attachment to new collective actors (such as new social movements and citizen initiative groups), on the other.

First of all, party memberships as well as party attachments have been in a declining trend since the 1950s (e.g. Dalton et al. 1984; Schmitt \& Holmberg 1995; Dalton 2000, 2004; Dalton \& Wattenberg 2000; Mair \& Van Biezen 2001; Scarrow 2000). Parties, interest groups, and voluntary associations, which are important social institutions for civic mobilization, are also increasingly deserted in Western postindustrial democracies especially among the post-war generations (see Putnam 1995, 2000) ${ }^{26}$; whereas new social movements which focus upon achieving social change through direct action strategies and community building are becoming more and more attractive for citizens (e.g. McAdam et al. 1996; Tarrow 1998; Dalton \& Küchler 1990).

\footnotetext{
${ }^{26}$ Note that the findings of these studies are limited to the United States. Other comparative studies have provided mixed evidence for the erosion in involvement in civic society (see e.g. Pharr \& Putnam 2000; Putnam 2002; Van Deth \& Kreuter 1998; Van Deth 1999; Hooghe \& Stolle 2003).
} 
As discussed in the previous section, one important factor underlying this realignment process is the increasing emphasis on and positive elaboration of the "self". Because they are more interested in and informed about political events and issues, citizens have a higher political self-efficacy, which means that they are convinced about their role as a political actor and their power to influence the political decision-making. Moreover, the priority given to the values of selfexpression, self-determination, and emancipation strengthens this feeling of efficacy; citizens perceive it as their basic right to express their demands and personal interests which increasingly are reflected in the domain of new politics ${ }^{27}$. Therefore, it can be expected that citizens who are highly self-efficacious are either completely detached from political groups or prefer new politics groups to the traditional ones, since they are more likely to represent their interests.

Another crucial change in political attitudes is the rapid decline of trust in and support for key institutions of representative democracy. Indeed, empirical findings from especially the past two decades reveal that there is a decreasing trend in orientations toward key actors of representative government. General trust in politicians and government has been sinking constantly since the 1980s in a majority of advanced industrial societies (e.g. Lipset \& Schneider 1983, 1987; Listhaug 1995; Nye et al. 1997; Holmberg 1999; Dalton 2004). Not only parties, but also parliaments belong to the institutions which are subject to the confidence decline (Listhaug \& Wiberg 1995; Klingemann 1999; Dalton 2004). Again here, the cross-national breadth of this decline suggests that it is a general feature of contemporary politics in advanced industrial democracies.

In the light of the discussion presented to this point, it is possible to elaborate again on the new participatory demands. We have shown already in chapter 3 that these demands have two forms of appearance. The significance of institutionalized or representative - forms of participation, in particular voting, diminishes while noninstitutionalized, or extra-representative forms of participation, emerge and increase. These demands, as to be taken from figure 4.1, are also supposed to be stimulated first of all by the post-materialist and individualist value change. Greater participation in political decision-making processes and the desire to influence these

\footnotetext{
${ }^{27}$ The relationship between this orientation and post-materialist value orientations have been supported by recent empirical studies (e.g. Inglehart 1990, 1997; Gabriel 1995); self-expression values have also been proven to be related to self-efficacy attitudes (e.g. Inglehart \& Welzel 2005).
} 
processes directly can be regarded as the political expression of the general value of self-actualization.

The emergence of new participation demands can, therefore, be seen as one consequence of the increasing importance of individual self-actualization ${ }^{28}$. It can be interpreted as a motivating factor for citizens to choose more direct forms of political action which take shape beyond the institutions of parliamentary politics. These types of political action, such as protesting, petition signing, boycotts, and other politically based consumerism, are more likely to meet citizens' demands to participate in making major decisions and not being "just a voice in selecting the decision-makers" (Inglehart 1977: 367). It is in this perspective that we can understand both increased distrust of and decreased interest in party politics, and increased participation in boycotts and other politically based consumerism. Yet as mentioned above, the change in participatory behavior is not thought to be associated solely with the new value orientations - the second reason for the emergence of new participation demands is the increase in personal skills. The more highly people evaluate their competence in a given field, the more likely they are to attain their goals in this field through their own efforts (e.g. Krampen 1988). New participation demands can thus be understood as the political consequence of not only the value of self-actualization but also the subjective ability to actively organize one's own life.

\subsection{Conclusion: A Post-Modern Political Culture}

In this chapter we focused on the recent societal transformation known as the emergence of post-industrial society and its individual-level implications. As shown above, the developments that have led to the emergence of post-industrial society and their implications at the individual level have triggered two crucial processes: cognitive mobilization and a shift in individual values. The revolutionary changes in people's skills and value systems in these societies have had direct consequences for the relationship between citizens and the state, since they have initiated the development of a new form of politics and a new political culture among the publics of these societies.

\footnotetext{
${ }^{28}$ The priority given to self-actualization may either arise from postmaterialist orientations or from individualist orientations. This discussion will be outlined in detail in the following chapter.
} 
The combined effects of these changes mean that the institutions of representative democracy which were shaped during the industrial era are now facing a great challenge due to these changes. Rising education levels and a broader availability of information lead to greater political interest in public life and the political world, and therefore even greater motivation to seek out information. Moreover, these processes affect the feeling of political efficacy of citizens positively, i.e. citizens become more convinced that they can play a role in the political decision-making process, thus they have significant participatory capacity. The shift in value orientations has further consequences for individuals' political beliefs and attitudes. Citizens with predominantly post-material value orientations give higher priority to autonomy and more open government. They tend to exhibit less confidence in particular government institutions and are more inclined to believe that governments are unresponsive. Moreover, they rely less upon social group loyalties and affective party attachments as participatory cues.

The decline of traditional means of participation in political decision-making such as voting and party memberships - and the simultaneous rise in more autonomous, more direct forms of political participation are thought to have decisive effects on the changing political involvement structures in contemporary societies. Secular social trends are producing citizens with improved cognitive and political skills, with the financial resources and time that facilitate political engagement. Education and socioeconomic status, in particular, have long been regarded as among the most significant determinants of civic engagement, where political interest and efficacy also count as facilitators. Processes of individualization and the rise of post-materialist self-expression values also lead to emphasis on more selfautonomy and higher participatory demands and therefore promote citizen participation in particularly non-institutionalized activities.

Thus we have reached our aim to create two crucial links in this chapter. One of them is between the process of post-industrialization and post-modernization as a macro-level constraint on the one hand and individual value orientations on the other. The second link is between values and political participation, whereas the former is thought to be related to both participation and the political orientations underlying it. Yet we still have to establish the relationship between these mechanisms and democratic stability. These significant recent changes in citizens' political attitudes and behavior in advanced industrial democracies have certainly added a new dimension to the scholarly discussion on the link between political involvement and democracy. It can be concluded from the arguments presented in this chapter that the process of post-modernization has indeed led to a "new type of 
post-modern citizen", and that there is indeed a new type of - critical but participant - political culture in these societies. However, this does not answer the question of how this new culture relates to the stability and effectiveness of democracy. To what extent is the new political culture congruent with the structures of Western postindustrial democracies? Is the post-modern political culture really a democratic political culture?

Many scholars have defended the position that the above described shift in political culture does not contradict with the ideal of stable and effectively functioning democratic governance (see e.g. Klingemann \& Fuchs 1995; Norris 1999; Dalton 2004). Ineffective government outputs may influence citizens' performance evaluations negatively and therefore they may create an unfavorable climate of opinion in the society, but it is disputable to what extent negative evaluations can endanger the legitimacy of the democratic system. Diffuse orientations towards democratic norms and principles, such as commitment to basic rights or democratic government, form the backbone of a democratic political culture and are more relevant for ensuring democratic legitimacy. As long as they are present, critical orientations toward present democratic procedures or institutions can be regarded rather as a challenge to democracy than a threat (Klingemann \& Fuchs 1995). Within this context, then, we can interpret citizens' critical orientations and demands for more participation in the policy-making process as well as the recent enlargement in the participatory repertoire as a challenge to representative government structures and an aspiration for more direct democratic institutions. The critical and participant citizen of the post-modern society can even serve as a resource to improve the quality of democratic governance, since the citizens' input is indispensable for political agenda-setting and the making of legitimate, effective policies (see e.g. SchmalzBruns 2002; Geissel 2008).

Yet this is true only if citizens make use of the participation channels rationally, i.e. with the specific motivation to influence the policy-making process. Alternative interpretations of post-modern citizenship are not very optimistic about this aspect of their participatory behavior. According to these views, post-modern citizens' political involvement is not characterized by a democratic orientation, but reflects rather a hedonistic self-actualization orientation. Though they agree that individual modernization leads to increasing participation levels, they assume that this has been accompanied by a selfish kind of individualism, leading citizens to have fewer stakes in political outcomes and more interest in satisfying their own intrinsic needs. This, in turn, is supposed to impair the rational input-output exchange between citizens and elites and lead to less effective governance, which may also undermine 
legitimacy irreparably in the long run. This possibility constitutes the "dark side of post-industrial society" (Huntington 1974), since it does not form a mere challenge but rather a real threat to the contemporary democratic systems.

The following chapter will focus more on these two contending interpretations on the relationship between the motivations of political involvement and democratic quality. By doing this we will delve more deeply into the description of the "postmodern citizen", which has been conceptualized differently by the two views, and then discuss possible consequences for democracy. 


\section{Chapter 5}

\section{Post-Modern Citizens, Political Involvement, and Democracy: Two Contending Perspectives}

The hitherto discussed consequences of post-modernization for the citizen-state relationships in advanced industrial democracies have influenced the reflections of researchers on the future of democracy. This chapter will focus on two diverging opinions on the changing values and motivations of citizens, their changing participatory behavior and, most importantly, the possible implications of these developments for contemporary democratic systems of the post-industrial countries.

We have shown in the previous chapter that growing skepticism about politics, disconnection from political parties, and particularly the increasing inclination to use unconventional political methods, have formed the key changes in the political realm of post-industrial democracies in the past decades. Considering these changes, we have concluded that a change in the political culture of these societies has taken place, and that it has given way to the development of a new type of citizen. The central characteristics of this new citizen type in post-industrial democracies consist of a high level of individual autonomy and emancipation, which are reflected in the political realm through less deference to political authorities and more demands for particularly direct, non-institutionalized forms of political participation. Moreover, these values, attitudes, and behaviors are thought to be prevalent mostly among the younger generations, since decreasing interest in traditional forms of political action such as voting and party membership is primarily attributed to the inclination of the youngest age groups to abstain from these activities. Meanwhile, there has been a simultaneous increase in petition signing or engagement in boycotts and demonstrations, which is again more common among young citizens. Thus, although young people apparently no longer feel inclined to join a political party, one can still speak of their high levels of involvement in politics, whereas it "no longer entails a formal long-term engagement but rather leads to short-term, non-institutionalized experiences" (Hooghe \& Dejaeghere 2007: 250). 
The behavioral patterns as well as major political attitudes of the post-modern citizen are thus so far clear. What remains to be addressed is the possible implication of this new political culture of individualization for the future of democratic governance in post-industrial societies. The process of individualization is a highly controversial concept and since it encompasses various - and often contradicting aspects, the opinions on its effects on democratic citizenship and political behavior also vary to a great extent. As we mentioned at the end of the previous chapter, we can speak of basically two theoretical views which offer two contending interpretations of individualization and its impacts on democratic citizenship. One of these views, the so-called theory of human development (Welzel et al. 2003; Inglehart \& Welzel 2005), delivers a rather positive interpretation of the post-modern citizen by assuming that these citizens are well-equipped by democratic values and attitudes and thus are closer to the ideal type of democratic citizen. The alternative view, which we will refer to as the theory of post-modern politics, assumes that post-modern citizens' political behavior is not determined by pro-democratic values but to a great extent by irrationality and hedonist value orientations due to the individualization process (Bell 1976).

This chapter will focus on this debate in order to evaluate the link between the new political culture emerging from the processes of post-modernization and individualization in post-industrial societies, and the future of their democratic systems. In order to provide a theoretical basis for this evaluation, we will first introduce the concept of the democratic citizen and its various cultural and behavioral characteristics in section 5.1. Following upon this, we will go on to discuss the conceptualization of post-modern citizens by two contradicting views, and to what extent they fit the ideal conception of a democratic citizen. It is crucial to address this discussion on whether post-modern citizens are dominated by a democratic political culture or whether they are prioritizing rather apolitical motivations, since these motivations are thought to affect the rationality of their political involvement and thus the quality of the democratic process.

In the second section we will discuss in detail how the motivations and political behaviors of post-modern citizens are related to each other; more specifically we will present our arguments on which type of post-modern citizen underlies which type of political involvement. By doing this, we will refer back to the typology of political involvement by Kaase and Barnes (1979) and their arguments on the rationality of instrumental versus expressive political action. By exploring the relationship between these types of political involvement to types of post-modern citizens discussed by the two interpretations of individualization, we aim to build a model 
which links post-modern political culture, political involvement, and democracy to each other and therefore make detailed predictions on the future of post-industrial democracies.

\subsection{The Concept of Democratic Citizenship}

Before we begin with different assessments of the post-modern citizen, it is essential to determine the key characteristics of democratic citizenship. While legal concepts of citizenship define a citizen as the owner of a bundle of civil and political rights through formal membership in a polity, the concept of democratic citizenship concentrates rather on how citizens should make use of their civil and political rights in order to make democracy as "rule of the people" possible. Our focus will be here on this latter conceptualization of citizenship which highlights the status of the individual in the society with respect to his or her relations to other individuals, as well as to the institutions of government (see e.g. Conover et al. 1991; Prior et al. 1995). In a democratic society, these relations are specified by the involvement of the citizen in democratic decision-making as well as the democratic attitudes and the democratic competences of citizens, such as civic norms, political motivations, and the cognitive ability and skills to understand the long-term trade-offs necessary in democracy (see Nie et al. 1996). Different theoretical approaches towards the appropriate level of participation for an effective and stable democracy were already addressed in chapter 2 . With respect to the desired civic orientations of democratic citizens, we can speak basically of four main traditions ${ }^{29}$.

In the classical Civic Culture Approach, the citizens which meet the requirements of democratic politics are described as politically interested, active, self-conscious, and critical, but at the same time loyal, trusting, and deferential (Almond \& Verba 1963: 337f.). As acknowledged by the authors themselves, this definition contains strongly contrasting elements. On the one hand, a critical orientation and political activism are required for effective democratic checks on political power. On the other hand, deference to political power is described as an ideal, which can give way to the risk of power abuse by political officeholders. The civic virtue of trustfulness, as we have discussed elsewhere, forms a basis for the legitimacy of the political system. Mass support for democratic governance and mass confidence in democratic institutions are considered to be crucial for an effectively functioning democracy (e.g.

${ }^{29}$ For detailed discussions on these concepts of citizenship see Kymlicka \& Norman (1995: 297f.) and Denters et al. (2007: 90f.). 
Easton 1965; Gibson 1997; Klingemann 1999; Newton \& Norris 2000; Mishler \& Rose 2001; Seligson 2002). Yet other scholars regard conformity to laws, and loyalty to rules and to hierarchical political structures, also as crucial characteristics of citizens which keep democracies stable (e.g. Crozier et al. 1975; Levi \& Stoker 2000).

In addition to these criteria, further characteristics for the democratic citizen have been suggested by three other views. The liberal view, for instance, defines the citizen as "homo economicus", driven by simple individualism, rationality, or self-interest (e.g. Rawls 1971, 1993). Therefore this view stresses the importance of political engagement as a means of pursuing and protecting one's own interest in politics. The communitarian view also places a high emphasis on active participation in social and political life as the core element of democratic citizenship, yet it rather stresses the importance of the values that link citizens to daily public life and strengthen their social ties as well as their loyalty to the community, such as involvement in voluntary associations, interpersonal trust, solidarity, community orientation, and tolerance (e.g. Bell 1993; Etzioni 1996; Putnam 1993, 2000). In other words, the citizens' role as "homo sociologicus" is more strongly pronounced in this tradition. The idea is that citizens must recognize the idea of democratic government, and in doing so accept the rules and outcomes of the democratic process. Finally, the participatory view defines active participation in democratic decision-making as the key element of citizenship, which fulfills an educative function in familiarizing citizens with public concerns and interests which go beyond the immediacy of personal interests (e.g. Barber 1984).

If we attempt to sum up the qualities associated with the democratic citizen by these different views, we can conclude that the notion of democratic citizenship has two main components: a behavioral and an attitudinal. Active participation in politics forms the behavioral component and there is little disagreement on its necessity. All of the views introduced above refer to political activism as a key concept within democratic citizenship. Participation is crucial since it literally enables "citizens' rule"; citizens can pursue and implement their demands and interests through participating in the political process. In dealing with the attitudinal component of democratic citizenship one can distinguish between those traits that are specific to individuals and those which characterize them as part of collectives (see Hadenius 2001) ${ }^{30}$. The individual level traits include attitudes such as a

\footnotetext{
30 Similar classifications have been made between individual-based and group-based forces driving political activism (Verba et al. 1978), or between human capital and social capital (Coleman 1990; Putnam 1993, 1995, 2000).
} 
developed political interest, a desire to become involved, and a wish to exert influence (Hadenius 2001: 18). A high level of conviction on the personal ability to influence democratic decision-making is also an essential motivation for citizens to become active (Abramson \& Aldrich 1982; Finkel 1985, 1987; Craig et al. 1990; Morrell 2003). The collective-level characteristics are those that affect the relations between individuals in a society and refer to the qualities of citizens that encourage commitment to the norms and principles of democracy. Relevant attitudes are trust, solidarity, and recognition of obligations, which form motives for action that are derived from more than the narrow self-interest of the individual. Especially the adherence to the rules of the democratic game is supposed to temper the "unbridled pursuit of self-interested political engagement" (Nie et al. 1996: 6). In this way, democratic enlightenment limits the harmful pursuit of self-interest and works to harness the practice of political engagement as a citizen's right by equipping the citizens with a sense of responsibility.

In sum, democratic citizenship entails the capability of pursuing political preferences within the framework of a polity in which there are shared interests in protecting both the normative goals of fairness and equality and the democratic process of free expression. The remaining question is on the extent to which contemporary citizens in post-industrial societies - namely, post-modern citizens possess the qualities of democratic citizenship. In the next section we will reflect on two theoretical views which have provided highly diverging answers to this question. We will start by presenting the arguments of the theory of human development on the democratic qualities of the post-modern citizen which result from the processes of individual modernization. Next, we will discuss the arguments of the opposing view, the theory of post-modern politics, which yields a rather negative interpretation of the highly individualized post-modern citizen and the future of democracy.

\subsection{The Theory of Human Development: An Optimist View of the Post-Modern Citizen}

As mentioned before, post-modern citizens are characterized by a high level of individualization, which manifests itself in the gradual transformation of traditional and civic values. Decreasing adherence to traditional and religious values, decreasing civic morality, increasing permissiveness, increasing emphasis on personal development and achievement in working life, and the change from materialist to post-materialist value orientations in the socio-political domain, are 
taken as main signs of individualization (Halman \& Pettersson 1995). It is also reflected in the pluralizing of choices: there is a multitude of religious beliefs, political ideas, and activity forms in contemporary societies.

In the classical as well as contemporary theory, the issue of increasing individualism is dealt with from largely different perspectives. Some theorists tend to be rather optimistic about the emancipating consequences of individualization (e.g. Yankelovich 1981; Klages 1985; Meulemann 1987; Inglehart 1990, 1997; Inglehart \& Welzel 2005), which they strongly associate with the phenomenon of the increasing autonomy of personal values choices (see also Halman \& Pettersson 1995). This section will focus on one of the most recent approaches defending this optimist position, namely the theory of human development.

The theory of human development is a revisited version of the theory of modernization conceptualized by Inglehart. It aims to serve as an integrating framework for the analysis of socio-political change as well as of emergence and stability of democratic systems. The main premise is that socioeconomic development, cultural modernization, and democratic regime performance are subdimensions of the whole process of "human development" which are connected by the phenomenon of broadening human choice. These dimensions are briefly described by table 5.1 below:

Table 5.1 The human development sequence

\begin{tabular}{|c|c|c|c|}
\hline & \multicolumn{3}{|c|}{ Human Development } \\
\hline & $\begin{array}{l}\text { Socioeconomic } \\
\text { Dimension }\end{array}$ & $\begin{array}{l}\text { Cultural } \\
\text { Dimension }\end{array}$ & $\begin{array}{l}\text { Institutional } \\
\text { Dimension }\end{array}$ \\
\hline $\begin{array}{l}\text { Processes advancing } \\
\text { human } \\
\text { development }\end{array}$ & Modernization & Value Change & Democratization \\
\hline $\begin{array}{l}\text { Components of } \\
\text { human } \\
\text { development }\end{array}$ & $\begin{array}{l}\text { Socioeconomic } \\
\text { resources }\end{array}$ & $\begin{array}{l}\text { Self-expression } \\
\text { values }\end{array}$ & $\begin{array}{l}\text { Civil and political } \\
\text { liberties }\end{array}$ \\
\hline $\begin{array}{l}\text { Contributions to } \\
\text { human } \\
\text { development }\end{array}$ & $\begin{array}{l}\text { Enhancing people's } \\
\text { capabilities to act } \\
\text { according to their } \\
\text { choices }\end{array}$ & $\begin{array}{l}\text { Increasing people's } \\
\text { priority to act } \\
\text { according to their } \\
\text { choices }\end{array}$ & $\begin{array}{l}\text { Broadening people's } \\
\text { entitlements to act } \\
\text { according to their } \\
\text { choices }\end{array}$ \\
\hline Underlying theme & \multicolumn{3}{|c|}{$\begin{array}{l}\text { The broadening of human choice } \\
\text { (an increasingly humanistic society) }\end{array}$} \\
\hline
\end{tabular}


As discussed in chapter 4, socioeconomic modernization has gone through two major processes of industrialization and post-industrialization, and its impact on cultural change operates in two phases. The bureaucratizing, centralizing, and standardizing tendencies of industrialization gave rise to a cultural shift reflected in the change from traditional to secular-rational values. By contrast, the cultural transformation of post-industrialization resulted from self-expression values winning priority over survival values. This second stage of societal development was characterized strongly by de-standardizing and individualizing tendencies, which have placed the main focus on the individual and his choices. As a result, citizens will increasingly have a culture characterized by individualism in terms of emancipation from authority, increasing emphasis on individual autonomy, and selfexpression (Ester et al. 1994; Nevitte 1996; Inglehart 1997; Welzel et al. 2003; Inglehart \& Welzel 2005).

This cultural change, in turn, is believed to strengthen people's subjective orientation towards the choice and preference for democracy. One important character of individualization is that it features the orientation "open-mindedness" (Inkeles 1978), which is assumed to have an overlap with a democratic character. Basing on the concept of "open and closed belief systems" by Rokeach (1960, 1973), Welzel (2007) established links between closed-mindedness and an authoritarian personality (Adorno et al. 1950) on the one hand, and between open-mindedness and a democratic personality on the other. Indeed, Inkeles and Diamond (1980) have also defined open-minded orientations as "anti-authoritarianism, efficacy, satisfaction, participation, trust, benevolence, and optimism” (cit f. Welzel 2007: 190). Crosscultural psychologists have gone a step further and described the closed/authoritarian versus open/democratic polarity in terms of "conformism versus individualism" (e.g. Hofstede 1980; Triandis 1995), postulating an inherent linkage between the prevalence of conformist orientations and dictatorial systems, and the prevalence of individualistic orientations and democratic systems.

Thus these three dimensions of human development are thought to be causally related to each other through probabilistic and time-lagged relationships that follow a two-stage sequence: first, the growth of human resources favors a culture of rising demands for self-expression reflected in liberty aspirations, and second, these liberty aspirations contribute to the emergence and consolidation of democracy (Inglehart \& Catterberg 2002; Welzel 2002; Welzel et al. 2003; Inglehart \& Welzel 2005; Welzel 2007). In the following, we will focus on these interactions. 
The first alleged link is the one between post-industrialization and the emergence of self-expression values ${ }^{31}$. Socioeconomic development in its second stage gives people the objective means of choice by providing them with even higher levels of individual resources, existential security and autonomy, which lead to an even increasing relevance of individualization and individual choice. This process has led to less emphasis on conformity and a greater priority for freedom of choice and individual autonomy. These characteristics are best reflected by the so-called selfexpression values, which include the following orientations:

“(1) An esteem of human freedom reflected in liberty aspirations;

(2) An esteem of political self-expression reflected in participating in elitechallenging actions such as petitions;

(3) An esteem of nonconformity reflected in a tolerance of homosexuality;

(4) An esteem of other people reflected in generalized interpersonal trust; and

(5) A sense of being at peace with oneself reflected in high levels of life satisfaction" (Welzel 2007: 201).

The second link refers to the relationship between self-expression values and democracy. The theory of human development suggests that this relationship should be positive since these values are more intrinsically directed toward the emancipative essence of democracy (Inglehart \& Welzel 2005: 248). The emergence of a culture with strong demands for self-expression leads to increasingly strong demands for political institutions that permit human freedom and autonomous choice. Individuals who give priority to self expression values should, in other words, have a greater preference for free public choice in the selection of collective goals, rules, and leaders. Based on this premise, it can be assumed that among the components of self-expression values, the liberty aspirations are particularly relevant to democracy, since they are most directly focused on human choice and the rights that guarantee it. The post-modern individual who emphasizes these liberal civil and political rights would be more likely to express his demand for the establishment of institutions that guarantee these rights and thus contribute to the further democratization of post-industrial countries.

The human development approach distinguishes itself most importantly by its emphasis on a political culture where emancipative values prevail. As we described above, former studies on the role of pro-democratic attitudes have either prioritized

\footnotetext{
${ }^{31}$ See also chapter 4 for a detailed description of how the concept of self-expression values have been developed by the modernization theorists.
} 
system support or deference to authority as crucial for the successive and effective functioning of democracy (e.g. Almond \& Verba 1963) or a strong community orientation, called "social capital", as democracy supporting attitudes and behaviors (e.g. Putnam 1993, 2000). Unlike these approaches, the theory of human development places the emphasis on free human choice and liberty aspirations. From this perspective, the involved but critical citizens of the post-industrial societies form exactly the type of the citizens that a democratic political system demands (Inglehart \& Welzel 2005; see also Dalton 2004). Inglehart and Welzel go even a step further and argue that weak or ineffective democracy does not reflect a lack of collective discipline, group conformity, and norm obedience. According to them, it is more likely that insufficient civic disobedience and self-expression make the job of authoritarian rulers easy. No more compliant but a more emancipative outlook is what societies need to become more democratic. The impact of socioeconomic modernization on democratization should, therefore, work "primarily through its tendency to give rise to cultural changes that place increasing emphasis on human emancipation and self-expression" (Inglehart \& Welzel 2005: 179).

Therefore, while other views approach declining political confidence and deference to rules with concern, the theory of human development does not regard it as an insurmountable problem for the stability and further development of democracies. Authority, being increasingly questioned in favor of an individualized preference, is mainly a result of rising emancipative orientations. While critical citizens may be less willing to express trust in political institutions, they remain strongly involved in politics and they adhere to basic democratic values (Norris 1999, 2003). Moreover, these citizens have a high interest for politics, which prevents them from becoming alienated. Thus, increasing criticism towards politics is rather seen as an indication of the maturity of the democratic political system and even a desire for more democracy (see Stolle \& Hooghe 2005).

Another development that has led many scholars to become concerned about the democratic character of the post-modern citizen was the weakening of community orientations and the alleged disappearance of social capital (Putnam 1995, 2000; Pharr \& Putnam 2000) Due to the increasing importance of individual autonomy, post-modern citizens today prefer participating in non-hierarchical and informal networks. This results indeed in a decline of attachments to traditional institutions such as political parties or trade unions, yet these developments are not perceived as a threat to democracy by the theory of human development. This, of course, does not mean that the arguments of the communitarian approach are being seen as completely irrelevant. The human development approach regards communal values 
and social capital as crucial to democracy but only the ones involving emancipative citizens whose communal engagement is the result of their intrinsic choices and not of social control or loyalty to the community. According to them, post-modern citizens will have a preference for egalitarian value patterns and although they might be rather critical toward traditional and institutionalized forms of solidarity, they will prefer a more tolerant and open society with equal opportunities for everyone (Welzel et al. 2003).

The emancipative and people-centered nature of self-expression values furthermore gives rise to growing citizen participation in political decision-making processes. As discussed in the previous chapter, traditional political participation forms are increasingly being replaced by less institutionalized and more individualized, elite-challenging forms of involvement. According to the theory of human development, this also contributes to the strengthening of democratic systems. Engaged citizenship is a form of individualized politics: citizens no longer simply accept the ideology of a party or group, but have the feeling they are sufficiently competent to develop their own political view. Furthermore, this political view needs to be articulated and to find resonance in the political decision-making process. Post-modern citizens, because of their increased emphasis on selfexpression, are more inclined to transmit their demands to the political system to accomplish results. They have a higher motivation to address government officials and to bring about the implementation of specific political goals. From this perspective, it is more rational to make use of these new forms of participation, since they can be deployed in all phases of the political decision-making process to influence the decision-makers, and besides, they are directly related to the realization of goals. Thus, besides better meeting citizens' needs for self-actualization, these forms of participation are more appropriate for the expression of demands in the political arena, and more effective for attaining specific political goals than traditional forms of participation (Fuchs \& Klingemann 1995: 18). Therefore, it is reasonable that citizens choose increasingly these action forms to express their demands.

In sum, the human development approach defends the view that the new political culture emerging in the post-industrial democracies of the West is a democratic political culture. In its view, the post-modern citizens tend to possess the attitudes crucial for democratic citizenship. They are interested in the political decision-making process, and wish to become involved in and exert influence upon this process which influences their personal interests. On the other hand, they tend not to be too focused upon self-interest; they are also characterized by community 
orientations such as tolerance, trust, and solidarity, though these orientations do not involve a strong group dependence or loyalty. According to the theory, the weak social circles are even of advantage for democratic citizens, since this provides a stronger opportunity for human choice and liberty orientations to flourish. Human choice, in turn, is at the heart of democracy, since democracy is a system of governance which institutionalizes civil and political liberties, providing people with legal guarantees to make free choices in their private and public activities. Therefore, the civic values that make democracies work are self-expression values which emphasize human freedom and choice. Therefore, individualization and the resulting post-modern political culture are supposed to have positive implications for the democratic system.

Yet, are the attitudinal and value change initiated by the individualization of post-industrial publics only characterized by a rise in liberty and self-expression orientations of the citizens? What other processes might have been initialized by the increasing emphasis on self-expression and individual autonomy? And what do they mean for the future of democracy? The following section will address these questions.

\subsection{Concerns on the Future of Democracy: The Theory of Post-Modern Politics}

The cultural implications of the transition from modernization to post-modernization and from industrial to post-industrial society have not only been interpreted in such an optimistic way as done by the human development approach. Many scholars who have reflected on the post-modern change have expressed their concern about the future of democracy in the advanced industrial countries where this change has taken place. Some of these concerns were related to the increasing levels of citizen participation as a result of post-modernization (e.g. Huntington 1974; Crozier et al. $1975)^{32}$, while others were rather concerned about the changing nature of individuals due to the post-modernization process and individualization. The source of their concern lies in the interpretation of individualization and the related terms of selfactualization and self-expression. As we will show, many scholars have associated individualization with characteristics that may be counterproductive for the stability of democracies. Therefore, they do not share the opinion of the human development theorists that individualization leads to the development of the ideal democratic

\footnotetext{
32 See chapter 1.
} 
citizen; on the contrary, they suggest that individualization forms the very source of threat to the future of democratic stability. A recent study even suggested that the growing individualism "may have grown cancerous [and] it may be threatening the survival of freedom itself" (Bellah et al. 1985: viii). Some other scholars regard consumerism, privatism, hedonism, and narcissism as negative side effects of growing individualism (e.g. Sennett 1977; Zijderveld 1979; Lasch 1979; Bloom 1987). As noted in the introductory section, we will refer in the following to these arguments generally as the theory of post-modern politics.

The theory of post-modern politics distinguishes itself from other theories on societal modernization - such as the theory of human development - above all in its approach to the interactions between economy, society, and politics. It suggests that the post-industrial society is not characterized by a causal relationship between these three factors; on the contrary, it exhibits a discontinuity between them (Gibbins 1989: 15). The post-industrial stage of modernization does not only mean the reorganization of economic resources and employment structures, but also a change in values and attitudes. This view is also shared by the human development approach, yet the theory of post-modern politics differs from this approach by the values and attitudes it ascribes to post-industrialization and individualization. According to this, the post-industrial society is characterized by a change in attitudes "especially to work and leisure; a heightened conflict between the private and public realms; an eclectic and amorphous culture exhibiting plurality; mixed lifestyles and new attitudes based on immediate gratifications, fantasy, novelty, play, hedonism, consumption and affluence" (Gibbins 1989: 15). The post-modern culture thus does not feature a linear pattern of change but is rather characterized by discontinuity, fragmentation, and unpredictability. This situation has been summarized with the following words: "the shock of post-modernization is that directionality is totally unclear: the only certainty is continuing uncertainty" (Crook et al. 1992: 3).

There have been a number of studies which have dealt with post-modernist values which are thought to be generated by the individualization process. Bell (1976), for instance, has stressed that the culture of post-modern society is characterized by self-expression, gratification, and hedonism. The transition to postmodernity, according to Bell, was the most significant rejection of the rationalistic, empirical, pragmatic world-view of the bourgeois class. Especially the recent changes such as the final collapse of family capitalism, changing political values, increasing individualism, and individual mobility led to changes in the lifestyles, popular culture, and mass society, where immediacy, spontaneity, and sensation gained in importance. In addition to this, the decline in importance of the old values of the 
Protestant ethic (achievement, saving, and discipline) has given rise to the development of a consumer culture, emphasized hedonistic self-gratification and enjoyment. The ascetic principles of production in the industrial societies were replaced by the hedonist principles of extended mass consumption in post-industrial ones. This has resulted in a tension between the economic, political, and cultural dimensions of the social order (see Turner 1989: 202).

Bell saw the post-industrial society as one characterized by major sources of instability. Even though it is a society free of ideological conflicts, there are new types of conflict and violence. The fragmentation of values, the absence of a coherent cultural legitimation of politics, the emergence of the narcissistic self, the degradation of the person through the impact of consumerism and the emergence of a postmodern irrationalism all contribute to the development of new lines of conflict in post-industrial society.

Bell's thoughts have also found reflection in later studies. Almost a decade later, Bellah et al. (1985) presented their views on contemporary society, putting a strong emphasis on the expression of feelings and intuitions for the sake of self-realization of the individual. Bellah et al. argue that the central characteristic of contemporary culture is the tension between individualism and commitment, where increasing individualism leads to an erosion of commitments and thus forms a danger for the society. They furthermore distinguish between utilitarian individualism and expressive individualism. Utilitarian individualism refers to a strong emphasis on work, career, and achievement; especially careers pursued by those seeking material rewards, power, and recognition, disrupt their connectedness to the community in the long run and make them strongly self-oriented. Expressive individualism, on the other hand, refers to an orientation towards pleasure and making the self happy: yet a harmless orientation as such can be disruptive when it goes along with a high emphasis on self-interest and a disregard of responsibilities for others' rights. Similarly, Turner (1989) has defined changes in the class structure, the growth of mass consumption and mass society, the transformation of the nature of work and production, the erosion of religious symbolism, and finally the development of a narcissistic self as the most significant characteristics of the post-modern culture. Furthermore, Reimer (1989) described the elements of the post-modern cultural orientation as the desire for the immediate gratification of one's own actions, and the priority given to individual goods over collective goods.

Several authors have thus clearly highlighted the expressivist and individualist nature of the post-modern citizen, but they have said relatively few things on the 
possible political consequences of these developments. Gibbins (1989) and Crook et al. (1992) observe that, in principle, the formalization, organization, and rationalization of modern politics is hardly compatible with expressive selfactualization. In a society, where the citizenry consists of individuals whose central priority is expressing and actualizing the self, the old civic culture is being replaced by forms of new populism, distrust of the state and its institutions, and a romantic revolt against orthodox politics. Community, stability, and collectivism are replaced by individualism, consumerism, and self-interested calculation. The rise of criticism towards the structures of representative democracy - including its centralized and large scaled bureaucracies as well as established political parties and interest groups, which were discussed extensively in chapter 4 - are thought to be associated rather with these processes than with political skills and pro-democratic orientations of citizens, as the theory of human development would suggest.

These characteristics are also thought to be reflected in the political behavior of the post-modern citizen. On the one hand, the political behavior of the post-modern citizen - like all other forms of human behavior in the post-modern society becomes highly unpredictable. On the other hand, a rise in "unconventional" forms of influencing governmental acts can be expected. Neither participation in elections, nor the mechanism by which citizens select parties and politicians for decisionmaking positions, nor the results of government action, could offer individuals convincing incentives to seek hedonistic self-actualization. Furthermore, it is impossible to achieve immediate results from this type of participation, since the utility of voting can only be realized in future government action, which is highly complex and takes place under hardly predictable conditions. Moreover, individual utility is low because most government action delivers collective goods, to which individual goals may be only vaguely connected.

All in all, the theory of post-modern politics points at the negative sides of individualization. Particularly the fragmentation of cultural standards accompanied by a consumerist and irrational orientation as well as the discontinuity between culture and other social structures are seen as destabilizing factors in post-modern politics. Moreover, the strong emphasis on the self means that self-interest rises above community interests, which is not in line with the qualities of democratic citizenship. This factor is also believed to play a role on citizens' political involvement. Although a strong participatory orientation is existent among the citizens, it is rather directed by self-interest; and because of the plurality of orientations one could assume that this interest does not necessarily need to be a 
political one. Individual needs which are directed at self-satisfaction and enjoyment could also play a role in the involvement of citizens in political activities.

Yet these arguments do not lead to a clear conclusion why these orientations would negatively affect the stability and functioning of democratic government. In the following, we will try to link the characteristics of the post-modern citizen types, illustrated by the both theories, to their political behavior, and argue that the contradicting value orientations of post-modern citizens lead to different motivations for political involvement. These motivations will be hypothesized to affect the "rationality" of political involvement, which is of great importance for democratic stability.

\subsection{The Post-Modern Citizen and the Rationality of Political Action: Instrumental vs. Expressive Political Involvement}

Above we have discussed two theoretical views on individualization and its consequences for democratic political culture and behavior. It can be concluded that the two theories share the prediction that unconventional political participation will increase; the point where they disagree is the impact of individualization on values and attitudes of post-modern citizens, and thus they predict diverging motivations for political behavior of contemporary citizens.

At this point we come back to the main premise that both levels of political participation, as well as the underlying motivations for participation, are relevant for the assessment of the future of democratic stability. As we have shown above, one can speak of contradicting motivations in post-industrial societies; political participation might be motivated by either pro-democratic orientations or purely self-oriented values and attitudes. And each type of political involvement will have different consequences for democratic stability. We mentioned in the introductory chapter that the first attempt to test these complex relationships has been made by Kaase and Barnes in the concluding chapter of the Political Action Study (1979). They particularly test the hypothesis concerning the potential hedonism and irrationality in post-industrial politics by using a set of modes of political action, which they developed on the basis of political activism and political interest (see table 1.1). In combining these dimensions, they aim to study the balance of rational-instrumental versus expressive political behavior to determine whether citizens get involved in politics with real political objectives in mind or whether they are driven by other motivations. Before we dwell upon these types of political involvement, we will first 
introduce the theoretical discussion on the rationality of political action in more detail. After that, we will focus on instrumental and expressive types of political involvement and try to establish links between them and the post-modern citizen types hypothesized by the theory of human development and the theory of postmodern politics.

\subsubsection{The rationality of political action}

In this section we will concentrate on the rationality which motivates political action. We will argue that the rationality of the action is reflected in the orientations underlying it, and exclusively focus on two types of orientations toward action: first, the instrumental orientations that motivate participation for the realization of specific political goals, and second, the expressive or individualistic orientations that refer to non-political motivations for getting involved in political activities. The orientation towards action matters, since potential dangers would emerge from a mismatch of rationalities between those of politically active citizens, and those of the target political institutions (Topf 1995a: 55).

One could speak of three main modes of individual orientations based on Parsons' analytical typology of subjective orientations to the action: instrumental, expressive, and moral (Fuchs \& Klingemann 1995). Moral orientations, to begin with, refer to universal norms and values. They are basically directed towards generating collective goods which no one can be excluded from using. Therefore, these orientations are more likely to be reflected in individual activities which aim at producing collective goods or preserving collective interests. However, in the postmodern societies where a strongly individualized culture dominates, these orientations are expected to play a less important role in determining people's political behavior; the process of individualization leads to a greater priority given to individual goods over collective goods, and to individual interests over collective ones. With instrumental and expressive orientations, the goods to which people aspire are generally individual goods; these orientations are thought to be central to citizens' orientations towards politics in post-modern countries.

Though both are motivated by individual interest, these orientations differ in a number of aspects. Instrumental orientations towards political activity refer to the attainment of a specific political outcome. When citizen participation in the political decision-making process is motivated by such orientations, then reaching the goal of implementing (or influencing the implementation of) a specific political decision is the main source of motivation to participate politically (Milbrath 1965). The activity, in this sense, is nothing but an instrument to achieve a goal. 
Expressive orientations towards political action, on the other hand, are based on the intrinsic satisfaction or pleasure of participation. Here, the main motivation for political participation is not the possible political output, but all sorts of psychological benefits, such as personal development, excitement, fun, or social contact (Heunks 1990). In other words, expressively motivated political action is simply directed at consuming the experience of engaging in the action. Thus, unlike instrumentally motivated participation, the activity is not a means to achieve a particular political goal; it is rather the goal itself. Of course, such acts may also have instrumental consequences, but the possible success of the acts is for the expressive participant not relevant. For him, the satisfaction of his intrinsic needs has its own reward (Brennan \& Lomasky 1993; Salisbury \& Conklin 1998).

It is important to determine which one of these orientations drives citizens' political participation, since they are relevant for the rationality of political participation. In Participation in America, Verba and Nie (1972) defined the rationality of political activities as follows:

"For a citizen to do so [participate rationally, B.H.-D.], he must know what he wants in terms of governmental response (i.e., know what policy he wishes the government to pursue or know what benefit he wishes the government to provide), he must know what action is likely to increase the chances of government providing what he wants, and he must act accordingly, taking into account the cost of that activity in relation to other uses of his time and effort" (p. 103).

Several elements of rationality can be derived from this definition. To act rationally as a citizen, there must be first of all a subjectively felt need for a certain governmental output. Second, appropriate channels of influencing politics must be available. Finally, the participant must choose the form of activity through which influencing the government activity is most likely and which involves the lowest costs. Since the political participation in this case is clearly directed at gaining political benefits, it is in line with an instrumental motivation and since it also involves minimizing costs, we can interpret this as rational behavior (Downs 1957; Riker \& Ordeshook 1968).

However, as Downs (1957) recognizes, behavior which is irrational according to the classical cost-benefit calculation may be highly rational in the psychic economy of the individual's personality. This can be reflected by a non-instrumental (or expressive) rationality, as in the case of voting for a party with which the voter identifies, irrespective of what it provides, or by a semi-instrumental rationality. Their rationale does not lie in the possible political output, but in all sorts of psychological benefits, such as personal development, excitement, fun, or social 
contact (see e.g. Riker \& Ordeshook 1968; Tullock 1971; Brennan \& Buchanan 1984; Whiteley 1995; Schuessler 2000). People may join local actions or demonstrations with the aim of meeting these private interests rather than with the expectation of gaining favorable political output. In this sense the political activity is still "rational", yet it is not "instrumental" since the result of the activity is irrelevant: One can speak of "expressive rationality" here due to the motivations underlying the activity (Heunks 1990: 157).

Though being regarded as rational from a rational-choice perspective, expressively motivated political action is not necessarily directed at influencing the political process and thus can be interpreted as irrational with respect to its influence on democratic decision-making. Policy-making based on irrational demands may in turn disrupt the effective functioning of democratic systems. Instrumentally motivated political action, on the other hand, is particularly directed at attaining political outcomes and therefore can be regarded as rational political behavior. As we mentioned above, a detailed elaboration of this has been made by Kaase and Barnes (1979). Building upon Bell's assumptions on the potential hedonism and irrationality in post-industrial politics, they have discussed which type of political involvement reflects best the behavioral pattern in post-industrial society, and what this means for the future of post-industrial democracies. The next section will particularly focus on these reflections.

\subsubsection{Instrumental and expressive political involvement}

In determining whether predictions concerning the hedonism and irrationality of post-industrial politics are well-founded or not, Kaase and Barnes rely upon the balance of rational-instrumental versus expressive political action from their typology of political action (1979: 527). As introduced in the first chapter, instrumental political action refers to political participation with political interest while expressive political action is defined as political action without interest in politics. According to Kaase and Barnes, it is this latter type of political involvement which contains hedonist elements and may hinder the rationality of political decision-making.

Expressive political involvement is considered to be harmful for the stability and efficiency of democracies since the goals of political action are ambiguous when it contains expressive-hedonistic elements, and this makes it a difficult task for authorities to react to similar political acts without knowing whether they are of instrumental or expressive kind. Government actions which are taken on the basis of these ambiguous demands, in turn, may lead to delegitimization and thus to the 
instability of the political system. In sum, it is not necessarily the amount of political participation that would lead to an overload and inefficiency of the democratic system, but rather the type of participation. Expressive types of action would form a potential threat for the rational conduct of politics.

This is a rather vague argument and does not discuss clearly why political action, which is not accompanied by political interest, should contain hedonistic elements. Fuchs and Klingemann (1995) have provided an elaborated connection between expressive political action on the one hand and irrational and hedonistic orientations on the other by focusing on post-modern individuals and their orientations towards politics. According to them, the central constituent of post-materialism is somewhat problematic according to the pessimist interpretation of the post-modern citizen. Fuchs and Klingemann regard greater participation in political decision-making processes as the political expression of the general value of self-actualization. The emergence of new participation demands can, therefore, be seen as one consequence of the increasing importance of individual self-actualization. Over the past decades, manifestations of self-actualization are more appropriately understood as evidence of expressive or hedonistic orientations. Following Kaase and Barnes, Fuchs and Klingemann define hedonistically oriented citizens as being marked by a lack of political interest and low participation; or, alternatively, by low political interest along with primarily non-institutionalized participation which happens only occasionally and lacks clear and stable goals (1995: 21).

Both studies have predicted that expressive political action should constitute a threat to democracy, yet they have not made clear why this would be the case. Generally, one can introduce two main arguments. The first one is based on the Rousseau-ist view that in a democracy, citizens are required to participate in public decision-making inspired by the will to serve the "common good" or the "general interest" (Holden 1988: 77). Citizens who only serve their own cause without being interested in public affairs neglect their role as citoyen, which in a democracy is required in addition to the role of bourgeois. In a post-modern society it is more likely that the balance between these roles might be disturbed (Bell 1976).

A second argument for why expressive political action should be a threat for the functioning of democracy could be borrowed from the rational choice tradition in political analysis. According to rational choice explanations of voting behavior, an instrumental voter would be interested in the outcome of the election, thus he would turn out to vote with the motivation to influence this outcome. In other words, instrumental political behavior seeks to bring about some concrete, material policy 
results. An expressive voter, on the other hand, would not necessarily be interested in the outcome of the election. His individual voting decision would rather depend on "the benefits and costs that derive from expressing support or opposition to the candidates as an end in itself" (Brennan 2001: 225). Just like football fans cheering for their team at a match, the political behavior of the expressive voter is directed at expressing himself and not at bringing about the outcome. He is motivated by solely individual incentives such as expressing deeply held beliefs (Whiteley 1995), deriving an entertainment value from participating (Tullock 1971), identification with a group (Schuessler 2000), or the sense of fulfilling a civic duty (Brennan \& Buchanan 1984; Riker \& Ordeshook 1968).

Especially "expressing oneself" could be a possible motivation for the political participation of post-modern individuals who give importance to self-expression and self-actualization. This behavior could be seen as "rational" in the sense that the individual is motivated by possible benefits that he expects from his behavior, but it is not in line with the type of rationality expected from a democratic citizen. Citizens with democratic orientations are more likely to be involved in politics with the aim of implementing a political outcome, to make the demand-output mechanism work, and therefore contribute positively to the democratic governance. The citizen whose political behavior is only directed at getting some psychological gratifications, however, could indeed be disruptive for good governance by hindering rational interchanges between authorities and partisans and thus undermine the basis for rational political decision-making, as Kaase and Barnes have predicted (1979: 528).

The prediction by Kaase and Barnes that an expressive political style will be the prevalent behavior in post-industrial societies is however still an open question. We discussed above that there are two contradicting interpretations of post-industrial society, its citizens and their orientations; and the argument on self-orientation and the irrationality of post-industrial politics is only one side of the coin. The reverse side is the possibility that a pro-democratic orientation and self-expression values are dominant in post-industrial societies, and that citizens' political behavior is affected by these values, as the theory of human politics would expect. Therefore, these two possibilities should be tested in the empirical reality. In the concluding section, we will sum up the arguments of both theoretical views and try to derive some empirically testable expectations. 


\subsection{Citizen Involvement and Post-Industrial Society: Quo Vadis?}

Looking back to the discussion on post-modern individual and democratic citizenship above, we can establish two points where the two views share the same arguments. First of all, both interpretations of post-modern citizens are based on the same premise that citizens in post-industrial societies have changed due to the process of post-modernization. Their diagnosis for the cause of the emergence of a new type of post-modern citizen is unequivocal: the processes of transition to postmodern society and growing individualization. Second, they make similar predictions about the development of political participation. Both assume that there will be a general increase in the levels of political participation, especially of those forms of action which are more direct and less institutionalized. They furthermore agree that the main cause of this phenomenon is the emergence of the post-modern citizen due to the above named processes.

The point where the two theories differ is threefold. The first disagreement is on the interpretation of the individualization effects on post-modern citizens. The theory of human development assumes a liberating and democratizing effect of individualization on people, while the theory of post-modern politics equalizes individualization with a fading saliency of politics and an increasing emphasis on an egoist kind of self-actualization in people's everyday lives. The two theories furthermore diverge on the rationalities of political involvement: a pro-democratic orientation shall lead to instrumentally driven political involvement whereas a pure individualist orientation shall facilitate rather expressive involvement in politics. Finally, they disagree on the consequences that both types of involvement may have for democracy; the theory of human development makes optimistic predictions for the future of democracy in post-industrial democracies while the theory of postmodern politics has a fairly pessimistic view. While there is disagreement on these points between the two views, they both predict that the development of whatever type of involvement will be a permanent one, since the values become established in the society as the older generations are replaced by the younger.

In short, both the theory of human development and the theory of post-modern politics are variants of the modernization theories, which provide contending interpretations of this societal process. We tried to summarize their arguments on the post-modern citizen, political participation, involvement, and democracy in figure 5.1 below: 
Figure 5.1 The two contending views on post-modernization effects

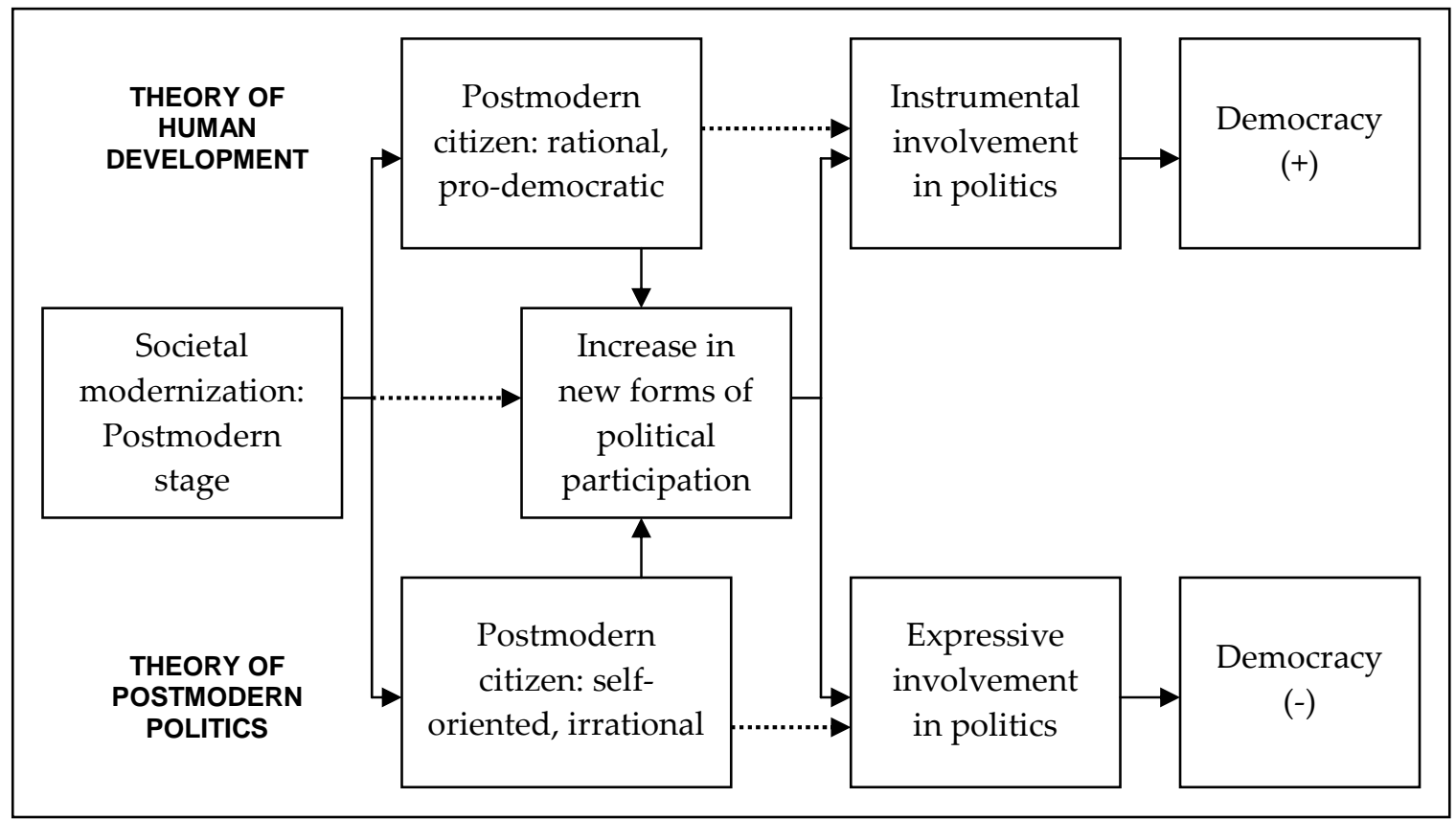

The two theories provide thus two alternative answers to the question which kind of citizen and which kind of political behavior post-modernization leads to. Therefore, they provide alternative answers to the empirical research questions of this study. Our first question was on the prevailing type of political involvement in post-industrial democracies. Following the arguments of the theory of human development, we can expect that instrumental political involvement will prevail in these societies, while the arguments by the theory of post-modern politics lead to the expectation that it is expressive political involvement that will dominate postindustrial politics. Accordingly, the second question on the possible development of political involvement can be answered by two alternative predictions. Finally, the third question on the factors underlying political involvement can be answered by referring to the value priorities of the post-modern citizen. Relying upon the theory of human development, we can predict that instrumental political behavior will be motivated by the pro-democratic self-expression values. Based upon the arguments by the theory of post-modern politics, on the other hand, we can hypothesize that hedonism and self-orientation underlie expressive political involvement.

In the forthcoming chapters, we will try to answer our research questions by conducting empirical tests of these alternative hypotheses. First, we will operationalize both instrumental and expressive political involvement utilizing the data at our disposal. Then we will analyze the levels and development of these involvement types in time and among generations. By doing this we will try to answer our first two research questions. After this, we will focus on our third 
research question and analyze the impact of the two groups of values on the two types of political involvement. Depending on the discussion on the rationality of political involvement and its meaning for democratic stability, we will then try to draw conclusions from the findings on what the future of democracy in postindustrial societies will be. 
PART II:

EMPIRICAL ANALYSES 


\section{Chapter 6}

\section{Levels and Development of Political Involvement Types in Post- Industrial Democracies}

In this chapter we will focus on our first two research questions: What is the prevailing type of political involvement in post-industrial democracies? And how are these involvement types likely to develop? Before starting to tackle these questions, however, it is essential to clearly formulate the expectations we have derived from the arguments of the two theories introduced in the previous chapter. Accordingly, we will formulate two alternative hypotheses for each question analogous to the contradicting arguments of the two theories.

We will then move on to discuss the operationalization of the main objects of our analyses: the dependent variables instrumental and expressive political involvement. Finally, we will test our hypotheses by observing both types of political involvement in all twelve post-industrial countries, their development in time as well as their actual levels. We will also focus on the development of the involvement types among birth cohorts in order to see if they are likely to become established patterns of development as younger cohorts get older. This will help us to make predictions about the possible future development of these involvement types and therefore about the future of democracy.

\subsection{Hypotheses on the Levels and Development of Involvement Types}

We have discussed at length in the previous chapter that both interpretations of the individual modernization process - the theory of human development and the theory of post-modern politics - argue that a new type of post-modern citizen has emerged, yet they diverge on the characteristics of this citizen type. Although both theories recognize that the new citizens have a significant inclination towards noninstitutionalized and extra-representational forms of political participation, the key distinction between them is their prediction of diverging value priorities for post- 
modern citizens. These value orientations, in turn, are supposed to be reflected in different motivations underlying participatory behavior. From the perspective of the theory of human development, post-modern citizens act on rational grounds, i.e. they participate in political activities with the aim of expressing their demands and thus achieving specific political goals. Contrarily, the theory of post-modern politics suggests that irrational and non-politic orientations determine post-modern citizens' political behavior. According to this, citizens have lost their attachment to political goals and ideals and are only interested in self-gratification, enjoyment, experiencing new things, and the expression of feelings as various kinds of consumption. Driven by these value orientations, these citizens seek to satisfy their intrinsic demands when they get involved in political activities; they do not necessarily aim at contributing to collectively binding political decisions.

Building upon these contending assumptions about the motivations of postmodern individuals, we hypothesized in the last section of chapter 5 that the arguments of both theories can be linked to an analytic distinction between politically motivated and a non-politically motivated participation in politics, namely, instrumentally versus expressively motivated political involvement. We have shown that Kaase and Barnes (1979) have labeled the latter type "expressive political action", which they described as political action without an interest in politics. This type of political action has further been linked with the motivations of the post-modern citizen type of the theory of post-modern politics, i.e. hedonism and irrationality (Fuchs \& Klingemann 1995). We claim, on the other hand, that "instrumental political action" from the same typology which refers to political participation with political interest, corresponds with the arguments of the theory of human development which assumes a rational and responsible post-modern citizenry.

Thus utilizing the typology of political action developed by Kaase and Barnes (1979) and their arguments on post-industrial politics, involvement and democracy, we aim to conduct empirical tests of two different and contradicting types of hypotheses parallel to these contradicting theoretical strands in the forthcoming sections. We will first test the hypothesis that political activity beyond representational participation forms is increasing, as both theoretical views would predict. With respect to political interest and the types of political involvement, we will test two groups of contrasting hypotheses. On the one hand, we will test the hypotheses that both political interest and political participation - and thus instrumental political involvement - will increase, which is rather in line with the theory of human development. Therefore, this view predicts an increase of 
instrumental political involvement. On the other hand, we will test whether there is a decline in political interest while participation is increasing, i.e. if expressive political involvement is increasing, as suggested by the theory of post-modern politics. Table 6.1 gives an overview of these hypotheses predicting contradictory developments:

Table 6.1 Hypotheses derived from contradicting interpretations of modernization

Theory of Human Development

H1 Increase of citizen activity beyond representational forms

H2a Increase of political interest

H3a Increase of instrumental political involvement
H2b Decline of political interest

H3b Increase of expressive political involvement

This strategy should help us to determine which one of the theories has more empirical validity with respect to the nature of participation of the post-modern individual. However, we will need more than this if we aim to predict whether this development reflects a general cultural shift that is supposed to be a permanent characteristic of post-industrial societies. Because only in the case of a long-term cultural shift can we discuss whether there is a challenge for the stability of democracy or not. Short-term fluctuations in political motivations or behavior are likely to be absorbed by short-term adjustments in the political-institutional domain; e.g. sporadic dissatisfactions with the government will be tempered by the change in incumbent government at the next elections. Similarly, a sudden rise in political participation can be due to periodic effects; participation will decline again when the events that have generated the rise cease to exist.

We have discussed in chapter 5 that cultural changes will only gradually occur by generation replacement (Inglehart 1971, 1977, 1990; Abramson \& Inglehart 1987, 1992; Inglehart \& Abramson 1994). Since both the theory of human development and the theory of post-modern politics suggest that the changes in political behavior have been caused by cultural shifts in terms of shifts in value orientations, an analysis of their predicted involvement types should take differences between generations into account. If the predictions of the human development approach are true, then the development towards the dominance of instrumental political action should be taking place due to generational replacement; that means younger generations will stick to the type of political behavior they have internalized during their adolescent years. If they are, on the other hand, likely to refrain from this involvement type at later stages of their lives, then we can predict that the development does not reflect a general cultural change and is rather due to a life-cycle effect. Similarly, the 
hypotheses of the theory of post-modern politics would find more support if the change towards expressive political involvement is caused by generational replacement. We will thus check for both cohort and life-cycle effects utilizing the hypotheses displayed in table 6.2.

Table 6.2 Hypotheses on the development of political involvement types by generation replacement

Theory of Human Development

H4a The increase of instrumental political involvement over time will take place due to generation replacement, i.e. because each successive generation has higher levels of instrumental political involvement than the previous one
Theory of Post-Modern Politics

$\mathbf{H} 4 \mathbf{b}$ The increase of expressive political involvement over time will take place due to generation replacement, i.e. because each successive generation has higher levels of expressive political involvement than the previous one

While testing these hypotheses, we expect to find two empirical phenomena. First, the relative occurrence of instrumental or expressive modes of political involvement will be higher among each new cohort than among previous ones. Second, the differences between cohorts will remain at each point of measurement, which will confirm that these developments are not likely to be due to a life-cycle effect. Based on the findings, one can also predict how both involvement types will develop in the future. If, for instance, expressive political involvement is more strongly represented among younger age cohorts and its development over time also follows the same pattern, it's likely that this type of involvement will establish itself as older cohorts are replaced by younger ones.

In the following section we will describe how we operationalize instrumental and expressive political involvement. For the analyses in this chapter we will make use of only one of our two cross-national data sets, namely, the European Values Survey. Since we will use the same typology of involvement as a dependent variable in the next chapter while testing the alleged causal relationships between involvement, values and the control variables, we will describe here also the operationalization of political involvement on the basis of the European Social Survey. A detailed introduction of this data set will however follow in the next chapter. 


\subsection{Data and Measurement}

\subsubsection{The European Values Survey}

The European Values Survey (EVS) is a large-scale, cross-national, and longitudinal survey research program which mainly focuses upon basic human values. It is the most comprehensive data source for gaining insights into the ideas, beliefs, preferences, attitudes, and values of Europeans on a broad range of topics such as family, religion, work, politics, and society. The surveys started in 1981, and have been repeated in four waves in nine-year intervals in an increasing number of countries. The fourth wave in 2008 covers about 45 European countries, and many of these countries were represented in the three previous waves of 1981-1982, 1989-1990 and 1996-200033. These data sets have allowed for broad research on individual or aggregate level backgrounds of value dimensions as well as on cultural and social changes in a number of countries ${ }^{34}$.

We will test our first four hypotheses on the development of instrumental and expressive types of political involvement in twelve European democracies relying upon data from the first three waves of the EVS ${ }^{35}$. The EVS offers itself as an appropriate tool for testing our hypotheses for two reasons. First of all, the data sets contain the necessary indicators - questions on unconventional participation forms as well as subjective political interest - to operationalize the two involvement types. Second, the study provides us with longitudinal data which allows comparative analysis of all twelve post-industrial countries that we are interested in, and which includes identical items for these countries at each wave. Since we use data from a relatively short time span with only three measurement points, we will not be able to test for generational effects on political involvement types over a longer time period. However, as the most important changes due to individual modernization are assumed to have happened in the past decades, the results obtained from an observation of cohort development based on these data sets will be appropriate to draw conclusions and to make predictions about future developments.

\footnotetext{
33 The exact time points of data collection vary among countries, see table 6.3.

34 See Arts et al. 2003; for a detailed list of publications see the EVS website www.europeanvalues.nl

35 Data from the fourth wave collected in 2008 has been made available for public use as of July 2010, while this book was prepared for publication. Yet because some of the countries we analyze here were still not included in the final release, we couldn't include this wave into our analyses. It is also for this reason that we decided to use the first wave of European Social Survey from 2002-2003 for the successive causal analyses, since it immediately follows up on the last wave of EVS from 1996-2000.
} 
Table 6.3 The European Values Survey (EVS): Number of respondents and year of data collection for each analyzed country

\begin{tabular}{|c|c|c|c|c|c|c|}
\hline & \multicolumn{2}{|c|}{$\begin{array}{c}\text { EVS 1. Wave } \\
\text { (1981-1982) }\end{array}$} & \multicolumn{2}{|c|}{$\begin{array}{c}\text { EVS 2. Wave } \\
\text { (1989-1990) }\end{array}$} & \multicolumn{2}{|c|}{$\begin{array}{c}\text { EVS 3. Wave } \\
(1996-2000)\end{array}$} \\
\hline & $N$ & Year & $N$ & Year & $N$ & Year \\
\hline Austria & -- & -- & 1460 & 1990 & 1522 & 1999 \\
\hline Belgium & 1145 & 1981 & 2792 & 1990 & 1912 & 1999 \\
\hline Denmark & 1182 & 1981 & 1030 & 1990 & 1023 & 1999 \\
\hline Finland & -- & -- & 588 & 1990 & 1038 & 2000 \\
\hline France & 1200 & 1981 & 1002 & 1990 & 1615 & 1999 \\
\hline Ireland & 1217 & 1981 & 1000 & 1990 & 1012 & 1999 \\
\hline Netherlands & 1221 & 1981 & 1017 & 1990 & 1003 & 1999 \\
\hline Norway & 1051 & 1982 & 1239 & 1990 & 1127 & 1996 \\
\hline Sweden & 954 & 1982 & 1047 & 1990 & 1009 & 1996 \\
\hline Switzerland & -- & -- & 1400 & 1989 & 1212 & 1996 \\
\hline UK & 1167 & 1981 & 1484 & 1990 & 1000 & 1999 \\
\hline W. Germany ${ }^{36}$ & 1305 & 1981 & 2101 & 1990 & 1017 & 1999 \\
\hline All Countries & 10442 & 1981-1982 & 16160 & 1989-1990 & 14490 & $1996-2000$ \\
\hline
\end{tabular}

\subsubsection{Measurement of instrumental and expressive political involvement}

Because the measurement of instrumental and expressive political involvement is based on the typology by Kaase and Barnes (1979), we will rely in the following upon their operationalization of these concepts. As can be taken from table 1.1 in the introductory chapter, these action types are thought to consist of two dimensions: political interest and political participation. Yet there are going to be some deviations from this original attempt, such as the items used to operationalize the concept of participation and the method used to build a single measure out of all forms of activity, which will be explained more in detail in the following sub-sections.

\subsubsection{Political participation}

In order to measure the types of political involvement, both political interest and political participation need to be dichotomized. Since there are a number of items for different participation forms in all data sets, we shall build an index of political participation and then differentiate between those who have participated in one or more of these activities and those who have not taken part in any. By doing this, we

\footnotetext{
${ }^{36}$ As mentioned in the introductory chapter, only the Western Bundesländer, which formed the Federal Republic of Germany before the German reunification in 1990, will be studied here since they fulfill the criterion of a long democratic experience. The Eastern part of Germany has thus been left out of the analyses covering the time period after 1990.
} 
will solely focus on extra-representational political activities ${ }^{37}$. This is not in line with Kaase and Barnes' original conceptualization, since they have used both conventional and unconventional types of political action in their study, however we choose to focus on the latter because of two reasons.

First of all, our theoretical discussion on post-modernization, participation and involvement has led to the conclusion that the increase in the use of extrarepresentational types of political action - while the popularity of traditional representative forms of political action is in a steady decline - is mainly a consequence of societal and individual modernization processes. In addition, it is the rise of the new action forms which is controversial within the future of democracy debate; and the motivation behind these activities has been the main contentious issue discussed by the two contradicting theories on post-modern citizenship.

Second, in the scholarly discussion on instrumental and expressive rationality of political action it has often been argued that the new forms of political participation are most likely to be led by expressive motivations. Milbrath, for example, has classified individual types of political action along the instrumental and expressive dimensions and has concluded that participating in a campaign, collecting information, or volunteering for a job are acts which are "primarily instrumental in orientation and emphasis" (1965: 13). On the contrary, participating in demonstrations, shouting at a protest, engaging in a political argument and pledging allegiance have been assumed to be rather expressive in nature. Similarly, according to Verba and Nie (1972: $105 \mathrm{ff}$.), activities such as contacting government officials and politicians or participating in communal activity are more likely to have specific goals and increase the likelihood of achieving those goals; therefore they are more closely associated with instrumental rationality. Other scholars have argued that protest behavior or rebellious collective action is not instrumental under conventional assumptions since the choice for a free ride seems more attractive (Muller \& Opp 1986: 471). Therefore we consider it crucial to observe the motivations especially behind the newer forms of political participation in order to provide general empirical evidence on their potential.

A single index will be constructed for the measurement of political participation by using items from both EVS and the European Social Survey (ESS) on whether the respondent has actually taken part in a number of activities ${ }^{38}$ (see table 6.4). We will

\footnotetext{
${ }^{37}$ See chapter 3 for an extensive discussion on the distinction between representational and extra-representational activities by Teorell et al. (2007).

${ }^{38}$ See Appendix A for exact question wordings.
} 
use exclusively extra-representational activities (Teorell et al. 2007) while building the index, whereas we will limit our focus with exit-based (consumer activities like boycotts) and non-targeted (protest activities such as petitioning and demonstrations) forms of this activity dimension ${ }^{39}$. Contacting officials and organizations, which form the targeted variant of extra-representational political participation, will not be taken into account: exactly because of the "targeted" nature of contacting, we assume by definition that the probability of carrying out this activity without the aim to achieve any political goal is extremely low.

Table 6.4 Political participation items (EVS and ESS)

\begin{tabular}{lll}
\hline \multicolumn{1}{c}{ EVS } & \multicolumn{1}{c}{ ESS } \\
\hline - Signing petitions & - Signing petitions \\
- Joining boycotts & - Buying products for political reasons \\
- Attending lawful demonstrations & - & Boycotting products for political reasons \\
& & - Attending public demonstrations \\
\hline
\end{tabular}

These activities will be counted and then the resulting participation index will be dichotomized in a way that the respondents who have taken part in none of the above mentioned activities have been classified in the category of non-participants, whereas those who have participated in at least one of the above mentioned activities have constituted the group of participants.

\subsubsection{Political interest}

In their typology, Kaase and Barnes have used "subjective political interest" as the attitudinal component of political involvement which determines the motivation underlying political action. This measure, where the respondents are asked to assess their level of interest in politics (Lazarsfeld et al. 1944), is one of the most used indicators of political interest in the literature; however its use can be problematic in some ways. The first problem associated with this measure is the so-called social desirability bias. This is a term used in scientific research to describe the tendency of respondents to reply in a manner that will be viewed favorably by others. This will generally take the form of over-reporting good behavior or under-reporting bad behavior. In the case of political interest, respondents may tend to declare themselves to be highly interested in politics because they think that this is a desirable characteristic of a good citizen or simply to look intellectual, which may lead to an

${ }^{39}$ See chapter 3 , table 3.3 . 
inflated reported level of political interest that does not comply with the reality (see e.g. Van Deth 1990).

The second problem that may occur is that a high level of political interest does not necessarily have to imply a "political" motivation; a person may be interested in political events for totally non-political reasons (see Klingemann 1979: 264). Since we use political interest within the concept of political involvement, the motivational component can not be avoided here. Third, the political interest which is measured by this item can be directed at various objects, for instance if young people are interested in new politics and perceive under "political interest" rather the traditional political institutions, then they would simply reject being interested in politics, which is, in fact, not at all the case.

Another widely used indicator for measuring political interest is the question on frequency of political discussions (Gabriel \& van Deth 1995; van Deth \& Elff 2000, 2004). This item is adequate for validating subjective political interest - i.e. for ensuring if there is indeed a political motivation or not - although its use is also afflicted with problems and is highly disputed in the literature. It has often been claimed that this indicator features a behavioral component and therefore may not be appropriate for the measurement of political interest. Indeed, it has been considered as a form of political participation in the literature (e.g. Marsh \& Kaase 1979; Topf 1995a). Thus, there's a great ambiguity in the literature about whether this is an indicator for interest or participation. Some authors describe the frequency of political discussion as a "dangerous and potentially flawed measure" because of the inherent uncertainty about how to interpret it (Parry et al. 1992: 40), while others regard it as "the most unambivalent indicator of interest in politics" (Gabriel \& Van Deth 1995: 396).

Despite their weaknesses, we consider both subjective political interest and frequency of political discussions to be appropriate measures of political interest and therefore we will apply both items for the operationalization of this concept. We admit that political discussions indeed involve a behavioral component, yet in our opinion this political behavior cannot be equated with political participation as such. Political participation pertains rather to influencing the governmental decisionmaking activity, while political discussions are not necessarily aimed at that. Moreover, we find that using subjective political participation would mitigate the behavioral accent of political discussions; similarly, as indicated above, the item on political discussions tends to compensate the shortcomings of subjective political interest. We choose to build our political interest measure by using exclusively these 
two items and leave out other items such as interest in public issues or the frequency of using various media to gather political news (see e.g. Delli Carpini \& Keeter 1996; Aarts et al. 2000), since we argue that these items do not distinguish sharply enough between political interest and its causes and consequences. For instance, media use could motivate political interest, whereas political interest could lead to more frequent use of the media to gather political information.

The attempt by Kaase and Barnes to differentiate between instrumental and expressive political action using solely political interest as a single indicator can be criticized as a highly simplistic approach to the concept of the rationality of political action. The assumption is that people who say they are uninterested in politics yet say they are politically active must be acting expressively rather than instrumentally, and it leads automatically to a second assumption that expressive and instrumental motivations for political action are mutually exclusive and that "expressive styles may be displacing instrumental purposes in political action" (see Topf 1995a: 72f.). However, the reality might look quite different. One should take into consideration that citizens may get involved in different types of political activity with different motivations. An individual can, for example, buy products for the protection of the environment with instrumental motivations but may at the same time participate in a demonstration with expressive motivations. The problem with using political interest as a single measure to determine which participants are instrumental and which participants are expressive is that we cannot observe the different motivations in different activities. This would ask for more than survey data, since most surveys use standardized research questions, and therefore more generalized indicators, which makes it most of the time impossible to detect the motivations behind every action type.

In our opinion, it is the simplicity and generalizability of Kaase and Barnes' measurement of instrumental and expressive political involvement that makes it a fairly appropriate tool to capture the motivations of action on a cross-country basis and to test the assumptions of the two contradicting theories on post-modernization effects by such a large scale analysis. Political interest is a good indicator to determine with what depth of conviction opinions are held, and activities are carried out. Besides, it serves as a strong attitudinal background for the personal saliency of certain political issues and the politicization of needs, both of which are defined as the main prerequisites of instrumental rationality in political behavior (Heunks 1990). Therefore, we choose to replicate the original measurement and operationalize political interest by a subjectively felt level of interest in politics. 
Subjective political interest has been captured both in EVS and ESS by a single question with four answer categories. We integrate those respondents who have stated that they are "actively interested" or "interested in politics but not active" (EVS 1981-1982) or respectively those who have stated that they are "interested" or "very interested" in politics (EVS 1989-1990, 1996-2000; ESS 2002-2003) in the category of the interested, whereas those with low (not greater than other interests, not very interested) and no interest at all fall under the category of the uninterested. Frequency of political discussions is also a single item in both surveys, yet answer categories differ for each survey. In all three waves of the EVS, the answer categories are "frequently", "occasionally" and "never", where we consider the ones that frequently discuss politics to fall into the category of the interested, and take other responses as a lack of political interest. In the ESS, there are seven answer categories which vary from "every day" to "never". Here, we considered those who discuss politics at least several times a month as interested and others as not interested in politics ${ }^{40}$.

The types of involvement will be measured by combining the two dichotomized indicators of political participation and political interest as suggested by Kaase and Barnes. According to this, the respondents who fall into the category of both "participants" and "high interest" are assumed to form the type of citizens who are instrumentally involved in politics. The category of expressive political involvement covers respondents which are "uninterested participants". Although there are two other categories in the original typology (detached and apathetic citizens), we will focus here exclusively on the instrumental and expressive types of involvement since it is the aim of this study to analyze the motivations of participants in order to draw conclusions on the relationship between rising citizen participation and democracy.

\subsection{Development of the Levels of Political Involvement}

In the following we will test our first three hypotheses by observing the plain development of political participation, political interest, and finally, instrumental and expressive political involvement in twelve European post-industrial countries. This will help us in the first place to determine which type of political involvement is more prevalent in these countries and therefore which one of the contradicting theories provides us with more plausible arguments. The findings will furthermore help to find out if we can speak of a general pattern in the distribution of both

\footnotetext{
${ }^{40}$ See Appendix A for exact question wordings.
} 
political involvement types among countries. Since all countries are post-industrial societies, the predicted type of political involvement - no matter if that is the expressive or the instrumental type - is expected to be common among all of them.

Table 6.5 Development of political participation in post-industrial countries, 1981-2000

\begin{tabular}{|c|c|c|c|c|c|c|c|}
\hline & \multicolumn{2}{|c|}{ 1981-1982 } & \multicolumn{2}{|c|}{ 1989-1990 } & \multicolumn{2}{|c|}{ 1996-2000 } & \multirow{2}{*}{$\begin{array}{c}\text { Net increase/ } \\
\text { decrease } \\
\text { \%-Points }\end{array}$} \\
\hline & $\%$ & $\mathbf{N}$ & $\%$ & $\mathbf{N}$ & $\%$ & $\mathbf{N}$ & \\
\hline Austria & -- & -- & 47 & 1460 & 56 & 1522 & +9 \\
\hline Belgium & 26 & 1145 & 49 & 2792 & 75 & 1912 & +49 \\
\hline Denmark & 48 & 1182 & 56 & 1030 & 65 & 1023 & +17 \\
\hline Finland & -- & -- & 40 & 588 & 51 & 1038 & +11 \\
\hline France & 50 & 1200 & 55 & 1002 & 72 & 1615 & +22 \\
\hline Ireland & 30 & 1217 & 45 & 1000 & 62 & 1012 & +32 \\
\hline Netherlands & 37 & 1221 & 53 & 1017 & 67 & 1003 & +30 \\
\hline Norway & 55 & 1051 & 62 & 1239 & 69 & 1127 & +14 \\
\hline Sweden & 56 & 954 & 72 & 1047 & 76 & 1009 & +20 \\
\hline Switzerland & -- & -- & 62 & 1400 & 68 & 1212 & +6 \\
\hline UK & 64 & 1167 & 76 & 1484 & 80 & 1000 & +16 \\
\hline W. Germany & 48 & 1305 & 57 & 2101 & 69 & 1017 & +21 \\
\hline All Countries & 46 & 10442 & 56 & 16160 & 68 & 14490 & +22 \\
\hline
\end{tabular}

Entries are the percentages within the whole population

Data: European Values Surveys, 1981-2000

Table 6.6 Development in the levels of political interest in post-industrial countries, 19812000

\begin{tabular}{|c|c|c|c|c|c|c|c|}
\hline & \multicolumn{2}{|c|}{ 1981-1982 } & \multicolumn{2}{|c|}{ 1989-1990 } & \multicolumn{2}{|c|}{ 1996-2000 } & \multirow{2}{*}{$\begin{array}{c}\text { Net increase/ } \\
\text { decrease } \\
\% \text {-Points }\end{array}$} \\
\hline & $\%$ & $\mathbf{N}$ & $\%$ & $\mathbf{N}$ & $\%$ & $\mathbf{N}$ & \\
\hline Austria & -- & -- & 56 & 1445 & 67 & 1503 & +11 \\
\hline Belgium & 28 & 1093 & 32 & 2702 & 42 & 1880 & +14 \\
\hline Denmark & 49 & 1169 & 57 & 1027 & 62 & 1013 & +13 \\
\hline Finland & -- & -- & 48 & 574 & 28 & 1030 & -20 \\
\hline France & 64 & 1192 & 39 & 985 & 38 & 1605 & -26 \\
\hline Ireland & 29 & 1198 & 40 & 993 & 49 & 1005 & +20 \\
\hline Netherlands & 46 & 1188 & 63 & 1012 & 68 & 1003 & +22 \\
\hline Norway & 47 & 1047 & 73 & 1229 & 69 & 1125 & +22 \\
\hline Sweden & 46 & 949 & 49 & 1045 & 53 & 988 & +7 \\
\hline Switzerland & -- & -- & 69 & 1364 & 42 & 1205 & -27 \\
\hline UK & 42 & 1160 & 50 & 1479 & 38 & 970 & -4 \\
\hline W. Germany & 52 & 1267 & 71 & 2063 & 79 & 1010 & +27 \\
\hline All Countries & 45 & 10263 & 53 & 15918 & 52 & 14337 & +7 \\
\hline
\end{tabular}

Entries are the percentages within the whole population

Data: European Values Surveys, 1981-2000 
Tables 6.5 and 6.6 provide an overview of the development of political participation and political interest in the time period between 1981 and 2000 in various countries and thus enable us to test the first two hypotheses of both views on the consequences of societal modernization. The findings in table 6.5 clearly corroborate the first hypothesis (H1) that extra-representational political participation is increasing in advanced post-industrial countries, which is in line with the arguments of both the theory of human development and the theory of postmodern politics. On average, there has been an increase of 22 percentage points over the years. Also individual countries show an unambiguously increasing trend of these types of political participation within the time period specified for each country. This means that the proportion of people who have taken part in at least one of the three activities - petition signing campaigns, boycotts or public demonstrations - has unequivocally increased over the past two decades. Thus the findings support the argument that people are indeed not becoming more apathetic towards politics while they are turning away from traditional participation forms, but they increasingly become more inclined towards participating in those forms of activities which directly express preferences and directly address the decision-makers.

It is important to note, however, that this increase has not taken place at the same pace in each analyzed country. The rashest increases in extra-representational forms of participation were in Belgium, the Netherlands, Ireland, and France, while these activity forms have not increased that much in Austria, Finland, and Switzerland ${ }^{41}$. Looking at individual political participation forms, we can establish that petition signing has become most popular in post-industrial societies, and that the biggest increases were in this type of participation ${ }^{42}$. These increases were again most significant in Belgium, the Netherlands, Ireland, and France. With respect to boycotting and demonstrations, we can again observe a major increase in Belgium and the Netherlands, but also Scandinavian countries such as Sweden and Denmark score high on these activities.

We can now turn to the development of political interest, where contradicting expectations have been derived from the two theories (hypotheses H2a and H2b). At a first glance, we can establish that the increase in political interest within the observed period was not as strong as the increase in extra-representational political

\footnotetext{
${ }^{41}$ One should take into account, however, that the time span in which the development has taken place is shorter in these countries, covering the period between 1989 and 2000.

42 The tables demonstrating the development of individual participation forms can be found in Appendix B.
} 
participation: the average increase amounts solely to 7 percentage points (see table 6.6). Also, unlike the development of political participation, the Western postindustrial countries display a very mixed trend with regard to political interest. In a majority of countries, interest in politics indeed seems to be growing which is in line with the arguments of the theory of human development. However, in four countries - Switzerland, France, Finland, and the United Kingdom - it has been decreasing as the theory of post-modern politics would predict. Generally, we can observe no clear trend in political interest due to country differences and fluctuations in its levels. Thus it is hard to conclude which one of the hypotheses of the two theories, with respect to political interest, is being supported by these findings.

A comparison of tables 6.5 and 6.6 shows that although political interest may be increasing in some countries parallel to the rise in political participation, it is not clear how much of a percentage of the politically interested citizens are actually taking part in extra-representational political activities. Similarly, it is hard to conclude from these findings to what extent politically uninterested citizens prefer to become active in politics and how many of them remain totally apathetic. The huge difference between the proportion of interested and active citizens within some countries is another striking fact that results from the comparison of both tables. In Belgium, for example, the percentage level of political interest in 1999 is around half of that of political participation. Forty-two percent of citizens have expressed interest in politics whereas 75 percent seem to have participated in extra-representational activities. This gap suggests that although both political interest and participation have been increasing over twenty years in this country, their proportion to each other indicates that expressive political involvement might outweigh instrumental political involvement. However, this is only a speculation based on the two independent observations. Clearer conclusions can be drawn only by analyzing the trends in instrumental and expressive political involvement (hypotheses H3a and $\mathrm{H} 3 \mathrm{~b})$.

Tables 6.7 and 6.8 present the development of both expressive and instrumental types of political involvement in the analyzed countries (see below). They show clearly that one cannot speak of a unique pattern of development of both types of involvement that is common to all -or a majority of- European post-industrial societies. Observing the average development from 1981 to 2000, we can conclude that both types of involvement have been increasing in post-industrial countries. This is in fact not very surprising since, as we have shown above, the level of extrarepresentational political participation, which forms a component of both involvement types, has been increasing as such in the observed period. We can 
conclude on the average that the increase in instrumental political involvement has been slightly higher than that of expressive political involvement. However, in individual countries the trends vary from increasing to declining; the decline or the increase of involvement types is stable in some countries and fluctuates in the others. In a majority of countries, an unequivocal increase in instrumental political involvement has taken place. Yet this increasing trend has been accompanied by a simultaneous decrease in expressive political involvement only in Denmark, Norway, and West Germany. In all other countries where instrumental political involvement has been in an increasing trend, expressive political involvement has also been increasing. A comparison of the net increase in both types of involvement does not lead to unequivocal results, either. In some countries the net increase in expressive political involvement exceeds the net increase in instrumental involvement, whereas in others the exact opposite is the case.

Table 6.7 Development of expressive political involvement in post-industrial countries, 19812000

\begin{tabular}{|c|c|c|c|c|c|c|c|}
\hline & \multicolumn{2}{|c|}{ 1981-1982 } & \multicolumn{2}{|c|}{ 1989-1990 } & \multicolumn{2}{|c|}{ 1996-2000 } & \multirow{2}{*}{$\begin{array}{c}\text { Net increase/ } \\
\text { decrease } \\
\% \text {-Points }\end{array}$} \\
\hline & $\%$ & $\mathbf{N}$ & $\%$ & $\mathbf{N}$ & $\%$ & $\mathbf{N}$ & \\
\hline Austria & -- & -- & 13 & 1445 & 14 & 1503 & +1 \\
\hline Belgium & 14 & 1093 & 28 & 2702 & 39 & 1880 & +25 \\
\hline Denmark & 21 & 1169 & 19 & 1027 & 20 & 1013 & -1 \\
\hline Finland & -- & -- & 15 & 574 & 32 & 1030 & +17 \\
\hline France & 12 & 1192 & 28 & 985 & 41 & 1605 & +29 \\
\hline Ireland & 18 & 1198 & 23 & 993 & 28 & 1005 & +10 \\
\hline Netherlands & 13 & 1188 & 13 & 1012 & 17 & 1003 & +4 \\
\hline Norway & 26 & 1047 & 15 & 1229 & 17 & 1125 & -9 \\
\hline Sweden & 26 & 949 & 33 & 1045 & 32 & 988 & +6 \\
\hline Switzerland & -- & -- & 15 & 1364 & 37 & 1205 & +22 \\
\hline UK & 36 & 1160 & 35 & 1479 & 46 & 970 & +10 \\
\hline W. Germany & 18 & 1267 & 12 & 2063 & 11 & 1010 & -7 \\
\hline All Countries & 20 & 10263 & 21 & 15918 & 29 & 14490 & +9 \\
\hline
\end{tabular}

Entries are the percentages of the whole population; Data: European Values Surveys, 1981-2000 
Table 6.8 Development of instrumental political involvement in post-industrial countries, 1981-2000

\begin{tabular}{|c|c|c|c|c|c|c|c|}
\hline & \multicolumn{2}{|c|}{ 1981-1982 } & \multicolumn{2}{|c|}{ 1989-1990 } & \multicolumn{2}{|c|}{$1996-2000$} & \multirow{2}{*}{$\begin{array}{c}\text { Net increase/ } \\
\text { decrease } \\
\%-P o i n t s\end{array}$} \\
\hline & $\%$ & $\mathbf{N}$ & $\%$ & $\mathbf{N}$ & $\%$ & $\mathbf{N}$ & \\
\hline Austria & -- & -- & 35 & 1445 & 44 & 1503 & +9 \\
\hline Belgium & 13 & 1093 & 22 & 2702 & 36 & 1880 & +23 \\
\hline Denmark & 27 & 1169 & 37 & 1027 & 45 & 1013 & +18 \\
\hline Finland & -- & -- & 25 & 574 & 19 & 1030 & -6 \\
\hline France & 38 & 1192 & 28 & 985 & 31 & 1605 & -7 \\
\hline Ireland & 13 & 1198 & 22 & 993 & 35 & 1005 & +22 \\
\hline Netherlands & 24 & 1188 & 40 & 1012 & 50 & 1003 & +26 \\
\hline Norway & 29 & 1047 & 48 & 1229 & 52 & 1125 & +23 \\
\hline Sweden & 30 & 949 & 39 & 1045 & 43 & 988 & +13 \\
\hline Switzerland & -- & -- & 48 & 1364 & 31 & 1205 & -17 \\
\hline UK & 28 & 1160 & 41 & 1479 & 34 & 970 & +6 \\
\hline W. Germany & 30 & 1267 & 46 & 2063 & 58 & 1010 & +28 \\
\hline All Countries & 26 & 10263 & 36 & 15918 & 39 & 14490 & +13 \\
\hline
\end{tabular}

Entries are the percentages of the whole population; Data: European Values Surveys, 1981-2000

These results thus do not provide clear support for any of the alternative hypotheses $\mathrm{H} 3 \mathrm{a}$ and $\mathrm{H} 3 \mathrm{~b}$. To overcome this ambiguity, we observe the ratios of the two involvement types in the following. As Kaase and Barnes also suggested, it is crucial to analyze the balance between expressive and instrumental political styles to get a better understanding of which type of involvement is of higher prominence. The figures in table 6.9 have been obtained by dividing the percentage of expressive political involvement at each wave of the EVS by the percentage of instrumental political involvement at the same measurement point. Accordingly, ratios over 1.00 point to the prevalence of expressive involvement, whereas a ratio under 1.00 means that instrumental involvement outweighs expressive. The advantage of using the proportions is that they give an idea about the extent to which one involvement type outweighs the other. 
Table 6.9 Development of the ratios of expressive over instrumental political involvement in post-industrial countries, 1981-2000

\begin{tabular}{lccccc}
\hline Period & $\mathbf{1 9 8 1 - 1 9 8 2}$ & $\mathbf{1 9 8 9 - 1 9 9 0}$ & $\mathbf{1 9 9 6 - 2 0 0 0}$ & $\begin{array}{c}\text { Net increase/ } \\
\text { decrease }\end{array}$ \\
\hline Austria & $1990-1999$ & -- & 0.37 & 0.32 & -0.05 \\
Belgium & $1981-1999$ & 1.08 & 1.27 & 1.08 & 0.00 \\
Denmark & $1981-1999$ & 0.78 & 0.51 & 0.45 & -0.33 \\
Finland & $1990-2000$ & -- & 0.60 & 1.68 & +1.08 \\
France & $1981-1999$ & 0.32 & 1.00 & 1.32 & +1.00 \\
Ireland & $1981-1999$ & 1.38 & 1.05 & 0.80 & -0.58 \\
Netherlands & $1981-1999$ & 0.54 & 0.33 & 0.34 & -0.20 \\
Norway & $1982-1996$ & 0.90 & 0.32 & 0.33 & -0.57 \\
Sweden & $1982-1999$ & 0.87 & 0.85 & 0.74 & -0.13 \\
Switzerland & $1989-1996$ & -- & 0.31 & 1.19 & +0.88 \\
UK & $1981-1999$ & 1.29 & 0.85 & 1.35 & +0.06 \\
W. Germany & $1981-1999$ & 0.60 & 0.26 & 0.20 & -0.40 \\
\hline All Countries & $1981-2000$ & 0.77 & 0.58 & 0.74 & -0.03 \\
\hline
\end{tabular}

Entries are figures obtained by dividing expressive by instrumental political involvement for each wave of data collection among the whole population.

Data: European Values Surveys, 1981-2000

The table informs us about both the predominant type of political involvement and the trends in the two involvement types in countries. In seven out of the twelve analyzed countries, instrumental political involvement prevails over expressive involvement, with a downward trend in the ratios meaning that instrumental political involvement is getting even more important in these societies. Thus we can say that the hypothesis $\mathrm{H} 3 \mathrm{a}$ is corroborated for these countries. However, in four countries - United Kingdom, Finland, France, and Switzerland - expressive political involvement prevails and tends to become even more prominent. Additionally, in Belgium the ratio has increased between 1981 and 1990, but declined to the original 1981 level in 1999. How it is likely to develop after this measurement point is hard to tell. Therefore, hypothesis $\mathrm{H} 3 \mathrm{~b}$, derived from the theory of post-modern politics, seems to find more support in these societies. There is also an inconsistency in the overall trend in Europe. Whereas the general tendency has leaned towards instrumental political involvement over almost two decades, the ratio has been fluctuating between the measurement points.

Thus, it is again not possible to draw a general conclusion which is valid for all post-industrial countries. Both of the alternative hypotheses - H3a and $\mathrm{H} 3 \mathrm{~b}$ - find support in different countries and the overall trends turned out to be ambiguous, so that a general trend of political involvement for all post-industrial societies cannot be established. It is however important to note here that the observed levels of expressive and instrumental political involvement as well as their proportions to 
each other might well reflect periodic fluctuations. Since the two involvement types differ from each other mainly with respect to the level of political interest, the results found here can be due to sudden changes in the levels of political interest, which can be influenced by specific incidents within a certain time period. The unclear trends found above can thus be a function of these short-term changes which can conceal the actual longer-term trends in the development of instrumental and expressive political involvement.

In order to have a more clear-cut picture of these trends, then, we have to shift our focus towards observations which reflect both long-term and aggregate effects on the development in involvement. We will therefore move on to test the hypotheses $\mathrm{H} 4 \mathrm{a}$ and $\mathrm{H} 4 \mathrm{~b}$ in the following, which predict a generational effect on the development of respective political involvement types. This will be done by observing the behavior of birth cohorts over time, which will help to make predictions on which type of involvement is bound to persist over time.

\subsection{Generational Effects on Political Involvement}

In line with the two theories on individualization we posed above the hypothesis that the changes in instrumental and expressive political involvement will be due to generation replacement, i.e. their levels are supposed to be higher in each successive birth cohort compared to their predecessors. The generation replacement thesis is common to both theories since the main premise underlying the whole modernization paradigm - to which the two theories belong - is that societal/cultural change takes place through the replacement of generations. People who are socialized under the same societal conditions are supposed to be influenced by the same youth experiences, which in turn shape their values, attitudes, preferences, and finally their behaviors throughout their lives. This leads to the inference that political participation as well as the motivation accompanying this behavior - interest in politics or no interest - are influenced by the specific experiences of a generation and remain the type of behavior characterizing this generation throughout their life-cycle.

However, the two theories also expect these two contending types of political involvement to be increasingly prevalent in each successive generation: younger generations will be more inclined to participate in extra-representational forms of political action and will be more (or respectively less) interested in politics than the preceding ones and this will repeatedly be the case with every new generation. This means that there will be a net increase in instrumental or expressive political 
involvement in time, while the respective types of involvement become established in the society with each newcomer generation.

These expectations can be tested by observing whether there are cohort effects in the development of both involvement types. A cohort effect is shared by a group of people born during a certain period and comes up in surveys at different points in time (either in panel surveys or in repeated cross-sectional surveys). Other possible time-related explanations for the changes in political involvement are life-cycle and period effects. A period effect is the impact of the context in which the survey has been conducted that affects all respondents. It is thus not helpful for explaining differences between age groups at a certain point in time, but its impact on a particular age group creates a cohort effect. A life-cycle effect on political involvement would mean that the same involvement level is common to people in the same age group. If this effect is playing a role in the change in political involvement, however, we can observe a "rise and fall" of types of political involvement, i.e. the level of involvement increases until the middle-age and then decreases again as people get older.

One could differentiate between political and socioeconomic cohorts ${ }^{43}$. Political cohorts refer to people who share certain political experiences, such as having experienced a certain political rule (e.g. the Nazi regime in Germany). Whereas a socioeconomic cohort includes those people who share the average probability of having a certain social characteristic that is higher or lower for other cohorts. A good example for this is the level of formal education. The probability of a younger person today having finished higher levels of education is much higher than of an older person. Similarly, as pointed out elsewhere, younger cohorts are more likely to be post-materialists than older ones since they grew up during times of economic affluence (Inglehart 1990, 1997).

In the following we will analyze life-cycle, period, and cohort effects on instrumental and expressive political involvement in order to be able to make predictions on how both types of involvement are likely to develop. For the analysis of life-cycle effects, we will observe the distribution of both involvement types among six age groups varying between "younger than 25" and "61 and older", each of which consists of nine-year intervals (in line with the nine-year intervals between each measurement wave of the EVS). In order to observe period and cohort effects,

\footnotetext{
${ }^{43}$ For a discussion on the distinction between different types of cohorts see Goerres 2009: 13ff., $25 \mathrm{ff}$.
} 
we will divide the respondents into six birth cohorts - again consisting of nine-year intervals - as follows:

Cohort 1: Respondents born in 1975 and later

Cohort 2: Respondents born between 1966 and 1974

Cohort 3: Respondents born between 1957 and 1965

Cohort 4: Respondents born between 1948 and 1956

Cohort 5: Respondents born between 1939 and 1947

Cohort 6: Respondents born in 1938 and before

The cohorts were designed so that at the third measurement point (1999-2000) the youngest birth cohort covers the age group under 25 and the oldest cohort covers respondents which are 61 years and older. Moreover, the cohorts correspond with the generations which reflect social-historical changes in the Western world within the past century. For instance, people born in the period after World War II and lasting until the mid-1960s are often being referred to as the "baby boom generation" or the "protest generation" in the literature (e.g. Jennings 1987; Strauss \& Howe 1992; Williamson 1998). This generation, which is supposed to be the pioneer of the drastic social and cultural changes starting in the 1960s, is covered by the cohorts 3 and 4 born between 1948 and 1965, and partly also by cohort 5 born between 1939 and 1947. Similarly, the so-called "Generation X" and "Generation Y" (see e.g. Strauss \& Howe 1992; Williamson 1998), who were born after this period and who are thought to be representing pragmatism, heterogeneity, and post-modernism more strongly than previous generations, are covered by cohorts 1 and 2. Finally, cohort 6 which is born before World War II corresponds to the "lost" and "silent" generations (Strauss \& Howe 1992), which has experienced the material and physical insecurity during the War and which is thought to have been least affected by the new post-modern culture (Inglehart 1990, 1997; Inglehart \& Welzel 2005).

We will analyze the long-term effects on expressive and instrumental political involvement in the following order: first, we will observe the distribution of both political involvement types among age groups at each of the three measurement points to test for possible life-cycle effects. Then we will focus on the development of these involvement types among birth cohorts with the aim to establish possible period and cohort effects. In case we observe a cohort effect in the development of one type of political involvement, it is possible to presume that this political behavior style is likely to become established over time. On the other hand, if a life-cycle influence is more clearly identified for one of these involvement types, this would 
mean that a general shift towards that type of involvement is unlikely, since the levels of involvement will gradually decrease in each cohort.

\subsubsection{Life-cycle and period effects on political involvement}

The distribution of instrumental and expressive political involvement in extrarepresentational political activities among age groups at each of the three survey points is presented in table 6.10 .

Table 6.10 Percentages of instrumental and expressive political involvement by age and year

\begin{tabular}{lcccccc}
\hline & \multicolumn{3}{c}{$\begin{array}{c}\text { Instrumental political } \\
\text { involvement }\end{array}$} & \multicolumn{3}{c}{$\begin{array}{c}\text { Expressive political } \\
\text { involvement }\end{array}$} \\
\hline$<25$ & $\mathbf{1 9 8 1 - 1 9 8 2}$ & $\mathbf{1 9 8 9 - 1 9 9 0}$ & $\mathbf{1 9 9 6 - 2 0 0 0}$ & $\mathbf{1 9 8 1 - 1 9 8 2}$ & $\mathbf{1 9 8 9 - 1 9 9 0}$ & $\mathbf{1 9 9 6 - 2 0 0 0}$ \\
& 24,1 & 31,6 & 28,5 & 26,0 & 27,0 & 37,2 \\
$25-33$ & $(592)$ & $(627)$ & $(396)$ & $(637)$ & $(537)$ & $(516)$ \\
& 29,6 & 38,8 & 38,4 & 24,3 & 24,2 & 33,8 \\
$34-42$ & $(552)$ & $(1143)$ & $(999)$ & $(453)$ & $(713)$ & $(880)$ \\
& 30,0 & 42,3 & 40,8 & 20,6 & 21,5 & 33,0 \\
$43-51$ & $(473)$ & $(1202)$ & $(1128)$ & $(325)$ & $(610)$ & $(912)$ \\
& 24,2 & 41,0 & 45,8 & 18,1 & 21,0 & 27,7 \\
$52-60$ & $(306)$ & $(1019)$ & $(1119)$ & $(229)$ & $(522)$ & $(676)$ \\
& 26,5 & 35,0 & 45,0 & 17,1 & 17,6 & 23,5 \\
61 and older & $(298)$ & $(717)$ & $(882)$ & $(192)$ & $(361)$ & $(462)$ \\
& 20,9 & 27,3 & 35,1 & 12,9 & 16,8 & 20,2 \\
& $(415)$ & $(985)$ & $(1114)$ & $(256)$ & $(607)$ & $(641)$ \\
\hline TOTAL & 25,7 & 35,8 & 39,3 & 20,4 & 21,0 & 28,5 \\
& $(2636)$ & $(5693)$ & $(5638)$ & $(2092)$ & $(3350)$ & $(4087)$ \\
\hline
\end{tabular}

Entries are percentages of instrumental and expressive political involvement within each age group

Number of respondents for involvement types within age groups is indicated in parentheses

Data: European Values Surveys, 1981-2000

With respect to instrumental political involvement, we can observe by reading the columns vertically that its distribution among age groups is rather curvilinear at each wave. The youngest and the oldest age groups are least inclined towards this type of political involvement, while the ratios between the two age groups have changed in time: The youngest age group turned out to be slightly more inclined towards instrumentally motivated political involvement than the oldest in the first and second waves of the EVS; yet they seem to be least inclined towards this involvement type among all age groups in the third wave of the survey conducted in 1999 and 2000. Observing the development of instrumental political involvement between the first and the third waves among all age groups, it is possible to establish that there has been a general shift in this involvement type in the three older age groups (43 years and above), while the inclination of the three younger age groups has dropped between the second and the third waves of the EVS, i.e. during the 
1990s. Yet these shifts have not affected the whole picture: The middle age groups seem to be most prone to get involved in politics with instrumental motivations at all three measurement points, which points to a consistent curvilinear distribution among age groups in spite of the periodic shifts in instrumental political involvement. Therefore, it is possible to speak of a clear life-cycle effect on this involvement type. The curvilinear relationship between age and instrumental political involvement can be more clearly seen in figure 6.1 .

Figure 6.1 Shifts in instrumental political involvement, 1981-2000

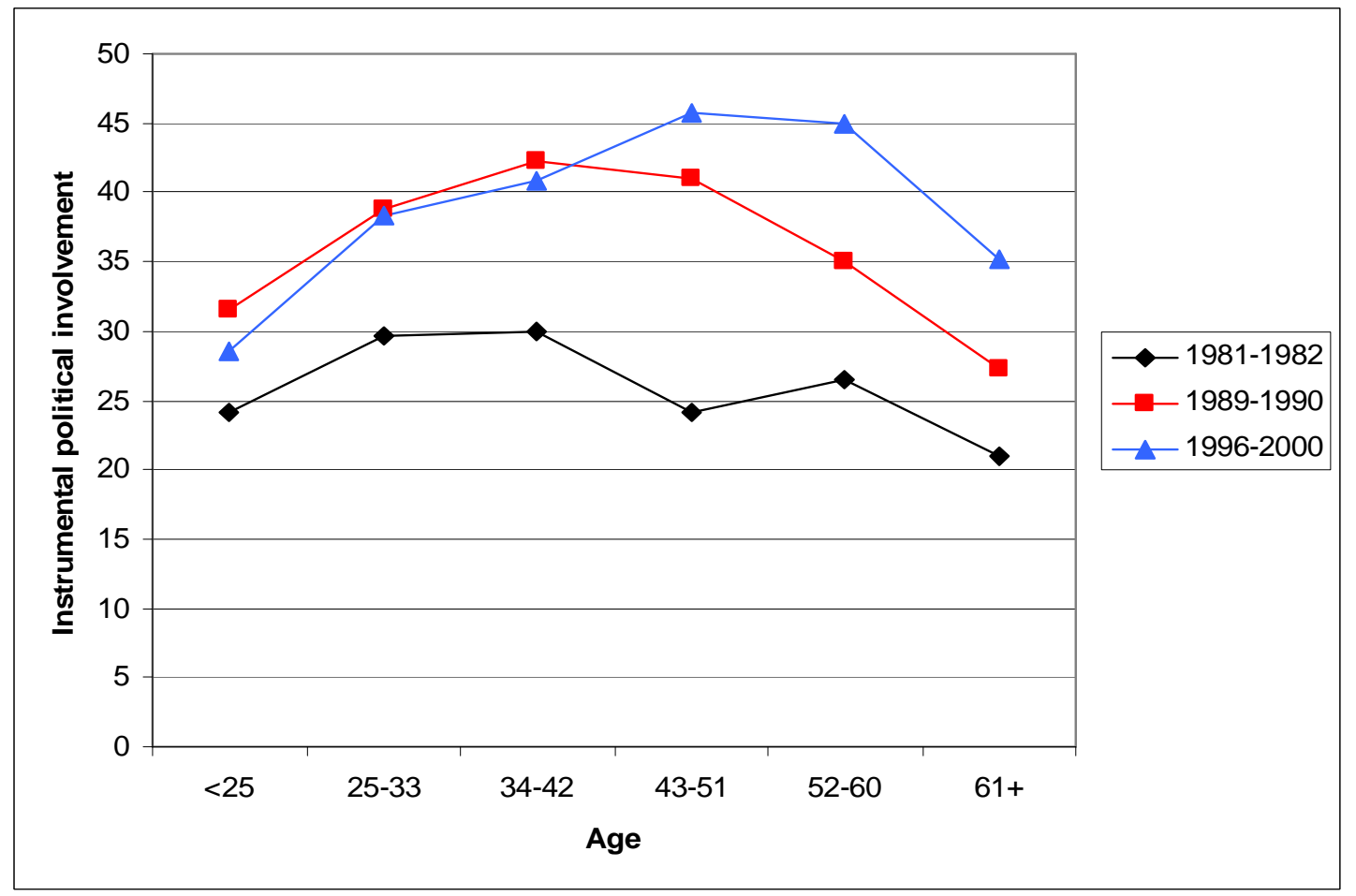

Data: European Values Surveys, 1981-2000

Next, we focus on the distribution of expressive political involvement among age groups. Table 6.10 indicates that there is - unlike instrumental political involvement - a clear inclination towards expressive political involvement among younger people. The middle-aged and the older age groups show lower levels of this involvement type at each wave of EVS. The linearity of the relationship between age and expressive political involvement can also be confirmed by figure 6.2 below. 
Figure 6.2 Shifts in expressive political involvement, 1981-2000

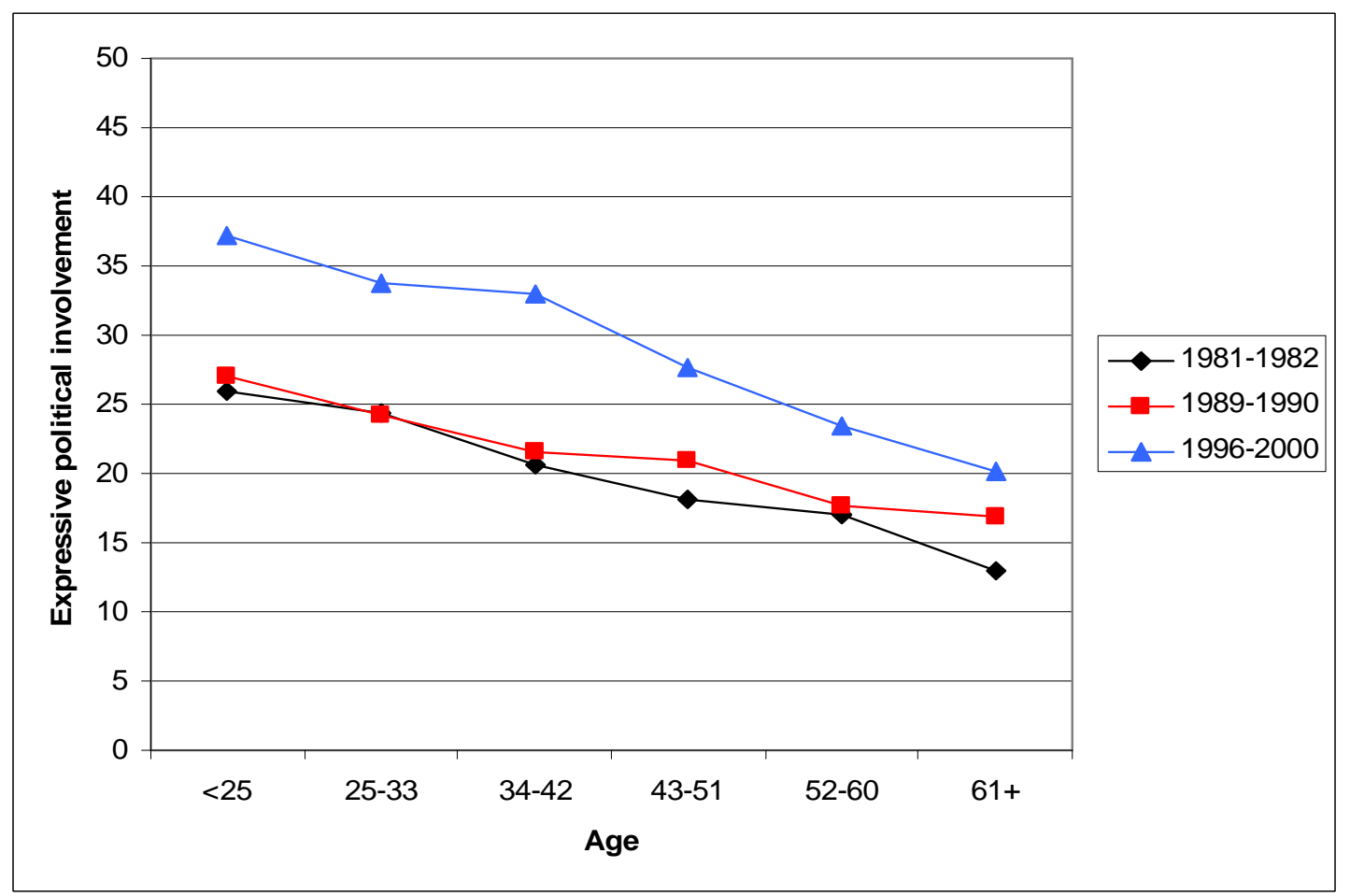

Data: European Values Surveys, 1981-2000

The figure shows clearly that younger age groups have higher levels of expressive political involvement than older ones at each political measurement point. Therefore, it is possible to conclude that there is also a life-cycle effect also for this type of involvement, whereas the relationship is linear and thus different than the relationship between age and instrumental political involvement. Another difference can be found in the development of both instrumental and expressive involvement types among age cohorts. Above we have presented the finding that an increase in instrumental political involvement has occurred particularly among older age groups. Contrarily, we observe here that an overall shift of expressive involvement throughout time has taken place most significantly among younger age groups. Furthermore, the strongest increase has occurred between 1990 and 1999, thus in the same time period where instrumental political involvement among these age groups is found to be declining (see table 6.10).

Depending on these analyses we can thus establish both life-cycle and period effects for both instrumental and expressive involvement types. Striking is however the demonstrative preference by younger people for expressively motivated political behavior over instrumental involvement. Based on this finding, there is reason to expect that forthcoming generations might become more inclined towards the expressive style of getting involved into politics and that this involvement type is 
likely to become an established pattern of political behavior in time. Similarly, since we have observed a decline of preference for instrumental political involvement among younger age groups, we cannot rule out the possibility that the observed general increasing trend in instrumental behavior might stabilize and the levels might even sink as time passes by. Yet before making such predictions, the development of both instrumental and expressive political involvement should also be analyzed with respect to possible cohort effects, which will be done in the following.

\subsubsection{Cohort effects on political involvement}

In this section we will observe the development of political involvement types among the six birth cohorts indicated above. This shall help to determine how the inclination for a specific type of political involvement develops throughout the course of life, i.e. as younger age groups get older. Table 6.11 gives an overview of the periodic fluctuations and generational differences in overall levels of instrumental and expressive political involvement during the two decades.

Table 6.11 Percentages of instrumental and expressive political involvement among birth cohorts

\begin{tabular}{lcccccc}
\hline & \multicolumn{3}{c}{$\begin{array}{c}\text { Instrumental political } \\
\text { involvement }\end{array}$} & \multicolumn{3}{c}{$\begin{array}{c}\text { Expressive political } \\
\text { involvement }\end{array}$} \\
\hline & $\mathbf{1 9 8 1 - 1 9 8 2}$ & $\mathbf{1 9 8 9 - 1 9 9 0}$ & $\mathbf{1 9 9 6 - 2 0 0 0}$ & $\mathbf{1 9 8 1 - 1 9 8 2}$ & $\mathbf{1 9 8 9 - 1 9 9 0}$ & $\mathbf{1 9 9 6 - 2 0 0 0}$ \\
\hline 1975 and later & & & 28,5 & & & 37,2 \\
& & & $(396)$ & & & $(516)$ \\
$1966-1974$ & & 31,6 & 38,4 & & 27,0 & 33,8 \\
& & $(627)$ & $(999)$ & & $(537)$ & $(880)$ \\
$1957-1965$ & 24,1 & 38,8 & 40,8 & 26,0 & 24,2 & 33,0 \\
& $(592)$ & $(1143)$ & $(1128)$ & $(637)$ & $(713)$ & $(912)$ \\
$1948-1956$ & 29,6 & 42,3 & 45,8 & 24,3 & 21,5 & 27,7 \\
& $(552)$ & $(1202)$ & $(1119)$ & $(453)$ & $(610)$ & $(676)$ \\
$1939-1947$ & 30,0 & 41,0 & 45,0 & 20,6 & 21,0 & 23,5 \\
& $(473)$ & $(1019)$ & $(882)$ & $(325)$ & $(522)$ & $(462)$ \\
1938 and before & 23,3 & 30,1 & 35,1 & 15,5 & 17,1 & 20,2 \\
& $(1019)$ & $(1702)$ & $(1114)$ & $(677)$ & $(968)$ & $(641)$ \\
\hline TOTAL & 25,7 & 35,8 & 39,3 & 20,4 & 21,0 & 28,5 \\
& $(2636)$ & $(5693)$ & $(5638)$ & $(2092)$ & $(3350)$ & $(4087)$ \\
\hline
\end{tabular}

Entries are percentages of instrumental and expressive political involvement within each birth cohort Number of respondents for involvement types within birth cohorts is indicated in parentheses Data: European Values Surveys, 1981-2000

With respect to instrumental political involvement, the table displays a constant overall increase among all birth cohorts throughout the three measurement points of the EVS. Yet the levels and the pace of this increase differ between cohorts. 
Particularly cohorts 4 and 5, which form the so-called protest generation, show the highest inclination towards instrumentally motivated political behavior and the increase in this inclination is most significant among these cohorts. The youngest three cohorts - which correspond to the generations $X$ and $Y$ and partly to the protest generation - show lower levels of instrumental political involvement than the two older cohorts born between 1939 and 1956 at each measurement point. Although the tendency of cohorts 2 and 3 towards this involvement type seems to increase as they age, they still can not catch up with the older cohorts 4 and 5. Figure 6.3 provides below a more clear overview of this development.

Figure 6.3 Development of instrumental political involvement among birth cohorts

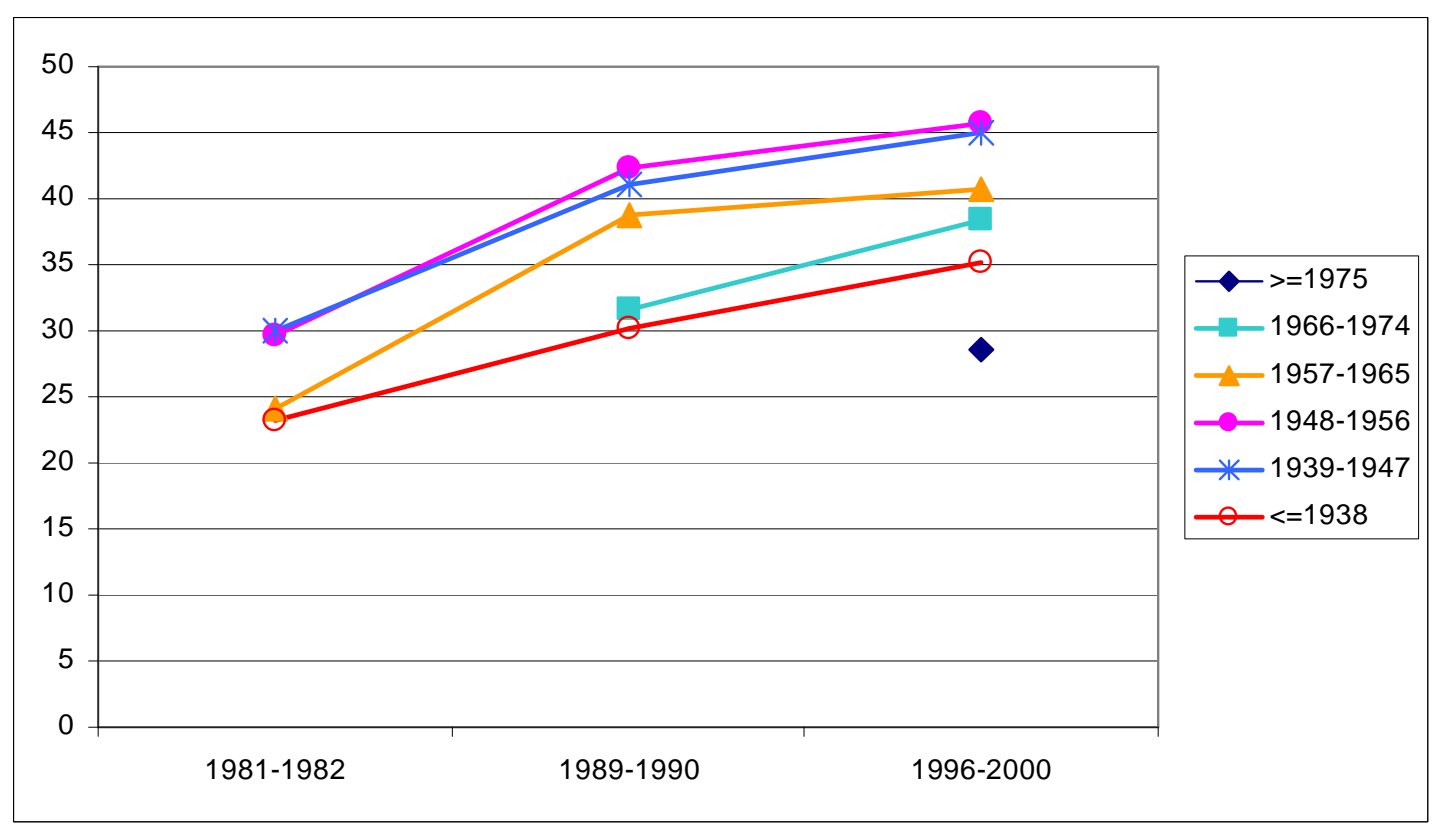

Data: European Values Surveys, 1981-2000

Again here, the overall increase in instrumental political involvement is clearly visible. A similar analysis of individual countries has shown that there are some deviations from the pattern shown above, yet most countries show a consistently increasing trend in the development of this involvement type among almost all birth cohorts $^{44}$. This overall increase indicates that there are period effects on the development of instrumental political involvement, since it increases simultaneously for all cohorts over the two decades. But because the differences between cohorts do not clearly remain stable over time, we can not speak of the presence of a cohort effect. In sum, we can conclude that the development of instrumental political involvement is due to life-cycle and period effects, but not due to a cohort effect.

\footnotetext{
${ }^{44}$ See Appendix $\mathrm{C}$ for the results of these analyses in individual countries.
} 
Also, there is no indication that instrumentally motivated political participation is likely to get established in post-industrial societies through generational replacement, as the youngest cohort at each measurement point has turned out to have the lowest levels of instrumental involvement. The shift towards a social, cultural, or political phenomenon through generational replacement is likely when the youngest birth cohorts show a higher level of that phenomenon than all their predecessors; yet the figure confirms that this is not the case for instrumental political involvement. Thus the hypothesis $\mathrm{H} 4 \mathrm{a}$ - derived from the arguments of the human development approach - is not given much support here.

We turn now to the alternative hypothesis $\mathrm{H} 4 \mathrm{~b}$ and test if the alleged shift towards expressive political involvement through generational replacement is likely to take place. Table 6.11 shows that a general increase among all cohorts can be observed also for expressive political involvement, yet this increase is less pronounced than the increase in instrumental involvement. Although there has been a slight decrease of expressive political involvement among the protest generations (cohorts 3 and 4) between the first and second waves of the EVS, it has been followed by a steep increase between the second and the third waves, which has also been the case for cohort 2 (generation X). Nevertheless, instrumental political involvement has remained the dominant type of behavior at almost all measurement points and among all birth cohorts. The only exception to this pattern is the youngest cohort born after 1975, which shows a higher level of expressive political involvement than older cohorts and a clear preference for this type of behavior over instrumentally motivated participation. The oldest two birth cohorts score notably lower on expressive political involvement, and there has been only a modest increase in their expressive behavior throughout the two analyzed decades. These developments are more clearly represented by figure 6.4 below. 
Figure 6.4 Development of expressive political involvement among birth cohorts

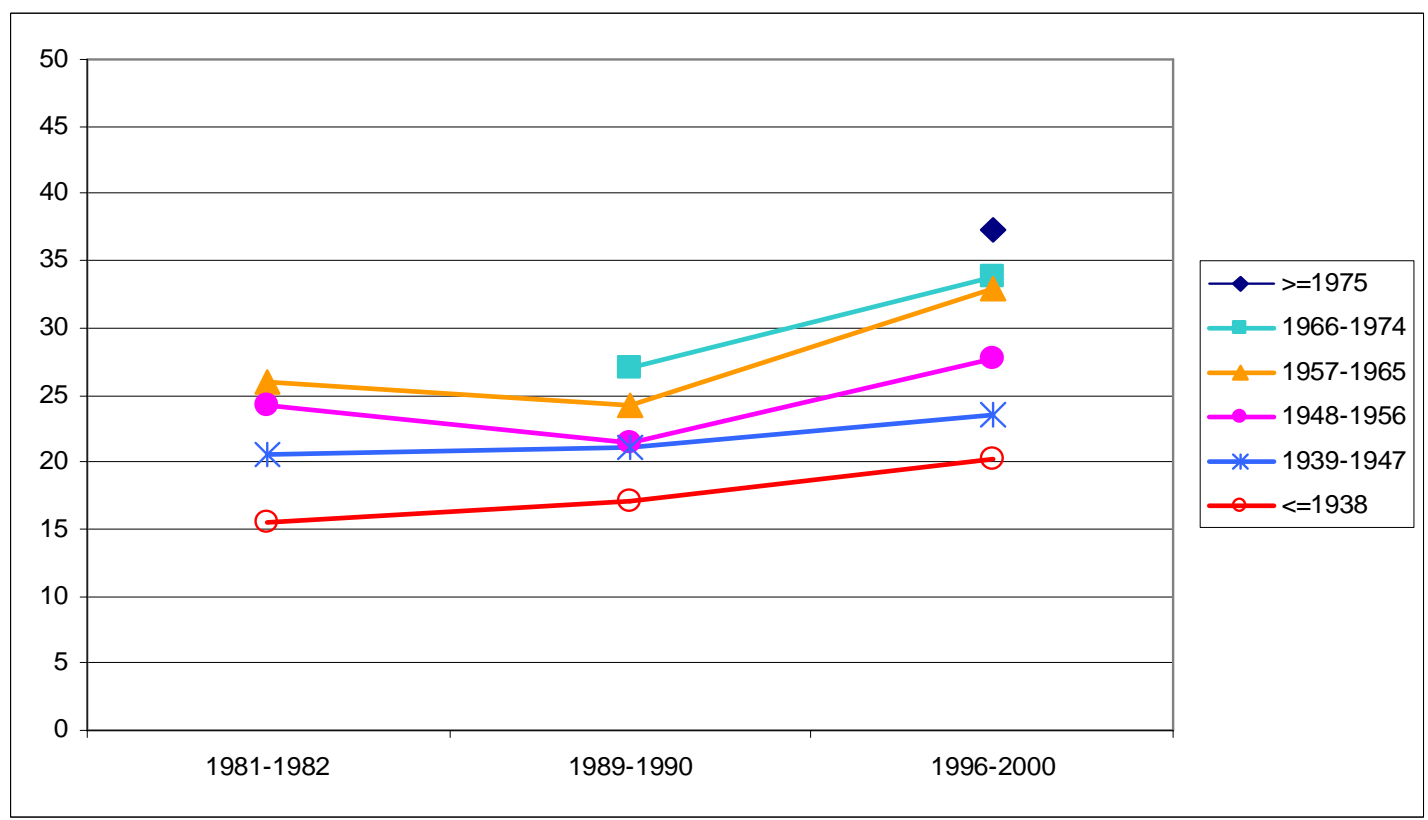

Data: European Values Surveys, 1981-2000

It can be clearly observed from the figure that younger cohorts are becoming more and more inclined to get involved into politics without political motivations. This is first of all visible through the distribution of expressive political involvement among cohorts. At all three survey waves, the youngest cohorts seem to have the higher levels of expressive behavior than their predecessors. Moreover, their level of expressive involvement is constantly higher than that of its preceding cohort in the preceding wave: In the second wave of the EVS, cohort 2 born between 1966 and 1974 shows a slightly higher level of expressive involvement than cohort 3 (born 1957-1965) in the first wave, which at that time formed the youngest cohort. Similarly, in the third wave, cohort 1 born after 1975 displays noticeably higher levels of expressive political behavior than cohort 2 does in the second wave. This pattern cannot be generalized to all analyzed countries, though. Some of them show a mixed trend in the development of expressive political involvement among generations ${ }^{45}$. However, the youngest two generations born after 1965, which are believed to have been more strongly characterized by a post-modern culture, show on average, as well as in almost all individual countries, notably higher levels and a higher pace of development of expressive political involvement compared to the older cohorts, which indicates that this pattern of involvement is highly likely to remain as time passes by in all of these societies.

\footnotetext{
${ }^{45}$ See Appendix $\mathrm{C}$ for the results of these analyses in individual countries.
} 
In sum, we can conclude that next to life-cycle and period effects, a cohort effect on the development of expressive political involvement can also be observed. Based on this cohort effect, we can predict that expressive political involvement is likely to become more widespread as older generations are replaced by younger, which gives support to the hypothesis $\mathrm{H} 4 \mathrm{~b}$ derived from the theory of post-modern politics.

\subsection{Conclusion}

In this chapter we tested the hypotheses derived from two contending theories on post-industrial politics by looking at the levels and development of both involvement types we have associated with their predictions. As predicted by both theories, extrarepresentational forms of political participation turned out to be increasing unequivocally in all countries, whereas the observation of the development of political interest led to mixed results. Similarly, analyzing the development of instrumental and expressive political involvement levels - as well as the development of their ratios to each other - has resulted in contradicting figures in individual countries. While hypothesis $\mathrm{H} 3 \mathrm{a}$, that instrumental political involvement will increase over time, has found support in a number of countries, expressive political involvement was also found to be increasing in others, which gives thus support to the contradicting hypothesis H3b. Overall results were also ambiguous: the absolute levels of both involvement types were found to be increasing, and the ratios between them fluctuated over time.

The test of the hypotheses $\mathrm{H} 4 \mathrm{a}$ and $\mathrm{H} 4 \mathrm{~b}$ on the establishment of both involvement types by generation replacement has delivered more interpretable results. Although instrumental political involvement was increasing over time and among all age groups, the low and ever decreasing inclination of younger age groups and birth cohorts towards instrumental involvement, which could be observed at each time point, led to the rejection of H4a. On the contrary, we found a cohort effect for the development of expressive political involvement, which supported the prediction that the inclination for this type of involvement may increase by generation replacement and thus hypothesis $\mathrm{H} 4 \mathrm{~b}$.

The results thus seem to provide support for the arguments of the theory of postmodern politics. Even if the absolute levels of expressive political involvement still appear to be lower than the instrumental, there is a shift towards expressive political involvement, as the systematic inter-generational differences indicate. Thus, the pessimistic view on societal modernization and the future of democracy is more 
likely to have a point. However, considering the fact that the time span in which these developments took place is rather brief, these results should be approached with caution. Also, we should avoid drawing rash conclusions on the future of democratic stability before testing the relationships of both involvement types with value orientations. The forthcoming chapters will focus on these causal relationships. 


\section{Chapter 7}

\section{The Impact of Values on Political Involvement: Hypotheses and Operationalizations}

In the previous chapter we focused on the distribution of instrumental and expressive political involvement among post-industrial societies as well as their development over time and among generations. Particularly the finding that the development of the expressive political involvement results from a generation effect has provided some support for the arguments of the theory of post-modern politics, which makes rather pessimistic predictions about the future of post-industrial democracy. The hypotheses derived from the theory of human development, as well as from the theory of post-industrial politics, were not unequivocally confirmed by the outcomes. However, since the rest of the analyses delivered rather inconsistent results, most of these hypotheses were not clearly rejected. Therefore, we did not allow ourselves to draw early conclusions on the plausibility of the arguments from both theories. Also, we still need to see if, and to what extent, specific value orientations underlie the two political involvement types in order to be able to make more reliable predictions about the future of democracy.

As we discussed in chapter 5, the theory of post-modern politics suggests that the individualist values, which post-modern citizens are equipped with, are the so-called self-expression values, consisting of rather liberal, rational, and emancipative orientations. The theory of post-modern politics, on the other hand, assumes that individualism means emphasizing personal satisfaction, gratification, and hedonism, which we shall generally from this point refer to as self-orientation values. This chapter will discuss the possible consequences of both self-expression and selforientation values ascribed to the post-modern citizens for the rationality of their political behavior, and thus attempt to build links between these values and the two contending political involvement types.

In the following we will first formulate our hypotheses about the causal relationships between values and types of political involvement based on the 
arguments provided by the theories of human development and post-modern politics. Next, we will describe the operationalization of both self-expression as well as self-orientation values on the basis of the European Social Survey (ESS). As we will show, this data set contains a broad battery of items on individual value orientations which forms a very convenient tool for the operationalization of the value sets. While testing the causal relationships between values and political involvement types, we will control for the other components of individual modernization, namely the indicators of cognitive mobilization as well as the new political orientations. These indicators and their operationalization will be discussed in the last section of this chapter.

\subsection{Individual Values and Political Involvement}

\subsubsection{Value effects on political involvement}

We discussed two main implications of the societal modernization process at the individual level in chapter 4: cognitive mobilization and a change in value orientations. Cognitive mobilization is the consequence of the major process of socioeconomic development, which has included among others an increase in material prosperity, life quality, education levels, and communication in the advanced industrial countries. Parallel to this, a change in prevailing worldviews of individuals in these societies, which has been referred to as "individual modernity" (Inkeles \& Smith 1974; Inkeles 1983; Welzel 2007) or as "post-materialist values" (Inglehart 1977, 1990, 1997) has taken place (see chapter 4, figure 4.1).

In what way are individual values related to politics? Values are mostly viewed as deep-rooted, abstract motivations that guide, justify, and explain attitudes, norms, opinions, and actions (Rokeach 1973; Schwartz 1992; Halman \& de Moor 1994; Feldman 2003). Thus also political attitudes and choices can be influenced by individual values, since "[v]alues may enable people to organize their political evaluations in a relatively consistent manner; they may provide a general structure to political attitudes" (Feldman 2003; cited in Davidov et al. 2008: 421). Through this structuring process, values may influence political preferences. As Inglehart has pointed out, the cultural change is "reshaping the social basis of political conflict, the reasons people support parties, the kinds of parties they support, and the ways in which they try to attain their political goals" (1990: 5).

The last part of this quotation indicates that values are also thought to be linked to political participation. It has been hypothesized that post-materialist values are 
positively related to particularly direct forms of political participation. Evidence from the past three decades has supported this expectation by showing that the rise in post-materialist values has been associated with increasing levels of political participation, even as support erodes for traditional institutions such as political parties (see e.g. Inglehart 1977, 1990; Inglehart \& Abramson 1999; Inglehart \& Norris 2003; Norris 2002). Additional research highlights links between post-materialist values and protest activity (Inglehart 1990, 1997; Inglehart \& Catterberg 2002). Inglehart has extended his earlier work on materialism and post-materialism to propose two value dimensions on which one can compare national cultures: traditional vs. secular-rational, and survival vs. self-expression values (e.g. Inglehart \& Baker 2000; Inglehart \& Welzel 2005).

Traditional values include an emphasis on male dominance, absolute standards of morality and strong national pride, whereas societies with secular-rational values have the opposite preferences, i.e. gender equality, flexible moral standards, and weak nationalism (Inglehart \& Baker 2000: 25). Inglehart defines particularly the selfexpression values as the central element of the human development process. These values are reflected in rising liberty aspirations. The libertarian values ${ }^{46}$ which are assumed to have increased with socioeconomic modernization (see Inglehart \& Baker 2000) weigh the autonomy of the individual more highly than the authority of the community and thus oppose the traditional communitarian orientations. Yet the strong demand for self-expression is not only linked with aspirations for private autonomy but also with aspirations for free public choices in the selection of collective goals, rules and leaders. In this way, self-expression values are by no means related only to the individual self. Especially values such as tolerance, or postmaterialist goals such as protection of environment, are components of the selfexpression values. Therefore, we can expect that people who have internalized these values would be more inclined to get involved in political decision making on these issues. In short, this theory expects self-expression values to be prevalent in postindustrial societies, and that they determine the motivations for goal-oriented political behavior; in other words, self-expression values are expected to lead to instrumental political involvement.

On the other hand, the counter argument - the theory of post-modern politics supposes that the process of individualization has not only led to the rise of new forms of political participation but also to a popular culture where mass

\footnotetext{
${ }^{46}$ They include the post-materialist preferences for self-expression, interpersonal tolerance, spontaneous engagement, generalized trust and life satisfaction, see chapter 4 .
} 
consumption, hedonistic self-gratification, and enjoyment are taking center stage. These values emerge in post-industrial societies as a counterpart of traditional ascetic Protestant values such as achievement and discipline which are likely to prevail in industrial societies. As a result, the rising levels of political participation are accompanied by a motivation to satisfy the need for personal satisfaction and less by the aim to influence political outcomes. Therefore, the self-orientation values are expected to facilitate the expressive type of political involvement.

As this study aims to compare the arguments of the two views on the implications of post-modernization empirically, the following will focus on the values predicted by both views. Elsewhere we have shown that both views share the assumptions that a change in the cognitive skills of people in post-industrial societies has taken place, and that the change in values is most visible among the younger generations. However, they differ from each other in the prevailing individual value orientations that are supposed to be established in these societies, and the resulting type of involvement in political decision-making. We can derive the following hypotheses:

Table 7.1 Hypotheses on values and their effects on political involvement

Theory of Human Development

H5a Self-expression values prevail over selforientation values among citizens of postindustrial societies

H6 Self-expression values tend to be associated with instrumental political involvement in post-industrial societies
Theory of Post-Modern Politics

H5b Self-orientation values prevail over self-expression values among citizens of post-industrial societies

H7 Self-orientation values tend to be associated with expressive political involvement in post-industrial societies

The hypotheses $\mathrm{H} 5 \mathrm{a}$ and $\mathrm{H} 5 \mathrm{~b}$ reflect the contradicting expectations of the two views on prevailing values in post-industrial societies. Hypotheses $\mathrm{H} 6$ and $\mathrm{H} 7$ are related to the association between values and types of political involvement. In line with the human development approach we hypothesize that self-expression values shall prevail in post-industrial societies, and encourage instrumental political involvement; while we assume that the self-orientation values prevail and tend to 
facilitate an expressive political style in these societies based on the theory of postmodern politics.

\subsubsection{Control factors for the value effects}

\subsubsection{Cognitive mobilization}

As mentioned before, we will examine the effects of self-expression and selforientation values on political involvement by controlling for other indicators of individual modernization. One of these control factors is cognitive mobilization, which is another significant manifestation of socioeconomic development and goes hand in hand with the change in value priorities. It generally refers to a significant increase in people's political skills and resources due to the rapid expansion of educational opportunities and the parallel decline in the costs of acquiring and processing information (Barnes \& Kaase et al. 1979, Dalton et al. 1984; Inglehart 1990). Key factors in the process of cognitive mobilization are education and media consumption because these provide the citizens with political knowledge and the necessary skills to process this knowledge. As a consequence of these processes, postindustrial societies have reached a level where political information is no longer a scarce commodity and people are equipped with high levels of sophisticated knowledge.

These processes have unavoidable consequences for citizen involvement in politics. Due to their increasing levels of education and political information, citizens become less likely to be passive subjects and more likely to demand a say in decisions affecting their lives (Dalton 2006). Therefore, they become politically more active. Previous research has provided empirical evidence showing a positive relationship between cognitive mobilization and engagement in the political process, especially in more citizen-initiated, policy-oriented, and more direct forms (Dalton et al. 1984; Inglehart 1990). This is often being explained by the fact that the bettereducated individuals are more likely to have the time, the money, the access to political information, the knowledge, and the ability to become involved in the political process. In this sense it is not just education, per se, that stimulates participation, but education as related to the skills and orientations that directly influence participation (Verba et al. 1995; Delli Carpini \& Keeter 1996; Nie et al. 1996). The same mechanism can also be assumed for the effects of media consumption on political participation. The key indicators may furthermore have an effect on the types of political involvement indirectly through their effect on political interest; both education and the level of political information are closely related to 
the level of interest in politics ${ }^{47}$. Therefore, we may assume that cognitively mobilized citizens are more likely to get active in politics with instrumental motivations.

\subsubsection{New political orientations}

The process of cognitive mobilization has transformed citizens' attitudes towards politics as well as towards themselves as a political object. Higher levels of education and political information have led, in the first place, to an increased belief among citizens that they have the competence to influence political decision-making processes (see e.g. Dalton 2006). This belief "about one's own competence to understand, and to participate effectively in, politics" is referred to as internal political efficacy in the literature (Niemi et al. 1991: 1407) ${ }^{48}$. On the other hand, cognitively mobilized citizens are also likely to be influenced by the performance of the state in responding to the demands posed by the citizenry. This means that they are more likely to have a critical orientation towards the government and political actors (Norris 1999; Pattie et al. 2004).

Both the increase in subjective political efficacy and political dissatisfaction are empirically proven facilitators of political participation. Political efficacy, first of all, is found to be associated with political participation (Parry et al. 1992; Dalton 2006), although some researchers suggest that this link may be a reciprocal one (e.g. Finkel 1985). Yet this association is mostly made with civic or electoral forms of participation. Former work on protest participation has found that it correlates positively with internal political efficacy (e.g. Barnes \& Kaase et al. 1979), yet other studies have not verified this relationship (e.g. Parry et al. 1992). Thus, since we use extra-representational forms of participation in our political involvement measure, it is not easy to predict how internal efficacy will be related to the types of political involvement. However, if we interpret internal political efficacy as the belief of being able to bring about social and political change, then we can expect it to motivate political involvement with an aim to achieve the desired outcomes (see Becker 2004); in other words, we can argue that internal political efficacy will be associated with instrumental political involvement.

\footnotetext{
${ }^{47}$ In the literature, political interest has often been treated as an indicator for cognitive mobilization. We will however prefer not to do this, since political interest is included in the measure for instrumental and expressive political involvement.

48 Although internal political efficacy is believed to be initiated by education and political knowledge, it is also being supposed to be strengthened by factors such as civic engagement, political participation, and even democratic institutions (Tocqueville 1945 [1840]; Almond \& Verba 1963; Pateman 1970; Barber 1984; Putnam 1993).
} 
Next to efficacy, the role of political dissatisfaction as a predictor of political participation has also been discussed in the literature, especially for the "unconventional" forms of participation such as protest (e.g. Thomassen 1990; Norris et al. 2005). However, with respect to the involvement types, it is not easy to draw a clear conclusion on which type of involvement would be mobilized by this orientation. On the one hand, dissatisfaction may be regarded as a sign of a strong stake in political issues and outcomes and a sense of urgency to do something about it; therefore it may be argued that it leads to instrumental political involvement. On the other hand, expressive political involvement may also result from negative orientations towards politics. Since the common belief among dissatisfied citizens is that the government is not being responsive to their demands, their action may not necessarily be directed at getting results, but rather to satisfy their need to express the dissatisfaction (Gurr 1970).

In sum, we have argued that the cognitive mobilization indicators (education and media exposure) shall have a direct positive effect on instrumental political involvement, whereas their indirect effects - which are supposed to run through internal political efficacy and political dissatisfaction as motivators of participation can be related to both types of political involvement. Therefore, we will control for both the direct and the indirect effects of cognitive mobilization while we test the causal relationships between values and types of political involvement.

\subsubsection{Age}

Finally, we will control for the effects of age in our analyses. We have shown in previous chapters that the new societal phenomena - cognitive mobilization and a shift in values - resulting from the individual modernization process are more likely to be common among younger generations and will remain as these generations get older. Besides, age has been a key variable in political participation research, next to cognitive mobilization indicators, which has often been associated with the so-called participatory revolution. Thus we will test how age is related to these two phenomena as well as instrumental and expressive political involvement, yet we will not test for the expected generation effects, since we do not conduct longitudinal analysis in this part of our analyses.

With respect to value orientations and political involvement, we can again formulate alternative hypotheses in line with the two contradicting theories. The theory of human development would predict that the younger age groups would be more inclined to have self-expression orientations, thus more likely to get instrumentally involved in politics. On the other hand, the theory of post-modern 
politics would suggest that self-orientation values and thus expressive political involvement would be more common among younger people. With respect to cognitive mobilization, it is suggested that young people are higher educated and more exposed to media and political information (Inglehart 1977; Dalton et al. 1984; Dalton 2006). Therefore, we can also expect higher subjective political efficacy and higher levels of political dissatisfaction among these age groups. However, the contending theories offer a clear expectation on the relationship, neither between cognitive mobilization and value orientations, nor between new political orientations and value orientations. Thus we also will not formulate any hypotheses on the relations between these phenomena.

In a nutshell, the analytical model that we intend to test in this chapter is illustrated in figure 7.1:

Figure 7.1 The causal model

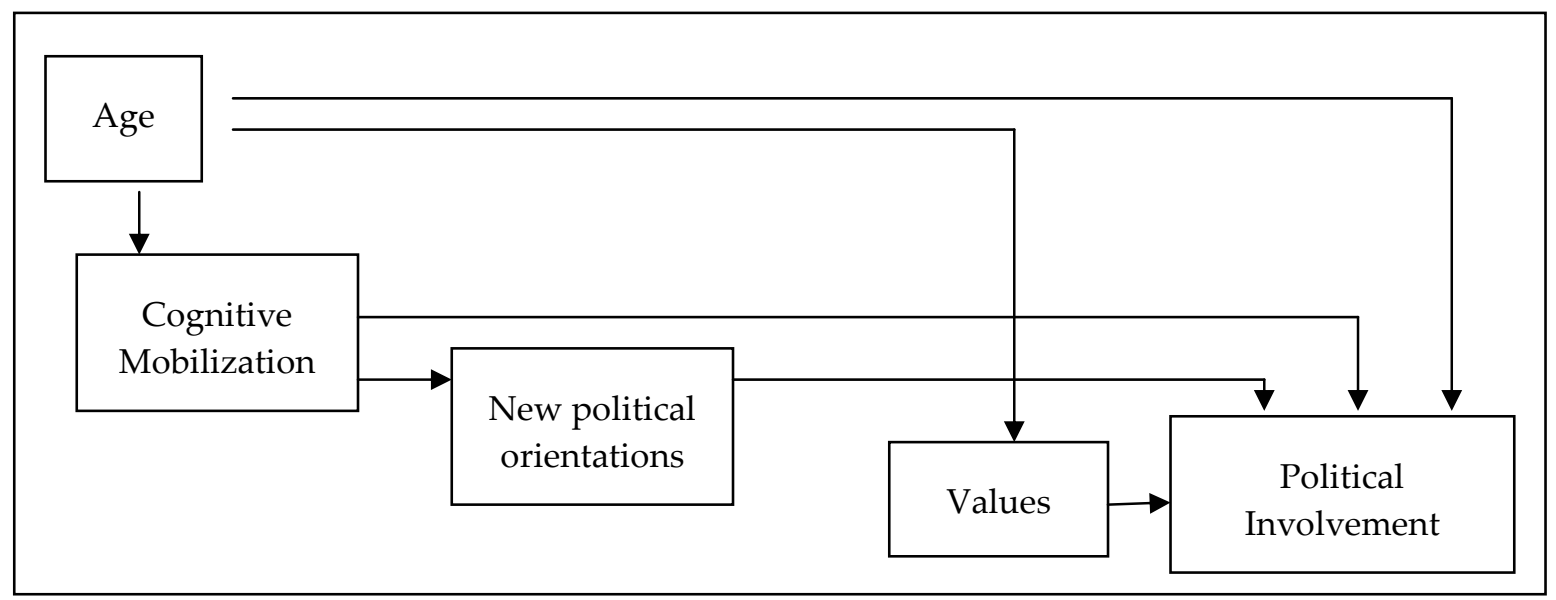

While testing this model, we will apply the following strategy: for the alleged interactions between the independent variables (values, cognitive mobilization, new political orientations, and age) we will calculate their bivariate correlations. For the effects of these variables on political involvement, we will do binary logit analyses on a pooled and country-by-country basis, whereas these analyses will be carried out in four steps. The first model will include only self-expression and self-orientation values as independent variables; in the second step, new political orientations will be added to the model; the third step will incorporate cognitive mobilization; and finally, the whole model will be tested by adding the age of respondents. This stepby-step approach will help to determine the indirect relationships by seeing how the individual effects of the variables change when new variables are introduced. As shown in the figure, age is supposed to be both related to values and political involvement. By adding this variable later on into the model, we can get a more 
robust picture about the nature of relationships between values and involvement, for instance about whether these relationships are spurious or not.

The dependent variable, political involvement, will be measured by a single variable. Since we focus only on instrumental and expressive involvement, i.e. if people are getting involved in extra-representational activities with or without political interest, those refraining from these activities will not be considered in the further analyses. Our data will only consist of those who participate in extrarepresentational political activities. Therefore the variable political involvement will reflect a dichotomy between the non-interested participants $(0=$ expressive involvement) and interested participants (1=instrumental involvement). The measurement of our independent variables is more complex and will be discussed in the following section.

\subsection{Data and Operationalizations}

\subsubsection{European Social Survey}

For the measurement of the above introduced concepts and for testing the causal model we will rely on data from the European Social Survey (ESS). Like the EVS, the ESS is a large-scale, multi-country survey, which is conducted on a biennial basis and currently contains more than 30 European countries. The data from the first four survey rounds fielded in 2002-2003, 2004-2005, 2006-2007, and 2008-2009 are available for analysis; and a fifth round has officially been started. The ESS questionnaire covers, at every point of data collection, a "core module" consisting of a wide range of social variables such as media use, social and public trust, political interest and participation, socio-political orientations, governance and efficacy, human values, demographics and socioeconomic status. The use of a core module allows the monitoring of change and continuity of these variables. Additionally, there are two or more "rotating modules" at each time point and these modules are to be repeated at certain intervals.

Since the ESS covers political interest and various modes of political participation, it is an appropriate data source for the operationalization of our dependent variable. Yet the most important reason why we chose to use this data set is that it covers a broad range of items that measure people's value orientations and thus allows us to operationalize our independent variables. This battery of items has been developed by Shalom Schwartz (1992) to measure his theory of basic human values, yet the individual items correspond quite well with the concept of self- 
expression values by Inglehart ${ }^{49}$. Moreover, it is the only available battery of items to measure the hedonist value orientations. We will use only one point in time while testing the hypotheses 5 and 6 on causal relationships between values and political involvement types using the ESS from 2002-2003. The control variables will also be measured on the basis of this data set.

\subsubsection{Measuring value orientations}

To measure self-expression and self-orientation values, we will rely upon the items on individual values from the ESS which have been developed by Shalom Schwartz. In 1992, Schwartz introduced a theory of basic human values, building on common elements of earlier approaches (e.g. Rokeach 1973; Hofstede 1980; Triandis 1988, 1994, 1995). This section will introduce Schwartz's value theory as well as his items to measure the values.

The theory of basic human values, introduced in 1992 by Shalom Schwartz, includes ten motivationally distinct values presumed to encompass the major value orientations recognized across cultures. Schwartz also presents an instrument for measuring these values which he validated cross-culturally (Schwartz 1992) ${ }^{50}$. Recently, the ESS incorporated a sequence of indicators designed to measure values which includes a series of twenty one questions developed by Schwartz. This is a reduced version of the item battery in Schwartz Values Survey (2003). The instrument's adequacy for measuring values within and across countries has also been assessed (Schwartz 2003; Davidov et al. 2008). The ten basic human values according to Schwartz are as follows:

\footnotetext{
49 See Inglehart \& Oyserman 2004; Schwartz 2004 for an extensive comparison of the value dimensions developed by Inglehart and Schwartz.

50 The so-called response bias, which occurs frequently in the measurement of value orientations, makes it necessary to take precautions in order to remove the response styles from the data. Schwartz (1992) has recommended using the respondent's mean across all items to control for the response bias effects in partial correlations or regression analyses.
} 
Table 7.2 Basic human values by Schwartz (2003)

\begin{tabular}{|c|c|}
\hline Power & $\begin{array}{l}\text { Social status and prestige, control or dominance over people and } \\
\text { resources }\end{array}$ \\
\hline Achievement & $\begin{array}{l}\text { Personal success through demonstrating competence according to social } \\
\text { standards }\end{array}$ \\
\hline Hedonism & Pleasure and sensuous gratification for oneself \\
\hline Stimulation & Excitement, novelty and challenge in life \\
\hline Self direction & Independent thought and action - choosing, creating, exploring \\
\hline Universalism & $\begin{array}{l}\text { Understanding, appreciation, tolerance and protection for the welfare of } \\
\text { all people and for nature }\end{array}$ \\
\hline Benevolence & $\begin{array}{l}\text { Preservation and enhancement of the welfare of the people with whom } \\
\text { one is in frequent personal contact }\end{array}$ \\
\hline Tradition & $\begin{array}{l}\text { Respect. Commitment and acceptance of the customs and ideas that } \\
\text { traditional culture or religion provide the self }\end{array}$ \\
\hline Conformity & $\begin{array}{l}\text { Restraint of actions, inclinations, and impulses likely to upset or harm } \\
\text { others and violate social expectations and norms }\end{array}$ \\
\hline Security & Safety, harmony and stability of society, of relationships, and of self \\
\hline
\end{tabular}

Source: Davidov et al. (2008: 424).

Just as Inglehart's later research on materialism and post-materialism adopts a two-dimensional approach (survival/self-expression and traditional/secular authority; see Inglehart \& Baker 2000), Schwartz (2003) notes that these ten basic values can function as a two-dimensional model, where one dimension consists of two opposing value sets. Accordingly, he has created four main value sets consisting of the following values: the individualist values of "openness to change" (selfdirection, stimulation, and hedonism); the altruist values of "self-transcendence" (universalism and benevolence); conformist values under the label "conservation" (tradition, conformity, and security); and finally, "self-enhancement" values (achievement and power) which are egoistic in nature. Each of these four value sets are combined with their opposites in order to create orthogonal variables of selftranscendence versus self-enhancement, and openness to change versus conservation (see figure 7.2). 


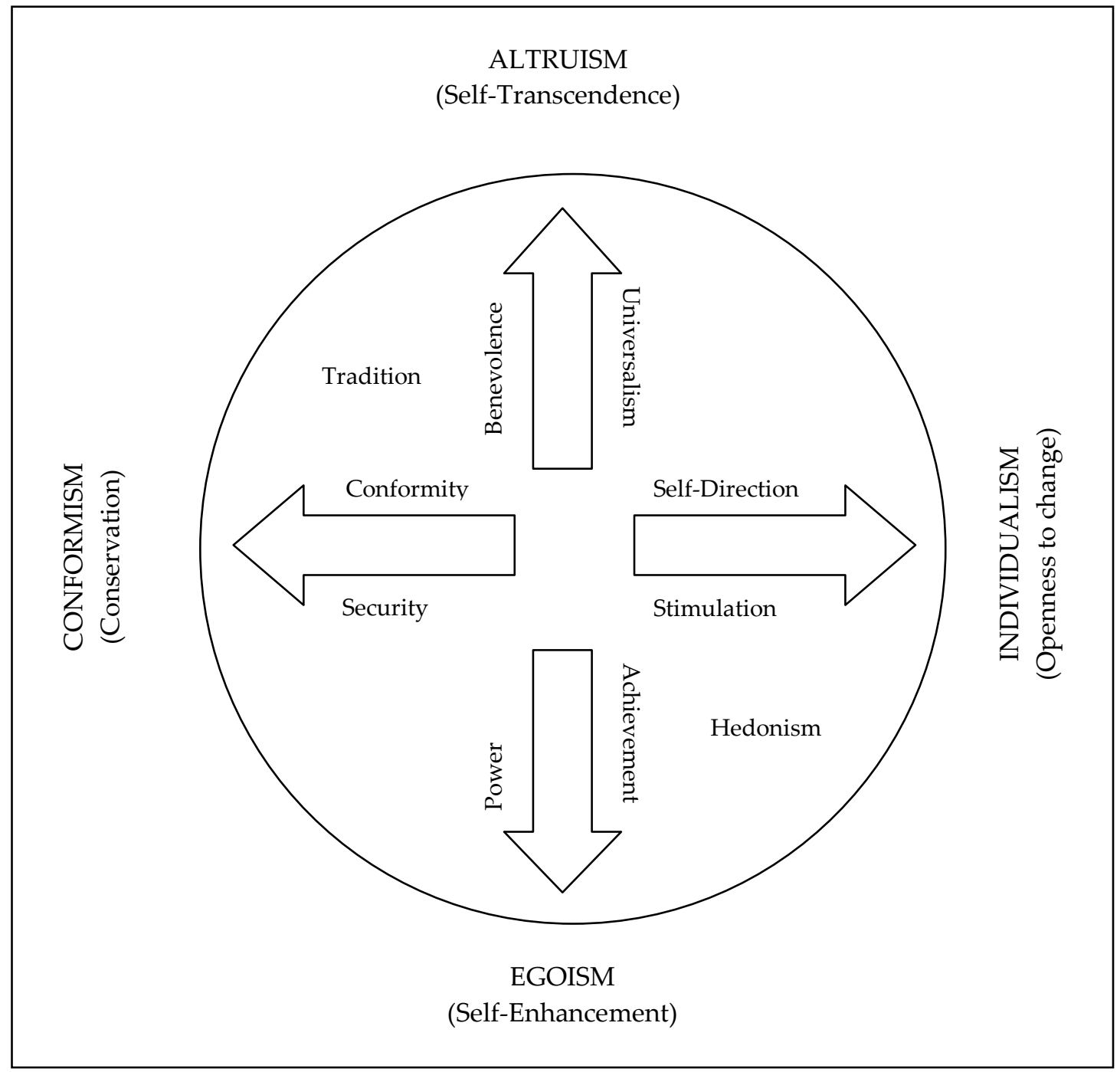

Source: Welzel (2009: 115)

At the end of both poles one can find value sets conflicting with each other. This means that self-transcendence (or altruism) builds the opposite pole of selfenhancement (egoism), whereas openness to change (individualism, autonomy) builds the conceptual opposite of conservation (conformity, also referred to as collectivism). Particularly the contrast between individualism and collectivism has been one of the central topics within the discipline of comparative cultural psychology (e.g. Hofstede 1980; Triandis 1995). These dimensions have especially been used to compare the differences between autonomous and interdependent cultures (e.g. Markus et al. 1996).

As we compare this model with Inglehart's survival versus self-expression dimension we see some conceptual overlap, which was also highlighted by both researchers (Inglehart \& Oysterman 2004; Schwartz 2004). Inglehart's survival/self- 
expression dimension is the one most clearly linked to his earlier materialism/postmaterialism construct. Schwartz (2004) has also shown how Inglehart's value dimensions overlap with his own. Using seven higher order, cultural-level value types at the level of different societies and regions ${ }^{51}$, he has found that his theoretical value dimensions are empirically related to Inglehart's value dimensions. His analyses suggest that one of the original questions designed by Inglehart to capture materialist values correlates highly with conservation values. Also, Inglehart's two questions designed to express post-materialism seem to be both correlated with the self-expression/self-transcendence factor in his model. Furthermore, there is a connection between the secular-rational values suggested by Inglehart and the selfdirection values by Schwartz. The decrease of encompassing structures and of absolute standards in secular-rational societies frees individuals to think, act and feel more independently, which is a core aspect of autonomy. Looking at table 7.3, we can see that the self-direction value are most closely related to the secular-rational values. Schwartz himself has established a fairly high correlation between these two values constructs (Schwartz 2004: 54).

Table 7.3 Comparing Schwartz's values concept with the traditional vs. secular-rational values by Inglehart

Schwartz Traditional vs. Secular-Rational Values (Inglehart)

\begin{tabular}{ll}
\hline Self-Direction & .55 \\
Hedonism \& Stimulation & .42 \\
Tradition, Security, Conformity & -.51 \\
Openness to Change vs. Conservation Dimension & .52 \\
\hline Self-Transcendence & .05 \\
Self-Enhancement & -.25 \\
Self-Transcendence vs. Self-Enhancement Dim. & .20 \\
\hline
\end{tabular}

Source: Schwartz 2004, pp. 54ff. While calculating these correlations, Schwartz has used the seven macro-level values mentioned above. We labeled them here after their equivalents at the individual level to avoid confusion.

51 These value orientations are as follows: Intellectual autonomy (corresponds with selfdirection), Affective autonomy (corresponds with stimulation and hedonism), Conservatism (corresponds with security, conformity, and tradition), Hierarchy (corresponds with power and achievement), Egalitarian commitment (corresponds with benevolence and universalism), Harmony, and Mastery. Schwartz has used a wider item battery in constructing these dimensions than the one in the ESS. 
Turning to the second dimension now, the survival vs. self-expression dimension, we can see more overlaps. This dimension contrasts societies in which people primarily focus on economic and physical security with societies in which security is high and quality-of-life issues play a central role. According to the theory of human development, many people are well educated and work in services in societies where self-expression values prevail. This grants them more freedom of judgment, innovation, and autonomous decision-making, and equips them with relevant communication and information-processing skills. Trust, tolerance, subjective well-being, political activism, and concern for the environment are high. Differences within the society and cultural change are accepted and even seen as enriching, and out-groups are increasingly seen as meriting equal rights. With these characteristics, self-expression values overlap conceptually with Schwartz's openness to change and self-transcendence values. Trust, tolerance, and support for equal rights of out-groups closely parallel some aspects of self-transcendence. Political activism and opposition are less related to this dimension, but a relationship exists. The empirical correlations support these inferences (see table 7.4).

Table 7.4 Comparing Schwartz's values concept with the survival vs. self-expression values by Inglehart

Schwartz Survival vs. Self-Expression Values (Inglehart)

\begin{tabular}{lc}
\hline Self-Direction & .58 \\
Hedonism \& Stimulation & .61 \\
Tradition, Security, Conformity & -.71 \\
Openness to Change vs. Conservation Dimension & .69 \\
\hline Self-Transcendence & .73 \\
Self-Enhancement & -.41 \\
Self-Transcendence vs. Self-Enhancement Dimension & .61 \\
\hline
\end{tabular}

Source: Schwartz 2004, pp. 54ff. While calculating these correlations, Schwartz has used the seven macro-level values mentioned above. We labeled them here after their equivalents at the individual level to avoid confusion.

At this point we shall come back to the contending interpretations of postmodern citizens by the two theoretical notions. As discussed in chapter 5 , the individualist orientations of this citizen type can either be manifested in selfexpression values (Inglehart's theory of human development) or in self-orientation values (the theory of post-modern politics). Based on the theoretical background, as well as on the most recent discussion on the measurement of values, we suggest that these opposing value types are captured to a great extent by the values covered by 
the dimension of individualism (or openness to change). However, in order to differentiate between the two opposing manifestations of individualism, we consider it necessary to rely upon the self-transcendence vs. self-enhancement dimension. Thus we will also use these concepts to operationalize self-expression and selforientation values, while we argue that these concepts only partly relate to these values. The following will clarify what we mean.

For the operationalization of self-expression values, we will use values from both self-transcendence and openness to change dimensions. The dimension of selftranscendence consists of the values benevolence and universalism. In our opinion, benevolence is less related to Inglehart's concept of self-expression values because it is about caring for the welfare of people in the immediate adjacencies, i.e. those with whom there is much closer contact (see table 7.2 for details). In this sense this value gets closer to collectivist value orientations, which is not compatible with the highly individualized self-expression values. On the contrary, we think that universalism is closer to this concept. People who have this value orientation are, according to the ESS items, emphasizing the virtues of equal chances and treatment, and tolerance towards different opinions (see table 7.2). According to Inglehart and Welzel (2005), respecting the opinions of others is a virtue which, among other virtues, belongs to the dimension of self-expression values. Emphasis on equality brings these highly individualized people somewhat closer to the ideal of common welfare. Finally, the importance of environmental protection can be interpreted as an indicator of issue orientation and interest in political issues. Therefore, we can expect that people with a universalist value orientation will be more inclined to instrumental political involvement then those who have not internalized these values.

The openness to change dimension consists of the values self-direction, stimulation, and hedonism ${ }^{52}$. Of these values, self-direction seems to be closest to the self-expression values since it embodies the orientation towards self-autonomy and liberty (see table 7.2). In this way, this value orientation comes close to the citizen type of the post-modernization optimists. We can then assume that people with a self-direction value orientation will also tend more towards instrumental political involvement.

Turning towards the citizen type of the theory of post-modern politics, we can detect three values which define the orientations of this citizen type best: hedonism,

\footnotetext{
52 In some countries hedonism turned out to be closer to the dimension of self-enhancement (dimension consisting of the values achievement and power), but Schwartz classifies it as a component of openness to change.
} 
stimulation and achievement. Hedonists are those who put a strong emphasis on having a good time, fun and pleasure (see table 7.2), which is in accordance with the definition of hedonism by Bell (1976, see also chapter 5). Although Schwartz has classified this concept under the dimension of openness to change (which also covers self-direction), it is important to note here that he has found hedonism to include also elements of self-enhancement, which has a stronger emphasis on self-interest in opposition to welfare and interests of others (Schwartz 2003; Davidov et al. 2008). Therefore, the items used to construct this value orientation are largely appropriate to operationalize the concept of hedonism. We assume that this item will be more related to expressive political involvement than instrumental.

Stimulation refers to the value priority for excitement, risk-taking, and challenge in life. These values can also easily be associated with the strong emphasis of selfinterest, consumption, and novelty, as predicted by the theory of post-modern politics as the central orientation pattern of post-modern citizens. Therefore, we expect these values as well to be related more closely to expressive political involvement. Although Schwartz has found that those who give priority to selfdirection values also tend to emphasize stimulation and hedonism, and that these values tend to oppose conformist values, we will treat self-direction in this analysis as alternative to hedonism and stimulation based on the conceptual background we have introduced in chapter 5. We argue that self-direction values are those individualist values which are more close to community orientation and liberty, while stimulation and hedonism are more appropriate indicators for the concept of egoist - or "expressive" - individualism described by the theory of post-modern politics.

Finally, achievement values are value priorities of those who prioritize personal success and demonstration of competence. Because of the strong emphasis on self interests and the orientation towards gratification and recognition, we can establish a correspondence with the arguments of the theory of post-modern politics. Contrary to the expressivist values of hedonism and stimulation, which place the emphasis on fun, enjoyment and consumption, achievement values are directed towards personal success and thus can be associated rather with the "utilitarian individualism" (see Bellah et al. 1985). Yet it is - just like hedonism and stimulation - an orientation towards pure self-realization without taking care of community interests. We can therefore hypothesize that these values will also be related to expressive political involvement. The ESS items which form these five variables are illustrated in table 7.5 . 
Table 7.5 Underlying items for self-direction, universalism and hedonism

\begin{tabular}{|c|c|c|c|c|}
\hline \multicolumn{2}{|c|}{ Theory of Human Development } & \multicolumn{3}{|c|}{ Theory of Post-Modern Politics } \\
\hline Self-Direction & Universalism & Hedonism & Stimulation & Achievement \\
\hline $\begin{array}{l}\text { Thinking up new ideas and } \\
\text { being creative is important } \\
\text { to him. He likes to do } \\
\text { things in his own original } \\
\text { way. }\end{array}$ & $\begin{array}{l}\text { He thinks it is important } \\
\text { that every person in the } \\
\text { world be treated equally. } \\
\text { He believes everyone } \\
\text { should have equal } \\
\text { opportunities in life. }\end{array}$ & $\begin{array}{l}\text { Having a good time is } \\
\text { important to him. He } \\
\text { likes to "spoil" himself. }\end{array}$ & $\begin{array}{l}\text { He likes surprises and is } \\
\text { always looking for } \\
\text { new things to do. He } \\
\text { thinks it is important } \\
\text { to do lots of different } \\
\text { things in life. }\end{array}$ & $\begin{array}{l}\text { It is important to him to } \\
\text { show his abilities. He } \\
\text { wants people to admire } \\
\text { what he does. }\end{array}$ \\
\hline \multirow[t]{2}{*}{$\begin{array}{l}\text { It is important to him to } \\
\text { make his own decisions } \\
\text { about what he does. He } \\
\text { likes to be free to plan and } \\
\text { not depend on others. }\end{array}$} & $\begin{array}{l}\text { It is important to him to } \\
\text { listen to people who are } \\
\text { different from him. Even } \\
\text { when he disagrees with } \\
\text { them, he still wants to } \\
\text { understand them. }\end{array}$ & $\begin{array}{l}\text { He seeks every chance he } \\
\text { can to have fun. It is } \\
\text { important to him to do } \\
\text { things that give him } \\
\text { pleasure. }\end{array}$ & $\begin{array}{l}\text { He looks for adventures } \\
\text { and likes to take risks. } \\
\text { He wants to have an } \\
\text { exciting life. }\end{array}$ & $\begin{array}{l}\text { Being very successful is } \\
\text { important to him. He } \\
\text { hopes people will } \\
\text { recognize his } \\
\text { achievements. }\end{array}$ \\
\hline & $\begin{array}{l}\text { He strongly believes that } \\
\text { people should care for } \\
\text { nature. Looking after the } \\
\text { environment is } \\
\text { important to him. }\end{array}$ & & & \\
\hline
\end{tabular}

Source: European Social Survey; Schwartz 2003; Davidov et al. 2008: 427-428. 
To this point, we have discussed on a theoretical basis how these value variables correspond to the two contending interpretations of individualization. In the following, we will provide statistical support for our arguments. In order to test whether the number of dimensions and the statistical correspondence of the indicators for these dimensions conform to our theoretical expectations, we conduct a confirmatory factor analysis as well as reliability tests, the results of which can be taken from table 7.6 below.

Table 7.6 Dimensional analyses with the value items

\begin{tabular}{lcc}
\hline \multicolumn{1}{c}{ Value Items } & Factor 1 & Factor 2 \\
\hline Important to seek adventures and have an exciting life (STIM) & .709 & \\
Important to seek fun and things that give (HED) & .695 & \\
$\begin{array}{l}\text { Important to be successful and that people recognize } \\
\text { achievements (ACH) }\end{array}$ & .683 & .645 \\
$\begin{array}{l}\text { Important to show abilities and be admired (ACH) } \\
\text { Important to have a good time (HED) }\end{array}$ & .615 & \\
Important to try new and different things in life (STIM) & .613 & .736 \\
\hline Important to understand different people (UNI) & & .678 \\
Important to care for nature and environment (UNI) & & .672 \\
Important that people are treated equally and have equal & & .466 \\
opportunities (UNI) & & .452 \\
Important to think new ideas and being creative (SELF) & & \\
Important to make own decisions and be free (SELF) & & \\
\hline
\end{tabular}

Confirmatory factor analysis based on ESS 2002/2003, data weighted by population weight. Entries are factor loadings.

The results of the factor analysis are in line with our argument that the items presented in table 7.5 build two different dimensions; they cluster with each other in the expected way. Each item is ordered according to the correlating dimension, illustrated by their factor loading $s^{53}$. Only the indicators of self-direction values appear to have lower correlations with both factors, which can be an effect of its simultaneous correlation with hedonism and stimulation. However, as it correlates more strongly with the second dimension, together with universalism values, we can regard this as supporting our argument that these values can be classified within the self-expression dimension. Furthermore, the results of the reliability tests we have conducted, by calculating the Cronbach's Alpha statistics for each dimension, have

\footnotetext{
${ }^{53}$ Factor loadings refer to the correlation coefficients between the factors (dimensions) and the items.
} 
given support to our expectation on the internal consistency of these dimensions. The self-expression dimension (self-direction and universalism) has a Cronbach's Alpha coefficient of 0.62 and the hedonism dimension 0.76 , which again provides support for our expectations ${ }^{54}$.

In the analyses which follow in chapter 8 we will use the values self-direction, universalism, achievement, hedonism, and stimulation as indices consisting of the items presented in table 7.5. These indices are computed by using the mean scores of the respective items associated with them ${ }^{55}$. We prefer this method to the alternative approach of building indices by simply adding the item values together since it ensures that as many respondents as possible get a valid value on the index. Thus, we hope to minimize the disadvantages that may arise from a high number of missing cases. Furthermore, these indices will be corrected for individual value "priorities", which are thought to have higher relevance for individual behavior. The raw values indicate the extent that respondents identify themselves with these values; yet the priorities are about the relative importance of these values to a person compared to other values. Therefore, we take the "centered value scores" of each individual for computing indices of value priorities, which are calculated by the distance of the absolute score of an individual for each value from his mean score on all answered value items. This helps locate the relative importance of each value in the individual's whole value system.

\subsubsection{Measurement of control variables}

As for the measurement of value orientations, we will also choose the indicators from the ESS 2002/03 for our control variables. For the measurement of cognitive mobilization we will rely on two indicators: media use and education. For the sake of comparability, we chose to measure education of the respondent by the years of completed formal education. Media use is an index composed of three items: the time spent on an average weekday with watching TV, listening to the radio, and reading newspapers to gather information about current political affairs.

New political orientations, which are - as discussed above - thought to result from the process of cognitive mobilization, will be measured by two indicators: internal political efficacy and political dissatisfaction. In the ESS 2002/03, internal

\footnotetext{
${ }^{54}$ Although the rule of thumb for the statistical reliability of a scale is that Cronbach's Alpha should be 0.70 or higher, slightly lower coefficients are also considered as acceptable in most of social science research.

${ }^{55}$ For a more detailed discussion on the practical use of the value items in the ESS by Schwartz see http://essedunet.nsd.uib.no/cms/topics/1/
} 
political efficacy is measured through three questions relating to the perceived complexity of politics, perceived own ability to take active role in politics, and perceived own ability to make up mind on political issues. We use, however, only the first and the last item to measure efficacy in our model since the item on perceived ability to take active role in politics would correlate too high with actual political participation. Political dissatisfaction will be measured through two groups of items. The first consists of those items which capture the (dis-)satisfaction with the state of economy, education, and health services in country, with the national government, and with the way democracy works in that country. As we discussed above, dissatisfaction with policies and institutions can be regarded as an indicator of stake in political issues and increase the likelihood of participating with instrumental motivations. The second group includes items on political cynicism, (or external political efficacy) which are measured by the two statements: "Politicians in general do not care what people like me think" and "Politicians are interested in votes rather than people's opinions". Convictions of this type may in most cases lead to a feeling of political powerlessness, which may end up in prioritizing non-political incentives and participating expressively. Age, finally, is measured by subtracting the respondent's year of birth from the survey year 2002. 


\section{Chapter 8}

\section{Values and Political Involvement: Testing the Causal Model}

In this chapter we will test the effect of self-expression and self-orientation values on the instrumental and expressive involvement types and therefore the hypotheses $\mathrm{H} 5 \mathrm{a}, \mathrm{H} 5 \mathrm{~b}, \mathrm{H} 6$, and H7. To test the alternative hypotheses on which values are prevalent in post-industrial societies ( $\mathrm{H} 5 \mathrm{a} \& \mathrm{H} 5 \mathrm{~b})$, we will analyze the distribution of self-expression and self-orientation values on a pooled basis as well as within countries. To test the hypotheses $\mathrm{H} 6$ and H7, we will make use of bivariate correlation analysis between the involvement types, values, and the control variables. This shall give us an idea about the strength and direction of the relationship between these variables.

We will then continue to test these relationships in a model where the individual effect of each influence factor is controlled by others. As discussed in the former chapter, we will make use of binary logistic regressions, which appear to be the most appropriate method to test the assumed relationships since our dependent variable consists of two types of involvement. We will first test the value effects on involvement types on a pooled basis and in four steps. In the first step we will test for the value effects where we include only self-expression and self-orientation values in the model. In a second step we will test for the same effects under the control of new political orientations (internal efficacy, political cynicism, and dissatisfaction with policies, government, and democracy). In the third step we will add cognitive mobilization indicators (education and media use) to the model. Finally, we will test the whole model under the control of age. Also, both bivariate and regression analyses will be repeated for individual countries to see if there are cross-country variations in the effects. 


\subsection{Distribution of Values among Post-Industrial Countries: Descriptive Analysis}

In the following, we will observe individuals' value priorities in the analyzed countries and thus test hypotheses H5a and H5b. Since it is the main argument of the modernization theories that post-industrial societies will have value systems which are similar to each other, we need to test this premise before we continue with the causal effects of these values on political involvement. The distribution of values is presented in table 8.1 below.

Table 8.1 Mean levels of value orientations in countries

\begin{tabular}{lccccc}
\hline Hedonism & Stimulation & $\begin{array}{c}\text { Achieve- } \\
\text { ment }\end{array}$ & $\begin{array}{c}\text { Self- } \\
\text { Direction }\end{array}$ & Universalism \\
\hline Austria & -0.18 & -0.67 & -0.17 & 0.53 & 0.61 \\
Belgium & $(2209)$ & $(2209)$ & $(2209)$ & $(2209)$ & $(2209)$ \\
Denmark & 0.19 & -0.63 & -0.53 & 0.37 & 0.58 \\
& $(1819)$ & $(1817)$ & $(1819)$ & $(1815)$ & $(1819)$ \\
Finland & 0.22 & -0.54 & -0.57 & 0.68 & 0.51 \\
& $(1457)$ & $(1456)$ & $(1456)$ & $(1457)$ & $(1457)$ \\
France & -0.27 & -0.46 & -0.73 & 0.45 & 0.76 \\
& $(1757)$ & $(1758)$ & $(1758)$ & $(1758)$ & $(1758)$ \\
Ireland & 0.13 & -0.55 & -0.83 & 0.49 & 0.79 \\
& $(1327)$ & $(1327)$ & $(1327)$ & $(1327)$ & $(1327)$ \\
Netherlands & -0.56 & -0.66 & -0.39 & 0.43 & 0.58 \\
& $(1842)$ & $(1842)$ & $(1842)$ & $(1842)$ & $(1842)$ \\
Norway & 0.04 & -0.55 & -0.50 & 0.52 & 0.55 \\
Sweden & $(2311)$ & $(2311)$ & $(2311)$ & $(2311)$ & $(2311)$ \\
& -0.36 & -0.57 & -0.52 & 0.47 & 0.60 \\
Switzerland & $(1807)$ & $(1807)$ & $(1807)$ & $(1807)$ & $(1807)$ \\
& 0.04 & -0.59 & -0.58 & 0.53 & 0.66 \\
UK & $(1677)$ & $(1677)$ & $(1677)$ & $(1676)$ & $(1677)$ \\
& 0.21 & -0.65 & -0.54 & 0.69 & 0.75 \\
W. Germany & $(2008)$ & $(2007)$ & $(2008)$ & $(2008)$ & $(2008)$ \\
& -0.35 & -0.45 & -0.36 & 0.51 & 0.52 \\
& $(1749)$ & $(1749)$ & $(1749)$ & $(1749)$ & $(1749)$ \\
& -0.13 & -0.78 & -0.49 & 0.64 & 0.65 \\
& $(2113)$ & $(2113)$ & $(2113)$ & $(2113)$ & $(2113)$ \\
\hline & -0.10 & -0.61 & -0.56 & 0.55 & 0.65 \\
& $(17567)$ & $(17563)$ & $(17567)$ & $(17565)$ & $(17567)$ \\
\hline
\end{tabular}

Source: European Social Survey, 2002/03

Entries are the means of the centered value scores calculated over the whole population. The range of these scores is different for each variable. Hedonism varies between -3.76 and 3.25. Stimulation varies between -4.25 and 2.90. Achievement varies between -4.14 and 3.25. Self-direction varies between -3.21 and 3.44. Finally, universalism varies between -2.57 and 3.19 .

The number of respondents is given in the parentheses. For individual country analyses the design weight was used. For the pooled analysis we applied the population weight. 
As discussed in the last chapter, we avoided using the raw ratings of values and preferred the centered value scores since these scores give the relative importance of this value orientation for the respondent. Accordingly, a positive score for a value would mean that the individual puts an above average emphasis on this value, and higher scores mean higher priority given to this value orientation. Contrarily, negative scores for a value orientation point to a lower importance of the value for the individual; the lower the score, the lower the priority. The mean levels of these figures in table 8.1 indicate in the first instance that self-expression values are clearly more emphasized over self-orientation values in all countries. Their mean centered value scores are positive and higher than those of self-orientation values, which score below 0 in most of the countries. This means that self-orientation has less relevance for the citizens of post-industrial societies, but we should take into consideration that this difference is not very pronounced. On the average, universalism is the value orientation with the highest priority among the post-industrial democracies, followed by self-direction. Achievement, hedonism, and stimulation score relatively lower in general; still, the hedonist values take mean scores above 0 in half of the analyzed countries, indicating that this value orientation has a relatively higher priority in these societies ${ }^{56}$. The results thus seem to support hypothesis H5a and thus the arguments of the theory of human development at first glance, since in none of the observed countries the mean levels of self-orientation values exceeds the levels of self-expression values; yet it is striking that the self-orientation values are also present in these societies to a notable extent. It would be helpful to observe the development of these values over time in order to predict if these values tend to take over in time or if self-expression orientations are likely to remain the prevalent values, yet unfortunately no longitudinal data covering these value orientations are available to make such an observation.

The question remains if these values are related to political involvement. A recent study into the relationship between Schwartz's value dimensions and political participation has found empirical support for the hypothesis that openness and selftranscendence values will be associated with higher levels of political participation (Besley 2006). Both increased openness to change and values associated with a desire to transcend the individual seem to be related to a higher number of participatory

\footnotetext{
56 It is remarkable that some of these countries - Belgium, France, and Switzerland - also turned out to have considerably high or increasing levels of expressive political involvement, as analyses in chapter 6 have shown. However, Denmark and the Netherlands, two countries where instrumental political involvement seems to have been increasing, score also higher on hedonism. Therefore, it is not yet possible to establish links between the values and involvement types on the basis of these results.
} 
acts. However, it is still an open question if and in what way they are related to political participation with or without political motivation. Therefore, we move further to analyze the relationship between these values and the types of political involvement.

As mentioned above, we will test bivariate correlations and then conduct stepwise logistic regression analyses to test hypotheses H6 and H7 on the effects of our independent constructs on political involvement. Before doing this, however, we consider it as necessary to first test how the independent variables and control variables are related to each other using pooled data. Providing insights into these relationships is important at this stage, since they can be relevant for interpreting the results of the causal analyses which will be presented in the next sections. Besides, it is essential to check for the strength of the correlations between these variables beforehand since correlations between independent variables that are too high referred to as "multicollinearity" - can create a serious problem in multivariate regression analysis. The correlation matrix presented in table 8.2 leads to the conclusion that our upcoming multivariate analyses are not likely to be endangered by multicollinearity, since the correlations between the variables are not very strong.

Focusing upon the correlations between values we can observe that achievement, hedonism, and stimulation show a significant positive association with each other; the same applies to self-direction and universalism as well ${ }^{57}$. Moreover, the negative relationships between the two value groups support the idea that they belong to opposing dimensions. The results of the factor analysis in the previous chapter (see table 7.6) thus seem to be confirmed here once again ${ }^{58}$.

\footnotetext{
${ }^{57}$ However, due to the large sample size (approximately 9000) these significance levels should be approached with caution.

${ }^{58}$ The only irregularity is the positive significant relationship between stimulation and selfdirection. This in fact is not very surprising, since in Shalom Schwartz's original work, the values stimulation and self-direction have been also found to build a dimension together (openness to change), whereas self-direction and universalism have been found to belong to different dimensions (universalism belongs to the dimension of self-transcendence, see e.g. Davidov et al. 2008 for a detailed description). Yet, as we have discussed at length in chapter 7, we will not adhere to this original conceptualization here. Based on our theoretical background we suggest that the original dimensions of openness to change and selftranscendence only partly overlap with self-expression values, i.e. only the aspects of selfdirection and universalism are related to self-expression values.
} 
Table 8.2 Correlation matrix independent variables

\begin{tabular}{|c|c|c|c|c|c|c|c|c|c|c|c|c|c|}
\hline & $\begin{array}{c}\text { Hedo- } \\
\text { nism }\end{array}$ & $\begin{array}{l}\text { Stimu- } \\
\text { lation }\end{array}$ & $\begin{array}{c}\text { Achieve- } \\
\text { ment }\end{array}$ & $\begin{array}{c}\text { Self- } \\
\text { Direction }\end{array}$ & $\begin{array}{c}\text { Univer- } \\
\text { salism }\end{array}$ & $\begin{array}{c}\text { Educa- } \\
\text { tion }\end{array}$ & $\begin{array}{c}\text { Media } \\
\text { use }\end{array}$ & $\begin{array}{l}\text { Internal } \\
\text { efficacy }\end{array}$ & $\begin{array}{l}\text { Political } \\
\text { cynicism }\end{array}$ & $\begin{array}{l}\text { Policy } \\
\text { disstf. }\end{array}$ & $\begin{array}{l}\text { Disstf. } \\
\text { gov. }\end{array}$ & $\begin{array}{c}\text { Disstf. } \\
\text { democracy }\end{array}$ & Age \\
\hline Hedonism & 1.00 & & & & & & & & & & & & \\
\hline Stimulation & $.28^{* * *}$ & 1.00 & & & & & & & & & & & \\
\hline Achievement & $.06^{* * *}$ & $.13^{* * *}$ & 1.00 & & & & & & & & & & \\
\hline Self-Direction & $-.02^{* *}$ & $.14^{* * *}$ & $-.06^{* * *}$ & 1.00 & & & & & & & & & \\
\hline Universalism & $-.23^{* * *}$ & $-.15^{* * *}$ & $-.37^{* * *}$ & $.09^{* * *}$ & 1.00 & & & & & & & & \\
\hline Education & $.06^{* * *}$ & $.18^{* * *}$ & $.14^{* * *}$ & $.17^{* * *}$ & $.08^{* * *}$ & 1.00 & & & & & & & \\
\hline Media use & $-.09^{* * *}$ & $-.03^{* * *}$ & $-.07^{* * *}$ & $.07^{* * *}$ & $.08^{* * *}$ & .01 & 1.00 & & & & & & \\
\hline Internal efficacy & $-.04^{* * *}$ & $.08^{* * *}$ & $.10^{* * *}$ & $.19^{* * *}$ & $.04^{* * *}$ & $.24^{* * *}$ & $.14^{* * *}$ & 1.00 & & & & & \\
\hline Political cynicism & .00 & $-.06^{* * *}$ & $-.05^{* * *}$ & $-.01^{+}$ & $-.07^{* * *}$ & $-.17^{* * *}$ & $-.05^{* * *}$ & $-.17^{* * *}$ & 1.00 & & & & \\
\hline Policy dissatisfaction & .01 & $.01^{+}$ & $-.03^{* * *}$ & $.07^{* * *}$ & $.02^{*}$ & $.02^{*}$ & .01 & $-.02 *$ & $.29^{* * *}$ & 1.00 & & & \\
\hline Disstf. government & .01 & .01 & .00 & $.08^{* * *}$ & -.01 & .01 & -.01 & .01 & $.35^{* * *}$ & $.55^{* * *}$ & 1.00 & & \\
\hline Disstf. democracy & .01 & $.04^{* * *}$ & $-.05^{* * *}$ & $.04^{* * *}$ & -.01 & $-.09^{* * *}$ & $-.02^{*}$ & $-.12^{* * *}$ & $.33^{* * *}$ & $.46^{* * *}$ & $.50^{* * *}$ & 1.00 & \\
\hline Age & $-.33^{* * *}$ & $-.33^{* * *}$ & $-.25^{* * *}$ & $-.02^{* *}$ & $.10^{* * *}$ & $-.32^{* * *}$ & $.23^{* * *}$ & .01 & $.06^{* * *}$ & $-.03^{* * *}$ & .00 & .01 & 1.00 \\
\hline
\end{tabular}

Entries are Pearson's correlation coefficients.

${ }^{* * *} \mathrm{p}<=.001 ;{ }^{* *} \mathrm{p}<=.01 ;{ }^{*} \mathrm{p}<=.05 ;+\mathrm{p}<=.10$

Media use is an index out of the variables "Following political news on the TV" and "Following political news on the radio" and "Following political news in the newspaper". It has been measured on a scale between 0 (no media use) and 7 (very high media use).

Internal efficacy is an index out of the variables "Politics not complicated" and "Can make up mind about political issues" and has been measured on a scale between 1 (not at all efficacious) and 5 (highly efficacious).

Political cynicism is an index out of the variables "Politicians don't care" and "Politicians only interested in votes" and has been measured on a scale between 0 (low cynicism) and 4 (high cynicism).

Policy dissatisfaction is an index out of the variables "Dissatisfaction with the state of education in country", "Dissatisfaction with the state of health in country", and "Dissatisfaction with the state of economy in country", and has been measured on a scale between 0 (low dissatisfaction) and 10 (high dissatisfaction). 
We have specified in our causal model that cognitive mobilization indicators should not only be related to political involvement types, but also facilitate new political orientations as well (see table 7.1). The results of the bivariate correlation analysis verify that there is such a relationship, even though not always in the expected way. Both education and media use seem to boost feelings of political efficacy, and they are both negatively related to political cynicism - i.e. those who think that politicians do not care about ordinary people's opinions and demands and to dissatisfaction with the way democracy works. This means that people with higher education and those who frequently get information about politics through the media tend to be less cynical about politicians or dissatisfied with democracy. With the evaluations of specific policy outputs and of government they have either a weak relationship or none at all. Thus the common proposition of societal modernization theories, that cognitively mobilized citizens would be more critical towards the government and political actors, is not given any support by the results of bivariate correlation analysis. Also, the argument that frequent use of mass media to gather information about politics would cause "civic malaise", i.e. lead to a negative opinion climate about politics and political actors, is not affirmed by the findings.

Finally, we have specified in the causal model that age is expected to be related to cognitive mobilization and value orientations (see figure 7.1). Also this expectation is supported by the results. As the modernization theory would also predict, younger age groups indeed profit more from rising education opportunities, since their education levels are significantly higher than older people. With respect to media use, we find that younger people tend to use the media to gather political information less than older ones. This might seem like an unexpected phenomenon, since we would expect younger and higher educated generations to be more inclined to inform themselves about politics. Yet because the indicators we use are limited to classical media like TV, radio, and newspapers, it may be possible that young generations have distanced themselves from these information channels to make use of more modern tools such as the internet while older people continue getting relevant political information predominantly from these media sources. Value orientations are found to be related to age in different directions. Hedonism, stimulation, and achievement have a negative significant correlation with age, which means that self-orientation values are more common among young generations. Selfdirection, on the other hand, is also negatively related to age, yet the correlation is quite weak. Universalism, finally, is positively correlated with age, which means that this value is not a phenomenon of the youth. 
Though not specified in the causal model, it seems also necessary to say a few words on the relationship between cognitive mobilization indicators and values, as well as between new political orientations and values. While the education level correlates positively with all values, media use is negatively related to the selforientation values. Self-expression values, on the other hand, are likely to be more common among frequent media users. With respect to the associations between values and new political orientations, we obtain mixed results. Internal efficacy turns out to be positively related to all values except hedonism, with which it has a negative correlation. Political cynicism is weakly but negatively associated with all values variables except hedonism, which means that people emphasizing these values tend to be less cynical about the responsiveness of political actors to their demands. Negative evaluations of specific policy outputs or with government are negatively related to self-orientation values, yet those with self-expression values seem to have a tendency towards these critical attitudes. Finally, dissatisfaction with the way democracy works, which reflects a negative evaluation of the system rather than criticism towards its actors, is not unequivocally related to the two value sets. Respondents prioritizing achievement values tend rather to be satisfied with the way democracy works; dissatisfaction seems to be more common among those with stimulation and self-direction values, yet the coefficients are so weak that we can not definitely speak of a relationship between these variables.

All in all, the relationships between the independent variables are not strong enough to create a multicollinearity problem, yet the analyses have shown that all concepts - cognitive mobilization, new political orientations, values, and age - are indeed related to each other in various ways. As mentioned above, this provides us with helpful information for interpreting their controlled effects on instrumental and expressive political involvement types later on. Having observed these relationships, we can now move on to analyze their influences on the two political involvement types.

\subsection{Testing the Causal Model}

\subsubsection{Bivariate analyses}

In this section we will test hypotheses $\mathrm{H} 6$ and $\mathrm{H} 7$ to determine how self-expression and self-orientation value priorities, and the instrumental and expressive involvement types, are related to each other. For this purpose we will first test the bivariate correlations between expressive and instrumental involvement on the one 
hand and value orientations on the other. Also, the relationship between the involvement types and the control variables age, cognitive mobilization, and new political orientations will be tested in this way, since we expect these factors to also be related to expressive and instrumental types of involvement (see figure 7.1).

The pooled and country-by-country results of these analyses are presented in table 8.3. As political involvement is coded as 0 and 1, 0 refers to expressive political involvement and 1 to instrumental. A negative sign of the correlation coefficient means that the respective variable is associated with expressive involvement and a positive sign indicates that the variable is likely to promote instrumental political involvement. With respect to value orientations, the table shows clearly that selfexpression values - self-direction as well as universalism - are significantly correlated with instrumental political involvement, i.e. both on a pooled basis and in a majority of countries. These findings thus support hypothesis H6 in all countries, since the self-expression values which are predicted to be the value priorities of postindustrial citizens are indeed related to instrumental political involvement. For H7 it is not possible to draw a similar conclusion, however. In two of the twelve countries - namely Belgium and Switzerland - this hypothesis finds no support at all, since none of the self-orientation value indicators are correlated significantly with any type of political involvement. Hedonism seems to be associated with an inclination towards expressive political involvement in only three countries (France, the Netherlands, and Norway), where in other cases it has no significant relationship with any of the political involvement types.

Stimulation and achievement, contrary to all expectations, are not related to expressive political involvement at all. In most countries they do not have significant correlations with political involvement; in the few cases where the correlation coefficient turned out to be significant, they seem to relate with instrumental political involvement instead of expressive involvement. These findings thus contradict our hypothesis that self-orientation values would be associated with an expressive style of getting involved in political decision-making; it finds some support only in three cases, where the correlations are not very strong. One should however keep in mind that these partial corroborations of expectations can only be tentative since the effects are not controlled for the other factors. The observed correlations between values and involvement are also relatively weak, even though they are significant, which suggests that these variables can explain political involvement only to a limited extent. 
The found correlations between the control variables and the dependent variable provide contradictory evidence and support our expectations only partly. As hypothesized, high education levels and frequent media use to gather political information tend to go along with instrumental political involvement, so does internal efficacy. On the other hand, citizens with critical orientations towards political institutions and actors, such as political cynicism and dissatisfaction with the functioning of democracy, are rather inclined towards expressive political involvement. Based on the intercorrelations between the independent variables we can say that this latter finding is not very surprising. Indicators of cognitive mobilization and internal efficacy have turned out to go hand in hand with low levels of political cynicism and dissatisfaction (see table 8.2), thus we can expect that low cynicism will lead to instrumentally motivated involvement just as the others have. Thus the hypothesis that the so-called "critical citizens" are driven by a personal stake or by a sense of responsibility to take action about the issues of discontent is not affirmed by this finding. Rather, the expectation that dissatisfied citizens would be more prone to get involved in political activities with other motivations than achieving desired political outcomes - since they believe that the government does not respond to their demands - is given more support here. This is rather in line with the pessimistic interpretation of individualization by the theory of post-modern politics. Age, finally, correlates with instrumental political involvement, which means that older people are more inclined towards this involvement type. 
Table 8.3 Bivariate correlations of values and control factors with involvement types on a pooled basis and in individual countries

\begin{tabular}{|c|c|c|c|c|c|c|c|c|c|c|c|c|c|}
\hline & $\mathrm{AT}$ & BE & DK & FI & FR & IR & NL & NO & SE & $\mathrm{CH}$ & UK & WG & ALL \\
\hline Hedonism & -.02 & -.03 & .01 & .01 & $-.06^{+}$ & -.02 & $-.11^{* * *}$ & $-.12^{* * *}$ & .02 & -.03 & -.02 & -.05 & $-.03^{* *}$ \\
\hline Stimulation & .02 & .03 & $.11^{* * *}$ & .04 & .04 & $.06^{+}$ & $.06^{+}$ & .01 & $.13^{* * *}$ & .01 & $.13^{* * *}$ & .03 & $.05^{* * *}$ \\
\hline Achievement & .04 & .04 & .05 & $.10^{* *}$ & -.02 & .04 & .03 & .04 & $.13^{* * *}$ & .00 & $.06^{+}$ & $.05^{+}$ & $.05^{* * *}$ \\
\hline Self-Direction & $.17^{* * *}$ & $.06^{+}$ & $.14^{* * *}$ & $.13^{* * *}$ & $.11^{* *}$ & .06 & $.09^{* *}$ & $.16^{* * *}$ & $.16^{* * *}$ & $.12^{* * *}$ & $.12^{* * *}$ & $.10^{* * *}$ & $.13^{* * *}$ \\
\hline Universalism & $.08^{* *}$ & $.08^{*}$ & $.11^{* *}$ & .03 & $.14^{* * *}$ & $.16^{* * *}$ & $.09^{* *}$ & $.19^{* * *}$ & $.12^{* * *}$ & $.06^{+}$ & $.09^{* *}$ & $.10^{* * *}$ & $.10^{* * *}$ \\
\hline Education & $.20^{* * *}$ & $.17^{* * *}$ & $.26^{* * *}$ & $.20^{* * *}$ & $.20^{* * *}$ & $.16^{* * *}$ & $.26^{* * *}$ & $.23^{* * *}$ & $.27^{* * *}$ & $.17^{* * *}$ & $.25^{* * *}$ & $.25^{* * *}$ & $.22^{* * *}$ \\
\hline Media use & $.20^{* * *}$ & $.25^{* * *}$ & $.09^{* *}$ & $.13^{* * *}$ & $.22^{* * *}$ & $.25^{* * *}$ & $.12^{* * *}$ & $.15^{* * *}$ & $.18^{* * *}$ & $.25^{* * *}$ & $.22^{* * *}$ & $.28^{* * *}$ & $.20^{* * *}$ \\
\hline Internal efficacy & $.35^{* * *}$ & $.27^{* * *}$ & $.34^{* * *}$ & $.32^{* * *}$ & $.33^{* * *}$ & $.37^{* * *}$ & $.39 * * *$ & $.35^{* * *}$ & $.34^{* * *}$ & $.38^{* * *}$ & $.31^{* * *}$ & $.39^{* * *}$ & $.36^{* * *}$ \\
\hline Political cynicism & $-.14^{* * *}$ & $-.21^{* * *}$ & $-.24^{* * *}$ & $-.19^{* * *}$ & $-.18^{* * *}$ & $-.25^{* * *}$ & $-.16^{* * *}$ & $-.16^{* * *}$ & $-.21^{* * *}$ & $-.14^{* * *}$ & $-.19^{* * *}$ & $-.13^{* * *}$ & $-.17^{* * *}$ \\
\hline $\begin{array}{l}\text { Policy } \\
\text { dissatisfaction }\end{array}$ & .03 & -.03 & -.05 & .00 & .02 & -.03 & -.03 & .04 & .03 & $.05^{+}$ & -.03 & $.05^{+}$ & $.02^{*}$ \\
\hline $\begin{array}{l}\text { Dissatisfaction } \\
\text { with government }\end{array}$ & $.08^{*}$ & $-.10^{* *}$ & .05 & -.02 & .02 & n.a. & -.02 & .04 & -.02 & -.05 & -.04 & $.05^{+}$ & $.02^{+}$ \\
\hline $\begin{array}{l}\text { Dissatisfaction } \\
\text { with democracy }\end{array}$ & $.07^{*}$ & $-.13^{* * *}$ & $-.11^{* *}$ & $-.09^{* *}$ & $-.08^{*}$ & $-.07^{+}$ & -.05 & $-.05^{+}$ & $-.09^{* *}$ & $-.16^{* * *}$ & $-.06^{+}$ & $-.06^{*}$ & $-.10^{* * *}$ \\
\hline Age & $.10^{* *}$ & $.06^{+}$ & -.02 & -.01 & $.09^{*}$ & $.07^{*}$ & .03 & $.11^{* * *}$ & -.05 & $.10^{* * *}$ & -.04 & $.09^{* *}$ & .02 \\
\hline
\end{tabular}

Entries are correlation coefficients (Pearson's $\mathrm{r})$ with the variable involvement types $(0=$ expressive $1=$ instrumental)

${ }^{* * *} \mathrm{p}<=.001 ;{ }^{* *} \mathrm{p}<=.01 ;{ }^{*} \mathrm{p}<=.05 ;+\mathrm{p}<=.10$ 


\subsubsection{Testing the multivariate model}

As already discussed, the above displayed bivariate correlations between values and expressive and instrumental political involvement can provide solely tentative results for the test of hypotheses $\mathrm{H} 6$ and H7. We need to have more solid evidence in order to claim definitely which one of the hypotheses is more in line with the empirical reality. Therefore, we will test these relationships in a four-step model to control for the effects of other factors which also are supposed to have an effect on political involvement. It is essential to analyze the impact of various influence factors simultaneously, since relationships resulting from bivariate analyses are dependable only to a small extent. The first problem with such analyses is the so-called omitted variables bias: social phenomena are likely to be determined by a multitude of factors, and not taking other important determinants into consideration can result in biased estimations of the correlations. Thus even if one is interested in the effects of only one of the independent variables, it is essential to control the estimated effects by conducting a multivariate regression analysis including other influence factors. Moreover, it is a well-known fact that bivariate correlations can be flawed by the problem of endogeneity, which means that spurious relationships between variables may result due to several factors such as the correlation of error terms. We can speak of a non-spurious relationship only if the correlation does not disappear when controlled for other factors.

In the following we will briefly discuss logistic regression analysis, the method we will make use of to test the multivariate model. Following upon this, we will present and discuss our results.

\subsubsection{The logistic regression model}

Since our dependent variable is nominal-dichotomous, we have to decide on a method which is appropriate for the explanation of dependent variables at this measurement level. This is an essential thing to do, since "[i]f the model chosen assumes the wrong level of measurement, the estimator could be biased, inefficient, or simply inappropriate" (Long 1997: 3). We decide here to make use of the logistic regression model, which is directed at estimating the relationship between a dichotomous dependent variable and at least one independent variable. Dichotomous dependent variables generally measure the occurrence of an event and have only two possible, mutually exclusive values, 0 and 1, where 0 stands for "event does not occur" and 1 for "event occurs". The logistic regression is aimed at finding the influence of the independent variable $(X)$ on the occurring event, in other words the probability of the dependent variable $(\mathrm{Y})$ taking the value 0 or 1 . With this 
method it is also possible to analyze with which probability the dependent variable will take the value 1 for which value of the independent variable.

It is, of course, also possible to analyze variables with dichotomous responses using linear regression analysis. The resulting model is known as the linear probability model (LPM). To be precise, this model is the Ordinary Least Squares (OLS) applied to a binary dependent variable, which is based on the simple equation:

$$
Y_{i}=\beta 0+\beta X_{i}+\varepsilon_{i}
$$

Interpretation of the coefficients from a linear probability model is straightforward: for every unit change in $\mathrm{X}$, holding all other variables constant, the expected change in the probability of an event occurring $(Y)$ is $\beta$. Since the model is linear on the probability scale, a unit change in $X$ always results in the same change in the probability of $\mathrm{Y}$. In spite of the advantages of using the least squares estimation and the simplicity of its interpretation, the LPM has also a number of drawbacks. The most important disadvantage of using the LPM is the linearity assumption, which implies that the probabilities increase by $\beta$ units as $X$ increases by one unit, regardless of the current value of $X$ and other independent variables in the model. This is because the marginal effect (the ratio of the change in $Y$ to the change in $X$, holding other independent variables constant) is the same at all values of $X$.

The logit model provides an alternative to the LPM model, since it is based on the assumption that there is a non-linear relationship between $\mathrm{Y}$ and independent variables; the specification allows for an S-shaped relationship, which means that the effect of predictors is not constant. The effect of a unit change in $\mathrm{X}$ differs according to the level of all independent variables in the model, and the same increase in X can have vastly different effects depending on the initial value. The marginal effect of $Y$ with respect to $\mathrm{X} 1$ is a function of both $\mathrm{X} 1$ and $\mathrm{X} 2$. In general, the effect of a unit change in a variable depends on the values of all variables in the model and is no longer simply equal to a parameter of the model. The logit model entails complex functional forms that are non-linear in the parameters. The least squares estimation is poorly equipped to handle these kinds of models, thus an alternative estimation method, namely the maximum likelihood estimation (MLE) is being used in these models. This estimation method is flexible and can handle both linear and non-linear models and it has desirable asymptotic properties such as consistency, efficiency, and normality. Its most known drawbacks are that it requires distributional assumptions (which are not required by OLS) and that it is less suited for small samples. However, this latter point will not form a disadvantage for our study purposes since we work with a large number of respondents. 


\subsubsection{The results}

As mentioned while introducing this chapter, we will first test the model using the pooled data in four steps. The findings are presented in table 8.4 below. The first model, where the effect of each single value is estimated under the control of other values, has a weak overall fit (Pseudo- $\mathrm{R}^{2}$ is equal to 0.03 which means that it can explain only $3 \%$ of the variance), but it provides some support for hypothesis H6. Self direction and universalism values are significantly related to instrumental political involvement, which supports the expectation derived from the theory of human development. About the alternative hypothesis H7, there is again here ambiguity. Hedonism is not related to expressive political involvement; stimulation and achievement, on the other hand, both seem to be associated with instrumental political involvement. This hypothesis, derived from the theory of post-modern politics, is thus not supported by the findings. As a next step we will check what these effects are under other conditions, i.e. the attitudinal disposition of the respondents as well as their cognitive capacities and their age.

To control for the value effects we first add the new political orientations (efficacy, cynicism, and political dissatisfaction) to the model. In model 2, we find that self-expression values (self direction and universalism) are again significantly associated with instrumental political involvement, but their effects are somewhat weakened. The effects of self-orientation values found in model 1 remain the same, with weaker relationships of stimulation and achievement with instrumental political involvement ${ }^{59}$. As cognitive mobilization indicators (model 3) are also introduced into the model, the effect of stimulation on instrumental involvement disappears. In the final model, where all control variables are included, only achievement, self-direction, and universalism values seem to matter in explaining political involvement. Under the control of age, hedonism is also related to instrumental behavior, but the effect is only marginal. In sum, hypothesis H6, derived from the theory of human development, is supported by the findings of the logistic regression model, as self-direction and universalism have repeatedly been found to be related to instrumental involvement also under the control of other factors. On the other hand $\mathrm{H} 7$, the alternative hypothesis related to the theory of post-modern politics, appears not to be valid.

\footnotetext{
${ }^{59}$ It should be noted here that particularly the effect of stimulation is quite weak and the significance can be due to the high number of respondents in the pooled data.
} 
Table 8.4 Stepwise logit analysis with pooled data

\begin{tabular}{|c|c|c|c|c|c|c|c|c|}
\hline & \multicolumn{2}{|c|}{ Model 1} & \multicolumn{2}{|c|}{ Model 2} & \multicolumn{2}{|c|}{ Model 3} & \multicolumn{2}{|c|}{ Model 4} \\
\hline Hedonism & -.01 & $(.02)$ & -.01 & $(.03)$ & .03 & (.03) & $.05^{+}$ & $(.03)$ \\
\hline Stimulation & $.08^{* * *}$ & $(.02)$ & $.04^{+}$ & (.02) & .02 & (.03) & .04 & (.03) \\
\hline Achievement & $.25^{* * *}$ & $(.02)$ & $.15^{* * *}$ & (.03) & $.16^{* *}$ & (.03) & $.18^{* * *}$ & $(.03)$ \\
\hline Self-Direction & $.35^{* * *}$ & (.03) & $.21^{* * *}$ & (.03) & $.19^{* * *}$ & (.03) & $.19^{* * *}$ & $(.03)$ \\
\hline Universalism & $.44^{* * *}$ & (.03) & $.36^{* * *}$ & $(.04)$ & $.34^{* * *}$ & (.04) & $.34^{* * *}$ & $(.04)$ \\
\hline Internal efficacy & & & $.88^{* * *}$ & $(.03)$ & $.82^{* * *}$ & (.03) & $.81^{* * *}$ & $(.03)$ \\
\hline Political cynicism & & & $-.34^{* * *}$ & $(.03)$ & $-.31^{* * *}$ & (.03) & $-.31^{* * *}$ & $(.03)$ \\
\hline Policy dissatisfaction & & & $.08^{* * *}$ & $(.02)$ & $.07^{* * *}$ & (.02) & $.07^{* * *}$ & $(.02)$ \\
\hline Disstf. with government & & & $.07^{* * *}$ & $(.01)$ & $.06^{* * *}$ & $(.01)$ & $.06^{* * *}$ & $(.01)$ \\
\hline Disstf. with democracy & & & $-.08^{* * *}$ & $(.01)$ & $-.08^{* * *}$ & (.01) & $-.08^{* * *}$ & $(.01)$ \\
\hline Education & & & & & $.11^{* * *}$ & $(.01)$ & $.12^{* * *}$ & $(.01)$ \\
\hline Media use & & & & & $.47^{* * *}$ & (.03) & $.46^{* * *}$ & $(.03)$ \\
\hline Age & & & & & & & $.07^{* *}$ & $(.02)$ \\
\hline Constant & $.30^{* * *}$ & $(.03)$ & $-1.79^{* * *}$ & (.13) & $-3.78^{* * *}$ & $(.18)$ & $-4.01^{* * *}$ & $(.20)$ \\
\hline Pseudo-R² & .0 & & .13 & & .16 & & .16 & \\
\hline Log likelihood & -725 & & -5830 & & -5589 & & -5551 & \\
\hline Correct classifications (\%) & 66 & & 72.2 & & 73. & & 73. & \\
\hline $\mathrm{N}$ & 11 & & 106 & & 105 & & 105 & \\
\hline
\end{tabular}

Entries are regression coefficients; ${ }^{* *} \mathrm{p}<=.001 ;{ }^{* *} \mathrm{p}<=.01 ;{ }^{*} \mathrm{p}<=.05 ;+\mathrm{p}<=.10$; standard errors in parentheses. Dependent variable: Involvement types $0=$ expressive 1=instrumental.

The control variables - new political orientations, cognitive mobilization, and age - also prove to be important factors that drive political involvement, although they turned out to be related to different types. As the results of bivariate analyses have also indicated, feelings of internal political efficacy, high education, frequent media use, and older age lead to instrumental political involvement; dissatisfaction with specific policy issues and the government also generate this involvement type. Political cynicism and dissatisfaction with democracy again seem to be determinants of expressive political involvement. The addition of control variables moreover improve the overall fit of the explanatory model, suggested by the increasing value of Pseudo- $\mathrm{R}^{2}$ and the increasing percentage of correct classifications.

In the following we will test the relationships in individual countries to see if this pattern is common to all twelve European countries. Table 8.5 illustrates the results of the binary logistic regressions for model 1 in individual countries. 
Table 8.5 Logit analyses with values in twelve countries

\begin{tabular}{|c|c|c|c|c|c|c|}
\hline & AT & BE & DK & FI & FR & IR \\
\hline Hedonism & $\begin{array}{l}-.02 \\
(.08)\end{array}$ & $\begin{array}{l}-.02 \\
(.08)\end{array}$ & $\begin{array}{l}.05 \\
(.09)\end{array}$ & $\begin{array}{l}.05 \\
(.08)\end{array}$ & $\begin{array}{c}-.15^{+} \\
(.09)\end{array}$ & $\begin{array}{l}.02 \\
(.08)\end{array}$ \\
\hline Stimulation & $\begin{array}{l}-.09 \\
(.07)\end{array}$ & $\begin{array}{l}.04 \\
(.07)\end{array}$ & $\begin{array}{l}.20^{* *} \\
(.07)\end{array}$ & $\begin{array}{l}.02 \\
(.08)\end{array}$ & $\begin{array}{l}.15^{+} \\
(.09)\end{array}$ & $\begin{array}{l}. \mathbf{1 4}^{+} \\
(.08)\end{array}$ \\
\hline Achievement & $\begin{array}{l}.22^{* *} \\
(.08)\end{array}$ & $\begin{array}{l}.16^{*} \\
(.08)\end{array}$ & $\begin{array}{c}.24^{* *} \\
(.08)\end{array}$ & $\begin{array}{c}. \mathbf{3 0}^{* * * *} \\
(.08)\end{array}$ & $\begin{array}{l}.10 \\
(.08)\end{array}$ & $\begin{array}{c}.26^{* *} \\
(.09)\end{array}$ \\
\hline Self-Direction & $\begin{array}{c}.47^{* * *} \\
(.10)\end{array}$ & $\begin{array}{l}.12 \\
(.10)\end{array}$ & $\begin{array}{c}.35^{* * *} \\
(.10)\end{array}$ & $\begin{array}{c}.38^{* * *} \\
(.10)\end{array}$ & $\begin{array}{l}.26^{*} \\
(.10)\end{array}$ & $\begin{array}{l}.12 \\
(.11)\end{array}$ \\
\hline Universalism & $\begin{array}{l}.27^{*} \\
(.11)\end{array}$ & $\begin{array}{c}.39^{* *} \\
(.13)\end{array}$ & $\begin{array}{c}. \mathbf{4 8} 8^{* * *} \\
(.12)\end{array}$ & $\begin{array}{l}.29^{*} \\
(.12)\end{array}$ & $\begin{array}{c}.38^{* *} \\
(.12)\end{array}$ & $\begin{array}{c}.65^{* * *} \\
(.14)\end{array}$ \\
\hline Constant & $\begin{array}{l}.37^{* *} \\
(.13)\end{array}$ & $\begin{array}{l}-.08 \\
(.13)\end{array}$ & $\begin{array}{c}.53^{* * *} \\
(.13)\end{array}$ & $\begin{array}{l}.33^{* *} \\
(.12)\end{array}$ & $\begin{array}{l}.09 \\
(.15)\end{array}$ & $\begin{array}{l}.02 \\
(.13)\end{array}$ \\
\hline Pseudo R2 & .03 & .01 & .04 & .03 & .03 & .03 \\
\hline Log likelihood & -586.18 & -589.90 & -510.53 & -632.13 & -461.38 & -497.47 \\
\hline Corr. classifications (\%) & 71.4 & 55.7 & 69.6 & 64.2 & 61.4 & 60.6 \\
\hline \multirow[t]{2}{*}{$\mathrm{N}$} & 1009 & 864 & 869 & 982 & 704 & 756 \\
\hline & NL & NO & SE & $\mathrm{CH}$ & UK & WG \\
\hline Hedonism & $\begin{array}{c}-.28^{* *} \\
(.10)\end{array}$ & $\begin{array}{l}-.16^{+} \\
(.08)\end{array}$ & $\begin{array}{l}.12^{+} \\
(.07)\end{array}$ & $\begin{array}{l}.05 \\
(.08)\end{array}$ & $\begin{array}{l}.04 \\
(.07)\end{array}$ & $\begin{array}{l}-.11 \\
(.10)\end{array}$ \\
\hline Stimulation & $\begin{array}{l}.22^{*} \\
(.09)\end{array}$ & $\begin{array}{l}.06 \\
(.08)\end{array}$ & $\begin{array}{c}.22^{* * *} \\
(.07)\end{array}$ & $\begin{array}{l}-.01 \\
(.07)\end{array}$ & $\begin{array}{c}.25^{* * *} \\
(.07)\end{array}$ & $\begin{array}{l}.08 \\
(.09)\end{array}$ \\
\hline Achievement & $\begin{array}{l}. \mathbf{1 8} \\
(.09)\end{array}$ & $\begin{array}{c}.34^{* * *} \\
(.08)\end{array}$ & $\begin{array}{c}.48^{* * *} \\
(.08)\end{array}$ & $\begin{array}{l}.15^{*} \\
(.07)\end{array}$ & $\begin{array}{c}.24^{* * * *} \\
(.07)\end{array}$ & $\begin{array}{c}.26^{* *} \\
(.10)\end{array}$ \\
\hline Self-Direction & $\begin{array}{l}.18 \\
(.12)\end{array}$ & $\begin{array}{c}. \mathbf{4 8} \\
(.09 * * \\
\end{array}$ & $\begin{array}{c}.36^{* * *} \\
(.08)\end{array}$ & $\begin{array}{c}.38^{* * * *} \\
(.09)\end{array}$ & $\begin{array}{c}.28^{* * *} \\
(.08)\end{array}$ & $\begin{array}{l}.24^{*} \\
(.12)\end{array}$ \\
\hline Universalism & $\begin{array}{l}.30^{*} \\
(.15)\end{array}$ & $\begin{array}{c}.76^{* * *} \\
(.12)\end{array}$ & $\begin{array}{c}.68^{* * * *} \\
(.10)\end{array}$ & $\begin{array}{l}.19^{+} \\
(.11)\end{array}$ & $\begin{array}{c}.36^{* * * *} \\
(.10)\end{array}$ & $\begin{array}{c}. \mathbf{4 2} * * * \\
(.13)\end{array}$ \\
\hline Constant & $\begin{array}{c}.95^{* * *} \\
(.15)\end{array}$ & $\begin{array}{l}.17 \\
(.11)\end{array}$ & $\begin{array}{l}.17 \\
(.11)\end{array}$ & $\begin{array}{c}.67^{* * * *} \\
(.13)\end{array}$ & $\begin{array}{l}.17^{+} \\
(.10)\end{array}$ & $\begin{array}{l}.89^{* * * *} \\
(.15)\end{array}$ \\
\hline Pseudo R ${ }^{2}$ & .03 & .07 & .06 & .02 & .03 & .02 \\
\hline Log likelihood & -509.34 & -629.30 & -768.78 & -747.80 & -676.54 & -485.34 \\
\hline Corr. classifications (\%) & 74.2 & 68.8 & 64.4 & 73.3 & 61.2 & 76.9 \\
\hline $\mathrm{N}$ & 920 & 1067 & 1225 & 1310 & 1032 & 919 \\
\hline
\end{tabular}

Entries are regression coefficients; ${ }^{* * *} \mathrm{p}<=.001 ;{ }^{* *} \mathrm{p}<=.01{ }^{*} \mathrm{p}<=.05 ;+\mathrm{p}<=.10$

Dependent variable: Involvement types $0=$ expressive $1=$ instrumental 
With respect to the effects of achievement, self-direction, and universalism, the findings in individual countries are generally in line with the findings provided by the first model of the pooled logit analysis. Controlled for the other values, selfexpression values - either self-direction or universalism or in some cases both - turn out to be significantly related to instrumental political involvement in a majority of cases; thus $\mathrm{H} 6$ can be confirmed also within individual post-industrial countries. Yet for the first time it is not possible to draw a certain conclusion about hypothesis H7, derived from the theory of post-modern politics. As it was the case in pooled analyses, achievement correlates with instrumental political involvement in almost all countries (except for Ireland); stimulation has the same effect in only some countries. However, in four countries - France, the Netherlands, Norway, and Sweden - hedonist values are indeed related to expressive political involvement, which simultaneously confirms H7 for these countries. In sum, the within-country analyses do not provide us with a clear pattern with respect to the relationship between expressive political involvement and self-orientation values and thus no clear evidence for the corroboration or rejection of the hypothesis H7.

As we test the fourth model of the pooled logit analysis in the individual countries, where the value effects are under the control of other variables, we get an ambiguous picture, however (see table 8.6). Both in pooled analyses as well as in country models containing only values, we have found a consistent effect of selfexpression values on instrumental political involvement. They remain important determinants of instrumental political involvement in a majority of countries when controlled for other variables. Only in two countries, Belgium and the Netherlands, their effects become insignificant with the introduction of control variables. Thus hypothesis $\mathrm{H} 6$ is supported for the majority of post-industrial countries, yet a general conclusion is not possible. Furthermore, we establish that the effects of stimulation and achievement on instrumental political involvement disappear in a number of countries with the introduction of control variables into the model, which means that they are not consistent determinants of this involvement type. Hedonism, finally, turned out to be related to expressive political involvement only in the Netherlands, which gives support to H7 only for this specific case. 
Table 8.6 Logit models in countries

\begin{tabular}{|c|c|c|c|c|c|c|}
\hline & AT & BE & DK & FI & FR & IR \\
\hline Hedonism & $\begin{array}{l}.09 \\
(.10)\end{array}$ & $\begin{array}{c}.02 \\
(.10)\end{array}$ & $\begin{array}{l}-.00 \\
(.11)\end{array}$ & $\begin{array}{l}.14 \\
(.09)\end{array}$ & $\begin{array}{l}-.09 \\
(.11)\end{array}$ & $\begin{array}{l}.14 \\
(.10)\end{array}$ \\
\hline Stimulation & $\begin{array}{l}-.09 \\
(.09)\end{array}$ & $\begin{array}{l}.12 \\
(.09)\end{array}$ & $\begin{array}{l}.20^{*} \\
(09)\end{array}$ & $\begin{array}{l}.02 \\
(.09)\end{array}$ & $\begin{array}{l}.10 \\
(.10)\end{array}$ & $\begin{array}{l}.21^{*} \\
(.10)\end{array}$ \\
\hline Achievement & $\begin{array}{l}.17 \\
(.11)\end{array}$ & $\begin{array}{l}.21^{*} \\
(.09)\end{array}$ & $\begin{array}{l}.08 \\
(.10)\end{array}$ & $\begin{array}{l}.13 \\
(.09)\end{array}$ & $\begin{array}{l}.06 \\
(.10)\end{array}$ & $\begin{array}{l}.21^{*} \\
(.11)\end{array}$ \\
\hline Self-Direction & $\begin{array}{l}.24^{*} \\
(.12)\end{array}$ & $\begin{array}{l}-.01 \\
(.11)\end{array}$ & $\begin{array}{l}.24^{*} \\
(.11)\end{array}$ & $\begin{array}{l}.22 * \\
(.11)\end{array}$ & $\begin{array}{l}.19^{+} \\
(.11)\end{array}$ & $\begin{array}{l}.05 \\
(.13)\end{array}$ \\
\hline Universalism & $\begin{array}{l}.18 \\
(.14)\end{array}$ & $\begin{array}{l}.14 \\
(.16)\end{array}$ & $\begin{array}{l}.24^{+} \\
(.14)\end{array}$ & $\begin{array}{l}.27^{*} \\
(.13)\end{array}$ & $\begin{array}{l}.24^{+} \\
(.14)\end{array}$ & $\begin{array}{c}.48^{* *} \\
(.16)\end{array}$ \\
\hline Internal efficacy & $\begin{array}{c}.76^{* * *} \\
(.10)\end{array}$ & $\begin{array}{c}.55^{* * *} \\
(.11)\end{array}$ & $\begin{array}{c}.77^{* * *} \\
(.11)\end{array}$ & $\begin{array}{c}.71^{* * *} \\
(.10)\end{array}$ & $\begin{array}{c}.71^{* * *} \\
(.11)\end{array}$ & $\begin{array}{c}.73^{* * *} \\
(.11)\end{array}$ \\
\hline Political cynicism & $\begin{array}{c}-.33^{* *} \\
(.11)\end{array}$ & $\begin{array}{c}-.43^{* * *} \\
(.11)\end{array}$ & $\begin{array}{c}-.39 * * * \\
(.09)\end{array}$ & $\begin{array}{c}-.45^{* * *} \\
(.10)\end{array}$ & $\begin{array}{c}-.36^{* * *} \\
(.11)\end{array}$ & $\begin{array}{c}-.53^{* * *} \\
(.11)\end{array}$ \\
\hline Policy dissatisfaction & $\begin{array}{l}-.03 \\
(.06)\end{array}$ & $\begin{array}{l}.10 \\
(.07)\end{array}$ & $\begin{array}{l}-.04 \\
(.07)\end{array}$ & $\begin{array}{l}.07 \\
(.08)\end{array}$ & $\begin{array}{l}.11^{+} \\
(.06)\end{array}$ & $\begin{array}{l}.07 \\
(.06)\end{array}$ \\
\hline Disstf. with government & $\begin{array}{l}.08^{+} \\
(.04)\end{array}$ & $\begin{array}{l}-.01 \\
(.06)\end{array}$ & $\begin{array}{l}.11^{*} \\
(.04)\end{array}$ & $\begin{array}{l}.08 \\
(.06)\end{array}$ & $\begin{array}{l}.09^{+} \\
(.05)\end{array}$ & n.a. \\
\hline Disstf. with democracy & $\begin{array}{l}.06 \\
(.04)\end{array}$ & $\begin{array}{c}-.09^{+} \\
(.05)\end{array}$ & $\begin{array}{l}-.06 \\
(.06)\end{array}$ & $\begin{array}{c}-.11^{+} \\
(.06)\end{array}$ & $\begin{array}{l}-.11^{*} \\
(.05)\end{array}$ & $\begin{array}{l}-.02 \\
(.04)\end{array}$ \\
\hline Education & $\begin{array}{c}.17^{* * *} \\
(.04)\end{array}$ & $\begin{array}{l}.09^{*} \\
(.04)\end{array}$ & $\begin{array}{c}.16^{* * *} \\
(.04)\end{array}$ & $\begin{array}{c}.12^{* * *} \\
(.03)\end{array}$ & $\begin{array}{c}.12^{* * *} \\
(.04)\end{array}$ & $\begin{array}{l}.11^{*} \\
(.05)\end{array}$ \\
\hline Media use & $\begin{array}{c}.63^{* * *} \\
(.14)\end{array}$ & $\begin{array}{c}.63^{* * *} \\
(.11)\end{array}$ & $\begin{array}{l}.26^{*} \\
(.11)\end{array}$ & $\begin{array}{c}.47^{* * *} \\
(.12)\end{array}$ & $\begin{array}{c}.41^{* * *} \\
(.10)\end{array}$ & $\begin{array}{l}.30^{* * *} \\
(.08)\end{array}$ \\
\hline Age & $\begin{array}{l}.24^{* *} \\
(.09)\end{array}$ & $\begin{array}{l}.14 \\
(.09)\end{array}$ & $\begin{array}{l}.02 \\
(.09)\end{array}$ & $\begin{array}{l}.03 \\
(.08)\end{array}$ & $\begin{array}{l}.08 \\
(.09)\end{array}$ & $\begin{array}{l}.07 \\
(.10)\end{array}$ \\
\hline Constant & $\begin{array}{c}-5.11^{* * *} \\
(.75)\end{array}$ & $\begin{array}{c}-2.66^{* * *} \\
(.70)\end{array}$ & $\begin{array}{c}-3.80^{* * *} \\
(.73)\end{array}$ & $\begin{array}{c}-3.13^{* * *} \\
(.60)\end{array}$ & $\begin{array}{c}-3.83^{* * *} \\
(.77)\end{array}$ & $\begin{array}{c}-3.22^{* * *} \\
(.82)\end{array}$ \\
\hline Pseudo-R² & .19 & .14 & .17 & .14 & .16 & .18 \\
\hline Log likelihood & -450.67 & -454.85 & -420.87 & -548.18 & -393.61 & -392.76 \\
\hline Corr. classifications (\%) & 77.4 & 68.0 & 77.4 & 70.9 & 69.2 & 71.5 \\
\hline $\mathrm{N}$ & 947 & 774 & 844 & 968 & 692 & 708 \\
\hline
\end{tabular}

Entries are regression coefficients; ${ }^{* * *} \mathrm{p}<=.001 ;{ }^{* *} \mathrm{p}<=.01 ;{ }^{*} \mathrm{p}<=.05 ;+\mathrm{p}<=.10$

Dependent variable: Involvement types $0=$ expressive $1=$ instrumental 
Table 8.6 Logit models in countries (contn.)

\begin{tabular}{|c|c|c|c|c|c|c|}
\hline & NL & NO & SE & $\mathrm{CH}$ & UK & WG \\
\hline Hedonism & $\begin{array}{c}-.23^{+} \\
(.12)\end{array}$ & $\begin{array}{l}-.09 \\
(.10)\end{array}$ & $\begin{array}{l}.12 \\
(.09)\end{array}$ & $\begin{array}{l}.03 \\
(.09)\end{array}$ & $\begin{array}{l}.00 \\
(.09)\end{array}$ & $\begin{array}{l}.04 \\
(.12)\end{array}$ \\
\hline Stimulation & $\begin{array}{l}.07 \\
(.10)\end{array}$ & $\begin{array}{l}.03 \\
(.09)\end{array}$ & $\begin{array}{c}.23^{* *} \\
(.08)\end{array}$ & $\begin{array}{l}-.07 \\
(.08)\end{array}$ & $\begin{array}{l}. \mathbf{1 4}^{+} \\
(.08)\end{array}$ & $\begin{array}{c}.05 \\
(.11)\end{array}$ \\
\hline Achievement & $\begin{array}{l}-.08 \\
(.11)\end{array}$ & $\begin{array}{l}.20^{*} \\
(.10)\end{array}$ & $\begin{array}{c}.30 * * * \\
(.09)\end{array}$ & $\begin{array}{l}\mathbf{. 1 5 ^ { + }} \\
(.09)\end{array}$ & $\begin{array}{l}. \mathbf{1 7 *} \\
(.08)\end{array}$ & $\begin{array}{l}.20 \\
(.13)\end{array}$ \\
\hline Self-Direction & $\begin{array}{l}-.16 \\
(.14)\end{array}$ & $\begin{array}{c}.28^{* *} \\
(.10)\end{array}$ & $\begin{array}{l}.21^{*} \\
(.10)\end{array}$ & $\begin{array}{l}.25^{*} \\
(.11)\end{array}$ & $\begin{array}{l}.16^{+} \\
(.10)\end{array}$ & $\begin{array}{l}-.09 \\
(.14)\end{array}$ \\
\hline Universalism & $\begin{array}{l}.04 \\
(.17)\end{array}$ & $\begin{array}{c}.52 * * * \\
(.13)\end{array}$ & $\begin{array}{c}.44^{* * *} \\
(.12)\end{array}$ & $\begin{array}{l}.13 \\
(.14)\end{array}$ & $\begin{array}{l}.21^{+} \\
(.12)\end{array}$ & $\begin{array}{c}.55^{* * *} \\
(.16)\end{array}$ \\
\hline Internal efficacy & $\begin{array}{c}.96^{* * *} \\
(.12)\end{array}$ & $\begin{array}{c}.93^{* * *} \\
(.12)\end{array}$ & $\begin{array}{c}.64^{* * *} \\
(.09)\end{array}$ & $\begin{array}{c}1.01^{* * *} \\
(.10)\end{array}$ & $\begin{array}{c}.71^{* * *} \\
(.09)\end{array}$ & $\begin{array}{c}1.19^{* * *} \\
(.14)\end{array}$ \\
\hline Political cynicism & $\begin{array}{c}-.24^{+} \\
(.12)\end{array}$ & $\begin{array}{c}-.30^{* *} \\
(.10)\end{array}$ & $\begin{array}{c}-.41^{* * *} \\
(.09)\end{array}$ & $\begin{array}{c}-.29^{* *} \\
(.10)\end{array}$ & $\begin{array}{c}-.36^{* * *} \\
(.09)\end{array}$ & $\begin{array}{l}-.18 \\
(.14)\end{array}$ \\
\hline Policy dissatisfaction & $\begin{array}{l}-.01 \\
(.07)\end{array}$ & $\begin{array}{l}.11^{+} \\
(.06)\end{array}$ & $\begin{array}{l}.12^{*} \\
(.05)\end{array}$ & $\begin{array}{l}.14^{*} \\
(.06)\end{array}$ & $\begin{array}{l}.00 \\
(.06)\end{array}$ & $\begin{array}{l}.10 \\
(.07)\end{array}$ \\
\hline Disstf. with government & $\begin{array}{l}-.01 \\
(.05)\end{array}$ & $\begin{array}{l}.10^{*} \\
(.05)\end{array}$ & $\begin{array}{l}.01 \\
(.05)\end{array}$ & $\begin{array}{l}.03 \\
(.05)\end{array}$ & $\begin{array}{l}.05 \\
(.05)\end{array}$ & $\begin{array}{l}.09 \\
(.06)\end{array}$ \\
\hline Disstf. with democracy & $\begin{array}{l}.03 \\
(.06)\end{array}$ & $\begin{array}{l}-.04 \\
(.05)\end{array}$ & $\begin{array}{l}-.03 \\
(.04)\end{array}$ & $\begin{array}{c}-.11^{*} \\
(.05)\end{array}$ & $\begin{array}{l}-.03 \\
(.04)\end{array}$ & $\begin{array}{c}-.09^{+} \\
(.05)\end{array}$ \\
\hline Education & $\begin{array}{c}.22^{* * *} \\
(.04)\end{array}$ & $\begin{array}{c}.18^{* * *} \\
(.04)\end{array}$ & $\begin{array}{c}.15^{* * *} \\
(.03)\end{array}$ & $\begin{array}{c}.11^{* * *} \\
(.03)\end{array}$ & $\begin{array}{c}.19^{* * *} \\
(.04)\end{array}$ & $\begin{array}{c}.18^{* * *} \\
(.05)\end{array}$ \\
\hline Media use & $\begin{array}{l}.25^{*} \\
(.10)\end{array}$ & $\begin{array}{c}.36^{* * *} \\
(.11)\end{array}$ & $\begin{array}{c}.64^{* * *} \\
(.11)\end{array}$ & $\begin{array}{c}.75^{* * *} \\
(.12)\end{array}$ & $\begin{array}{c}.55^{* * *} \\
(.09)\end{array}$ & $\begin{array}{c}1.22^{* * *} \\
(.19)\end{array}$ \\
\hline Age & $\begin{array}{l}.11 \\
(.10)\end{array}$ & $\begin{array}{l}.15^{+} \\
(.09)\end{array}$ & $\begin{array}{l}.01 \\
(.07)\end{array}$ & $\begin{array}{l}.00 \\
(.08)\end{array}$ & $\begin{array}{c}-.13^{+} \\
(.09)\end{array}$ & $\begin{array}{c}.11 \\
(.10)\end{array}$ \\
\hline Constant & $\begin{array}{c}-4.74^{* * *} \\
(.84)\end{array}$ & $\begin{array}{c}-6.11^{* * *} \\
(.74)\end{array}$ & $\begin{array}{c}-4.14^{* * *} \\
(.60)\end{array}$ & $\begin{array}{c}-4.25^{* * *} \\
(.61)\end{array}$ & $\begin{array}{c}-3.99 * * * \\
(.69)\end{array}$ & $\begin{array}{c}-7.39 * * * \\
(.95)\end{array}$ \\
\hline Pseudo-R² & .18 & .19 & .18 & .19 & .18 & .25 \\
\hline Log likelihood & -412.80 & -543.32 & -632.87 & -579.17 & -559.83 & -359.11 \\
\hline Corr. classifications (\%) & 78.6 & 73.2 & 71.4 & 78.0 & 70.3 & 81.5 \\
\hline $\mathrm{N}$ & 895 & 1057 & 1164 & 1261 & 1004 & 896 \\
\hline
\end{tabular}

Entries are regression coefficients; ${ }^{* * *} \mathrm{p}<=.001 ;{ }^{* *} \mathrm{p}<=.01 ;{ }^{*} \mathrm{p}<=.05 ;+\mathrm{p}<=.10$

Dependent variable: Involvement types $0=$ expressive $1=$ instrumental 
Despite the inconsistencies found between countries, the overall fit of the models has improved considerably after introducing the remaining indicators of individual modernity into the models. The most powerful explanatory variables in each country are unequivocally the indicators of subjective political efficacy. According to the results, people with a higher feeling of political competence tend to get more involved in politics with instrumental motivations in all countries. The effect of political cynicism on expressive political involvement is almost unambiguous as well. With respect to political dissatisfaction, there is not much evidence on its effects on political involvement. Whereas in some countries dissatisfaction with the government tends to facilitate instrumental political involvement, in some other countries dissatisfaction with the functioning of democracy motivates expressive political involvement. Education and indicators of following political news in the media are consistently related to instrumental involvement, i.e. people with a higher level of education and with a frequent media use to gather political information are more likely to participate with instrumental orientations in the political decisionmaking process. Finally, we find that age is not at all related to political involvement under the control of the other variables in most of the analyzed countries; the sporadic effects in a few countries are not remarkably strong and also not consistent with each other. This might be due to the fact that age has no direct effects on any of the political involvement types; its effects may rather run through other variables such as value orientations or cognitive mobilization indicators, with which it has proven to correlate significantly in the earlier analyses (see table 8.2). Yet this, as indicated above, cannot be generalized to all twelve countries that we have analyzed.

\subsection{Conclusions}

In this chapter we have tested the causal model in which influences of various characteristics of the post-modern citizen on the nature of his political involvement instrumental or expressive - were specified. The first part of our analyses was directed towards testing the alternative hypotheses on the prevailing value priorities in the twelve post-industrial societies we analyze in this book (H5a and H5b). A comparison of mean levels of all five value orientations on a pooled basis and in individual countries has shown that self-expression values dominate over selforientation value orientations in all countries, which unequivocally confirmed hypothesis $\mathrm{H} 5 \mathrm{a}$. The alternative hypothesis $\mathrm{H} 5 \mathrm{~b}$ was thus rejected. However, in light of the relatively high mean levels of self-orientation values - which in some cases 
approach the levels of self-expression values - we concluded that this finding should be treated with caution.

The second part of our analyses concentrated on finding the patterns of causal relationships between values and political involvement types. Relying upon the arguments by the two contending interpretations of individual modernity in the earlier chapters, we had hypothesized in chapter 7 that self-expression values would promote instrumental political involvement (H6) while expressive involvement would be motivated by self-orientation values (H7). The findings from pooled and country specific logistic regressions supported H6 to a great extent: self-expression values - self-direction and universalism -which allegedly emphasize pro-democratic orientations proved to be related to instrumental political involvement in most countries. This was also the case when the effects were controlled for other values and also other indicators of individual modernity. This finding leads to the conclusion that the optimistic predictions of the human development approach about the future of democratic governance in post-industrial societies is supported by the outcomes provided by this study.

Hypothesis H7, which was derived from the pessimist views of the theory of post-modern politics on the future of post-industrial democracies, was not given support here. First of all, contrary to the expectations, stimulation was not found to be related to expressive political involvement. Although the effect of hedonism on this involvement type turned out to be significant in the bivariate analyses as well as in the first steps of logistic regressions, it disappeared with the introduction of the control factor age into the model. This means that age determines both hedonism and expressive political involvement, yet we cannot speak of a causal relationship between hedonist values and expressive behavior. The most surprising outcome of the analyses was however that achievement values turned out to be significant determinants of instrumental political involvement. These differences can be ascribed to the distinction made by Bellah et al. (1985) between "utilitarian" and "expressive" individualism (see chapter 5). Our analyses have shown that these individualism types differ also in their implications. Achievement values, which reflect a utilitarian approach, are related to instrumental behavior while hedonism and stimulation, stressing an expressive orientation, do not seem to have any implications for political involvement. Finally, hedonism was found to be a determinant of expressive political involvement only in the Netherlands, which has given support to hypothesis H7 only in this country. 
The strongest predictors of political involvement turn out to be the new political orientations (subjective political efficacy, political cynicism, and dissatisfaction) and cognitive mobilization indicators (education and media use). They improve the fit of the models by a total of almost 15 percent. This means that the process of cognitive mobilization has indeed led citizens to act on more rational grounds when they get involved in politics. Yet citizens' inclinations towards expressive political involvement when they are dissatisfied with politics reduce the probability that they actually participate in politics in order to make their demands heard, and bring about policy outcomes in line with these demands, since they do not believe that their demands will be heard anyway.

Although we have found self-expression values and instrumental political involvement to be related to each other in a majority of the analyzed countries, the findings from chapter 6 on a general tendency towards the development of expressive political involvement, as well as a possible establishment of this involvement type through generation replacement, lead us to be hesitant about drawing optimistic conclusions about the future of these democracies. Also, the influence of cynicism and dissatisfaction on expressive behavior arouses concern, since these phenomena are increasing in post-industrial societies, as we have discussed in a former chapter. All in all, it is not possible to make clearly optimist or pessimist predictions on the future of European post-industrial democracies on the basis of these findings. The evidence is quite mixed and varies across countries. We find that instrumental political involvement, which is assumed to have positive implications for the stability and effectiveness of democracies, is indeed associated with self-expression and pro-democratic value orientations, yet we do not have a clear picture of how it is likely to develop in the future. For expressive political involvement we can say with more clarity that it is likely to increase in the future due to cohort replacement, but this is no reason to draw pessimist conclusions about the future of democracy since the results of the causal analyses do not indicate that they are related to hedonist value orientations. 


\section{Chapter 9}

\section{The Future of Post-Industrial Politics: Benign or Less Benign?}

The main objective of this book was to discuss the link between political involvement and democracy in post-industrial societies with the aim of finding out how "benign" the future of democracy in these societies, in the light of the recent developments in involvement, would be. Unlike Huntington (1974), who has tackled this issue more than thirty-five years ago by expounding the problems of the rising levels of involvement in these societies, we pursued the strategy of focusing upon specific types of involvement in order to answer this question. Our main premise on which we based our research was the following:

The quality of democracy is not only determined by the extent of citizen involvement in the political decision-making, but also by the motivations driving these activities.

This premise was mainly inspired by Kaase and Barnes (1979), who developed a typology of political involvement based on the level of both political participation and political interest as the motivation behind participation. According to them, two of the resulting involvement types, namely, instrumental and expressive political involvement, are the key motivational-behavioral categories that are relevant for the stability and functioning of democratic government in these societies. These involvement types were also central objects of our analysis; we observed their levels, development, and societal-cultural influence factors in twelve post-industrial societies. In the following section, we will briefly sum up our research questions and main findings. Based on this overview, we will then discuss the possible impacts on democratic government in the analyzed societies. We will conclude by discussing the implications of this research. More specifically, we will give attention to future research prospects by focusing on possible institutional-level determinants of political involvement types and how they could contribute to dealing with the participatory challenge in post-industrial societies. 


\subsection{Political Involvement in Post-Industrial Societies: What Have We Found?}

As indicated in the introductory chapter, our aim here was to establish clear links between instrumental-expressive involvement types and the characteristics of citizens generated by post-industrialization and post-modernization processes in Western societies. This relationship has not been clearly outlined by Kaase and Barnes; later studies which provided a well-founded discussion on the relationship between post-modernization and instrumental-expressive motivations have not tested their arguments empirically. We therefore posed the following research question in our study:

What kind of political involvement is generated by the changes in social-cultural conditions in post-industrial societies?

The social, cultural, and political changes caused by the processes of postindustrialization and post-modernization were outlined in chapters 3 and 4 . In chapter 3, we portrayed the radical increase in citizen participation in political decision-making and the change in its patterns in Western post-industrial societies. The rapid expansion of political participation forms has led to the development of a multi-dimensional approach in the research of participation. A separate observation of these dimensions resulted in the conclusion that especially the newer, less conventional and extra-representational forms of political participation have indeed increased, while traditional forms like voting and party-related activities were losing their popularity among citizens. Especially younger citizens turned out to be influenced by these changes. We showed in the subsequent chapter 4 how these changes can be associated with the process of post-modernization in Western democracies. The social and economic shifts in these societies have led to a cultural change that has influenced citizens' political attitudes and behavior. They led to cognitive mobilization and a shift towards individualized values, which are commonly referred to as individual modernization. We gave an extensive overview of these processes and concluded that the emerging values of post-materialism, individual autonomy, and emancipation have generated a new post-modern political culture which accounts for new participatory demands.

Chapter 5 focused on two contradicting interpretations of this new post-modern culture which differ with respect to their views on the individualization process and its impacts on value priorities of post-modern citizens. The theory of human development has stressed the prevalence of self-expression values among these citizens. These values imply a higher emphasis on democratic values such as 
freedom, tolerance, and participation, but also self-determination and quality of life orientations. The theory presupposes that the post-modern citizen is a democratic citizen because of his critical approach towards authorities and his individualistic approach towards politics. Stronger demands for liberty, autonomy, life quality, and freedom of expression are reflected in the increasing criticism towards politicians and political institutions, which leads in turn to demands for more participation especially elite-challenging forms such as protest - in the political process to channel interests and achieve collective as well as individual goals. The theory of postmodern politics, on the other hand, offers an alternative interpretation of individualization and its political consequences. It argues that the emerging values in post-industrial societies are anything but pro-democratic ones. Citizens in these societies are rather characterized by a culture of mass consumption, enjoyment, and hedonism. Their central priority is expressing the self, manifesting their own identity, and the achievement of benefits in terms of intrinsic needs. Social or political orientations or goals are only minimally relevant; the individual and his needs take center stage.

Turning to the political behavior of the post-modern citizen, we have established that the two theories have divergent opinions on the meaning of individualization for the rationality of political actions. The theory of human development predicts rational and instrumental value orientations for post-modern citizens. This results in a clear goal-oriented thinking and action, and is thus also supposed to be reflected in political participation. Since post-modern citizens can formulate political demands and goals due to their high cognitive abilities and they are motivated to implement them autonomously, they are expected to get involved in especially extrarepresentational forms of political action and to do this on rational-instrumental grounds. The theory of post-modern politics, on the contrary, expects a rise in irrational political participation. Because the main motivation of hedonist citizens is to express their self and identity, they would also be expected to participate through direct and extra-representational channels in the political decision-making process; yet the goals of participation would be in this case satisfying individual needs such as expressing beliefs, entertainment, or group-belonging rather than implementing concrete policy outcomes. This refers to an "expressive" rationality and might be regarded just as rational as instrumental behavior from an individual rational-choice perspective, yet from a systemic perspective it is highly irrational because it disrupts the working of the classical input-output mechanism and therefore the democratic decision-making process. 
This extensive discussion has shown that our research question can be answered differently from the perspective of the two theoretical views, since they predict two different groups of value orientations for post-modern citizens, which do not only differ from each other with respect to their content, but also with respect to their relation to the two types of involvement. Thus it was possible to derive two alternative preliminary answers for each of the four sub-questions presented in chapter 1, which were put under an empirical test in the second part of this book. We observed the levels and development of both instrumental and expressive political involvement, their development among generations, the levels of post-modern value orientations, and their effects on political involvement types in all twelve countries in order to find out which one of the arguments of these two views is more valid. Below we will sum up how the four sub-questions were answered through these observations.

\subsubsection{What is the prevailing type of political involvement in post-industrial democracies?}

Both theories predict a rise in extra-representational forms of political participation, yet utilizing their arguments on the motivations of political participation one could formulate different expectations with respect to the types of political involvement. We tested the following hypotheses:

\begin{tabular}{|l|l|}
\hline H1 & Increase of citizen activity beyond representational forms \\
\hline $\mathrm{H} 2 \mathrm{a}$ & Increase of political interest \\
\hline $\mathrm{H} 2 \mathrm{~b}$ & Decline of political interest \\
\hline $\mathrm{H} 3 \mathrm{a}$ & Increase of instrumental political involvement \\
\hline $\mathrm{H} 3 \mathrm{~b}$ & Increase of expressive political involvement \\
\hline
\end{tabular}

The observation of the development of political participation led to the clear conclusion that the common hypothesis $\mathrm{H} 1$ has been confirmed, since extrarepresentational forms of participation have been increasing continuously in all countries. On the contrary, none of the hypotheses of either theory on political interest ( $\mathrm{H} 2 \mathrm{a}$ and $\mathrm{H} 2 \mathrm{~b}$ ) could be corroborated with the same clarity. It seems to be increasing in some countries while it is declining in others; in some there are serious fluctuations so that we cannot speak of a clear trend. At most we can conclude that these hypotheses have been confirmed in several countries, but we cannot draw a general conclusion for all post-industrial countries. 
With respect to the development of instrumental and expressive involvement ( $\mathrm{H} 3 \mathrm{a}$ and $\mathrm{H} 3 \mathrm{~b}$ ) we also found that the evidence is quite mixed among countries. The trends vary across countries from increasing to declining, from stable to fluctuating. Although instrumental political involvement seems to prevail in a majority of countries, we could also observe considerable levels of expressive political involvement in many of them due to the simultaneous development in this involvement type. In others, it has reached levels that outweigh the instrumental type of involvement. Also, the examination of the development of the balance between the two types of involvement has led to similar results. Thus, we cannot provide an unequivocal answer to the question of which involvement type prevails in post-industrial countries. This finding makes the second question on the possible future development of both involvement types even more relevant.

\subsubsection{How are instrumental and expressive involvement types likely to develop in post-industrial democracies?}

In order to answer this question, we focused on the development of both involvement types among generations. The following hypotheses were formulated parallel to the two diverging theories on post-modern citizens and their values.

\begin{tabular}{|l|l|}
\hline H4a & $\begin{array}{l}\text { The increase of instrumental political involvement over time will take place due to } \\
\text { generation replacement, i.e. because each successive generation has higher levels of } \\
\text { instrumental political involvement than the previous one }\end{array}$ \\
\hline H4b & $\begin{array}{l}\text { The increase of expressive political involvement over time will take place due to } \\
\text { generation replacement, i.e. because each successive generation has higher levels of } \\
\text { expressive political involvement than the previous one }\end{array}$ \\
\hline
\end{tabular}

With respect to these two hypotheses, it was possible to present some clear evidence. The analysis of the development of instrumental political involvement among six birth cohorts in section 6.4 has shown that this involvement type has been increasing among all cohorts, but we cannot conclude that this increase is due to generational replacement since it was not possible to observe higher levels of this involvement type among younger cohorts. As could be taken from figure 6.2, the youngest generation shows lower levels of instrumental political involvement than the previous cohort at all three measurement points. Although their inclination towards instrumentally motivated political action increases with age, they do not reach the same levels as the older members of the so-called protest generation (cohorts 4 and 5). Thus, hypothesis H4a has not been supported by the findings. On the contrary, the results of the analyses do provide some support for hypothesis H4b. The increase in expressive political involvement is indeed taking place by 
generational replacement: we could observe at each measurement point that the youngest cohort has a considerably higher inclination to participate with expressive motivations than their predecessors, and this inclination does not seem to wear off as they get older (see figure 6.4). Therefore, we can expect that political involvement without political motivation may continue to increase over time. In the long run, we can even expect expressive political involvement to become the prevalent type of getting involved in the political process. Yet given the short time span in which these developments have been observed, the differences between countries and the lack of knowledge on the mechanisms which underlie these developments, it would be too early to draw solid conclusions.

\subsubsection{Which value orientations prevail in post-industrial democracies?}

Having established the levels and trends of both instrumental and expressive political involvement, we turned our focus to our question on the prevailing values in post-industrial democracies. Both the theory of human development and the theory of post-modern politics provide direct answers to this question, on the basis of which we formulated the following hypotheses:

\begin{tabular}{|l|l|}
\hline H5a & $\begin{array}{l}\text { Self-expression values prevail over self-orientation values among citizens of post- } \\
\text { industrial societies }\end{array}$ \\
\hline H5b & $\begin{array}{l}\text { Self-orientation values prevail over self-expression values among citizens of post- } \\
\text { industrial societies }\end{array}$ \\
\hline
\end{tabular}

The analyses in the first section of chapter 8 showed that self-expression values self-direction and universalism - are indeed prevailing in all post-industrial societies, which is in line with hypothesis H5a and thus with the arguments of the theory of post-industrial politics. Self-orientation values - hedonism, stimulation, and achievement - are given less priority by the citizens of these countries. The alternative hypothesis $\mathrm{H} 5 \mathrm{~b}$, derived from the theory of post-modern politics can clearly be rejected in this case. We noted, however, that self-orientation values, especially the hedonist ones, are also present in these societies to a strikingly high extent. The question of whether self-orientation values might outweigh selfexpression values in the future would make observations based on longitudinal data necessary, which is not available at the moment. 


\subsubsection{To what extent do value orientations account for the type of political involvement?}

Finally, we tested the causal relationships between the above mentioned value orientations and instrumental-expressive political involvement in section 8.2 to answer our last sub-question. The following hypotheses were tested in this last step:

\begin{tabular}{|l|l|}
\hline H6 & $\begin{array}{l}\text { Self-expression values tend to be associated with instrumental political involvement } \\
\text { in post-industrial societies }\end{array}$ \\
\hline H7 & $\begin{array}{l}\text { Self-orientation values tend to be associated with expressive political involvement in } \\
\text { post-industrial societies }\end{array}$ \\
\hline
\end{tabular}

The results of the binary logit analyses corroborated hypothesis H6, showing that self-expression values are related to instrumental political involvement on a pooled basis: the relationship exists also under the control of new political orientations, cognitive mobilization indicators and age. This finding could be generalized to individual countries to a large extent, since both self-direction and universalism values were found to be significantly related to instrumental political involvement in a majority of countries. One should however take into consideration that these values can determine instrumental involvement only to a limited extent: internal efficacy, and the use of media to gather political information, proved to be much more strongly related to this involvement type in all twelve countries.

With respect to self-orientation values, the analyses delivered inconsistent results. Hedonism was found to be unrelated to expressive political involvement in all countries except the Netherlands, where the expected relationship was significant. The results of the bivariate analyses provided support for the hypothesized relationship in more countries, yet this relationship disappeared with the introduction of control variables into the models. Stimulation turned out to be associated with instrumental political involvement contrary to our expectations, yet this finding was limited to only a few countries and the relationship was not significant in the pooled analysis. Finally, achievement also proved to be significantly related to instrumental political involvement on the pooled basis as well as in half of the analyzed countries. Thus generally none of these values turned out to be associated with expressive political involvement, which led to the rejection of hypothesis H7, derived from the theory of post-modern politics. The only variable which was found to be consistently related to expressive political involvement in all countries was political cynicism. Dissatisfaction with the functioning of democracy also proved to be related to expressive involvement in a small number of countries. 


\subsection{Political Involvement and Democracy: What is the Future Likely to Bring?}

In light of these findings, what can be predicted for the future of democracy in postindustrial societies? Our analyses have provided inconsistent findings with respect to both instrumental and expressive involvement types and their value backgrounds, which cannot lead to a straightforward conclusion. The hypothesis on the basis of the human development approach, which foresaw pro-democratic self-expression values among citizens of post-industrial societies, has been widely corroborated. Moreover, a positive relationship between self-expression values and rational-instrumental political behavior was found in these countries, which supports the expectation that citizens emphasizing these values think and act in ways that contribute to an effective functioning of the democratic system. However, we found not only that self-expression values lead to instrumental motivations in political behavior, but also that self-orientation values are related to the instrumental type of involvement to some extent. Thus the findings delivered no indication that the new value orientations - regardless of nature - generated by the post-modernization processes in advanced industrial countries would lead to the disruptive expressive political involvement; on the contrary, these values increase altogether the probability of getting involved in the political decision-making process with rational-instrumental motivations. Our main research question could therefore be answered as follows: instrumental political involvement is likely to be generated by the new societalcultural conditions of post-industrial societies.

However optimistic this finding may sound for the future of the stability of these democracies, other results found in this book keep us from drawing rash conclusions. Analyses of the levels and development of both involvement types - net development as well as the development among generations - have shown that instrumentally motivated political action is not the only type of behavior that is prevalent and increasing in post-industrial societies. Expressive political involvement is also present to a considerable extent with an increasing trend; the observation of its development among birth cohorts has even indicated that this political style is more likely to become an established characteristic of post-industrial societies than instrumental political involvement.

Another striking result was that expressively motivated action was not at all associated with non-political orientations; quite the contrary, it seems to have political backgrounds. As indicated above, dissatisfaction with the functioning of democracy in a country has been shown to motivate this kind of political 
involvement. Moreover, a general cynicism towards politicians and their responsiveness to citizens' interests and demands is the most important determinant of expressive involvement among all other variables. This indicates that citizens who are convinced that they would never be able to achieve political goals by transmitting their interests to the poorly functioning political system are more likely to lose their interest in politics as we know it. It is not clear from our analyses whether this group of people will have a higher inclination to participate in extrarepresentational political activities or not. We have not analyzed the category of apathetic citizens - those who are not interested and do not participate in politics from the typology of Kaase and Barnes, thus we cannot rule out the possibility that citizens with a general feeling of cynicism become rather apathetic towards politics. But the evidence we have provided shows clearly that when they do get involved in these activities, they seem to do this just to express their dissatisfaction, not really because they want to do something about it. Political participation with these motivations, once it becomes widespread, can indeed be disruptive for the functioning of democratic government first of all because they are not directed at problem solving. This would mean that there will be less emphasis on shaping and developing democratic principles and institutions. Second, this political style could gradually create a negative climate of opinion about politics, which would possibly erode the legitimacy of the system in the long run. The forms of alienation and dissatisfaction that possibly emerge as a consequence of these developments could make way for the rise of political extremist movements, which again form a fundamental challenge to democratic systems.

Though none of the individualized value orientations proved to be related to this type of political involvement, we consider it necessary to say a few words on their implications for the stability of post-industrial democracies. The self-expression values which include stronger demands for liberty, autonomy, freedom of expression, and life quality are prevalent value orientations in post-industrial societies, as the theory of human development predicted. Because of this composition of the self-expression values, it can be argued that the theory converges towards the opinions of the liberal and participatory views on the characteristics of the democratic citizen discussed in chapter 5. Yet one can say that a communitarian orientation is also present in the arguments of the human development approach, since tolerance of diversity and interpersonal trust are supposed to serve as basic values which protect the freedom of others and guarantee the societal coherence. Thus, the challenge invoked by the rise of expressive political involvement could be met by the presence of citizens who have internalized basic democratic values and 
adhere to a democratic form of governance. The only obstacle could be created by the role of achievement values on instrumental political involvement. Since these values emphasize personal success and recognition, there is a potential that the aim of achieving political goals, directly related to self-interest, could eclipse the pursuit of communitarian goals related to public interest. Yet considering the relatively low levels of this value orientation among the publics in post-industrial societies and its weak effect on instrumental political involvement, this scenario does not appear to be realistic in the short run.

\subsection{Perspectives for Future Research}

In this study we discussed the role of individual-level factors in explaining instrumental and expressive political involvement. The main focus while doing this was on human values which are associated with the process of individualization as possible predictors of these political involvement types. The modernization thesis is of a general nature and in principle applies to all post-industrial democracies, which means that countries at a similar level of modernization are all supposed to have similar levels of economic and democratic development. In line with this assumption we have therefore chosen those democracies which fulfill the main criteria of postindustrialization: a high level of GDP per capita, a long democratic experience in years, and a larger proportion of work power in the services sector compared to the industrial and agrarian sectors. The main premise of the modernization theory is that such countries should not display great variations with respect to individual value priorities and since the nature of citizens' political attitudes and political behavior are supposed to be determined to a great extent by values, the countries should also not differ strongly with respect to these variables. This basic assumption has led us to the hypothesis that certain political involvement structures are resulting from certain individual value priorities, and that these are common to all post-industrial countries.

However, we observed that this is not the case. Our analyses in chapter 6 have shown first of all that there is no common secular trend in any type of political involvement in the post-industrial democracies, and the analysis of the development of these involvement types among generations showed that expressive political involvement is likely to become established in these societies due to a cohort effect. Second, we have seen that self-expression values do indeed prevail in these societies, but self-orientation values are also present to a considerable extent. Moreover, the findings from logistic regression models in chapter 8 showed that individual 
modernization indicators could explain a small part of the variance of political involvement types. The explained variance in the end models varied from 14 to 25 percent in individual countries. This suggests that individual modernization can explain political involvement only to a small extent, and the rest of the variance can be explained by other factors. We cannot exclude the possibility that one may find other individual-level or contextual-level indicators of the societal modernization process among these factors. As discussed in chapter 4, societal modernization is a complex macro-level factor which includes several different processes and phenomena, and they might in turn provide additional constraints for the motivations of political action.

Other influential macro-level factors that could play a decisive role in explaining patterns of political involvement are the country-specific political-institutional arrangements. Previous studies on voter turnout and electoral participation have shown that these factors are strong determinants of individuals' political attitudes and behavior (e.g. Powell 1982, 1986; Jackman 1987; Crepaz 1990; Jackman \& Miller 1995; Franklin 1996, 2002; Norris 2002). Particularly the electoral and party system features have been proven to influence turnout and voting behavior to a great extent (see e.g. Blais 2000, 2006; Colomer 2004; Franklin 2002, 2004; Norris 2004). With respect to explaining newer forms of political behavior, however, institutional characteristics have been seldom referred to as their possible determinants. The few studies which have made this attempt focus exclusively on protest behavior and new social movements, where they have referred either to general indicators of postindustrialization such as the GDP levels or the age of democracy (e.g. Roller \& Wessels 1996) or political opportunity structures (e.g. Kitschelt 1986; Kriesi et al. 1995; Tarrow 1998). Finally, the institutional-level determinants of instrumental and expressive motivations of political involvement have hardly been explored; the existing studies focus solely on voting and partisanship (see Tóka 2009).

Focusing upon the political-administrative backgrounds of the political involvement types analyzed here is essential in our opinion due to two reasons. First of all, our research has confirmed findings from previous research that there is a significant commitment to democratic norms and values in advanced post-industrial democracies (e.g. Dalton 2004; Inglehart \& Welzel 2005). Second, we have shown that these values account for rational-instrumental political action in these countries. These findings indicate that innovative measures at the institutional level which help to enhance this type of citizen involvement would not only respond to the increasing demands for participation, but also guarantee a more effectively functioning democracy by increasing inclusiveness, responsiveness, and transparency of the 
political decision-making process. Also, the challenge of rising expressive political behavior can be met by such arrangements.

As discussed in chapter 3, the inclination towards traditional representative channels of participation shows a declining trend while newer, more direct, extrarepresentational participatory forms gain in popularity. Unavoidably, the institutions of representative government have responded to this change. The use of direct democracy both at the national and sub-national level has expanded substantially since 1970 in many established democracies, mainly in the form of more frequent direct election of local officials, greater popular influence over party affairs, and greater use of local and national referenda. In addition to this, there have been attempts in a number of countries to limit the size of democracy by transferring a great deal of governmental competences to the local level of government. These attempts were directed at overcoming the obstacles that faced citizen involvement, which were caused by the larger size of democratic government, by giving citizens more opportunities for more direct and influential participation in decisions which affect their daily lives. Thus the ideals of participatory democracy, although generally assumed to be hard to adapt, are being increasingly implemented in the political practices of advanced Western democracies in accordance with the growing participatory demand in these societies.

We suggest that future research should focus more on the potential effects of these two institutional measures for instrumental political involvement. Local authorities guarantee the legitimacy of the democratic system not only by providing for a diffusion of power that allows for the consideration of diversity and difference and thus providing for responsiveness (see e.g. Sharpe 1970; Stoker 1996), but also by socializing citizens to pro-democratic attitudinal and behavioral patterns (see Stoker 1996; Vetter 2007). Therefore, it could be argued that local government reforms which include inclusive and interactive strategies might facilitate instrumentally motivated political behavior. Local democracy does not only motivate political participation by providing easier access to the political system, but also by helping citizens develop the necessary skills and attitudes to participate in politics. Dahl and Tufte have pointed to the positive influence of local autonomy on citizens' feelings of competence (1974: 13ff.) As can be taken from their argument, more competences at the local level increase citizens' feelings of efficacy; it facilitates their beliefs that they can influence political decisions. This increases the chance that people get involved in politics out of political motivations, i.e. to implement a certain political decision in accordance with their demands. The more political decisions that citizens can control, i.e. the higher the degree of local discretion, the higher their political interest and 
their feelings of political competence should be (Vetter 2007: 47). Also, issue mobilization is supposed to be higher in decentralized systems where the decisive competences at the local level are stronger (Dahl \& Tufte 1974; Denters \& Rose 2005). Since citizens' immediate needs and demands find better reflection at the local level, it can be expected that local democracy in terms of strong local authorities increases their stake and interest in political issues and therefore enforces instrumental political involvement.

A similar expectation can be formulated for direct democratic practices. Institutional procedures giving citizens a direct voice in government decisionmaking shall encourage a more engaged and active citizenry and thus increase civic engagement (e.g. Citrin 1996; Hibbing \& Theiss-Morse 2002; Tolbert et al. 2003). This link works through several channels. Allowing citizens to act as lawmakers heightens first of all their interest in politics (Schmidt 1989; Zimmerman 1999; Goebel 2002). The existence and use of direct democratic institutions shall furthermore help citizens to learn about and judge key political issues, which, in turn, shall help to develop a feeling of political efficacy (e.g. Bowler \& Donovan 2002). Furthermore, direct participatory mechanisms enhance government responsiveness to citizen demands (Budge 1996; Peters 1996). Especially the argument that direct democratic practices enhance participation through facilitating political interest leads to the hypothesis that instrumental political involvement would be the resulting type of citizen involvement from direct democratic institutions. Another reason such a relationship can be expected is the mobilization effect of direct democratic institutions. Just as local authorities, these institutions also encourage citizens to think that they can influence the political process, which increases the chance of having a political motivation while getting involved in the policy-making process rather than non-political ones.

Finally, future research should consider the potential impact of new information and communication technologies (ICT) on political involvement and its underlying motivations. Such technologies do not only provide the informational resources for rational-instrumental political participation at an extraordinarily high pace, they could also contribute to a more effective interaction between citizens and the state and thus increase the chances of responsiveness, e.g. through virtual "town meetings" or open discussion forums (see Smith 2009: 144ff.). The accessibility of government by larger public spheres could furthermore enhance the inclusiveness of decision-making and thus facilitate political interest and efficacy among larger groups of citizens. In short, if used efficiently, the opportunities offered by ICT could possibly foster instrumental motivations in citizen involvement. This assumption 
requires however the availability of micro-level data on participation forms via the new ICT applications, which is still quite limited. A fairly big part of the existing participation repertoire is covered by the European Values and Social Surveys, yet still a considerable amount of participation forms are not captured by the data, including the above specified online participation forms. Measuring and analyzing the use of these forms of political activity will surely provide new insights for designing political institutions which can contribute to democratically oriented and rationally acting citizens in post-industrial societies and thus contribute to an effectively functioning democracy in these countries. 


\section{Appendix A}

\section{List of Used Items for the Operationalization of Variables}

\section{A1 European Values Survey 1981-2000}

\section{A 1.1 Political Participation}

I'm going to read out some different forms of political action that people can take, and I'd like you to tell me, for each one, whether you have actually done any of these things, whether you might do it or would never, under any circumstances, do it (All waves).

\begin{tabular}{|l|l|l|l|}
\hline & Have done & Might do & $\begin{array}{l}\text { Would never } \\
\text { do }\end{array}$ \\
\hline Signing a petition & 1 & 2 & 3 \\
\hline Joining in boycotts & 1 & 2 & 3 \\
\hline Attending lawful demonstrations & 1 & 2 & 3 \\
\hline
\end{tabular}

\section{A 1.2 Political Interest}

Index out of the following two items:

A 1.2.1 Subjective political interest:

1. Wave (1981):

Which of these statements comes nearest to describing your interest in politics?

1 I take an active interest in politics

2 I am interested in politics but don't take any active part

3 My interest in politics is not greater than other interests

4 I'm not interested in politics at all 
2. and 3. Waves (1990-2000):

How interested would you say you are in politics?

1 Very interested

2 Somewhat interested

3 Not very interested

4 Not at all interested

A 1.2.2 Frequency of political discussions:

When you get together with your friends, would you say you discuss political matters frequently, occasionally or never? (All waves)

1 Frequently

2 Occasionally

3 Never

\section{A 2 European Social Survey 2002-2003:}

\section{A 2.1 Political Participation}

There are different ways of trying to improve things in [country] or help prevent things from going wrong. During the last 12 months, have you done any of the following?

\begin{tabular}{|l|l|l|l|}
\hline & & Yes & No \\
\hline sgnptit & Signed a petition & 1 & 2 \\
\hline pbldmn & Taken part in a lawful public demonstration & 1 & 2 \\
\hline bctprd & Boycotted certain products & 1 & 2 \\
\hline bghtprd & $\begin{array}{l}\text { Deliberately bought certain products for political, ethical or } \\
\text { environmental reasons }\end{array}$ & 1 & 2 \\
\hline
\end{tabular}

\section{A 2.2 Political Interest}

Index out of the following two items:

\section{A 2.2.1 Subjective political interest:}

polintr: How interested would you say you are in politics -are you...

1 very interested,

2 quite interested, 3 hardly interested, or,

4 not at all interested? 
A 2.2.2 Frequency of political discussions:

discpol: How often would you say you discuss politics and current affairs?

1 Every day

2 Several times a week

3 Once a week

4 Several times a month

5 Once a month

6 Less often

7 Never

\section{A 2.3 Values Variables}

Here we briefly describe some people. Please read each description tick the box on each line that shows how much each person is or is not like you.

Answer categories:

1 Very much like me

2 Like me

3 Somewhat like me

4 A little like me

5 Not like me

6 Not like me at all

\section{A 2.3.1 Hedonism:}

Index out of the following two items:

ipgdtim: Having a good time is important to him. He likes to "spoil" himself.

impfun: He seeks every chance18 he can to have fun. It is important to him to do things that give him pleasure.

\section{A 2.3.2 Stimulation:}

Index out of the following two items:

impdiff: He likes surprises and is always looking for new things to do. He thinks it is important to do lots of different things in life.

ipadvnt: He looks for adventures and likes to take risks. He wants to have an exciting life. 


\section{A 2.3.3 Achievement:}

Index out of the following two items:

ipshabt: It is important to him to show his abilities. He wants people to admire what he does.

ipsuces: Being very successful is important to him. He hopes people will recognize his achievements.

\section{A 2.3.4 Self-Direction:}

Index out of the following two items:

ipcrtiv: Thinking up new ideas and being creative is important to him. He likes to do things in his own original way.

impfree: It is important to him to make his own decisions about what he does. He likes to be free to plan and not depend on others.

\section{A 2.3.5 Universalism:}

Index out of the following three items:

ipeqopt: He thinks it is important that every person in the world be treated equally. He believes everyone should have equal opportunities in life.

ipudrst: It is important to him to listen to people who are different from him. Even when he disagrees with them, he still wants to understand them.

impenv: He strongly believes that people should care for nature. Looking after the environment is important to him.

\section{A 2.4 Education}

eduyrs: How many years of full-time education have you completed?

Answers recoded as follows:

8 Up to 8 yrs.

9

10

11

12

13

14

15 yrs. and more 


\section{A 2.5 Media Use}

Index out of the following three items:

topol: On an average weekday, how much of your time watching television is spent watching news or programmes about politics and current affairs?

rdpol: On an average weekday, how much of your time listening to the radio is spent listening to news or programmes about politics and current affairs?

nwsppol: (On an average weekday) how much of (your) time is spent reading (newspapers) about politics and current affairs?

\section{Answer categories:}

0 No time at all

1 Less than $1 / 2$ hour

$21 / 2$ hour to 1 hour

3 More than 1 hour, up to $1 \frac{1 / 2}{2}$ hours

4 More than $1 \frac{1}{2}$ hours, up to 2 hours

5 More than 2 hours, up to $2 \frac{1}{2}$ hours

6 More than $2 \frac{1}{2}$ hours, up to 3 hours

7 More than 3 hours

\section{A 2.6 New political orientations:}

\section{A 2.6.1 Internal efficacy:}

Index out of the following two items:

polcmpl: How often does politics seem so complicated that you can't really understand what is going on?

1 Never

2 Seldom

3 Occasionally

4 Regularly

5 Frequently

poldcs: How difficult or easy do you find it to make your mind up about political issues?

1 Very difficult

2 Difficult

3 Neither difficult nor easy

4 Easy

5 Very easy 


\section{A 2.6.2 Political cynicism:}

Index out of the following two items:

pltcare: Do you think that politicians in general care what people like you think?

1 Hardly any politicians care what people like me think

2 Very few care

3 Some care

4 Many care

5 Most politicians care what people like me think

pltinvt: Would you say that politicians are just interested in getting people's votes rather than in people's opinions?

1 Nearly all politicians are just interested in votes

2 Most politicians are just interested in votes

3 Some politicians are just interested in votes, others aren't

4 Most politicians are interested in people's opinions

5 Nearly all politicians are interested in people's opinions

\section{A 2.6.3 Policy dissatisfaction:}

Index out of the following three items:

stfeco: On the whole how satisfied are you with the present state of the economy in [country]?

\begin{tabular}{|l|l|l|l|l|l|l|l|l|l|l|}
\hline 0 & 1 & 2 & 3 & 4 & 5 & 6 & 7 & 8 & 9 & 10 \\
\hline $\begin{array}{l}\text { Extremely } \\
\text { dissatisfied }\end{array}$ & & & & & & & & & & $\begin{array}{l}\text { Extremely } \\
\text { satisfied }\end{array}$ \\
\hline
\end{tabular}

stfedu: Now, using this card, please say what you think overall about the state of education in [country] nowadays?

\begin{tabular}{|l|l|l|l|l|l|l|l|l|l|l|}
\hline 0 & 1 & 2 & 3 & 4 & 5 & 6 & 7 & 8 & 9 & 10 \\
\hline $\begin{array}{l}\text { Extremely } \\
\text { bad }\end{array}$ & & & & & & & & & & $\begin{array}{l}\text { Extremely } \\
\text { good }\end{array}$ \\
\hline
\end{tabular}

stfhlth: Still using this card, please say what you think overall about the state of health services in [country] nowadays?

\section{A 2.6.4 Dissatisfaction with government:}

stfgov: Now thinking about the [country] government, how satisfied are you with the way it is doing its job? 


\begin{tabular}{|l|l|l|l|l|l|l|l|l|l|l|}
\hline 0 & 1 & 2 & 3 & 4 & 5 & 6 & 7 & 8 & 9 & 10 \\
\hline $\begin{array}{l}\text { Extremely } \\
\text { dissatisfied }\end{array}$ & & & & & & & & & & $\begin{array}{l}\text { Extremely } \\
\text { satisfied }\end{array}$ \\
\hline
\end{tabular}

A 2.6.5 Dissatisfaction with democracy:

stfdem: And on the whole, how satisfied are you with the way democracy works in [country]?

\begin{tabular}{|l|l|l|l|l|l|l|l|l|l|l|}
\hline 0 & 1 & 2 & 3 & 4 & 5 & 6 & 7 & 8 & 9 & 10 \\
\hline $\begin{array}{l}\text { Extremely } \\
\text { dissatisfied }\end{array}$ & & & & & & & & & & $\begin{array}{l}\text { Extremely } \\
\text { satisfied }\end{array}$ \\
\hline
\end{tabular}

\section{A 2.7 Age}

yrbrn: In what year were you born?

Answer subtracted from the survey year 2002 and then classified as follows:

$115-25$ yrs

2 26-40 yrs

$341-55$ yrs

4 56-70 yrs

571 yrs and older 


\section{Appendix B}

\section{Development of Individual Participation Forms in Countries}

Table B.1 Development of petition signing in post-industrial countries, 1981-2000

\begin{tabular}{lccccc}
\hline & Period & 1. Wave & 2. Wave & 3. Wave & Trend \\
\hline Austria & $1990-1999$ & -- & 0.48 & 0.56 & +0.08 \\
Belgium & $1981-1999$ & 0.24 & 0.47 & 0.72 & +0.48 \\
Denmark & $1981-1999$ & 0.44 & 0.51 & 0.57 & +0.13 \\
Finland & $1990-2000$ & -- & 0.41 & 0.51 & +0.10 \\
France & $1981-1999$ & 0.45 & 0.54 & 0.68 & +0.23 \\
Ireland & $1981-1999$ & 0.29 & 0.42 & 0.61 & +0.32 \\
Netherlands & $1981-1999$ & 0.35 & 0.51 & 0.61 & +0.26 \\
Norway & $1982-1996$ & 0.55 & 0.61 & 0.65 & +0.10 \\
Sweden & $1982-1999$ & 0.54 & 0.72 & 0.72 & +0.18 \\
Switzerland & $1989-1996$ & -- & 0.63 & 0.68 & +0.05 \\
UK & $1981-1999$ & 0.63 & 0.75 & 0.81 & +0.18 \\
W. Germany & $1981-1999$ & 0.47 & 0.57 & 0.66 & +0.19 \\
All Countries & $1981-2000$ & 0.44 & 0.56 & 0.65 & +0.21 \\
\hline
\end{tabular}

Entries are mean levels on a scale from 0 to 1

Data: European Values Surveys, 1981-2000

Table B.2 Development of boycotting in post-industrial countries, 1981-2000

\begin{tabular}{lccccc}
\hline & Period & 1. Wave & 2. Wave & 3. Wave & Trend \\
\hline Austria & $1990-1999$ & -- & 0.05 & 0.10 & +0.05 \\
Belgium & $1981-1999$ & 0.03 & 0.09 & 0.12 & +0.09 \\
Denmark & $1981-1999$ & 0.10 & 0.11 & 0.25 & +0.15 \\
Finland & $1990-2000$ & -- & 0.13 & 0.15 & +0.02 \\
France & $1981-1999$ & 0.12 & 0.12 & 0.13 & +0.01 \\
Ireland & $1981-1999$ & 0.07 & 0.07 & 0.08 & +0.01 \\
Netherlands & $1981-1999$ & 0.07 & 0.09 & 0.22 & +0.15 \\
Norway & $1982-1996$ & 0.07 & 0.12 & 0.18 & +0.11 \\
Sweden & $1982-1999$ & 0.08 & 0.16 & 0.33 & +0.25 \\
Switzerland & $1989-1996$ & -- & -- & 0.11 & -- \\
UK & $1981-1999$ & 0.07 & 0.14 & 0.17 & +0.10 \\
W. Germany & $1981-1999$ & 0.08 & 0.10 & 0.18 & +0.10 \\
All Countries & $1981-2000$ & 0.08 & 0.11 & 0.16 & +0.08 \\
\hline
\end{tabular}

Entries are mean levels on a scale from 0 to 1

Data: European Values Surveys, 1981-2000 
Table B.3 Development of demonstrations in post-industrial countries, 1981-2000

\begin{tabular}{lccccc}
\hline & Period & 1. Wave & 2. Wave & 3. Wave & Trend \\
\hline Austria & $1990-1999$ & -- & 0.10 & 0.16 & +0.06 \\
Belgium & $1981-1999$ & 0.14 & 0.23 & 0.40 & +0.26 \\
Denmark & $1981-1999$ & 0.19 & 0.27 & 0.29 & +0.10 \\
Finland & $1990-2000$ & -- & 0.14 & 0.15 & +0.01 \\
France & $1981-1999$ & 0.27 & 0.33 & 0.39 & +0.12 \\
Ireland & $1981-1999$ & 0.13 & 0.17 & 0.22 & +0.09 \\
Netherlands & $1981-1999$ & 0.13 & 0.25 & 0.32 & +0.19 \\
Norway & $1982-1996$ & 0.19 & 0.20 & 0.26 & +0.07 \\
Sweden & $1982-1999$ & 0.15 & 0.23 & 0.30 & +0.15 \\
Switzerland & $1989-1996$ & -- & 0.16 & 0.17 & +0.01 \\
UK & $1981-1999$ & 0.10 & 0.14 & 0.13 & +0.03 \\
W. Germany & $1981-1999$ & 0.15 & 0.10 & 0.26 & +0.11 \\
All Countries & $1981-2000$ & 0.16 & 0.20 & 0.27 & +0.11 \\
\hline
\end{tabular}

Entries are mean levels on a scale from 0 to 1

Data: European Values Surveys, 1981-2000 


\section{Appendix C}

Development of Political Involvement Types among Birth Cohorts: Country Graphs

\section{1 Austria}

Instrumental political involvement

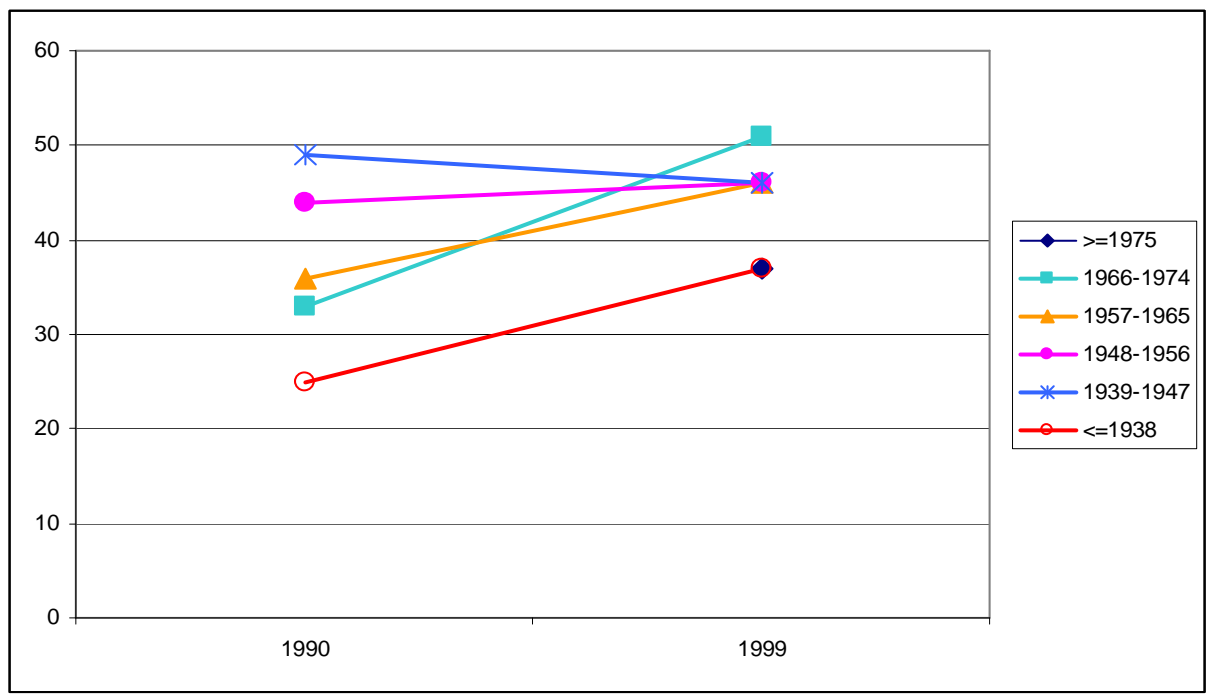

Expressive political involvement

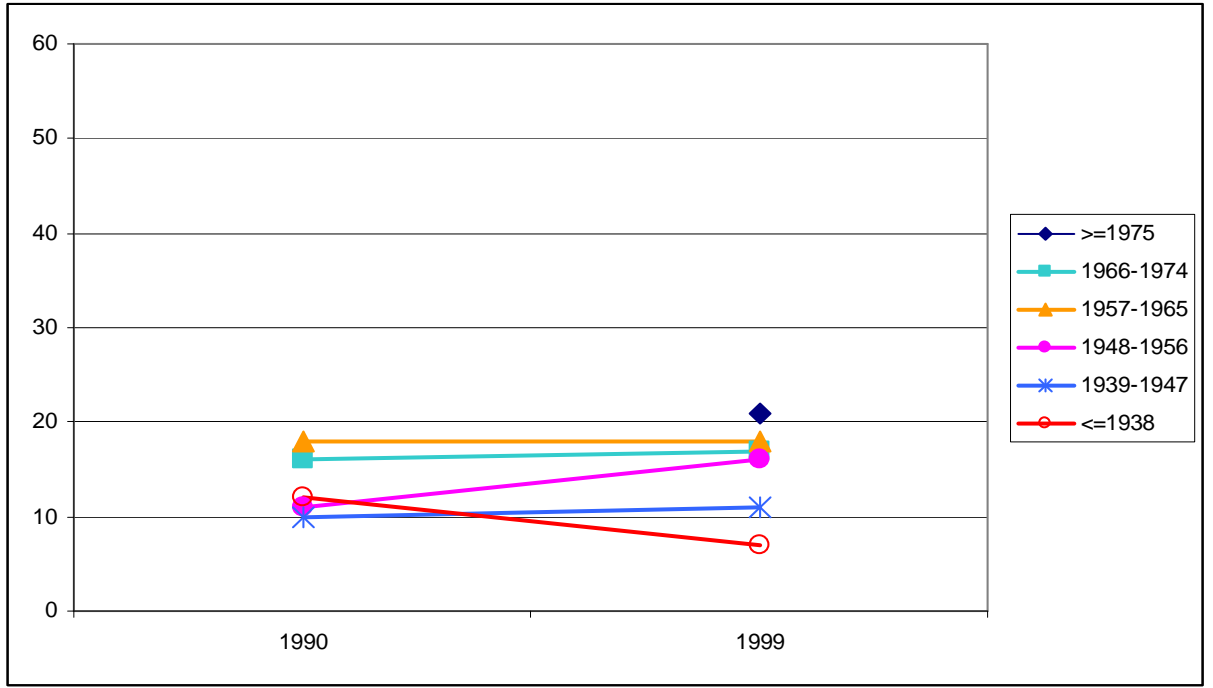




\section{2 Belgium}

Instrumental political involvement

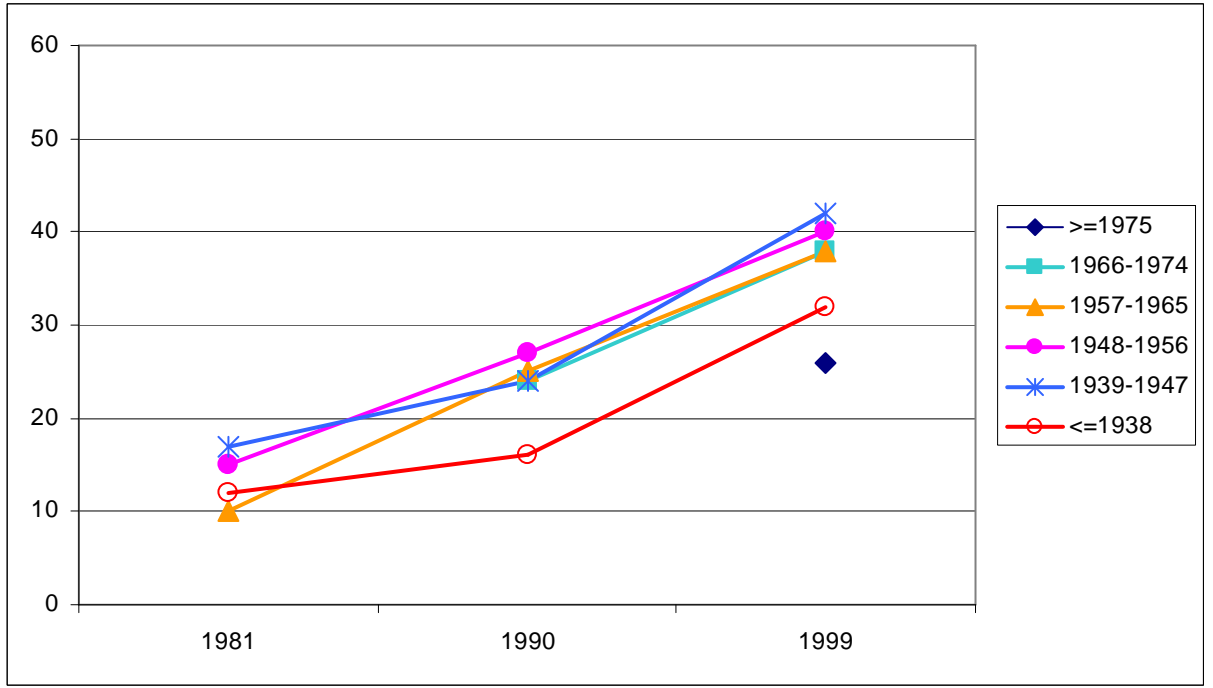

Expressive political involvement

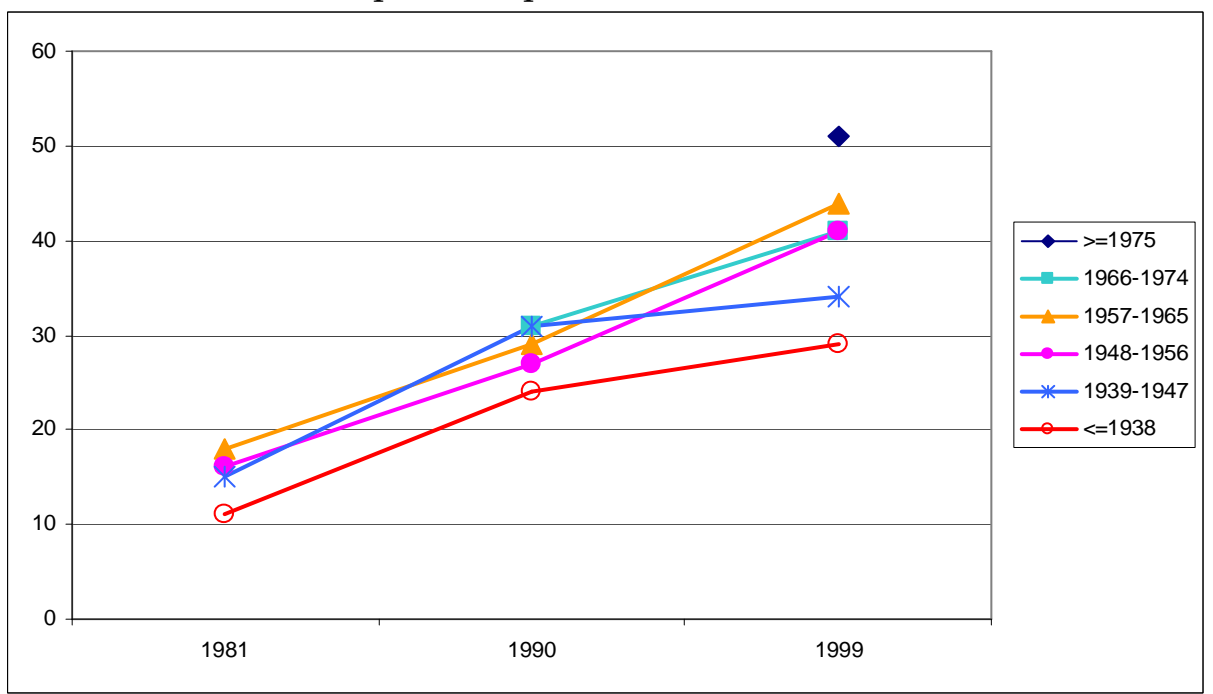




\section{3 Denmark}

Instrumental political involvement

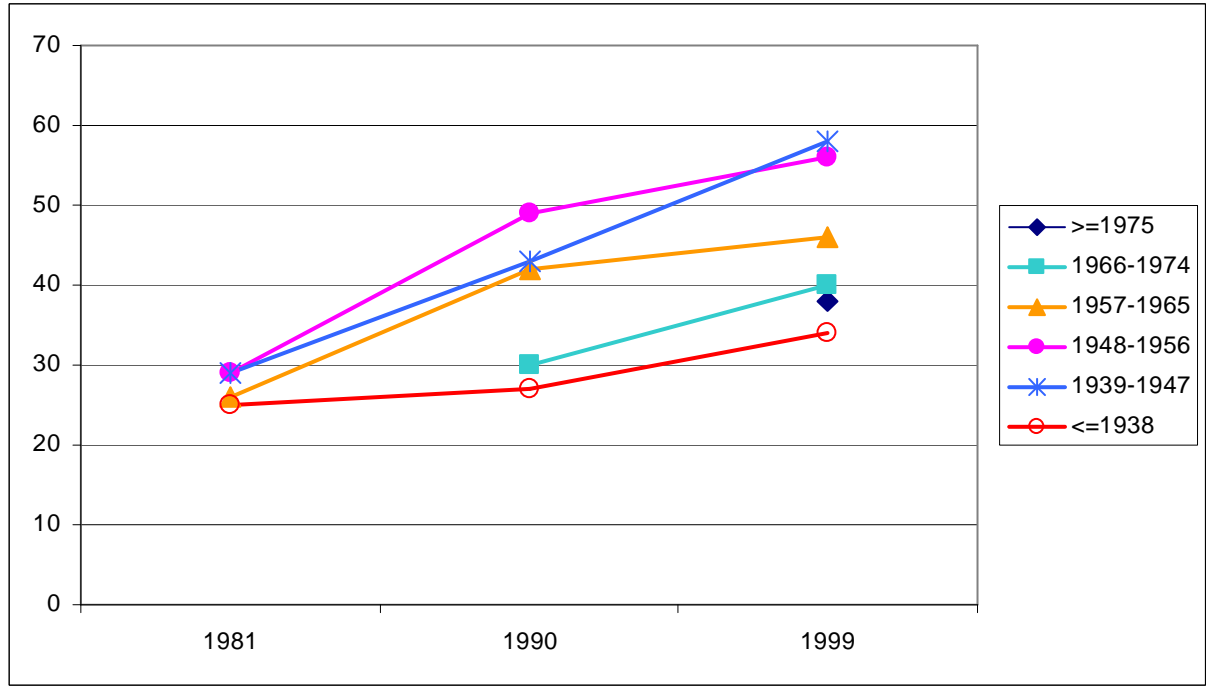

Expressive political involvement

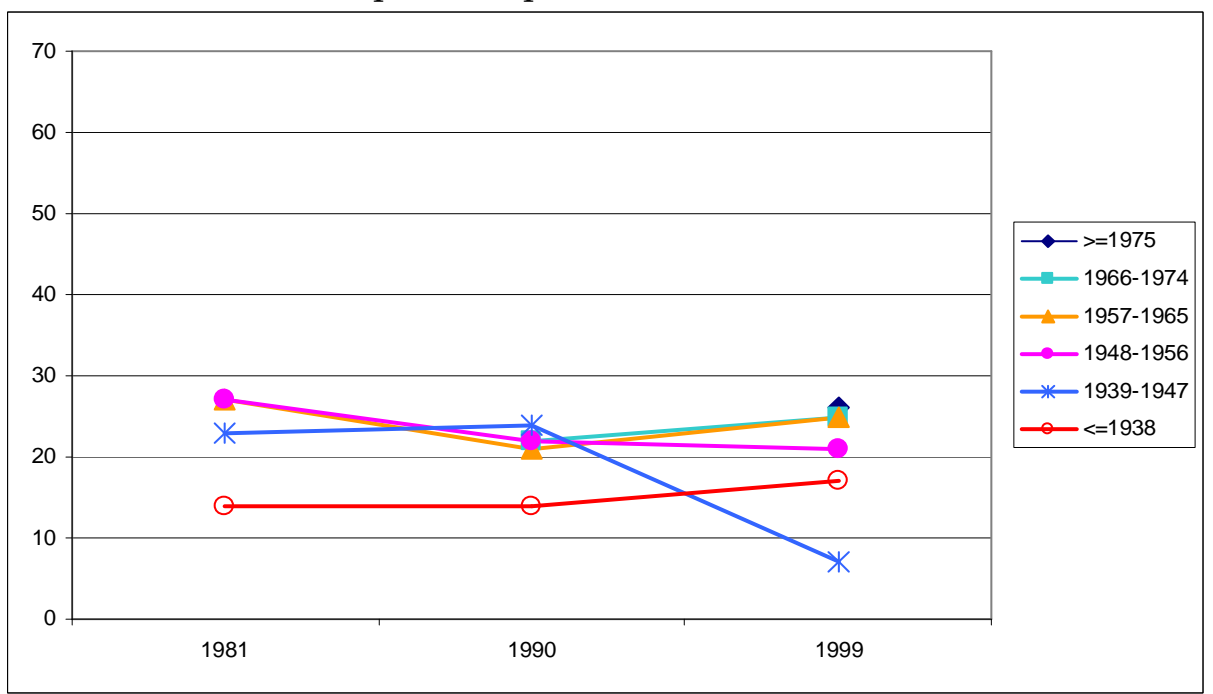




\section{4 Finland}

Instrumental political involvement

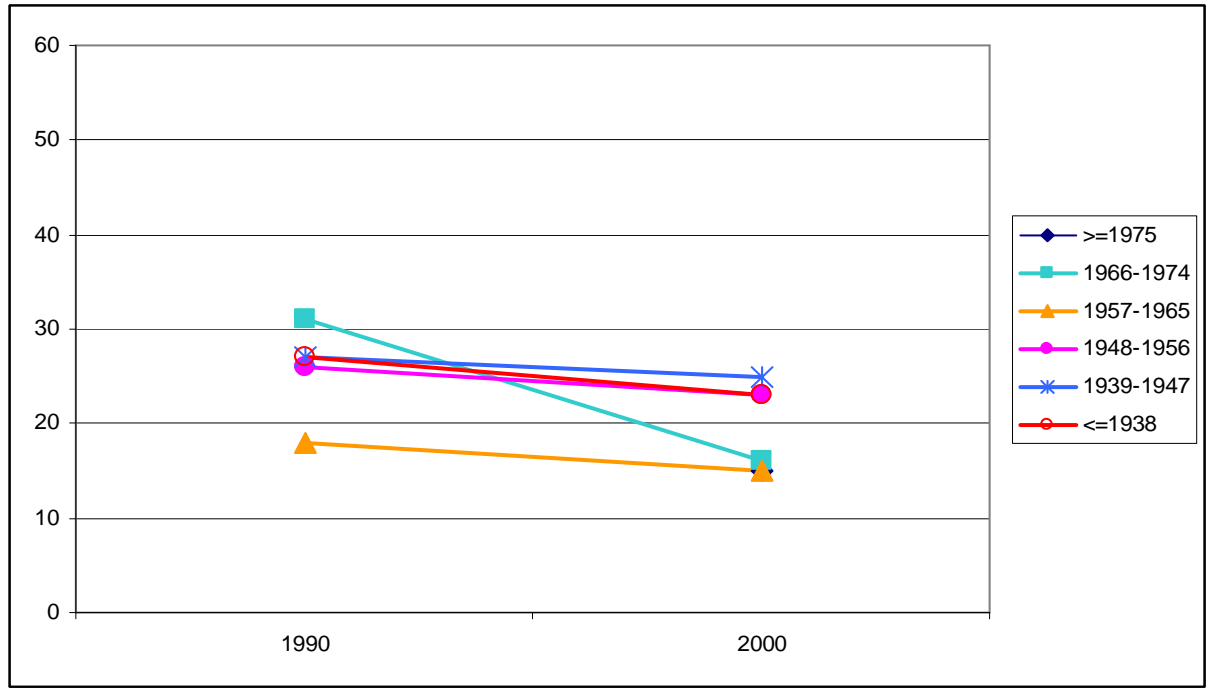

Expressive political involvement

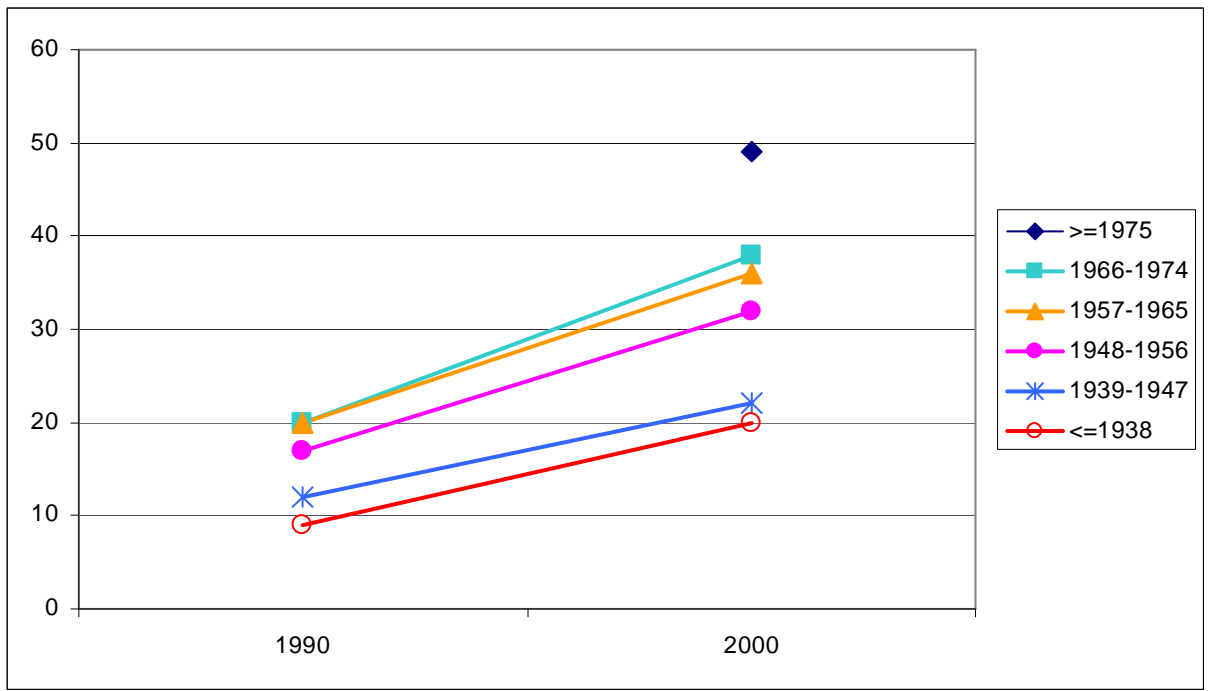




\section{5 France}

Instrumental political involvement

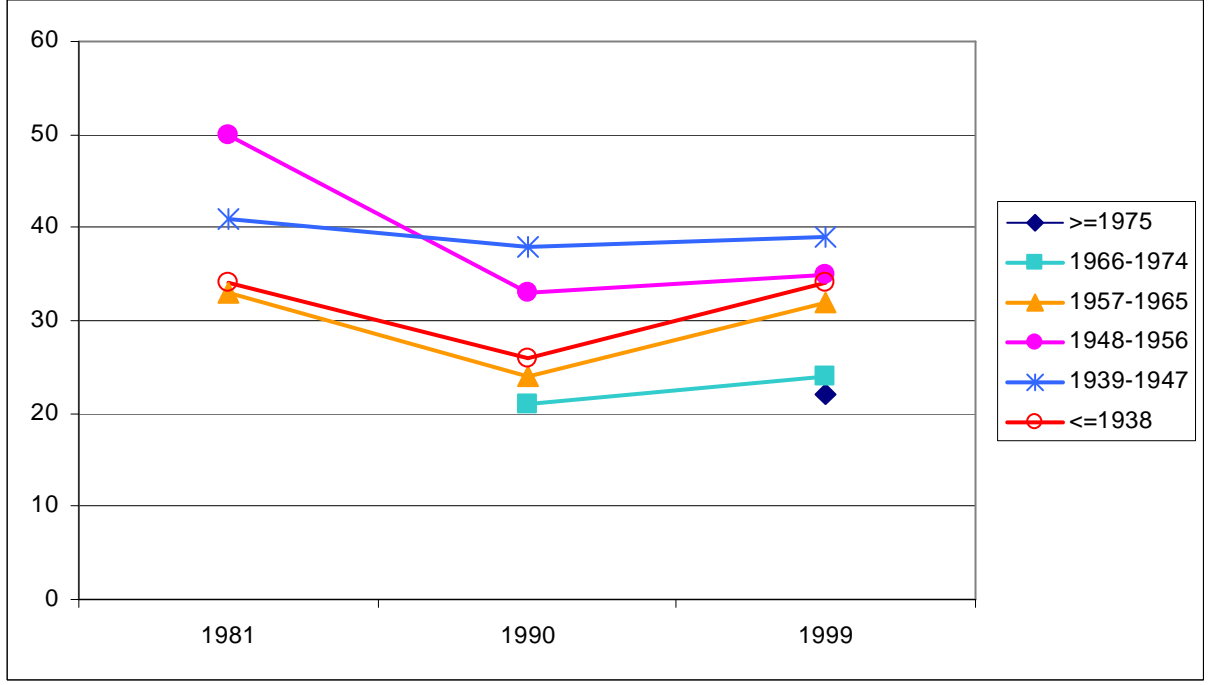

Expressive political involvement

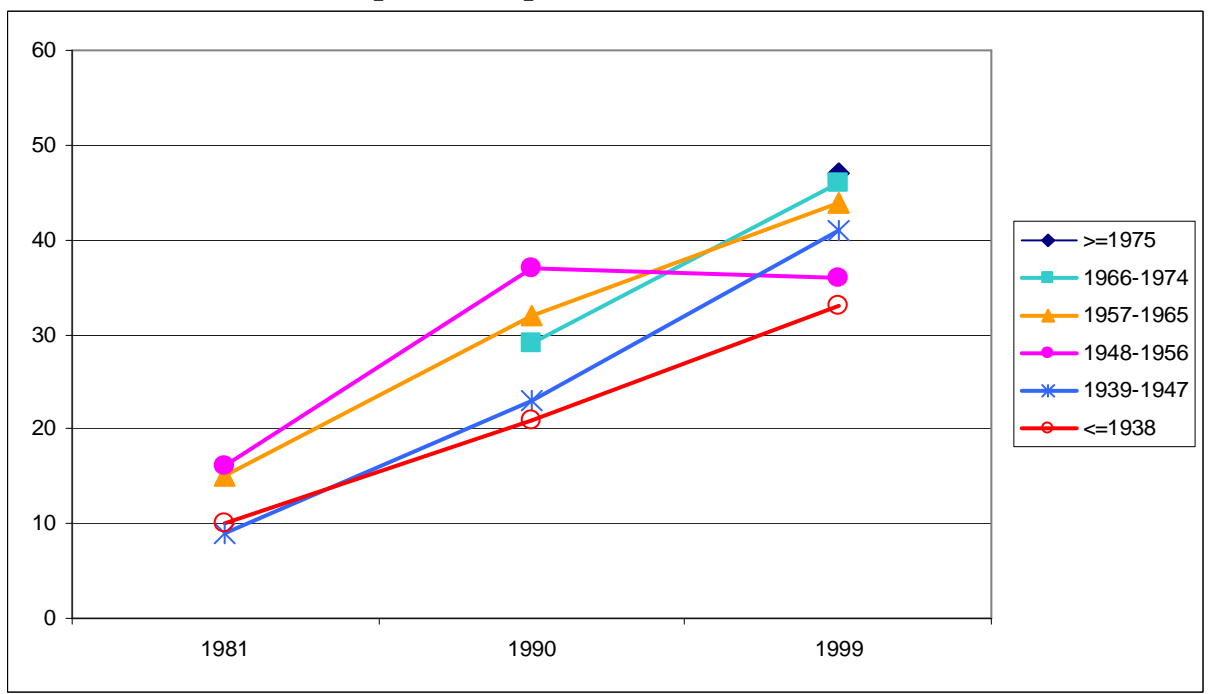




\section{6 Ireland}

Instrumental political involvement

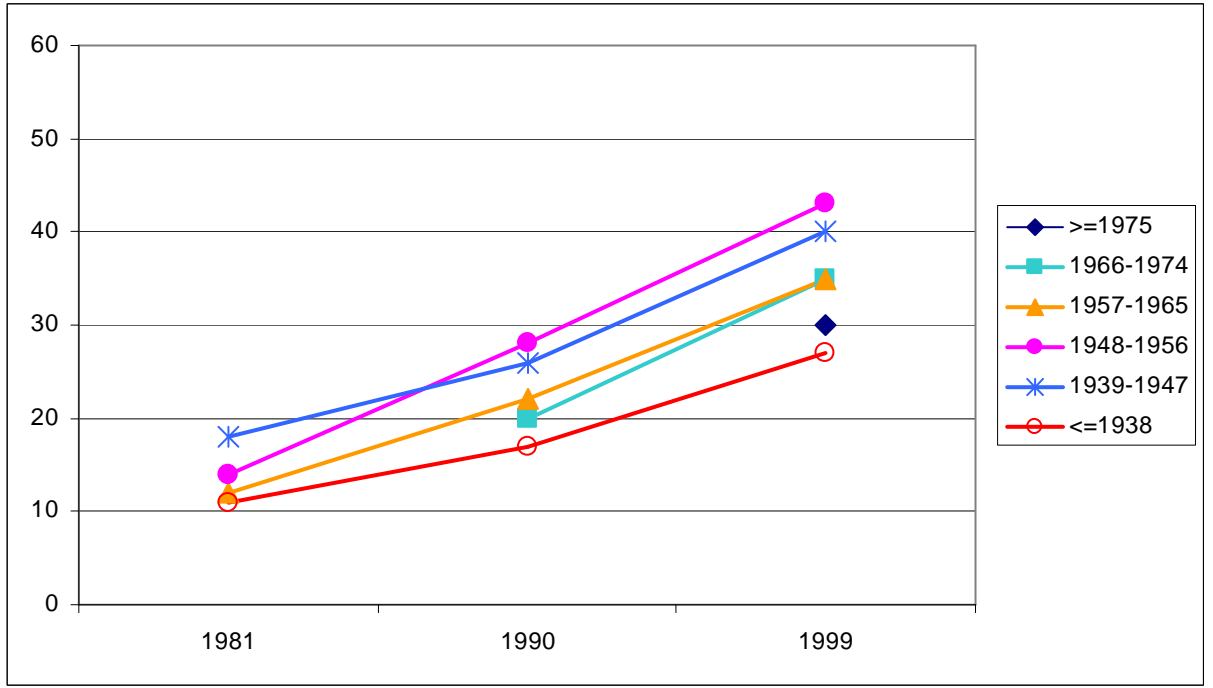

Expressive political involvement

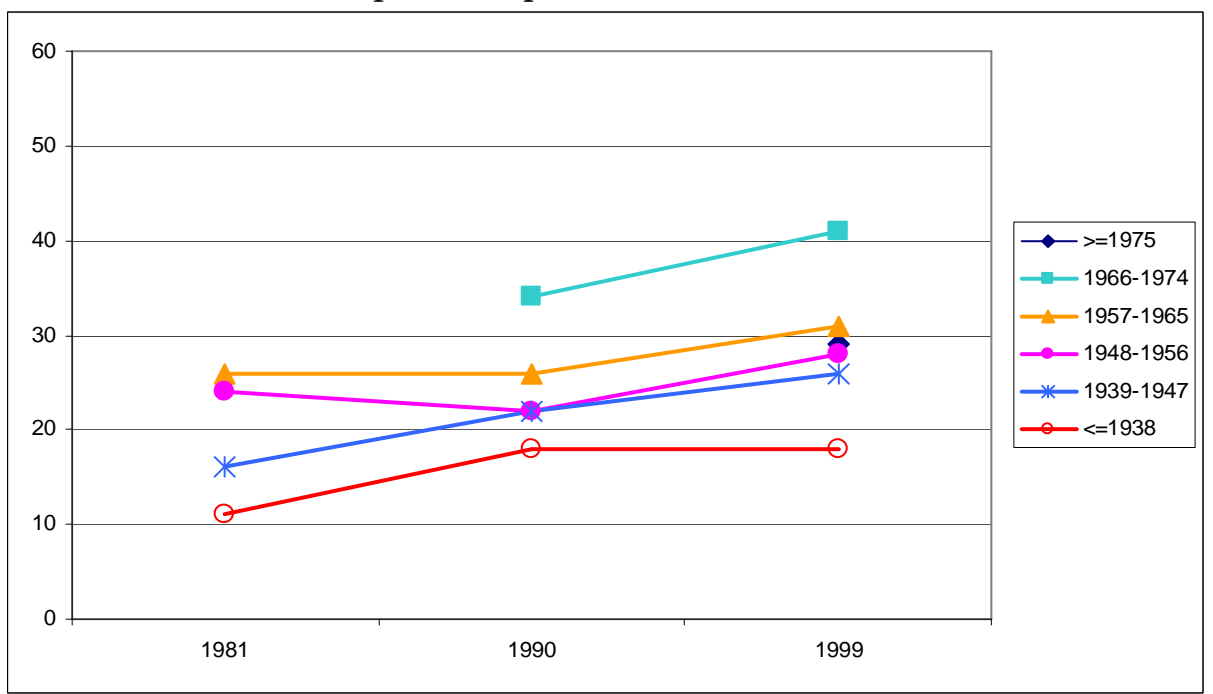




\section{7 Netherlands}

Instrumental political involvement

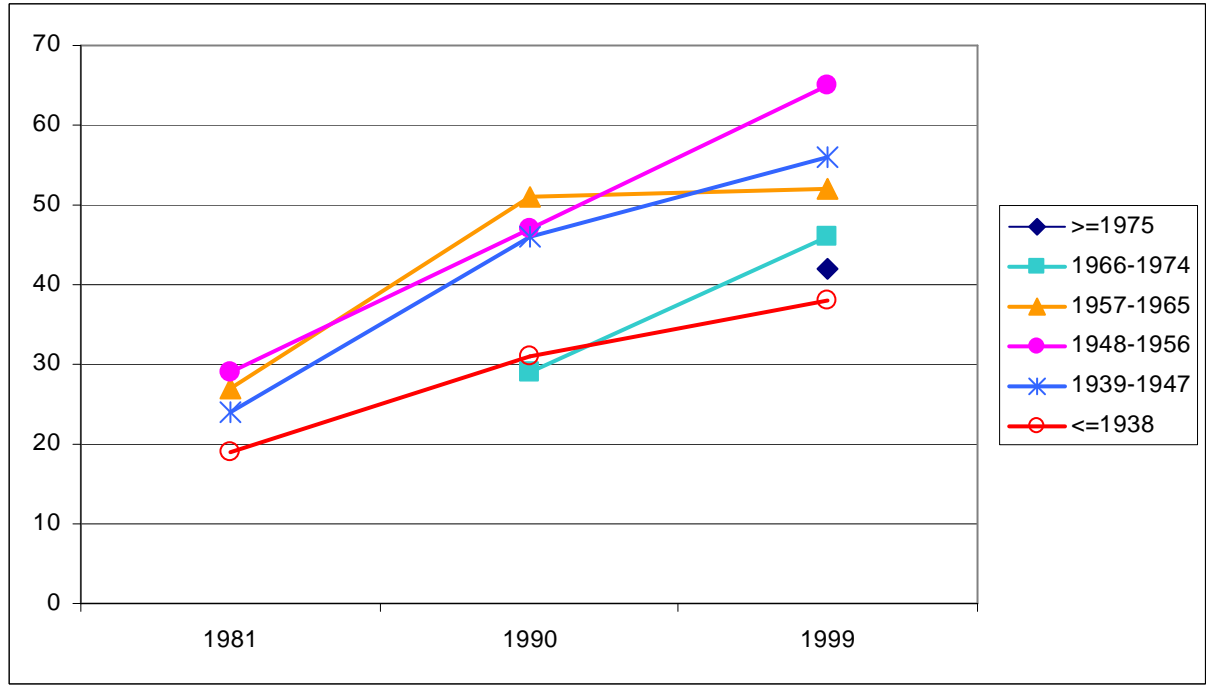

Expressive political involvement

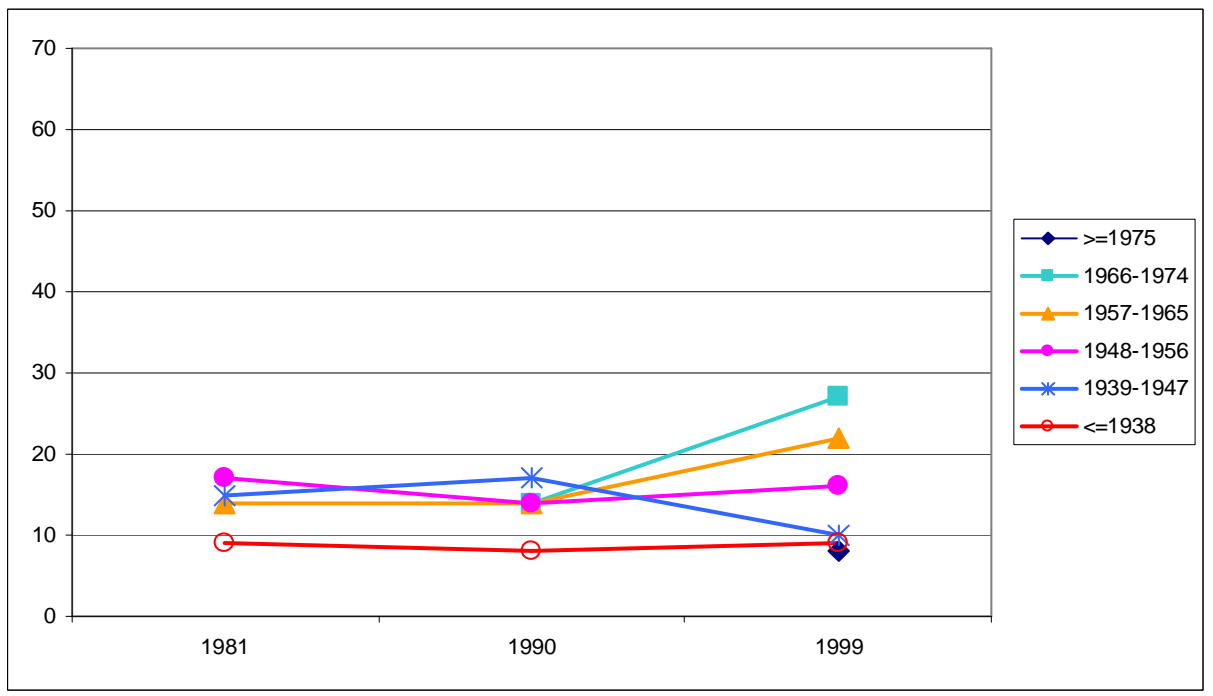




\section{8 Norway}

Instrumental political involvement

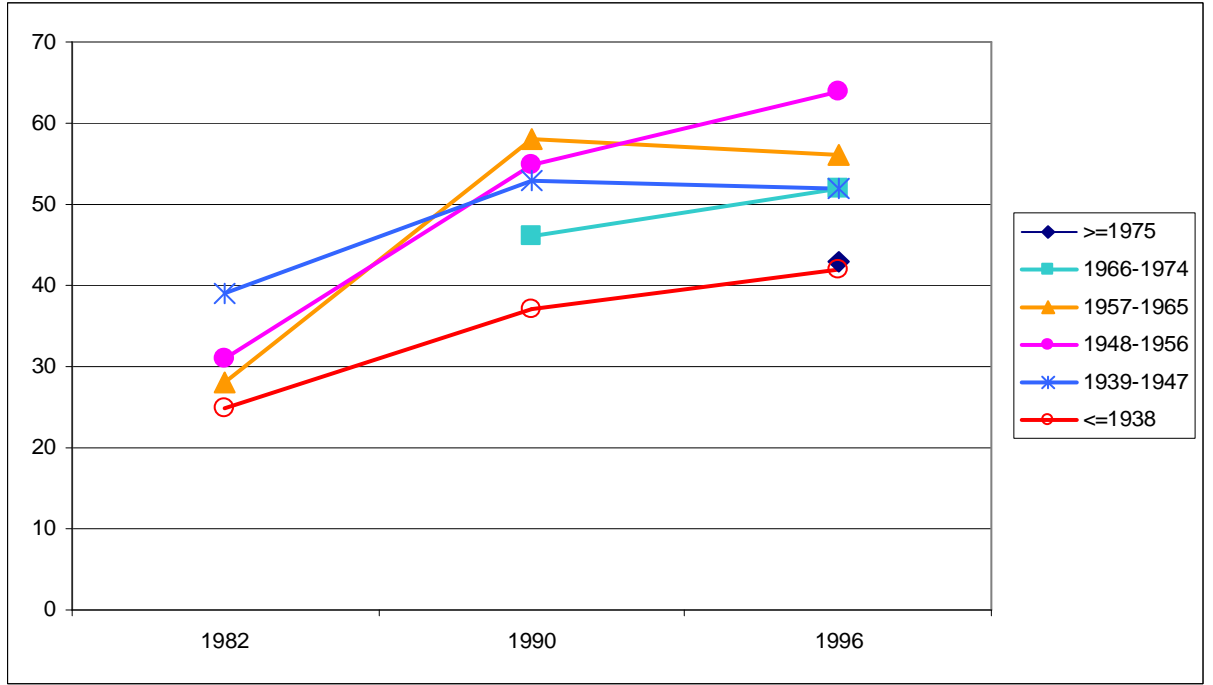

Expressive political involvement

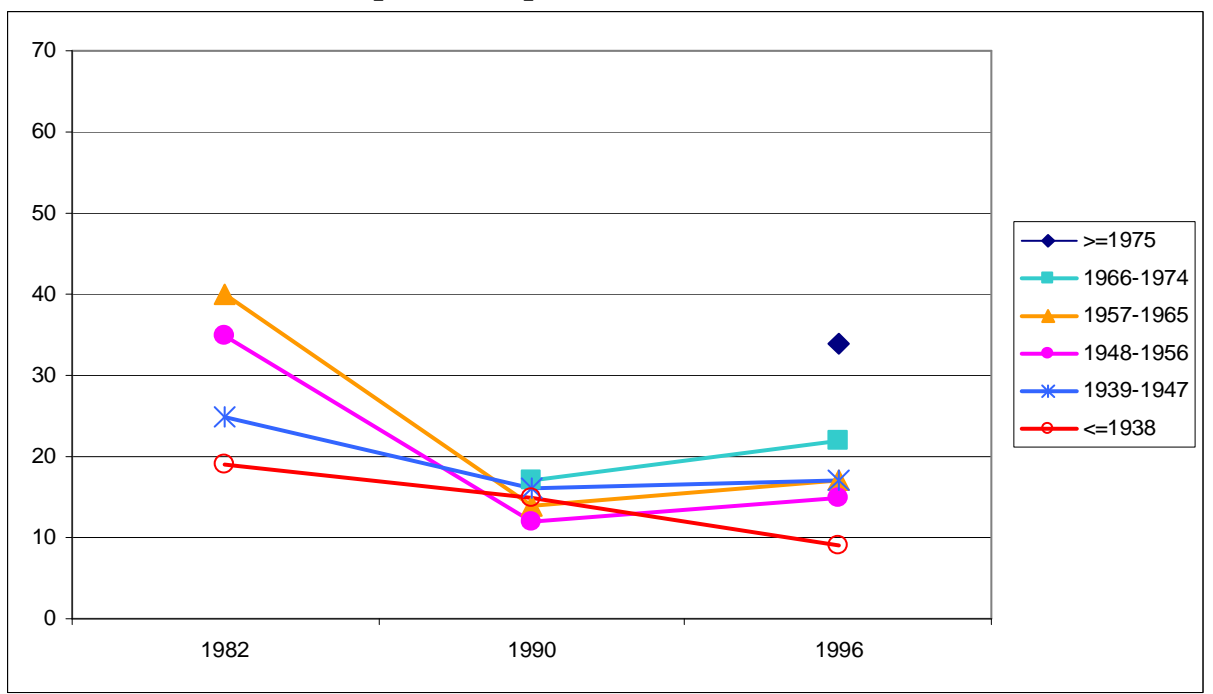




\section{9 Sweden}

Instrumental political involvement

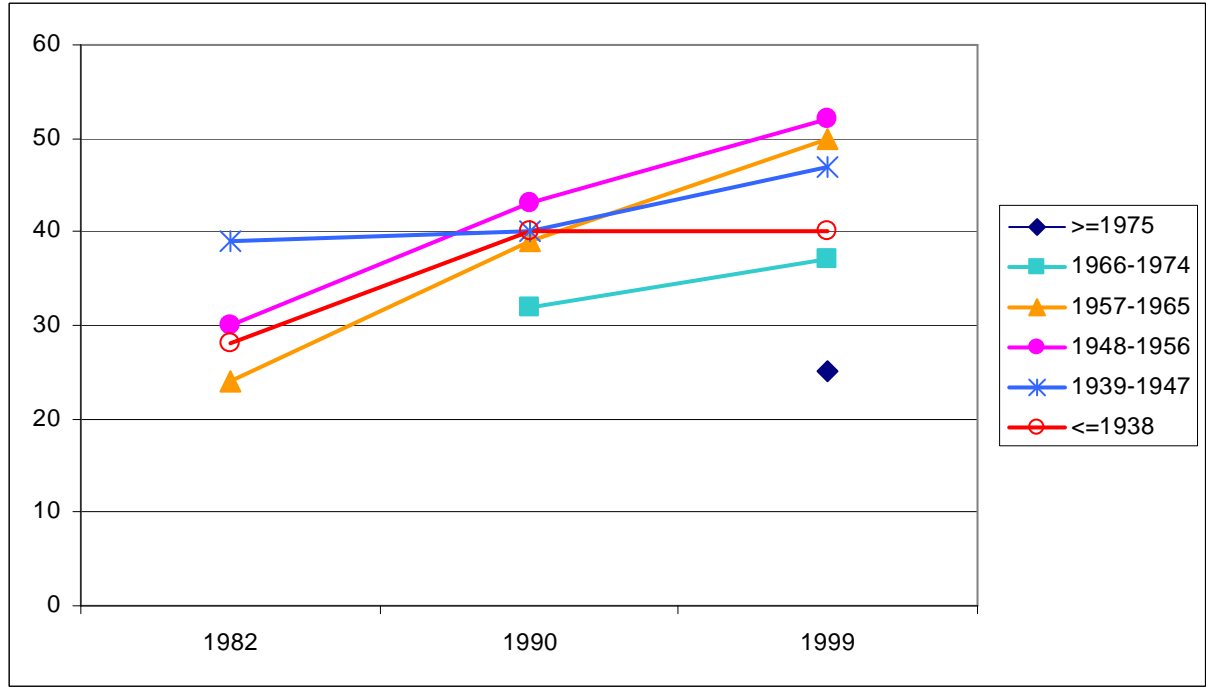

Expressive political involvement

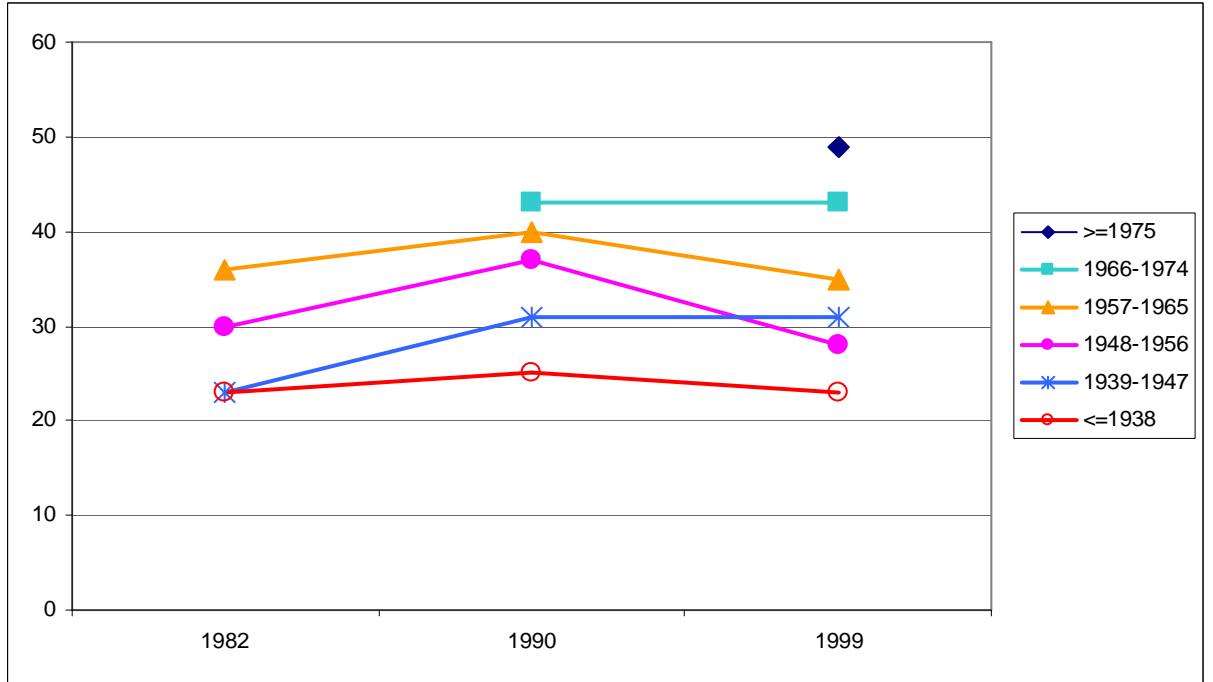




\section{10 Switzerland}

Instrumental political involvement

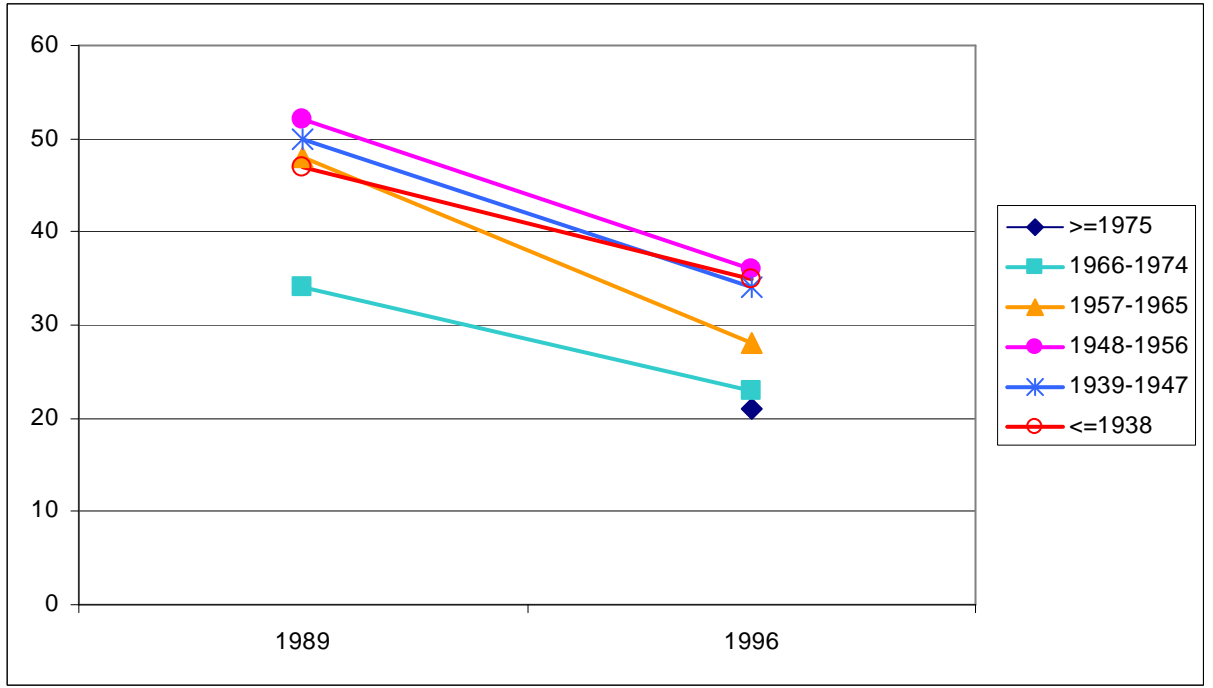

Expressive political involvement

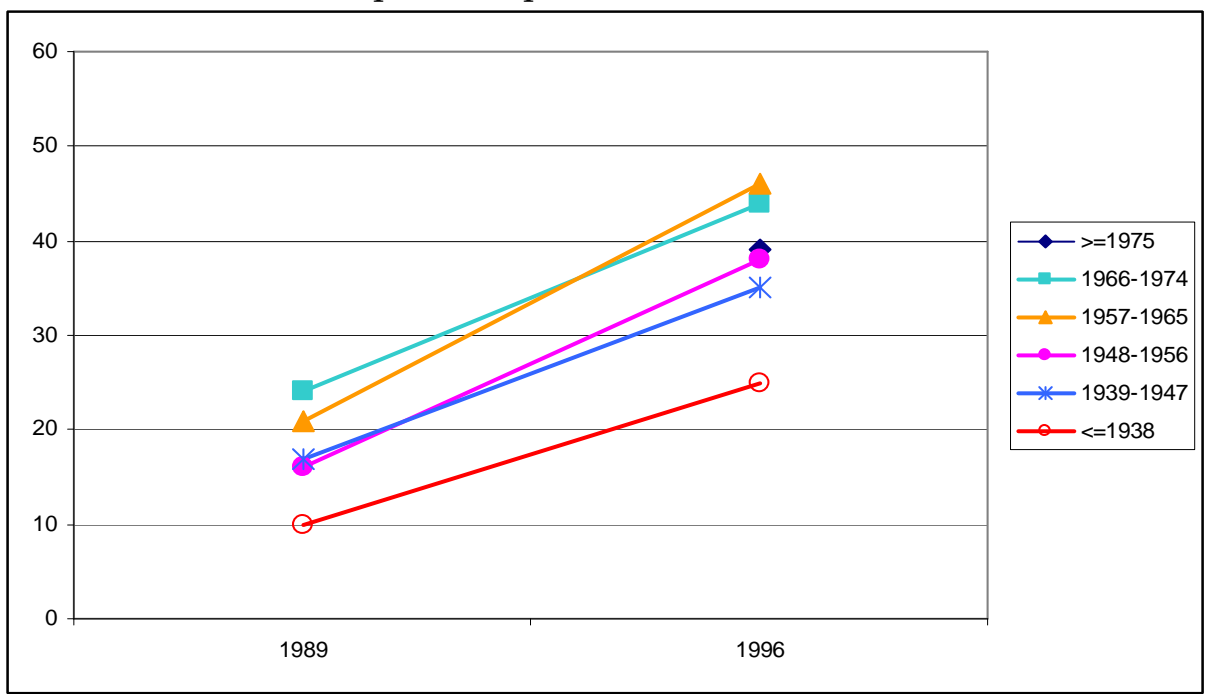




\section{11 United Kingdom}

Instrumental political involvement

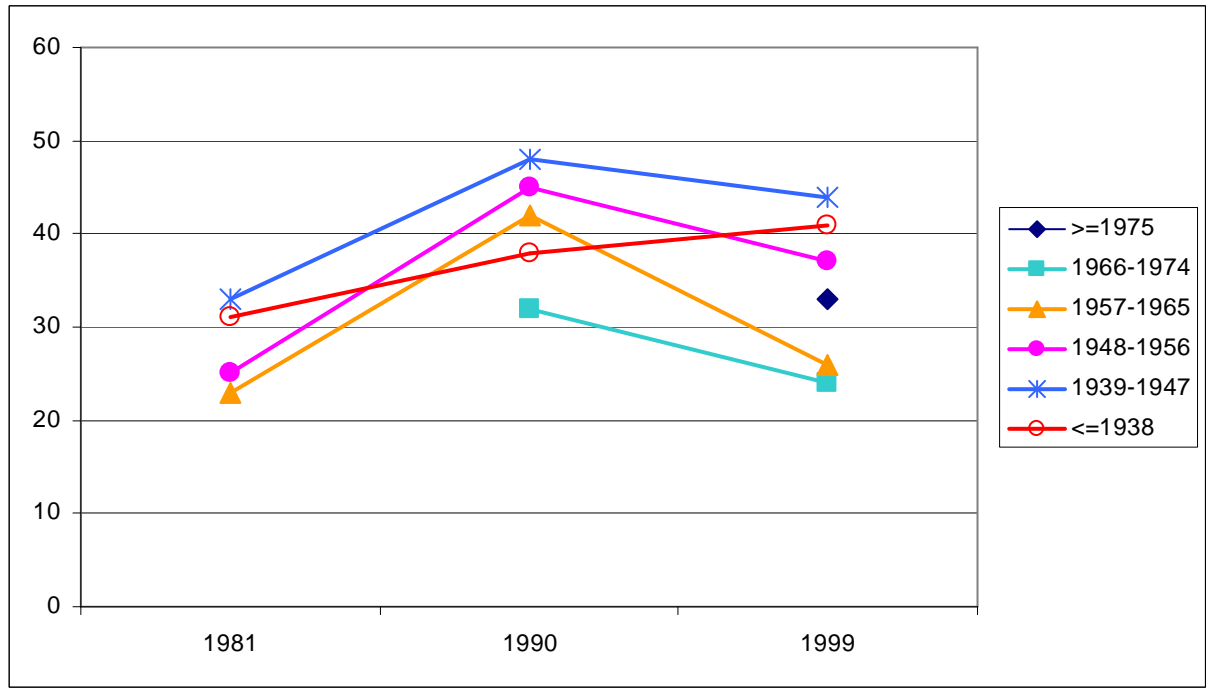

Expressive political involvement

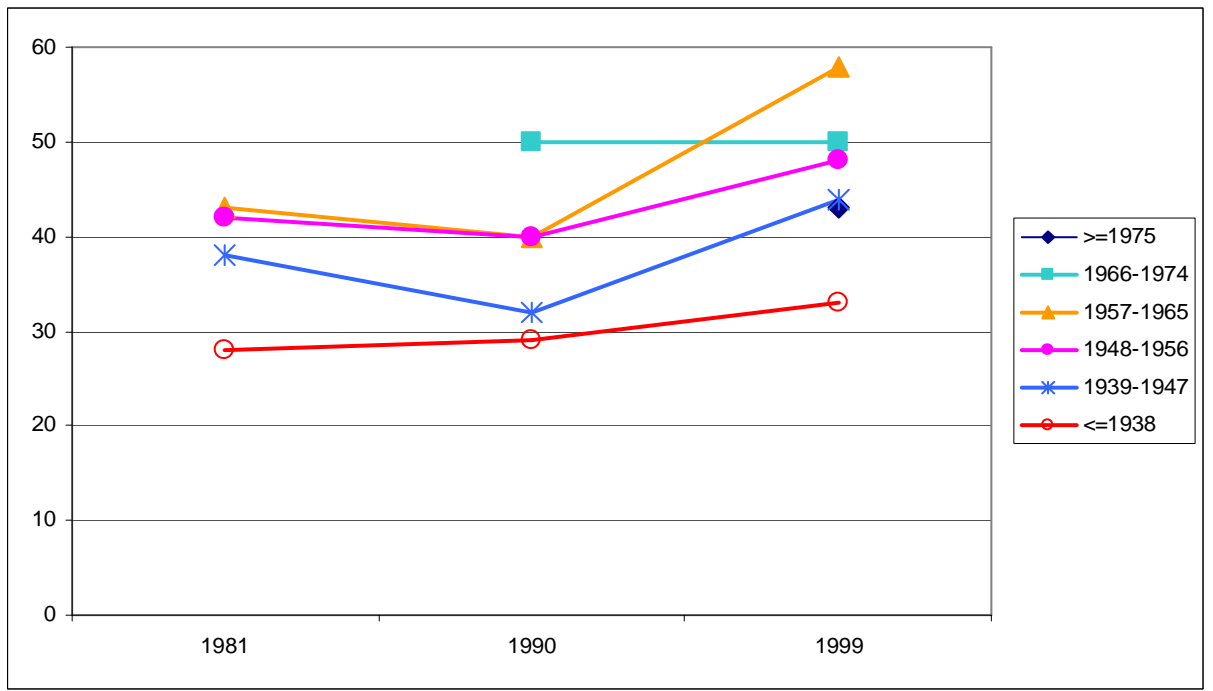




\section{12 West Germany}

Instrumental political involvement

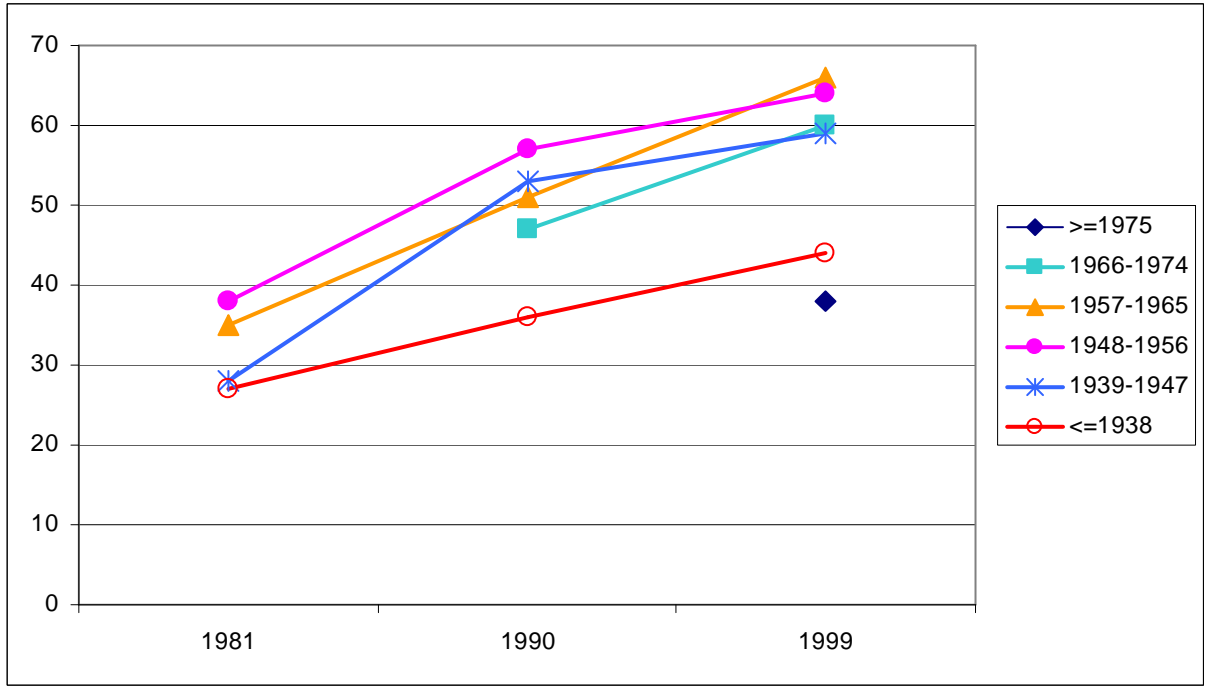

Expressive political involvement

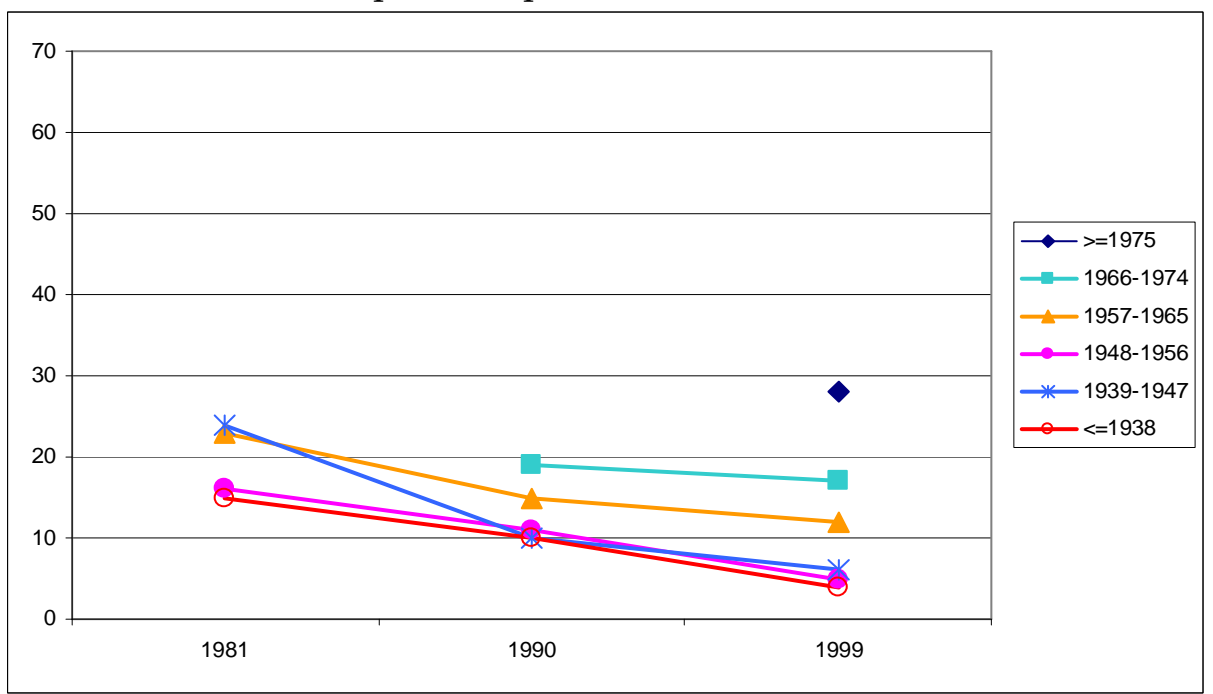




\section{References}

Aarts, K. and Thomassen, J. (2000) 'Belangstelling voor Politiek en Politiek Zelfvertrouwen', in: J. Thomassen, K. Aarts and H. Van der Kolk (eds.) Politieke Veranderingen in Nederland, Den Haag: SDU, pp. 35-55.

Aarts, K. and Wessels, B. (2005) 'Electoral Turnout', in: J.Thomassen (ed.) The European Voter: A Comparative Study of Modern Democracies, New York: Oxford University Press, pp. 64-83.

Aarts,K., Thomassen, J. and Van Wijnen, P. (2000) 'The Swamp of Dutch Politics: How the Impact of Modernization on Political Behavior is Modified by Institutional Context', in: O. Van Heffen, W.J.M. Kickert and J. Thomassen (eds.) Governance in Modern Society, Dordrecht, Boston and London: Kluwer Academic Publishers, pp. 87-108.

Abramson, P.R. and Aldrich, J.H. (1982) 'The Decline of Electoral Participation in America', American Political Science Review 76: 502-521.

Abramson, P.R. and Inglehart, R. (1987) 'Generational Replacement and the Future of Post-Materialist Values', Journal of Politics 49: 231-241.

Abramson, P.R. and Inglehart, R. (1992) 'Generational Replacement and Value Change in Eight West European Societies', British Journal of Political Science 22: 183-228.

Adorno, T.W., Frenkel-Brunswick, E., Levinson, D. and Sanford, R. (1950) The Authoritarian Personality, New York: Harper.

Almond, G.A. and Verba, S. (1963) The Civic Culture: Political Attitudes in Five Western Democracies, Princeton: Princeton University Press.

Arts, W., Hagenaars, J. and Halman, L. (eds.) (2003) The Cultural Diversity of European Unity: Findings, Explanations and Reflections from the European Values Study, LeidenBoston: Brill.

Baker, K.L., Dalton, R.J. and Hildebrandt, K. (1981) Germany Transformed. Cambridge, MA: Harvard University Press.

Barber, B.R. (1984) Strong Democracy. Participatory Politics for a New Age, Berkeley, CA: University of California Press.

Barber, B.R. (1995) 'Participatory Democracy', in: S.M. Lipset (ed.) The Encyclopedia of Democracy, London: Routledge, pp. 921-924. 
Barnes, S.H., Kaase, M. et al. (1979) Political Action: Mass Participation in Five Western Democracies, Beverly Hills CA: Sage.

Beck, U. (1992) Risk Society: Towards a New Modernity, London: Sage.

Beck, U., Giddens, A. and Lash, S. (1994) Reflexive Modernization: Politics, Tradition and Aesthetics in the Modern Social Order, Cambridge: Polity Press.

Bell, D. (1973) The Coming of Post-Industrial Society, New York: Basic Books.

Bell, D. (1976) The Cultural Contradictions of Capitalism, New York: Basic Books.

Bell, D. (1993) Communitarism and Its Critics, Oxford: Clarendon Press.

Bellah, R.N., Madsen, R., Sullivan, R.M., Swidler, A. and Tipton, S.M. (1985) Habits of the Heart: Individualism and Commitment in American Life, Berkeley: University of California Press.

Bennett, S.E. (1986) Apathy in America 1960-1984: Causes and Consequences of Citizen Political Indifference, Dobbs Ferry, NY: Transnational.

Berelson, B. (1952) 'Democratic Theory and Public Opinion', Public Opinion Quarterly 16: 313-330.

Berelson, B., Lazarsfeld, P.F. and McPhee, W. (1954) Voting, Chicago: University of Chicago Press.

Blais, A. (2000) To Vote or Not to Vote? The Merits and Limits of Rational Choice, Pittsburgh: University of Pittsburgh Press.

Blais, A. (2006) 'What Affects Voter Turnout?', Annual Review of Political Science 9: 111-125.

Blais, A., Gidengil, E., Nadeau, R. and Nevitte, N. (2002) Anatomy of a Liberal Victory: Making Sense of the Vote in the 2000 Canadian Election, Peterborough: Broadview Press.

Bleicken, J. (1994) Die athenische Demokratie, Paderborn: Ferdinand Schöningh.

Bloom, A. (1987) The Closing of the American Mind, New York: Simon and Schuester.

Borg, S. (1995) 'Electoral Participation', in: J.W. Van Deth and E. Scarbrough (eds.) The Impact of Values, Oxford: Oxford University Press, pp. 441-460.

Bowler, S. and Donovan, T. (2002) 'Democracy, Institutions and Attitudes about Citizen Influence on Government', British Journal of Political Science 32: 371-390.

Brand, K.-W. (ed.) (1985) Neue soziale Bewegungen in Westeuropa und den USA: Ein internationaler Vergleich, Frankfurt: Campus Verlag.

Brecht, A. (1959) Political Theory. The Foundations of Twentieth-Century Political Thought, Princeton N.J.: Princeton University Press.

Brennan, G. and Buchanan, J. (1984) 'Voter Choice and the Evaluation of Political Alternatives', American Behavioral Scientist 28: 185-201.

Brennan, G. and Lomasky, L. (1993) Democracy and Decision, Cambridge: Cambridge University Press. 
Brennan, G. (2001) 'Five Rational Actor Accounts of the Welfare State', Kyklos 54: 213234.

Broder, D. (2000) Democracy Derailed: Initiative Campaigns and the Power of Money, New York: Harcourt Brace Publishers.

Brody, R.A. (1978) 'The Puzzle of Political Participation in America', in: A. King (ed.) The New American Political System, Washington DC: American Enterprise Institute, pp. 287-324.

Budge, I. (1996) The New Challenge of Direct Democracy, Cambridge: Polity Press.

Butler, D. and Stokes, D. (1969) Political Change in Britain, London: Macmillan.

Campbell, A., Converse, P., Miller, W. and Stokes, D. (1960) The American Voter, New York: Wiley.

Citrin, J. (1996) 'Who's the Boss? Direct Democracy and Popular Control of Government', in: S. Craig (ed.) Broken Contract: Changing relationships between Americans and their government, Boulder: Westview, pp. 268-293.

Cohen, J. and Sabel, C. (1997) 'Directly-Deliberative Polyarchy', European Law Journal 3: 313-342.

Coleman, J.S. (1990) Foundations of Social Theory, Cambridge, MA: Harvard University Press.

Colomer, J. (ed.) (2004) Handbook of Electoral System Choice, Basingstoke: Palgrave.

Conover, P. J., Crewe, I. M., \& Searing, D. D. (1991) 'The Nature of Citizenship in the United States and Great Britain: Empirical Comments on Theoretical Themes', The Journal of Politics 53: 800-832.

Craig, S.C., Niemi, R.C. \& Silver, G.E. (1990) 'Political Efficacy and Trust: A Report on the NES Pilot Study Items', Political Behaviour 12: 289-314.

Crepaz, M. (1990) 'The Impact of Party Polarization and Postmaterialism on Voter Turnout', European Journal of Political Research 18: 183-205.

Crook, S., Pakulski, J. and Waters, M. (1992) Postmodernization: Change in Advanced Society. London: Sage.

Crozier, M. Huntington, S.H. and Watanuki, J. (1975) The Crisis of Democracy: Report on the Governability of Democracies to the Trilateral Commission, New York: New York University Press.

Curtice, J. and Seyd, B. (2003) 'Is There a Crisis of Political Participation?', in: A. Park et al. (ed.) British Social Attitudes: The 20 th Report. Continuity and Change over Two Decades, London, Thousand Oaks \& New Delhi: Sage, pp. 93-107.

Dahl, R.A. and Tufte, E.R. (1974) Size and Democracy, Stanford, CA: Stanford University Press. 
Dahl, R.A. (1956) A Preface to Democratic Theory, Chicago, IL: Chicago University Press.

Dahl, R.A. (1961) Who Governs? Democracy and Power in an American City, New Haven, CT: Yale University Press.

Dahl, R.A. (1989) Democracy and its Critics, New Haven, CT: Yale University Press.

Dahl, R.A. (1994) 'A Democratic Dilemma: System Effectiveness versus Citizen Participation', Political Science Quarterly 1: 23-34.

Dalton, R.J. and Küchler, M. (eds.) (1990) Challenging the Political Order: New Social and Political Movements in Western Democracies, Cambridge: Polity Press.

Dalton, R.J. and Wattenberg, M.P. (eds.) (2000) Parties without Partisans: Political Change in Advanced Industrial Democracies, Oxford: Oxford University Press.

Dalton, R.J. (1984) 'Cognitive Mobilization and Partisan Dealignment in Advanced Industrial Democracies', Journal of Politics 46: 264-284.

Dalton, R.J. (2000) 'Citizen Attitudes and Political Behavior', Comparative Political Studies 33: 912-940.

Dalton, R.J. (2004) Democratic Challenges, Democratic Choices: The Erosion of Political Support in Advanced Industrial Democracies, Oxford: Oxford University Press.

Dalton, R.J. (2006) Citizen Politics. Public Opinion and Political Parties in Advanced Industrial Democracies. $4^{\text {th }}$ Edition, Washington DC: CQ Press.

Dalton, R.J., Flanagan, S.C. and Beck, P.A. (eds.) (1984) Electoral Change in Advanced Industrial Democracies, Princeton: Princeton University Press.

Davidov, E., Schmidt, P. and Schwartz, S.H. (2008) 'Bringing Values Back In: The Adequacy of the European Social Survey to Measure Values in 20 Countries', Public Opinion Quarterly 72: 420-445.

Delli Carpini, M. and Keeter, S. (1996) What Americans Know about Politics and Why it Matters, New Haven, CT: Yale University Press.

Denters, B. and Rose, L.E. (eds.) (2005) Comparing Local Governance. Trends and Developments, New York: Palgrave MacMillan.

Denters, B., Gabriel, O.W. and Torcal, M. (2007) 'Norms of Good Citizenship', in: J.W. Van Deth, J.R. Montero and A. Westholm (eds.) Citizenship and Involvement in Europe: A Comparative Analysis, London and New York: Routledge, pp. 88-108.

Downs, A. (1957) An Economic Theory of Democracy, New York: Harper.

Easton, D. (1965) A Systems Analysis of Political Life, New York: Wiley.

Easton, D. (1975) 'A Re-Assessment of the Concept of Political Support', British Journal of Political Science 5: 435-457.

Eder, W. (1998) 'Aristocrats and the Coming of Athenian Democracy', in: I. Morris and K.A. Raaflaub (eds.) Democracy 2500? Question and Challenges, Archeological 
Institute of America, Colloquia and Conference papers No. 2, Dubuque, IA: Kendall/Hunt, pp. 105-140.

Ester, P., Halman, L. and De Moor, R. (eds.) (1994) The Individualizing Society: Value Change in Europe and North America, Tilburg: Tilburg University Press.

Etzioni, A. (1996) The New Golden Rule: Community and Morality in a Democratic Society, New York: Basic Books.

Feldman, Stanley (2003) 'Values, Ideology, and Structure of Political Attitudes', in: D.O. Sears, L. Huddy, and R. Jervis (eds.) Oxford Handbook of Political Psychology, New York: Oxford University Press, pp. 477-508.

Finkel, S.E. (1985) 'Reciprocal Effects of Participation and Political Efficacy: A Panel Analysis', American Journal of Political Science 29: 891-913.

Finkel, S.E. (1987) 'The Effects of Participation on Political Efficacy and Political Support: Evidence from a West German Panel', Journal of Politics 49: 441-464.

Fiorina, Morris. (1990) 'Information and Rationality in Elections', in: J. Ferejohn and J. Kuklinski (eds.) Information and Democratic Processes, Urbana: University of Illinois Press, pp. 329-342.

Fischer, F. (2000) Citizens, Experts, and the Environment. The Politics of Local Knowledge, Durham and London: Duke University Press.

Franklin, M.N. (1996) 'Electoral Participation', in: L. LeDuc, R.G. Niemi and P. Norris (eds.) Comparing Democracies: Elections and Voting in Global Perspective, Thousand Oaks: Sage, pp. 216-235.

Franklin, M. (2002) 'The Dynamics of Electoral Participation', in L. Leduc, R. Niemi, and P. Norris (eds.) Comparing Democracies 2, Thousand Oaks CA: Sage, pp. 148168.

Franklin, M. (2004) Voter Turnout and the Dynamics of Electoral Competition in Established Democracies Since 1945, Cambridge: Cambridge University Press.

Fuchs, D. and Klingemann, H.-D. (1995) 'Citizens and the State: A Changing Relationship?', in: H.-D Klingemann and D. Fuchs (eds.) Citizens and the State, Oxford: Oxford University Press, pp. 1-23.

Fuchs, D. (1991) 'The Normalization of the Unconventional: New Forms of Political Action and New Social Movements', in: G. Meyer and F. Ryszka (eds.) Political Participation and Democracy in Poland and West Germany, Warsaw: Wydawca, pp. 148-169.

Fuchs, D. (2000) 'Demokratie und Beteiligung in der modernen Gesellschaft: einige demokratietheoretische Überlegungen', in: O. Niedermayer and B. Westle (eds.) Demokratie und Partizipation. Festschrift für Max Kaase, Wiesbaden: Westdeutscher Verlag, pp. 250-280. 
Fuchs, D. (2007) 'Participatory, Liberal and Electronic Democracy', in: T. Zittel and D. Fuchs (eds.) Participatory Democracy and Political Participation: Can participatory engineering bring citizens back in?, London and New York: Routledge, pp. 29-54.

Gabriel, O.W. and Van Deth, J.W. (1995) 'Political Interest', in: J.W. Van Deth and E. Scarbrough (eds.) The Impact of Values, Oxford: Oxford University Press, pp. 390411.

Gabriel, O.W. and Völkl, K. (2005) 'Politische und soziale Partizipation', in: O.W. Gabriel and E. Holtmann (eds.) Handbuch Politisches System der Bundesrepublik Deutschland. 3., völlig überarbeitete und erweiterte Auflage, München and Wien: Oldenbourg, pp. 523-573.

Gabriel, O.W. and Völkl, K. (2008) 'Politische und soziale Partizipation', in: O.W. Gabriel and S, Kropp (eds.) Die EU-Staaten im Vergleich. Strukturen, Prozesse, Politikinhalte, Wiesbaden: VS Verlag für Sozialwissenschaften, pp. 268-268.

Gabriel, O.W. (1995) 'Political Efficacy and Trust', in: J.W. Van Deth and E. Scarbrough (eds.) The Impact of Values, Oxford: Oxford University Press, pp. 357389.

Gabriel, O.W. (2004) 'Politische Partizipation', in: J.W. Van Deth (ed.) Deutschland in Europa, Wiesbaden: Verlag für Sozialwissenschaften, pp. 317-338.

Geissel, B. (2008) ‘Do Critical Citizens Foster Better Governance? A Comparative Study', West European Politics 31: 855-873.

Gerber, E. (1999) The Populist Paradox: Interest Group Influence and the Promise of Direct Legislation, Princeton: Princeton University Press.

Gibbins, J.R. and Reimer, B. (1995) 'Postmodernism', in: J.W. Van Deth and E. Scarbrough (eds.) The Impact of Values, Oxford: Oxford University Press, pp. 301331.

Gibbins, J.R. and Reimer, B. (1999) The Politics of Postmodernity. An Introduction to Contemporary Politics and Culture, London, Thousand Oaks and New Delhi: Sage.

Gibbins, J.R. (1989) 'Contemporary Political Culture: An Introduction', in: J.R. Gibbins (ed.) Contemporary Political Culture: Politics in a Postmodern Age, London: Sage, pp. 1-30.

Gibson, J.L. (1997) 'Mass Opposition to the Soviet Putsch of August 1991: Collective Action, Rational Choice, and Democratic Values', American Political Science Review 91: 671-684.

Giddens, A. (1990) The Consequences of Modernity, Cambridge: Polity Press.

Goebel, T. (2002) A Government by the People: Direct Democracy in America, 1890-1940, Chapel Hill: University of North Carolina Press.

Goerres, A. (2009) The Political Participation of Older People In Europe: The Greying of Our Democracies, London and New York: Palgrave Macmillan. 
Gosnell, H.F. (1927) Getting Out the Vote: An Experiment in the Stimulation of Voting, Chicago: University of Chicago Press.

Gosnell, H.F. (1930) Why Europe Votes, Chicago: University of Chicago Press.

Gould, C. (1988) Rethinking Democracy: Freedom and Social Cooperation in Politics, Economy and Society, Cambridge: Cambridge University Press.

Gray, M. and Caul, M. (2000) 'Declining Voter Turnout in Advanced Industrial Democracies, 1950-1997', Comparative Political Studies 33: 1091-1122.

Gurr, T.R. (1970) Why Men Rebel, Princeton: Princeton University Press.

Habermas, J. (1992) Faktizität und Geltung. Beiträge zur Diskurstheorie des Rechts und des demokratischen Rechtsstaats, Frankfurt am Main: Suhrkamp.

Hadenius, A. (2001) Institutions and Democratic Citizenship, New York: Oxford University Press.

Halman, L. and De Moor, R. (1994) 'Value Shift in Western Societies', in: P. Ester, L. Halman, and R. de Moor (eds.) The Individualizing Society: Value Change in Europe and North America, Tilburg: Tilburg University Press, pp. 1-20.

Halman, L. and Nevitte, N. (eds.) (1996) Political Value Change in Western Democracies, Tilburg: Tilburg University Press.

Halman, L. and Pettersson, T. (1995) 'Individualization and Value Fragmentation', in: R. De Moor (ed.) Values in Western Societies, Tilburg: Tilburg University Press, pp. 297-316.

Hansen, M.H. (1991) The Athenian Democracy in the Age of Demosthenes. Structure, Principles, and Ideology, Oxford: Blackwell.

Hansen, M.H. (1996) 'The Ancient Athenian and the Modern Liberal View of Liberty as a Democratic Ideal, in: J. Ober and C. Hedrick (eds.) Demokratia. A Conversation on Democracies. Ancient and Modern, Princeton: Princeton University Press, pp. 91104.

Heath, D. and Topf, R. (1987) 'Political Culture in British Social Attitudes', in: R. Jowell, S. Witherspoon and L. Brook (eds.) British Social Attitudes Survey: The 1987 Report, Aldershot: Gower, pp. 50-69.

Held, D. and Krieger, J. (1984) 'Theories of the State: Some Competing Claims', in: S. Bornstein, D. Held and J. Krieger (eds.) The State in Capitalist Europe, London: Allen and Unwin, pp. 1-20.

Held, D. (2006) Models of Democracy. Third Edition, Cambridge and Malden: Polity Press.

Heunks, F. (1990) 'From Personal to Political', in: M.K. Jennings and J.W. Van Deth et al. (eds.) Continuities in Political Action: A Longitudinal Study of Political Orientations in Three Western Democracies, Berlin: de Gruyter, pp. 135-160.

Hibbing, J.R. and Theiss-Morse, E. (2002) Stealth Democracy: Americans' Beliefs about How Government Should Work, Cambridge: Cambridge University Press. 
Hirschman, A.O. (1970) Exit, Voice, and Loyalty: Responses to Decline in Firms, Organizations, and States, Cambridge, MA: Harvard University Press.

Hofstede, G. (1980) Culture's Consequences: International Differences in Work-Related Values, Beverly Hills, CA: Sage.

Holden, B. (1988) Understanding Liberal Democracy, London: Philip Allan Publishers.

Holmberg, S. (1999) 'Down and Down We Go: Political Trust in Sweden', in: P. Norris (ed.) Critical Citizens: Global Support for Democratic Governance, New York: Oxford University Press, pp. 103-122.

Hooghe, M. and Dejaeghere, Y. (2007) 'Does the "Monitorial Citizen" Exist? An Empirical Investigation into the Occurrence of Postmodern Forms of Citizenship in the Nordic Countries', Scandinavian Political Studies 30: 249-271.

Hooghe, M. and Stolle, D. (eds.) (2003) Generating Social Capital: Civil Society and Institutions in Comparative Perspective, New York: Palgrave Macmillan.

Hooghe, M. (2004) 'Political Socialization and the Future of Politics', Acta Politica 39: 331-341.

Hooghe, M., Stolle, D. and Stouthuysen, P. (2004) 'Head Start in Politics. The Recruitment Function of Youth Organizations of Political Parties in Belgium (Flanders)', Party Politics 10: 193-212.

Huckfeldt, Robert, Dalton, Russell J., and Beck, Paul. (1998) 'Ambiguity, Distorted Messages, and Environmental Effects on Political Communication', Journal of Politics 60: 996-1030.

Huntington, S.P. (1968) Political Order in Changing Societies, New Haven, CT: Yale University Press.

Huntington, S.P. (1974) ‘Postindustrial Politics: How Benign Will It Be?', Comparative Politics 6: 163-191.

Inglehart, R. and Abramson, P. (1994) 'Economic Security and Value Change', American Political Science Review 88: 336-354.

Inglehart, R. and Abramson, P. (1999) 'Measuring Postmaterialism', American Political Science Review 93: 665-677.

Inglehart, R. and Baker, W. (2000) 'Modernization, Cultural Change, and the Persistence of Traditional Values', American Sociological Review 65: 19-51.

Inglehart, R. and Catterberg, G. (2002) 'Trends in Political Action: The Developmental Trend and the Post-Honeymoon Decline', International Journal of Comparative Sociology 43: 300-316.

Inglehart, R. and Norris, P. (2003) Rising Tide: Gender Equality and Cultural Change around the World, New York: Cambridge University Press.

Inglehart, R. and Oyserman, D. (2004) 'Individualism, Autonomy, Self-Expression: The Human Development Syndrome', in: H. Vinken, J. Soeters and P. Ester (eds.) 
Comparing Cultures: Dimensions of Culture in a Comparative Perspective, Leiden and Boston: Brill, pp. 74-96.

Inglehart, R. and Welzel, C. (2005) Modernization, Cultural Change, and Democracy: The Human Development Sequence, Cambridge and New York: Cambridge University Press.

Inglehart, R. (1971) 'The Silent Revolution in Europe: Intergenerational Change in Post-Industrial Societies', American Political Science Review 65: 991-1017.

Inglehart, R. (1977) The Silent Revolution: Changing Values and Political Styles among Western Democracies, Princeton: Princeton University Press.

Inglehart, R. (1979) 'Value Priorities and Socioeconomic Change', in: S.H. Barnes, M. Kaase et al. (1979) Political Action: Mass Participation in Five Western Democracies, Beverly Hills CA: Sage, pp. 305-342.

Inglehart, R. (1988) 'The Renaissance of Political Culture', American Political Science Review 82: 1203-1230.

Inglehart, R. (1990) Culture Shift in Advanced Industrial Societies, Princeton: Princeton University Press.

Inglehart, R. (1997) Modernization and Postmodernization: Cultural, Economic and Political Change in 43 Societies, Princeton: Princeton University Press.

Inglehart, R. (ed.) (2003) Human Values and Social Change. Findings from the Values Survey, Leiden: Brill.

Inglehart, R. (2007) 'Postmaterialist Values and the Shift from Survival to SelfExpression Values', in: R.J. Dalton and H.-D. Klingemann (eds.) The Oxford Handbook of Political Behavior, New York: Oxford University Press, pp. 223-239.

Inglehart, R. (2008) 'Changing Values Among Western Publics from 1970 to 2006', West European Politics 31: 130-146.

Inkeles, A. and Diamond, L. (1980) 'Personal Development and National Development: A Cross-National Perspective', in: A. Szalai and F. Andrews (eds.) The Quality of Life: Comparative Studies, London: Sage, pp. 73-110.

Inkeles, A. and Smith, D. (1974) Becoming Modern: Individual Changes in Six Developing Societies, Cambridge, MA: Harvard University Press.

Inkeles, A. (1978) 'National Differences in Individual Modernity', Comparative Studies in Sociology 1: 47-72.

Inkeles, A. (1983) Exploring Individual Modernity, New York: Columbia University Press.

Jackman, R. (1987) 'Political Institutions and Voter Turnout in the Industrial Democracies', American Political Science Review 81: 405-423.

Jackman, R. and Miller, R. (1995) 'Voter Turnout in the Industrial Democracies During the 1980s', Comparative Political Studies 27: 467-492. 
Jennings, M.K. and Niemi, R. (1981) Generations and Politics, Princeton: Princeton University Press.

Jennings, M.K., Van Deth, J.W. et al. (1990) Continuities in Political Action: A Longitudinal Study of Political Orientations in Three Western Democracies, Berlin: de Gruyter.

Jennings, M.K. (1979) 'Another Look at the Life Cycle and Political Participation', American Journal of Political Science 73: 755-71.

Jennings, M. K. (1987) 'Residues of a Movement: The Aging of the American Protest Generation', American Political Science Review 81: 367-382.

Junn, J. (1991) 'Participation and Political Knowledge', in: W. Crotty (ed.) Political Participation and American Democracy, New York: Greenwood Press, pp. 193-212.

Kaase, M. and Marsh, A. (1979) 'Political Action: A Theoretical Perspective', in: S.H. Barnes, M. Kaase et al. (eds) Political Action: Mass Participation in Five Western Democracies, Beverly Hills, CA: Sage, pp. 27-56.

Kaase, M. (1984) 'The Challenge of the Participatory Revolution in Pluralist Democracies', International Political Science Review 5: 299-317.

Kaase, M. and Barnes, S.H. (1979) 'In Conclusion: The Future of Political Protest in Western Democracies', in: S.H. Barnes and M. Kaase et al. (1979) Political Action: Mass Participation in Five Western Democracies, Beverly Hills CA: Sage, pp. 523-536.

Kielmansegg, P. Graf (1988) Das Experiment der Freiheit: Zur gegenwärtigen Lage des demokratischen Verfassungsstaates, Stuttgart: Klett-Cotta.

Kitschelt, H. (1986) 'Political Opportunity Structures and Political Protest', British Journal of Political Science 16: 57-86.

Klages, H. (1985) Wertorientierungen im Wandel, New York and Frankfurt: Campus Verlag.

Klingemann, H.-D. (1979) 'The Background of Ideological Conceptualization', in: S.H. Barnes, M. Kaase et al. (1979) Political Action: Mass Participation in Five Western Democracies, Beverly Hills CA: Sage, pp. 255-278.

Klingemann, H.-D. (1999) 'Mapping Political Support in the 1990s: A Global Analysis', in: P. Norris (ed.) Critical Citizens: Global Support for Democratic Governance, New York: Oxford University Press, pp. 31-56.

Kohli, M. and Künemund, H. (eds.) (2005) Die zweite Lebenshälfte: Gesellschaftliche Lage und Partizipation im Spiegel des Alters-Survey. 2., erweiterte Auflage, Wiesbaden: VS Verlag für Sozialwissenschaften.

Koopmans, R. (2007) 'Social Movements', in: R.J. Dalton and H.-D. Klingemann (eds.) The Oxford Handbook of Political Behavior, New York: Oxford University Press, pp. 693-707.

Krampen, G. (1988) 'Toward an Action-Theoretical Model of Personality', European Journal of Personality 2: 39-55. 
Kriesi, H., Koopmans, R., Duyvendak, J.W. and Giugni, M.G. (1995) New Social Movements in Western Europe: A Comparative Analysis, London: UCL Press.

Kymlicka, W. and Norman, W. (1995) 'Return of the Citizen: A Survey of Recent Work on Citizenship Theory', in: R. Beiner (ed.) Theorizing Citizenship, Albany, NY: State of the University of New York Press, pp. 283-322.

Lane, J.-E. and Ersson, S. (1999) Politics and Society in Western Europe. $4^{\text {th }}$ Edition, London: Sage.

Lane, R. (1959) Political Life: Why People Get Involved in Politics, Glencoe: Free Press.

Lasch, C. (1979) The Culture of Narcissism, New York: Norton and Company.

Lazarsfeld, P.F., Berelson, B. and Gaudet, H. (1944) The People's Choice: How the Voter Makes Up His Mind in a Presidential Campaign, New York: Columbia University Press.

Leighley, J. (1995) 'Attitudes, Opportunities and Incentives: A Field Essay on Political Participation', Political Research Quarterly 48: 181-209.

Levi, M. and Stoker, L. (2000) 'Political Trust and Trustworthiness', Annual Review of Political Science 3: 475-507.

Lijphart, A. (1999) Patterns of Democracy, New Haven, CT: Yale University Press.

Lindblom, C.E. (1965) The Intelligence of Democracy. Decision Making through Mutual Adjustment, New York and London: The Free Press Collier-Macmillan Limited.

Lipset, S.M. and Rokkan, S. (eds.) (1967) Party Systems and Voter Alignments: Cross National Perspectives, New York: The Free Press.

Lipset, S.M. and Schneider, W. (1983) The Confidence Gap, New York: Free Press.

Lipset, S.M. and Schneider, W. (1987) 'The Confidence Gap During the Reagan Years, 1981-1987', Political Science Quarterly 102: 1-23.

Lipset, S.M. (1959) Political Man: The Social Bases of Politics, Baltimore: Johns Hopkins University Press.

Listhaug, O. and Wiberg, M. (1995) 'Confidence in Political and Private Institutions', in: H.-D Klingemann and D. Fuchs (eds.) Citizens and the State, Oxford: Oxford University Press, pp. 298-322.

Listhaug, O. (1995) 'The Dynamics of Trust in Politicians', in: H.-D Klingemann and D. Fuchs (eds.) Citizens and the State, Oxford: Oxford University Press, pp. 261297.

Lively, J. (1975) Democracy, Oxford: Basil Blackwell.

Long, J.S. (1997) Regression Models for Categorical and Limited Dependent Variables, Thousand Oaks: Sage.

Lupia, A. and McCubbins, M. (1998) The Democratic Dilemma: Can Citizens Learn What They Need to Know?, Cambridge, UK: Cambridge University Press. 
Lupia, A. (1994) 'Shortcuts versus Encyclopedias', American Political Science Review 88: 63-76.

Lyons, W. and Alexander, R. (2000) 'A Tale of Two Electorates', Journal of Politics 62: 1014-1034.

McAdam, D., McCarthy, J.D. and Zald, M.N. (1996) Comparative Perspectives on Social Movements, New York: Cambridge University Press.

McDonald, M. and Popkin, S. (2001) 'The Myth of the Vanishing Voter', American Political Science Review 95: 963-974.

Macpherson, C.B. (1977) The Life and Times of Liberal Democracy, Oxford: Oxford University Press.

Mair, P. and Van Biezen, I. (2001) 'Party Membership in Twenty European Democracies 1980-2000', Party Politics 7: 7-22.

Mair, P. (2002) 'In the Aggregate: Mass Electoral Behavior in Western Europe, 19502000', in: H. Keman (ed.) Comparative Democratic Politics, Thousand Oaks: Sage, pp. 122-140.

Maloney, W.A. and Rossteutscher, S. (eds.) (2007) Social Capital and Associations in European Democracies. A Comparative Analysis, London: Routledge.

Maloney, W.A. and Van Deth, J.W. (eds.) (2010) Civil Society and Activism in Europe. Contextualizing Engagement and Political Orientations, London: Routlege.

Mannheim, K. (1952) 'The Sociological Problem of Generations', in: P. Kecksemeti (ed.) Essays on the Sociology of Knowledge, London: Routledge \& Kegan Paul, pp. 276-322.

Markus, H.R., Kitayama, S., Heiman, R.J. (1996) 'Culture and Basic Psychological Principles', in: E.T. Higgins and A.W. Kruglanski (eds.) Social Psychology: Handbook of Basic Principles, New York: Guilford, pp. 857-913.

Marsh, A. and Kaase, M. (1979) 'Measuring Political Action', in: S.H. Barnes, M. Kaase et al. (1979) Political Action: Mass Participation in Five Western Democracies, Beverly Hills CA: Sage, pp. 57-96.

Meier, C. (1993) Athen. Ein Neubeginn der Weltgeschichte, Berlin: Siedler.

Meulemann, H. (1987) 'Religiöse und politische Werte in Alters- und Bildungsgruppen', Politische Vierteljahresschrift 28: 220-241.

Micheletti, M. (2003) Political Virtue and Shopping, New York: Palgrave Macmillan.

Micheletti, M., Follesdal, A, and Stolle, D. (eds.) (2006): Politics, Products, and Markets. Exploring Political Consumerism Past and Present, New Brunswick: Transaction Publishers.

Milbrath, L.W. and Goel, M.L. (1977) Political Participation: How and Why Do People Get Involved in Politics. $2^{\text {nd }}$ Edition, Chicago: Rand McNally. 
Milbrath, L.W. (1965) Political Participation: How and Why Do People Get Involved in Politics?, Chicago: Rand McNally.

Miller, W. and Shanks, M. (1996) The New American Voter, Cambridge, MA: Harvard University Press.

Miller, D. (1983) 'The Competitive Models of Democracy' in: G. Duncan (ed.) Democratic Theory and Practice, Cambridge: Cambridge University Press, pp. 133155.

Miller, D. (1992) 'Deliberative Democracy and Social Choice', in: D. Held (ed.) Prospects for Democracy: North, South, East, West, Oxford: Polity Press, pp. 54-67.

Mishler, W. and Rose, R. (2001) 'Political Support for Incomplete Democracies: Realist vs. Idealist Theories and Measures', International Political Science Review 22: 303-320.

Morrell, M. E. (2003) 'Survey and Experimental Evidence for a Reliable and Valid Measure of Internal Political Efficacy', Public Opinion Quarterly, 67, 589-602.

Muller, E. and Opp, K.-D. (1986) 'Rational Choice and Rebellious Collective Action', American Political Science Review 80: 471-487.

Muller, E.N. (1979) Aggressive Political Participation, Princeton: Princeton University Press.

Nevitte, N. (1996) The Decline of Deference. Canadian Value Change in Cross-National Perspective, Peterborough: Broadview Press.

Nevitte, N. (2000) 'Value Change and Reorientations in Citizen-State Relations', Canadian Public Policy 26: 73-94.

Newton, K. and Norris, P. (2000) 'Confidence in Public Institutions: Faith, Culture, or Performance?', in: S.J. Pharr and R.D. Putnam (eds.) Disaffected Democracies: What's Troubling the Trilateral Countries?, Princeton: Princeton University Press, pp. 52-73.

Nie, N.H., Junn, J. and Stehlik-Barry, K. (1996) Education and Democratic Citizenship in America, Chicago: University of Chicago Press.

Nie, N., Powell, G., and Prewitt, K. (1969) 'Social Structure and Political Participation: Developmental Relationships II', American Political Science Review 63: 808-832.

Niemi, R.G., Craig S.C. and Mattei, F.( 1991) 'Measuring Internal Political Efficacy in the 1988 National Election Study', American Political Science Review 85: 1407-1413.

Norris, P. (ed.) (1999) Critical Citizens: Global Support for Democratic Governance, New York: Oxford University Press.

Norris, P. (2002) Democratic Phoenix: Political Activism Worldwide, Cambridge: Cambridge University Press.

Norris, P. (2004) Electoral Engineering, New York: Cambridge University Press. 
Norris, P. (2007) 'Political Activism: New Challenges, New Opportunities', in: C. Boix and S.C. Stokes (eds.) The Oxford Handbook of Comparative Politics, New York: Oxford University Press, pp. 628-649.

Norris, P., Walgrave, S. and Van Aelst, P. (2005) 'Who Demonstrates? Antistate Rebels, Conventional Participants, or Everyone?', Comparative Politics 37: 189-205.

Nye, J.S., Zelikow, P.D. and King, D. (eds.) (1997) Why People Don't Trust Government, Cambridge, MA: Harvard University Press.

O'Toole, T., Lister, M., Marsh, D., Jones, S. and McDonagh, A. (2003) 'Tuning Out or Left Out? Participation and Non-Participation among Young People', Contemporary Politics 9: 45-61.

Olson, M. (1965) The Logic of Collective Action, Cambridge, MA: Harvard University Press.

Parry, G., Moyser, G. and Day, N. (1992) Political Participation and Democracy in Britain, New York: Cambridge University Press.

Parsons, T. (1959) 'Voting and the Equilibrium of the American Political System', in: E. Burdick and A.J. Brodbeck (eds.) American Voting Behavior, Glencoe: Free Press, pp. 80-120.

Pateman, C. (1970) Participation and Democratic Theory, Cambridge: Cambridge University Press.

Pateman, C. (1985) The Problem of Political Obligation: A Critique of Liberal Theory, Cambridge: Polity Press.

Patterson, T. (2001) The Vanishing Voter, New York: Knopf.

Pattie, C., Seyd, P. and Whiteley, P. (2004) Citizenship in Britain: Values, Participation and Democracy, Cambridge: Cambridge University Press.

Pederson, J.T. (1982) 'On the Educative Function of Political Participation: A Comparative Analysis of John Stuart Mill's Theory and Contemporary Survey Research Findings', Political Studies 30: 557-568.

Pennock, J.R. (1979) Democratic Political Theory, Princeton: Princeton University Press.

Peters, B.G. (1996) The Future of Governing: Four Emerging Models, Lawrence: University Press of Kansas.

Pharr, S.J. and Putnam, R.D. (eds.) (2000): Disaffected Democracies: What's Troubling the Trilateral Countries?, Princeton: Princeton University Press.

Popkin, S. (1991) The Reasoning Voter, Chicago: University of Chicago Press.

Powell Jr., G.B. (1980) 'Voting Turnout in Thirty Democracies: Partisan, Legal and Socioeconomic Influences', in: R. Rose (ed.) Electoral Participation: A Comparative Analysis, London: Sage, pp. 5-34. 
Powell Jr., G.B. (1982) Contemporary Democracies: Participation, Stability and Violence, Cambridge, MA: Harvard University Press.

Powell Jr., G.B. (1986) 'American Voter Turnout in Comparative Perspective', American Political Science Review 80: 17-43.

Prior, D., Stewart, J. and Walsh, K. (1995) Citizenship: Rights, Community and Participation, Pitman Publishing, London, UK.

Putnam, R.D. (1993) Making Democracy Work: Civic Traditions in Modern Italy, Princeton: Princeton University Press.

Putnam, R.D. (1995) 'Tuning In, Tuning Out: The Strange Disappearance of Social Capital in America', PS: Politics and Political Science 28: 664-683.

Putnam, R.D. (2000) Bowling Alone: The Collapse and Revival of American Community, New York: Simon and Schuster.

Putnam, R.D. (ed.) (2002) Democracies in Flux: The Evolution of Social Capital in Contemporary Society, New York: Oxford University Press.

Rawls, J. (1971) A Theory of Justice, Cambridge, MA: Harvard University Press.

Rawls, J. (1993) Political Liberalism, New York: Columbia University Press.

Reimer, B. (1989) 'Postmodern Structures of Feeling. Values and Life Style in the Postmodern Age', in: J.R. Gibbins (ed.) Contemporary Political Culture: Politics in a Postmodern Age, London: Sage, pp. 110-126.

Riker, W.H. and Ordeshook, P.C. (1968) 'A Theory of the Calculus of Voting', American Political Science Review 62: 25-42.

Riker, W.H. (1982) Liberalism against Populism: A Confrontation between the Theory of Democracy and the Theory of Social Choice, Prospect Heights: Waveland Press.

Rohrschneider, Robert. (1992) 'Environmental Belief Systems in Western Europe: A Hierarchical Model of Constraint', Comparative Political Studies, 26, 3-29.

Rokeach, M. (1960) The Open and Closed Mind: Investigations into the Nature of Belief Systems and Personality Systems, New York: Basic Books.

Rokeach, M. (1973) The Nature of Human Values, New York: Free Press.

Rokkan, S. (1962) 'The Comparative Study of Political Participation. Notes toward a Perspective on Current Research', in: A. Ranney (ed.) Essays on the Behavioral Study of Politics, Urbana: University of Illinois Press, pp. 47-90.

Roller, E. and Wessels, B. (1996) 'Contexts of Political Protest in Western Democracies: Political Organization and Modernity', in: F. Weil et al. (eds.) Extremism, Protest, Social Movements, and Democracy and Society, Vol. 3, Greenwich: JAI Press, pp. 91-134.

Rosenstone, S.J. and Hansen, J.M. (1993) Mobilization, Participation, and Democracy in America, New York: MacMillan. 
Rubenson, D., Blais, A., Fournier, P., Gidengil, E. and Nevitte, N. (2004) 'Accounting for the Age Gap in Turnout', Acta Politica 39: 407-421.

Rucht, D. (1994) Modernisierung und Neue Soziale Bewegungen. Deutschland, Frankreich und USA im Vergleich, Frankfurt: Campus Verlag.

Rucht, D. (2007) 'The Spread of Protest Politics', in: R.J. Dalton and H.-D. Klingemann (eds.) The Oxford Handbook of Political Behavior, New York: Oxford University Press, pp. 708-723.

Salisbury, R.H. and Conklin, L. (1998) 'Instrumental Versus Expressive Group Politics: The National Endowment for the Arts', in: A. Cigler and B. Loomis (eds.) Interest Group Politics, Washington, DC: CQ Press, pp. 283-302.

Sartori, G. (1987) The Theory of Democracy Revisited, Chatham, NJ: Chatham House Publishers.

Sartori, G. (1992) Demokratietheorie, Darmstadt: Wissenschaftliche Buchgesellschaft.

Scarrow, S. (2000) 'Parties without Members?', in: R.J. Dalton and M. Wattenberg (eds.) Parties without Partisans: Political Change in Advanced Industrial Democracies, Oxford: Oxford University Press, pp. 79-101.

Schmalz-Bruns, R. (2002) 'The Normative Desirability of Participatory Governance', in: H. Heinelt, P. Getimis, G. Kafkalas, R. Smith and E. Swyngedouw (eds) Participatory Governance in a Multi-Level Context, Opladen: Leske + Budrich, pp. 59-74.

Schmidt, D. (1989) Citizen Lawmakers: The Ballot Initiative Revolution, Philadelphia: Temple University Press.

Schmidt, M.G. (2000) Demokratietheorien. Eine Einführung. 3., überarbeitete und erweiterte Auflage, Wiesbaden: VS Verlag für Sozialwissenschaften.

Schmitt, H. and Holmberg, S. (1995) 'Political Parties in Decline?', in: H.-D Klingemann and D. Fuchs (eds.) Citizens and the State, Oxford: Oxford University Press, pp. 95-133.

Schmitter, P.C. and Trechsel, A.H. (2004) The Future of Democracy in Europe. Trends, Analysis and Reforms, Strasbourg: Council of Europe Publishing.

Schuessler, A.A. (2000) The Logic of Expressive Choice, Princeton: Princeton University Press.

Schumpeter, J. (1942) Capitalism, Socialism, and Democracy, New York and London: Harper.

Schwartz, S.H. (1992) 'Universals in the Content and Structure of Values: Theoretical Advances and Empirical Tests in 20 Countries', Advances in Experimental Social Psychology 25: 1-65.

Schwartz, S.H. (2003) A Proposal for Measuring Value Orientations across Nations, ESS Questionnaire Development Report, http://www.europeansocialsurvey.org. 
Schwartz, S.H. (2004) 'Mapping and Interpreting Cultural Differences around the World', in: H. Vinken, J. Soeters and P. Ester (eds.) Comparing Cultures: Dimensions of Culture in a Comparative Perspective, Leiden: Brill, pp. 43-73.

Seligson, M. (2002) 'The Renaissance of Political Culture or the Renaissance of Ecological Fallacy', Comparative Politics 34: 273-292.

Sennett, R. (1977) The Fall of Public Man, New York: Knopf.

Sharpe, L.J. (1970) 'Theories and Values of Local Government', Political Studies 18: 153-174.

Smith, G. (2009) Democratic Innovations. Designing Institutions for Citizen Participation, Cambridge: Cambridge University Press.

Sniderman, P. (1975) Personality and Democratic Politics, Berkeley: University of California Press.

Sniderman P. (1993) 'The New Look in Public Opinion Research', in: A.W. Finifter, (ed.) Political Science: The State of the Discipline II, Washington DC: The American Political Science Association, pp. 219-245.

Sniderman, P., Brody, R.A. and Tetlock, P.E. (1991) Reasoning and Choice: Explorations in Political Psychology, New York: Cambridge University Press.

Stoker, G. (1996) 'Redefining Local Democracy', in L. Pratchett and D. Wilson (eds.) Local Democracy and Local Government, London: Macmillan, pp. 188-210.

Stolle, D. and Hooghe, M. (2005) 'Review Article: Inaccurate, Exceptional, One-Sided or Irrelevant? The Debate About the Alleged Decline of Social Capital and Civic Engagement in Western Societies', British Journal of Political Science 35: 149-167.

Stolle, D., Hooghe, M. and Micheletti, M. (2005) 'Politics in the Supermarket: Political Consumerism as a Form of Political Participation', International Political Science Review 26: 245-269.

Strauss, W. \& Howe, N. (1992) Generations: The History of America's Future, 1584 to 2069, New York: Perennial.

Tarrow, S. (1989) Democracy and Disorder: Protest and Politics in Italy 1965-1975, Oxford: Clarendon Press.

Tarrow, S. (1998) Power in Movement: Social Movements and Contentious Politics, Cambridge: Cambridge University Press.

Teixeira, R.A. (1987) Why Americans Don't Vote: Turnout Decline in the United States 1960-1984, New York: Greenwood Press.

Teixeira, R.A. (1992) The Disappearing American Voter, Washington, DC: Brookings.

Teorell, J. (2006) 'Political Participation and the Three Theories of Democracy: A Research Inventory and Agenda', European Journal of Political Research 45: 787-810.

Teorell, J., Torcal, M. and Montero, J.R. (2007) 'Political Participation: Mapping the Terrain', in: J.W. Van Deth, J.R. Montero and A. Westholm (eds) Citizenship and 
Involvement in European Democracies: A Comparative Perspective, London: Routledge, pp. 334-357.

Theiss-Morse, E. and Hibbing, J.R. (2005) 'Citizenship and Civic Engagement', Annual Review of Political Science 8: 227-249.

Thomassen. J. and Van der Kolk, H. (2002) 'The Face of Post-Industrial Politics: Modernist or Post-Modernist?', Paper presented at the Joint Sessions of Workshops of the European Consortium for Political Research, Turin, 22-28 March 2002.

Thomassen, J. and Van Deth, J.W. (1998) 'Political Involvement and Democratic Attitudes', in: S.H. Barnes and J. Simon (eds.) The Postcommunist Citizen, Budapest: Erasmus Foundation and Institute for Political Science of the Hungarian Academy of Sciences, pp. 139-163.

Thomassen, J. (1983) 'Politicologie en Staatsrecht', in: Staatsrecht en Politicologie, Nijmegen: Ars Aequi, pp. 73-102.

Thomassen, J. (1990) Economic Crisis, Dissatisfaction and Protest Behavior, in: M. K. Jennings and J.W. Van Deth et al. (eds.) Continuities in Political Action: A Longitudinal Study of Political Orientations in Three Western Democracies, Berlin: de Gruyter, pp. 103-134.

Thomassen, J. (1995) 'Support for Democratic Values', in: H.-D Klingemann and D. Fuchs (eds.) Citizens and the State, Oxford: Oxford University Press, pp. 383-416.

Thomassen, J. (2007) 'Democratic Values', in: R.J. Dalton and H.-D. Klingemann (eds.) The Oxford Handbook of Political Behavior, New York: Oxford University Press, pp. 418-434.

Tilly, C. (1995) Popular Contention in Great Britain, 1758-1834, Cambridge and London: Harvard University Press

Tingsten, H. (1937) Political Behavior, London: King and Son.

Tocqueville, A. de (1945 [1840]) Democracy in America, Vol. 2, trans. H. Reeve, New York: Knopf.

Tóka, Gábor (2009) 'Expressive Versus Instrumental Motivation of Turnout, Partisanship, and Political Learning', in: H.-D. Klingemann (ed.) The Comparative Study of Electoral Systems, New York: Oxford University Press, pp. 269-288.

Tolbert, C.J., McNeal, R.S. and Smith, D.A. (2003) `Enhancing Civic Engagement: The Effect of Direct Democracy on Political Participation and Knowledge', State Politics and Policy Quarterly 3: 23-41.

Topf, R. (1995a) ‘Beyond Electoral Participation', in: H.-D. Klingemann and Fuchs, D. (eds.) Citizens and the State, Oxford: Oxford University Press, pp. 52-91.

Topf, R. (1995b) 'Electoral Participation', in: H.-D. Klingemann and Fuchs, D. (eds.) Citizens and the State, Oxford: Oxford University Press, pp. 27-51.

Triandis, H.C. (1988) 'Collectivism vs. Individualism: A Reconceptualization of a Basic Concept in Cross-Cultural Psychology', in: G.K. Verma and C. Bagley (eds.) 
Cross-Cultural Studies of Personality, Attitudes, and Cognition, London: Macmillan, pp. 60-95.

Triandis, H.C. (1994) Culture and Social Behavior, New York: McGraw-Hill.

Triandis, H.C. (1995) Individualism and Collectivism, Boulder, CO: Westview Press.

Truman, D.B. (1951) The Governmental Process: Political Interests and Public Opinion, New York: Knopf.

Tullock, G. (1971) 'The Paradox of Revolution', Public Choice 11: 89-99.

Turner, B.S. (1989) 'From Postindustrial Society to Postmodern Politics: The Political Sociology of Daniel Bell', in: J.R. Gibbins (ed.) Contemporary Political Culture: Politics in a Postmodern Age, London: Sage, pp. 199-217.

Van Aelst, P. and Walgrave, S. (2001) 'Who is That (Wo)Man in the Street? From the Normalization of Protest to the Normalization of the Protester', European Journal of Political Research 39: 461-486.

Van den Broek, A, and Heunks, F. (1994) 'Political Culture: Patterns of Political Orientations and Behavior', in: Ester, P., Halman, L. and De Moor, R. (eds.) The Individualizing Society: Value Change in Europe and North America, Tilburg: Tilburg University Press, pp. 67-96.

Van Deth, J.W. and Elff, M. (2000) 'Political Involvement and Apathy in Europe 19731998', Working Paper No. 33, Mannheim: Mannheimer Zentrum für Europäische Sozialforschung.

Van Deth, J.W. and Elff, M. (2004) 'Politicisation, Economic Development and Political Interest in Europe', European Journal of Political Research 43: 477-508.

Van Deth, J.W. and Kreuter, F. (1998) 'Membership of Voluntary Associations', in: J.W. Van Deth (ed.) Comparative Politics: The Problem of Equivalence, London: Routledge, pp. 135-155.

Van Deth, J.W. and Scarbrough, E. (eds.) (1995) The Impact of Values. Oxford: Oxford University Press.

Van Deth, J.W. (1990) 'Interest in Politics', in: M.K. Jennings, J.W. Van Deth et al. (eds.) Continuities in Political Action: A Longitudinal Study of Political Orientations in Three Western Democracies, Berlin: de Gruyter, pp. 275-312.

Van Deth, J.W. (1995) 'Introduction: The Impact of Values', in: J.W. Van Deth and E. Scarbrough (eds.) The Impact of Values, Oxford: Oxford University Press.

Van Deth, J.W. (1996) 'Politisches Interesse und Apathie in Europa', in: T. König, E. Rieger and H. Schmitt (eds.) Das Europäische Mehrebenensystem: Konzeptionen und Perspektiven, Frankfurt and New York: Campus, pp. 383-402.

Van Deth, J.W. (ed.) (1997) Private Groups and Public Life: Social Participation, Voluntary Associations and Political Involvement in Representative Democracies, London: Routledge. 
Van Deth, J.W. (ed.) (1999) Social Capital and European Democracy, New York: Routledge.

Van Deth, J.W. (2000) 'Interesting but Irrelevant: Social Capital and the Saliency of Politics in Western Europe', European Journal of Political Research 37: 115-147.

Van Deth, J.W., Montero, J.R. and Westholm, A. (eds.) (2007) Citizenship and Involvement in European Democracies: A Comparative Analysis, London and New York: Routledge.

Verba, S. and Nie, N. (1972) Participation in America: Political Democracy and Social Equality, New York: Harper and Row.

Verba, S. Nie, N.H. and Kim, J.-O. (1978) Participation and Political Equality: A Seven Nation Comparison, Cambridge: Cambridge University Press.

Verba, S., Schlozman, K.L. and Brady, H.E. (1995) Voice and Equality. Civic Voluntarism in American Politics, Cambridge, MA: Harvard University Press.

Vetter, A. (2007) Local Politics: A Resource for Democracy in Western Europe?, Plymouth: Lexington Books.

Warren, M. (1992) 'Democratic Theory and Self-Transformation', American Political Science Review 86: 8-23.

Warren. M. (2001) Democracy and Association, Princeton: Princeton University Press.

Wattenberg, M. (2002) Where Have All the Voters Gone?, Cambridge, MA: Harvard University Press.

Wattenberg, M. (2006) Is Voting for Young People?, New York: Longman.

Welzel, C. (2002) Fluchtpunkt Humanentwicklung: Über die Grundlagen der Demokratie und die Ursachen ihrer Ausbreitung, Opladen: Westdeutscher Verlag.

Welzel, C. (2007) 'Individual Modernity', in: R.J. Dalton and H.-D. Klingemann (eds.) The Oxford Handbook of Political Behavior, New York: Oxford University Press, pp. 185-205.

Welzel, C. (2009) 'Werte- und Wertewandelforschung', in: V. Kaina and A. Römmele (eds.) Politische Soziologie: Ein Studienbuch, Wiesbaden: VS Verlag für Sozialwissenschaften, pp. 109-139.

Welzel, C., Inglehart, R. and Klingemann, H.-D. (2003): 'The Theory of Human Development: A Cross-Cultural Analysis', European Journal of Political Research 42: 341-380.

Whiteley, P.F. (1995) 'Rational Choice and Political Participation: Evaluating the Debate', Political Research Quarterly 48: 211-233.

Williamson, J.B. (1998) 'Political Activism and the Aging of the Baby Boom', Generations 22: 55-59.

Wolfinger, R.E. and Rosenstone, S.J. (1980) Who Votes?, New Haven: Yale University Press. 
Yankelovich, D. (1981) New Rules, New York: Random House.

Zaller, J. (1990) 'Political Awareness, Elite Opinion Leadership, and the Mass Survey Response', Social Cognition 8: 125-153.

Zijderveld, A. (1979) 'Het Ethos van de Verzorgingsstaat', Sociale Wetenschappen 22: 179-203.

Zimmerman, J. (1999) The Initiative: Citizen Law-Making, Westport, CT: Praeger. 


\section{Nederlandse Samenvatting}

\section{Inleiding}

Westerse democratieën zijn de afgelopen decennia onderhevig geweest aan diepgaande veranderingen. Eén van de belangrijkste componenten van deze veranderingen wordt gevormd door de fundamentele verschuiving in de rol van de burger in het politieke proces, in het bijzonder in de landen die door hun sterk gemoderniseerde economie en democratie worden geschaard onder de zogenaamde "post-industrial societies" (Bell, 1973; Huntington, 1974; Inglehart, 1990). Waar tot de late jaren zestig stemmen nog veruit de belangrijkste vorm van politieke participatie was in deze landen, heeft de "participatieve revolutie" in de jaren die daarop volgden gezorgd voor een snelle proliferatie van nieuwe vormen van politieke participatie, alsmede voor een snelle stijging in deelname van burgers aan deze nieuwe politieke participatie. Deze ontwikkelingen in politieke participatie, waarvan vaak wordt vermoed dat ze het resultaat zijn van brede maatschappelijke moderniseringsprocessen, hebben in de afgelopen decennia tot veel discussies geleid. Veel politici and politicologen verwelkomden de ontwikkeling naar nieuwe vormen van politieke participatie als een stap richting een diepgaander, fundamenteler vorm van democratie, maar dit enthousiasme werd niet door iedereen gedeeld. De groter wordende rol van "nieuwe" politieke participatie leidde bij een aantal opiniemakers namelijk tot kritiek en zorgen met betrekking tot de rol die deze participatie mogelijk zou kunnen spelen in het veroorzaken van een crisis in de Westerse democratie.

Eén van de meest prominente criticasters was de Amerikaanse politicoloog Samuel P. Huntington, die in zijn essay "Post-industrial Politics: How Benign Will It $B e$ ?" beargumenteerde dat de steeds betere opleiding van burgers, en de daaraan verbonden verschuiving naar post-materialistische waarden en intensievere politieke participatie bij deze burgers, juist een bedreiging vormde voor het democratische bestel in post-industriële samenlevingen. Volgens Huntington leidt een grotere variatie in politieke participatie, alsmede een intensivering in politieke participatie, tot oplopende verwachtingen van overheidsprestaties bij burgers. Deze oplopende verwachtingen zorgen op hun beurt weer voor een overbelaste overheid ("overload of government"), waardoor diezelfde overheid slechter in staat is een robuust bestuur te voeren, met als gevolg dat burgers ontevreden raken met de prestaties die door de overheid worden neergezet. Dit bij elkaar, zo voorspelde Huntington, zou er voor zorgen dat de post-industriële samenlevingen langzaam steeds moeilijker te 
besturen zouden worden, waardoor democratie in de post-industriële gekenmerkt zou worden door een veel harder, en minder soepel, karakter dan in de daaraan voorafgaande 'industriële' decennia (1974: 166).

Het debat rond politieke participatie, dat zich in de jaren zeventig sterk rond potentiële gevolgen voor de politieke stabiliteit had geconcentreerd, nam een nieuwe wending toen Max Kaase en Samuel H. Barnes in het concluderende hoofdstuk van hun boek Political Action Study (1979) zich focusten op de vraag wat nou eigenlijk het karakter van politieke participatie is. Eén van de belangrijkste conclusies van het betreffende boek was dat nieuwe vormen van politieke activiteit - door de auteurs 'onconventionele acties' of 'protestacties' genoemd - aan het toenemen waren. Daarnaast beargumenteerden Barnes en Kaase dat deze nieuwe vormen van politieke participatie an sich geen probleem voor de democratie vormen, maar dat dit afhangt van het karakter van deze politieke participatie. Hierbij maakten ze onderscheid tussen 'expressieve politieke participatie' en 'instrumentele politieke participatie'. Expressieve politieke participatie behelst het voeren van actie zonder duidelijke politieke motivatie, en wordt door de auteurs gezien als storend voor het democratische proces, omdat het rationeel contact tussen politici en burgers verhindert (1979: 528). Instrumentele politieke participatie, waarin politieke actie vergezeld gaat van een duidelijke politieke motivatie, aan de andere kant, wordt door de auteurs als een perfect legitieme vorm van politieke participatie gezien, die de banden tussen burgers en politici, en dus de fundamenten van de democratie, enkel versterkt.

Samenvattend kan gesteld worden dat, volgens Barnes en Kaase, niet alleen de vorm en intensiteit van politieke participatie van belang zijn voor de kwaliteit van democratie, maar dat ook de motivatie achter politieke participatie van essentieel belang zijn voor hoe de toekomst van democratie eruit ziet. Ze argumenteren dat politieke actie zonder politieke motivatie moet worden beschouwd als irrationeel gedrag dat een potentiële bedreiging vormt voor democratische besluitvorming, maar ze motiveren hierbij niet waarom dit het geval zou zijn; ook worden de rol van zowel rationeel-instrumentele participatie als irrationeel-expressieve participatie binnen de post-industriële samenleving niet helder gedefinieerd. Dit onderzoek zal proberen dit gat te vullen door in twaalf post-industriële democratieën te onderzoeken hoe instrumentele en expressieve participatie zich binnen deze democratieën hebben ontwikkeld. Daarnaast zullen we door het leggen van verbanden tussen deze twee vormen van participatie en een aantal kenmerken van post-industriële samenlevingen en hun burgers (en in het specifiek, waardeoriëntaties die bestaan onder deze burgers) trachten een idee te krijgen van hoe 
democratie zich in deze samenlevingen zal ontwikkelen. De centrale onderzoeksvraag van dit onderzoek is dan ook als volgt:

"Welke vormen van politieke participatie ontstaan uit sociaal-culturele veranderingen in post-industriële samenlevingen?"

Om deze vraag te beantwoorden, zullen we onderzoeken in hoeverre instrumentele and expressieve politieke participatie zich hebben verspreid onder burgers in post-industriële samenlevingen, en in hoeverre deze vormen van participatie zijn gerelateerd aan waarde-oriëntaties onder burgers. Dit zal gebeuren middels de volgende subvragen:

1. Wat is het meest voorkomende type van politieke participatie in post-industriële democratieën?

2. Hoe zullen expressieve participatie en instrumentele participatie zich waarschijnlijk (verder) ontwikkelen in post-industriële democratieën?

3. Welke waarde-oriëntaties zijn dominant in post-industriële democratieën?

4. In hoeverre verklaren waarde-oriëntaties onder burgers de manier waarop zij politieke participatie bedrijuen?

\section{Theoretisch kader}

We hebben een uitgebreid theoretisch kader ontwikkeld voor de analyse van de causale verbanden tussen bepaalde kenmerken and attitudes van burgers, en hun paticipatie in het politieke proces. De evaluatie van normatieve democratietheorieën, die een fundering moeten vormen voor het onderzoek naar de achterliggende redenen waarom een specifiek type participatie bevordelijk of juist schadelijk zou zijn voor een stabiele democratie, zijn een essentieel onderdeel van dit kader. Een diepgaande discussie over de visie op burgerparticipatie laat zien dat men door de jaren van democratieontwikkeling in de geschiedenis heen verdeeld blijft over het normatieve ideaal van burgerparticipatie. In tegenstelling tot de werking van de democratie in de oude Atheense stadsstaten, waar democratie letterlijk inhield dat het volk zichzelf regeerde, zijn er liberale democratietheorieën die pleiten voor zo weinig mogelijk burgerparticipatie in het besluitvormingsproces. Het belangrijkste argument voor deze herdefinitie van de rol van de burger was ten eerste dat, sinds het moderne democratische bestuur veel uitgebreider en complexer is geworden, de werkelijkheid van het democratisch bestuur niet meer overeen kwam met het ideaaltype democratie in de oude Atheense stadsstaten. Bovendien is een 
meerderheid van de burgers niet geïnteresseerd in politiek en bezitten deze burgers niet de benodigde vaardigheden om de juiste beslissingen te nemen. Echter, dit laatste argument wordt in twijfel getrokken vanwege de toename in burgerparticipatie in de laatste decennia en de ontwikkeling van verschillende vormen van participatie. De theorie van de participatieve democratie, die zich gelijktijdig ontwikkeld heeft aan deze toename, was kritisch ten opzichte van de de visie van de liberale theorieën en bood een alternatief theoretisch inzicht. Deze theorie houdt in dat participatie een noodzakelijk onderdeel van een legitieme democratie is. De toename in participatie en het benutten van directe vormen van participatie is daarom geen bedreiging maar een verrijking voor de democratie. Volgens deze theorie zijn burgers niet ongeinteresseerd in politiek; in tegendeel, hun interesse en politieke vaardigheden kunnen verder worden ontwikkeld door hen de mogelijkheid te bieden om actief deel te nemen aan collectieve besluitvormingsprocessen. Doordat beide theorieën een uitgangspunt bieden in de disucssie over de juiste hoeveelheid politieke participatie voor efficiënt democratisch bestuur, kan op beide theorieën de kritiek geleverd worden dat er normatieve beweringen afgeleid worden uit de empirische werkelijkheid in plaats van dat er beschreven wordt wat wenselijk is in een democratisch systeem.Daar komt bij dat geen van beide theorieën rekening houdt met de motieven achter participatie, die voor een stabiele democratie even belangrijk zijn als de hoeveelheid participatie.

Voor de verklaring waarom burgers participeren, en in het bijzonder waarom ze in specifieke politieke activiteiten participeren, refereren we aan de theorieën in maatschappelijke modernisering. Eén van de meest prominente wetenschappers op dit gebied, Ronald Inglehart (1971, 1977), heeft herhaaldelijk aangegeven dat de recente toename in politieke participatie wordt veroorzaakt door postmaterialistische waardeveranderingen die het resultaat zijn van processen van modernisering in post-industriële democratieën. De economische welvaart in deze maatschappijen heeft geleid tot twee belangrijke veranderingen in eigenschappen van burgers. Ten eerste heeft er een verschuiving plaatsgevonden van burgers hun waarde prioriteiten. Dit houdt in dat de waarden materiële en fysieke veiligheid minder belangrijk gevonden worden en dat de nadruk meer komt te liggen op postmaterialistische waarden als vrijheid, zelfontplooiing en kwesties omtrent de kwaliteit van leven. Ten tweede, zorgen de stijging van het opleidingsniveau en betere informatiebronnen ervoor dat burgers meer vaardigheden en zelfvertrouwen hebben. Hiermee zijn ze beter in staat om hun politieke doeleinden - die door de hierboven besproken verschuivingen zijn uitgebreid - te bereiken. Volgens Inglehart zijn deze ontwikkelingen, die ook bekend staan als "individuele modernisering", de 
verklaring waarom burgers geneigd zijn om deel te nemen aan nieuwe vormen van politieke participatie in post-industriële democratieën, waaraan we hier referen als "extra-representationele" activiteiten (zie hoofdstuk 3). Ten eerste hebben burgers door een betere opleiding, meer informatiebronnen en de ontwikkeling van vaardigheden beter de mogelijkheid om met deze nieuwe politieke activiteiten pragmatisch hun politieke doelen na te streven. Ten tweede zijn burgers, vanwege de komst van nieuwe politieke actoren als sociale bewegingen en actiegroepen die een betere vertegenwoordiging van de post-materialistische waarde-oriëntaties vormen, sneller geneigd zich aan te sluiten bij een groep om hun politieke doel te verwezenlijken. Daarnaast zijn de extra-representationele vormen van participatie voor burgers een meer geschikt middel om hun eigen potentiele capaciteiten volledig te benutten.

Vooral de waardeverandering als component van het proces van individuele modernisering is onderwerp van debat geweest tussen theoretici die de implicaties van het proces vanuit verschillende perspectieven interpreteren. Hoewel er consensus is over het feit dat er een verandering in waardeoriëntaties van burgers in post-industriële samenlevingen heeft plaatsgevonden, verschillen theoretici in hun visie op de inhoud en consequenties van de prioritering van waarden door burgers als gevolg van processen van modernisatie. Men zou hier kunnen spreken van twee hoofdtheorieën die beide hun eigen interpretatie hanteren van postmoderne burgers en hun prioritering van waarden. De zogenoemde "theory of human development" (Welzel et al. 2003; Inglehart \& Welzel 2005) benadrukt dat waarden van zelfexpressie bij burgers prevaleren, iets wat hen dichterbij het ideaaltype van de democratische burger brengt. Dit impliceert dat waarden als vrijheid, tolerantie en participatie, maar ook zelfbeschikking and kwesties omtrent de kwaliteit van leven veel meer benadrukt worden. Er is meer behoefte aan vrijheid, autonomie, kwaliteit van leven en vrijheid van meningsuiting; een prioritering van waarden die tot groeiende kritiek op politieke instituties en politici leidt. Deze kritiek leidt tot een grotere behoefte aan participatie - in het bijzonder aan vormen van protest - in het politieke proces om sturing te geven aan behoeften en zowel collectieve als individuele doelen te bereiken. Er is dus reden voor optimisme over de toekomst en het functioneren van de democratie in deze maatschappijen, als we bedenken dat de hoger opgeleide en beter geinformeerde burgers niet veel meer vragen dan meer directe kanalen waardoor zij hun toenemende vraag kenbaar kunnen maken, alsmede hun behoefte aan meer responsiviteit van de autoriteiten. Hiermee maken ze slecht de behoefte kenbaar maken voor meer democratie. Gebaseerd op deze behoeften van burgers verwachten wij dat zij, omwille van het bereiken van hun 
politieke doelen, meer en meer betrokken raken bij het besluitvormingsproces door hun stem duidelijk te laten horen. Doordat postmoderne burgers vanwege hun sterke cognitieve capaciteiten in staat zijn om hun politieke behoeften en doelen adequaat te formuleren en zij gemotiveerd zijn om deze doelen zelf te verwezenlijken, verwachten wij dat deze burgers in het bijzonder betrokken zijn bij extra-representationele vormen van politieke activiteiten. Daarnaast verwachten we dat ze hierbij betrokken zijn op basis van rationeel-instrumentele gronden.

Daarentegen, neemt "the theory of postmodern politics" aan dat opkomende nieuwe waarden in post-industriële maatschappijen alles behalve pro-democratische waarden zijn. Volgens deze theorie worden burgers in deze maatschappijen eerder gekenmerkt door een cultuur van massa-consumptie, vermaak en hedonisme (e.g. Bell 1976; Bellah et al. 1985; Turner 1989; Crook et al. 1992). In deze theorie heeft zelfexpressie, het uiting geven aan de eigen identeit en het verkrijgen van intrinsieke voordelen de centrale prioriteit. Sociale of politieke oriëntatie zijn weinig relevant en het individu en zijn persoonlijke behoeften staan op de voorgrond. Omdat de voornaamste motivatie van hedonistische burgers is om hun eigen identiteit uit te dragen, is de verwachting dat ze participeren in extra-representationele vormen in het politieke besluitvormingsproces. Echter, de doelen die deze burgers met participtie willen bereiken zijn in dit geval het tegemoet komen aan de individuele behoefte, zoals het uiten van hun mening, vermaak, en het horen bij een groep in plaats van de concrete implementatie van beleid. Hoewel burgers zich wel sterk georiënteerd hebben op het gebied van participatie, is die oriëntatie eerder gestoeld op hun persoonlijke behoeften; en door de veelheid aan oriëntaties kunnen we aannemen dat die persoonlijke behoeften niet per se politieke behoeften hoeven te zijn. We zouden derhalve kunnen voorspellen deze burgers een meer expressieve stijl van politieke participatie hebben. Dit type participatie kunnen we zien als net zo rationeel als instrumenteel gedrag vanuit een rationeel-instrumenteel perspectief; echter, vanuit een systematisch perspectief is dit gedrag juist niet rationeel omdat het de werking van het klassieke input-output mechanisme verstoort en zo ook het democratisch besluitvormingsproces.

Als gevolg kan onze onderzoeksvraag - en daarmee ook de vier empirische deelvragen hierboven vermeld - verschillende worden beantwoord vanuit de twee verschillende theoretische perspectieven. $\mathrm{Zij}$ voorspellen twee verschillende groepen met waarde-oriëntaties voor postmoderne burgers; die niet alleen van elkaar verschillen wat betreft de inhoud, maar ook wat betreft hun samenhang met de twee typen van politieke betrokkenheid. Zo hebben deze theorieën in beginsel twee alternatieve antwoorden op elke vraag. We hebben de volgende hypothesen 
ontwikkeld en getest om te onderzoeken welke theorie de meest geldige verklaring biedt:

\section{Hypothesen}

Theory of human development

Theory of postmodern politics

H1 Toename van extra-representationele burgerparticipatie

H2a Toename van politieke interesse

H3a Toename van instrumentele politieke participatie

H4a De toename van instrumentele politieke participatie zal over de tijd plaatsvinden door de komst van nieuwe generaties, omdat elke volgende generatie meer instrumenteel politiek participeert dan de vorige generatie

H5a Waarden van zelfexpressie komen vaker voor dan waarden van zelforiëntatie bij burgers in post-industriële samenlevingen

H6 Waarden van zelfexpressie neigen tot samenhang met instrumentele politieke participatie in post-industriële samenlevingen
H2b Afname van politieke interesse

H3b Toename van expressieve politieke participatie

H4b De toename van expressieve politieke participatie zal over de tijd plaatsvinden door de komst van nieuwe generaties, omdat elke volgende generatie meer expressief politiek participeert dan de vorige generatie

H5b Waarden van zelf-oriëntatie komen vaker voor dan waarden van zelfexpressie bij burgers in post-industriële samenlevingen

H7 Waarden van zelforiëntatie neigen tot samenhang met expressieve politieke participatie in post-industriële samenlevingen

\section{Case selectie, Data, en Methoden}

Deze hypothesen zijn empirisch getest in twaalf Europese post-industriële democratieën. We hebben deze cases geselecteerd op basis van de drie meest gemeenschappelijke indicatoren van post-industriële samenlevingen: een hoog BBP per hoofd, enige jaren ervaring met democratisch bestuur, en de meerderheid van de beroepsbevolking is werkzaam in de tertiaire sector. Op basis van deze criteria hebben we de volgende landen uitgekozen: Oostenrijk, België, Denemarken, Finland, Frankrijk, Ierland, Nederland, Noorwegen, Zweden, Zwitserland, het Verenigd 
Koninkrijk en West-Duitsland. Landen zoals Spanje, Portugal en Griekenland en ook het oostelijk deel van Duitsland zijn niet meegenomen omdat zij relatief kort ervaring hebben met democratisch bestuur. Daarnaast is het percentage werknemers in de industriële sector in Portugal en Griekenland hoger dan het percentage werknemers in de dienstverlenende sector en voldoen deze landen daarom niet aan dit belangrijke criterium voor post-industrialisme. Tenslotte is ook Italië niet meegenomen omdat de items waarmee de waarden gemeten worden niet zijn opgenomen in de vragenlijst in dit land. Met deze methode proberen we vast te stellen of er een algemeen patroon is in de politieke participatie in alle landen met gelijkwaardig post-industrieel niveau of dat er verschillen bestaan tussen landen.

Om $\mathrm{H} 1$ tot en met $\mathrm{H} 4 \mathrm{~b}$ te kunnen testen, hebben we de eerste drie golven van de European Values Study gebruikt waarvan de data is verzameld in het tijdsbestek van 1981 tot 2000. We hebben eerst gekeken naar het algemene niveau en de ontwikkeling van politieke participatie, politieke interesse en types van politieke betrokkenheid. Om de hypothesen $\mathrm{H} 4 \mathrm{a}$ en $\mathrm{H} 4 \mathrm{~b}$ te testen hebben we gebruik gemaakt van cohort analyse, dat wil zeggen dat we gekeken hebben naar de ontwikkeling van patronen van betrokkenheid in verschillende geboortecohorten om te kunnen zien of het bij deze typen van betrokkenheid -net zoals bij waarden- waarschijnlijk is dat ze worden gevormd door de de komst van nieuwe generaties. Om de hypothesen $\mathrm{H} 5 \mathrm{a}$ tot en met $\mathrm{H} 7$ te testen hebben we gekeken naar de prioritering van waarden in de verschillende landen en hebben we logistische regressie toegepast om uit te vinden door welk mechanisme het verband tussen processen van individualisatie en politieke betrokkenheid gestalte krijgt. Ook hier waren we geinteresseerd in mogelijke verschillen tussen landen.

\section{Belangrijkste bevindingen van het onderzoek}

Wat is het meest voorkomende type van politieke participatie in post-industriële democratieën?

De analyse van de ontwikkeling van politieke participatie laat een toename van extra-representationele vormen van participatie in alle landen zien, wat tot de conclusie leidt dat de hypothese $\mathrm{H} 1$ bevestigd is. Daarentegen kon geen van de hypothesen van beide theorieën over politieke interesse (H2a en $\mathrm{H} 2 \mathrm{~b}$ ) met dezelfde overtuiging worden bevestigd. Politieke interesse lijkt in sommige landen toe te nemen terwijl het in andere afneemt; in sommige landen fluctueert het sterk waardoor we niet kunnen spreken van een duidelijke trend. We kunnen hoogstens 
concluderen dat deze hypothesen zijn bevestigd in verschillende landen, maar we kunnen geen algemene conclusie trekken over alle post-industriële landen.

Met betrekking tot de ontwikkeling van instrumentele en expressieve betrokkenheid ( $\mathrm{H} 3 \mathrm{a}$ en $\mathrm{H} 3 \mathrm{~b}$ ) hebben we ook geen eenduidig bewijs gevonden waarmee één van de hypothesen bevestigd kan worden. De trend varieert per land van toename naar afname en van stabiliteit naar sterke fluctuaties. Hoewel instrumentele politieke participatie de boventoon lijkt te voeren in de meerderheid van de landen, hebben we door de gelijktijdige ontwikkeling van expressieve politieke participatie ook aanzienlijk veel van dit participatie type kunnen waarnemen. In andere landen heeft het zelfs het niveaus bereikt dat het zwaarder weegt dan het instrumentele type participatie. Ook heeft het onderzoek naar de ontwikkeling van het evenwicht tussen de twee typen van participatie geleid tot hetzelfde resultaat. We kunnen dus geen ondubbelzinnig antwoord geven op de vraag welk type participatie het meest voorkomt in post-industriële landen. Dit resultaat geeft extra relevantie aan de tweede vraag over de mogelijke toekomstige ontwikkelingen van beide participatie typen.

Wat is het meest voorkomende type van politieke participatie in post-industriële democratieën?

Om deze vraag te kunnen beantwoorden hebben we gekeken naar de ontwikkeling van beide participatie typen tijdens verschillende generaties ( $\mathrm{H} 4 \mathrm{a}$ en $\mathrm{H} 4 \mathrm{~b}$ ). Het was mogelijk om enig duidelijk bewijs te vinden met betrekking tot deze ontwikkeling. De analyse van de ontwikkeling van instrumentele politieke participatie in zes geboortecohorten laat zien dat dit participatie type toeneemt in alle cohorten. We kunnen echter niet concluderen dat deze toename veroorzaakt is door de komst van nieuwe generaties, omdat we niet hebben geconstateerd dat er meer participatie onder jongere generaties was dan onder oudere generaties. Zoals we kunnen zien in figuur 6.2, laat de jongste generatie op drie meetmomenten minder instrumentele politieke participatie zien dan het cohort daarvoor. Hoewel oudere burgers eerder geneigd zijn tot instrumenteel gemotiveerde politieke activiteiten, wordt het niveau van instrumentele participatie van de zogenaamde protestgeneratie (cohorten 4 en 5) niet gehaald. Hypothese H4a wordt dus niet bevestigd door de resultaten. Daarentegen bieden de resultaten van de analyse wel enig bewijs voor hypothese H4b. Expressieve politieke participatie neemt toe met de opkomst van nieuwe generaties. We zien dat het jongste cohort op alle meetmomenten meer geneigd is om te participeren met expressieve beweegredenen dan hun voorgangers; en deze neiging lijkt niet af te nemen wanneer deze burgers ouder worden (zie figuur 6.4). 
We kunnen daarom verwachten dat de politieke participatie zonder politieke beweegredenen zal blijven toenemen over tijd. Op de lange termijn kunnen we zelfs verwachten dat expressieve politieke participatie de meest voorkomende vorm van politieke betrokkenheid wordt. Echter, gezien de korte tijdsperiode waarin we deze ontwikkelingen hebben beschouwd, de verschillen tussen landen en het gebrek aan kennis van de mechanismen die ten grondslag liggen aan deze ontwikkelingen, is het te vroeg om harde conclusies te trekken.

\section{Welke waarde-oriëntaties zijn dominant in post-industriële democratiën?}

Nadat we van zowel instrumentele participatie als expressieve participatie het niveau en de trens hebben vastgesteld, hebben we gekeken naar onze vraag over de meest voorkomende waarden in post-industriële democratieën. De analyses in het eerste deel van hoofdstuk 8 laten zien dat waarden van zelfexpressie - zelfsturing en universalisme - inderdaad het meest voorkomend zijn in alle post-industriële samenlevingen; een bevinding die strookt met hypothese H5a en dus met de argumenten van de theorie van de post-industriële politiek. Waarden van zelforiëntatie - hedonisme, stimulering en prestatie - hebben minder prioriteit voor burgers uit deze landen. De alternatieve hypothese H5b, afgeleid van de theorie van de postmoderne politiek kan in dit geval zeker worden verworpen. We hebben echter wel gevonden dat waarden van zelf-oriëntatie, in het bijzonder de hedonistische waarden, opvallend veel voorkomend zijn in deze samenlevingen. Om de vraag te beantwoorden of het in de toekomst zo zou kunnen zijn dat waarden van zelf-oriëntatie meer voorkomend zijn dan waarden van zelfexpressie is longitudinale data nodig die niet beschikbaar is op dit moment.

In hoeverre verklaren waarde-oriëntaties onder burgers de manier waarop zij politieke participatie bedrijuen?

Tenslotte hebben we in paragraaf 8.2 de causale verbanden getest tussen de bovengenoemde waardeoriëntaties en instrumenteel-expressieve politieke participatie. Hiermee hebben we de laatste empirische vraag beantwoord en $\mathrm{H} 6$ en H7 getest. De resultaten van de binaire logistische regressie laten zien dat waarden van zelfexpressie te allen tijde verband houden met politieke betrokkenheid: de relatie houdt stand wanneer gecontroleerd voor nieuwe politieke oriëntaties, indicatoren voor cognitieve mobilisatie en leeftijd, en bevestigen hiermee hypothese H6. We kunnen deze resultaten grotendeels generaliseren naar andere landen, omdat we in de meerderheid van de landen een significant verband hebben gevonden tussen zowel waarden van zelfsturing en instrumentele politieke participatie als waarden van universalisme en instrumentele politieke participatie. We moeten 
echter wel rekening houden met het feit dat deze waarden maar tot op zekere hoogte instrumentele participatie kunnen bepalen: er is bewezen dat intern politiek zelfvertrouwen en het gebruik van media om politieke informatie te verzamelen veel sterker gerelateerd zijn aan dit type participatie in alle twaalf landen.

Met betrekking tot waarden van zelf-oriëntatie leverde de analyse inconsistente resultaten op. We hebben gevonden dat hedonisme in alle landen behalve Nederland geen verband houdt met expressieve politieke participatie. De resultaten van de bivariate analyse brachten bewijs voor de veronderstelde relatie in meer landen, echter verdween deze relatie wanneer we de controlevariabelen toevoegden aan de modellen. In tegenstelling tot onze verwachtingen bleek stimulering gerelateerd te zijn aan instrumentele politieke participatie, maar deze bevindingen waren beperkt tot een paar landen en bleken niet significant in de gemeenschappelijke analyse. Tenslotte bleek ook prestatie significant verband te houden met instrumentele politieke participatie in zowel de gemeenschappelijke analyse als in de helft van de geanalyseerde landen. Geen van deze waarden bleek gerelateerd te zijn aan expressieve politieke participatie; hetgeen heeft geleid tot het verwerpen van hypothese H7 die was afgeleid van de theorie van de postmoderne politiek. Politiek cynisme was de enige variabele waarvan we in alle landen een consistent verband hebben gevonden met expressieve politieke participatie. Ook ontevredenheid met het functioneren van de democratie bleek in een klein aantal landen gerelateerd te zijn aan expressieve participatie.

Gebaseerd op deze resultaten is het antwoord dat we kunnen geven op de hoofdvraag van dit onderzoek dat het instrumentele type participatie het resultaat is van de nieuwe sociaal-culturele omstandigheden in post-industriële samenlevingen. Dit type participatie is meer voorkomend dan de expressieve stijl van politieke betrokkenheid. Om op basis van deze bevinding het democratisch bestuur in deze samenlevingen een voorspoedige toekomst te voorspellen is echter om twee redenen niet verstandig. Ten eerste hebben onze analyses ook laten zien dat expressieve politieke participatie ook aanzienlijk vaak voorkomt in deze samenlevingen en dat het waarschijnlijk zal toenemen in de toekomst: de ontwikkeling van expressieve politieke participatie over geboortecohorten heeft uitgewezen dat het waarschijnlijker is dat deze stijl van participatie een vast kenmerk van postindustriële samenlevingen wordt dan dat instrumentele participatie dat wordt. Daarnaast hebben we gevonden dat deze stijl geleidelijk aan een negatief klimaat voor de opinie over de politiek zou kunnen creëren, iets wat mogelijk op de lange termijn de legitimiteit van de democratie zal ondermijnen. Ten tweede hebben de analyses opmerkelijke verschillen tussen landen laten zien met betrekking tot zowel 
het niveau van de ontwikkeling van beide participatie typen als de effecten die waarden daarop hebben. Dit doet denken dat instrumentele of expressieve participatie kan worden bepaald door andere contextuele of individuele factoren. Mogelijke factoren die verantwoordelijk zijn voor de verschillende tussen landen zijn politiek-institutionele kenmerken, zoals invloed van de lokale overheid of de toepassing van direct democratische beginselen in de verscheidene samenlevingen.

Translated by: Leonie van Grootel 